\title{
State Capacity, Inequality and Inter-group Violence in Sub-Saharan Africa
}

\author{
Ida Rudolfsen
}

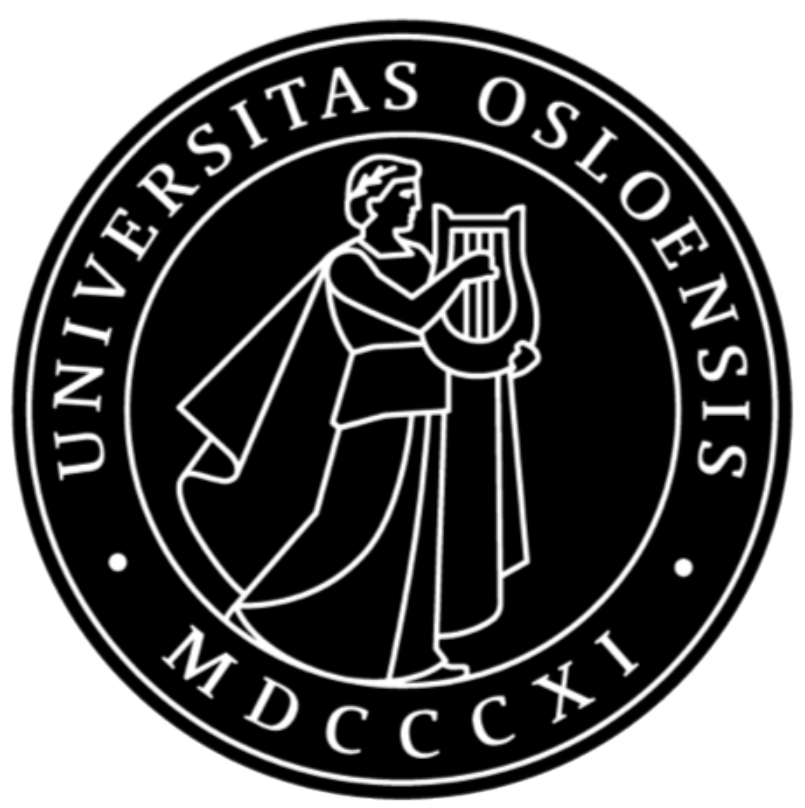

Department of Political Science

Faculty of Social Sciences

University of Oslo

Spring/May 2013 
State Capacity, Inequality and Inter-group Violence in Sub-Saharan Africa

Ida Rudolfsen 
(C)Ida Rudolfsen

2013

State Capacity, Inequality and Inter-group Violence in Sub-Saharan Africa

Ida Rudolfsen

http://www.duo.uio.no/

Print: Kopisten, Oslo 


\section{Abstract}

Why do non-state groups engage in armed conflict with each other? Most studies on internal conflict focus on the dyadic interaction between the state and a rebel group, providing less attention to inter-group fighting. In an attempt to contribute to the limited body of quantitative research on non-state violence, I argue that the opportunity structures and security problems created by weak state institutions may help explain the occurrence of violence between groups. Drawing on the argument that state capacity is important for domestic peace, I claim that non-state violence is more likely when groups are forced to provide for their own security within the state sphere. However, although weak state capacity structures create opportunities for groups to engage in fighting, an anarchical environment in itself might not explain inter-group violence. Thus, I argue that the interplay between economic and political exclusion of groups and weak state capacity further increases the risk of non-state conflict, creating both opportunities and motivation to engage in conflict. Whereas the majority of quantitative studies that focus on marginalization emphasize rebel groups in relation to the state, I argue that violence to ameliorate uneven distribution is just as likely to be directed at non-state groups who receive a larger share of economic and political welfare.

Utilizing data on Sub-Saharan Africa from 1989 to 2011, I conduct a quantitative analysis studying the effect of weak state capacity on inter-group violence. The empirical analysis provides support for the theoretical expectation that weak state capacity increases the risk of inter-group violence, and that the combined presence of economic marginalization and weak state capacity further increases this risk. However, I find no support for a combined effect of weak state structures and political marginalization. The findings highlight the importance of state capacity for internal peace, and lend support to the literature emphasizing the relationship between state strength and conflict. Also, they illustrate the advantages of a more uniform theoretical framework, focusing on a specific type of violence between organized groups. 


\section{Acknowledgements}

First, I would like to thank my supervisors, Hanne Fjelde and Håvard Mokleiv Nygård, for sharing their knowledge on the field. The interesting conversations, helpful comments and constant presence during the writing process is much appreciated. Despite the fact that one was in Nairobi and the other in New York, this was no impediment for guidance, and I would undoubtedly have chosen the same supervisors again. Second, I would like to thank Håvard Hegre, Carl Henrik Knutsen and Håvard Mokleiv Nygård for giving me the opportunity to write this master thesis in conjunction with the project Conceptualization and Measurement of Democracy ${ }^{1}$. I would also like to thank the other master students who participated in the seminars for helpful comments, long sought-after coffee brakes and new friendships: Ingrid Selle Rasmussen, Lars Petter Berg, Jonas Kjærvik, Jørn Wichne Pedersen, Øyvind Stiansen, Solveig Hillesund, Katrine Heggedal, Kristin Alveng and Idunn Kristiansen. Third, I would like to thank Espen Geelmuyden Rød, Tore Wig, Rune Busch and Ranveig Drolsum Flaten, as their master theses have been of much inspiration and help. Fourth, I would like to thank Arve, usually in the field of case study research, for stepping into the world of statistics for the occasion, correcting spelling mistakes and giving constructive feedback. Fifth, I would like to thank my family for always stressing the importance of an education.

All remaining errors in this thesis are my responsibility alone.

Word count: 36761

Ida Rudolfsen

Oslo, 22.05.2013

\footnotetext{
${ }^{1}$ RCN Project 204454/V10. See http://www.sv.uio.no/isv/english/research/projects/conceptualizationand-measurement/index.html.
} 


\section{Contents}

List of Figures $\quad$ XI

List of Tables $\quad$ XIII

1 Introduction 1

1.1 Core Concepts . . . . . . . . . . . . . . . . . 4

1.1.1 Inter-group Violence . . . . . . . . . . . . . . . 4

1.1.2 Weak State Capacity . . . . . . . . . . . . . 5

1.1.3 Economic and Political Inequality . . . . . . . . . . . . . 5

1.2 Main Findings . . . . . . . . . . . . . . . . . 6

1.3 Structure ........................... 7

2 Literature Review 9

2.1 Informal Organized Groups . . . . . . . . . . . . . . . 9

2.2 Quantitative Studies: The link to the Civil War Literature . . . . . . . . 10

3 Theoretical Framework $\quad 15$

3.1 State Capacity . . . . . . . . . . . . . . . . 16

3.2 Economic and Political Exclusion in a Weak State . . . . . . . . . . . 20

3.3 Summary . . . . . . . . . . . . . . . . . . . . 27

4 Research Design $\quad 29$

4.1 Why Quantitative Analysis? . . . . . . . . . . . . . . . . 29

4.2 The Models . . . . . . . . . . . . . . . . . . . . . . . . 30

4.2 .1 Logistic Regression . . . . . . . . . . . . . . . . 30

4.2 .2 Negative Binomial Model . . . . . . . . . . . . . . . . 31

4.2 .3 Regression Models . . . . . . . . . . . . . . . . . . . . . 33

4.3 Summary . . . . . . . . . . . . . . . . . . . . 34 
5 Data and Unit of Analysis 35

5.1 Regional and Temporal Scope . . . . . . . . . . . . . . . . . . 35

5.2 Operationalizing Concepts . . . . . . . . . . . . . . . . 36

5.2.1 Dependent Variable: Non-State Violence . . . . . . . . . . . . . . 37

5.2 .2 Main Independent Variable: Weak State . . . . . . . . . . . . . . 42

5.2.3 Independent Variables: Economic and Political Inequality . . . . . 47

5.2 .4 Making the Case for Interactions . . . . . . . . . . . . . . 51

5.2 .5 Control Variables . . . . . . . . . . . . . . . . . . 52

5.3 Methodological Challenges . . . . . . . . . . . . . . . . 56

5.3 .1 Omitted Variable Bias . . . . . . . . . . . . . . 56

5.3 .2 Reverse Causality . . . . . . . . . . . . . . . 57

5.3 .3 Multicollinearity ................... 57

5.3 .4 Missing and Multiple Imputation . . . . . . . . . . . . 58

5.4 Summary: The Dataset . . . . . . . . . . . . . . . . . . . . . 63

6 Analysis $\quad 65$

6.1 Descriptive Statistics . . . . . . . . . . . . . . . . . . 65

6.2 Multivariate Regression Results . . . . . . . . . . . . . . . . . 68

6.2.1 Weak State Capacity . . . . . . . . . . . . . . . 68

6.2.2 Weak State in Combination with Economic and Political Inequality 73

6.2.3 Scenarios . . . . . . . . . . . . . . . . 80

6.2.4 Model Performance . . . . . . . . . . . . . . . . . . . 86

6.3 Summary . . . . . . . . . . . . . . . . . . . . . . . 90

7 Model Robustness and Diagnostics $\quad 93$

7.1 Non-Independent Observations . . . . . . . . . . . . . . . . . . . . 93

7.2 Residuals and Influence . . . . . . . . . . . . . . . . . . . . 94

7.3 Omitted Variables . . . . . . . . . . . . . . . . . . . . . . 97

7.4 Alternative Operationalizations and Estimation Methods . . . . . . . . 99

7.5 Summary . . . . . . . . . . . . . . . . . . . . . . 102

8 Conclusion $\quad 103$

8.1 The Scope of the Theory . . . . . . . . . . . . . . . . . . . . 104

8.2 Implications . . . . . . . . . . . . . . . . . . . . . . . 104

8.3 Moving Further . . . . . . . . . . . . . . . . 106

8.4 Concluding Remarks . . . . . . . . . . . . . . . . . . 107 
9 Bibliography

$\begin{array}{ll}\text { A Descriptives } & 125\end{array}$

$\begin{array}{lr}\text { B Missing } & 127\end{array}$

C Additional Regressions and Diagnostics 133

$\begin{array}{ll}\text { D Robustness } & 137\end{array}$

$\begin{array}{ll}\text { E Do-file } & 149\end{array}$ 


\section{List of Figures}

4.1 Distribution of Non-State Conflicts: 1989-2011 . . . . . . . . . . . . . 32

5.1 Number of Non-State Fatalities in Thousands: 1989-2011 . . . . . . . . . 38

6.1 Number of Non-State Conflicts: 1989-2011 . . . . . . . . . . . . . . . 66

6.2 Model 5, Logistic Regression: Box plot of simulated probability of intergroup violence in strong and weak states. . . . . . . . . . . . 71

6.3 Model 6, Negative Binomial Regression: Box plot of simulated probability of inter-group violence in strong and weak states . . . . . . . . . . . . 72

6.4 Interactions: Statistically different effect for weak and strong states . . . 79

6.5 Interactions: Simulated probability of inter-group violence over increasing levels of inequality . . . . . . . . . . . . . . . . 81

6.6 Interactions: Simulated probability of inter-group violence over increasing levels of inequality in eight scenarios . . . . . . . . . . . . 84

6.7 ROC-curve: Model 1, 3, 5 and $7 \ldots \ldots \ldots$. . . . . . . . 87

7.1 Predicted versus Observed Values: Model $15 \ldots \ldots$. . . . . . . . . . . 96

B.1 Missingness Map . . . . . . . . . . . . . . . . . . . . . . . . . . 128

B.2 Testing the Missing at Random Assumption: Kernel density plot . . . . . 129

B.3 Overimputation . . . . . . . . . . . . . . . . . . . 130

B.4 Scatterplot: Missing . . . . . . . . . . . . . . . 131

C.1 All Interactions: Statistically different effect for weak and strong states . 135

C.2 Coefficient Plot: The effect of inequality conditioned on state capacity . . 136

D.1 Influential Observations: Cook's statistic . . . . . . . . . . . . . 148 


\section{List of Tables}

5.1 Sample of Inter-group Conflicts in Sub-Saharan Africa: 1989-2011 . . . . 40

5.2 Cross-Correlation Table for Interactions . . . . . . . . . . . . . . . . 58

5.3 Descriptive Statistics: Imputed data . . . . . . . . . . . . . . . . . . 64

6.1 Inter-group Conflicts by Regime Strength . . . . . . . . . . . . . 66

6.2 Inter-group Conflicts by Amount of Economic Exclusion . . . . . . . . 67

6.3 Inter-group Conflicts by Size of Largest Excluded Group . . . . . . . . . 67

6.4 Conflict Events within States _ . . . . . . . . . . . . . . . . . 68

6.5 Logistic and Count Regressions: Estimated odds and incidence odds of inter-group violence in Sub-Saharan Africa, 1989-2011 . . . . . . . . . . 69

6.6 Count Regressions with Interactions: Estimated incidence odds of intergroup violence in Sub-Saharan Africa, 1989-2011 . . . . . . . . . . . . . 74

6.7 Overview of the eight scenarios used for simulation . . . . . . . . . . 80

6.8 Out-of-Sample Predictions: Model 11, 12, 15 and 16 . . . . . . . . . 89

7.1 Fit Statistics . . . . . . . . . . . . . . . . . . . 97

A.1 Descriptive Statistics: Non-imputed data . . . . . . . . . . . . . 125

A.2 Countries Included in the Analysis f . . . . . . . . . . . . . . 126

B.1 Countries with Completely Missing . . . . . . . . . . . . . 127

C.1 Logistic and Count Regressions: Baseline models, 1989-2011 . . . . . . . 133

C.2 Count Regressions with All Interactions: Estimated incidence odds for inter-group violence in Sub-Saharan Africa, 1989-2011 . . . . . . . . . . . 134

D.1 Logistic and Count Regressions: Clustered on year and unclustered, 1989$2011 \ldots \ldots \ldots \ldots \ldots$

D.2 Count Regressions with Interactions: Clustered on year and unclustered, $1989-2011 \ldots \ldots \ldots \ldots \ldots$ 
D.3 Logistic Regressions: Influential observations removed, 1989-2011 . . . . 140

D.4 Logistic and Count Regressions: Education, ethnic diveristy, youth bulges and oil added, 1989-2011 . . . . . . . . . . . . . . . . . . . 141

D.5 Count Regressions with Interactions: Education, ethnic diveristy, youth bulges and oil added, 1989-2011 . . . . . . . . . . . . . . . . . . 142

D.6 Logistic and Count Regressions: Alternative operationalization of state capacity, 1989-2011 . . . . . . . . . . . . . . . . . . 143

D.7 Count Regressions with Interactions: Alternative operationalization of state capacity, 1989-2011 . . . . . . . . . . . . . . . . . . . . 144

D.8 Alternative Methods: Rare event logistic and zero inflated negative binomial regression, 1989-2011 . . . . . . . . . . . . . . . . . . . . . 145

D.9 Alternative Methods: Interactions with rare event logistic regression, 1989$2011 \ldots \ldots \ldots \ldots \ldots$

D.10 Alternative Methods: Interactions with zero inflated negative binomial regression, 1989-2011 . . . . . . . . . . . . . . . . . . 147 


\section{Chapter 1}

\section{Introduction}

Why do non-state groups engage in violent conflict with each other? Inter-group violence has been prevalent in countries such as D.R. Congo, Nigeria, Burundi, and Liberia, and non-state violence can have equally damaging effects as other types of conflict. According to Sundberg, Eck and Kreutz (2012a), more than 60000 people lost their lives in Africa between 1989 and 2008 in armed conflicts between non-state groups. Yet, most studies on conflict have focused on armed conflicts with the state as one of the belligerents, paying little attention to inter-group fighting (Fjelde and Nilsson 2012).

For the groups and communities affected by non-state conflict, the consequences of this type of violence can be very similar to that of civil war, both in terms of loss of human lives and property, displacement and war-related diseases (Fjelde and Østby 2012). However, there is great variation in the occurrence of inter-group violence across African states. While some areas have no armed conflicts between societal groups, other areas, such as Darfur in Sudan and eastern D.R. Congo, have seen several instances of inter-group violence. What factors can explain this variation? A limited amount of quantitative studies have sought to answer this question. In an attempt to address this gap in the literature, this thesis will seek to evaluate the role of weak state capacity in explaining the risk of armed conflict between groups. Drawing on the argument that institutional setup is critical to domestic peace, I argue that weak state capacity can increase the risk of inter-group violence when groups within the state are forced to provide for their own security. When central authority is weak, the groups cannot depend on the state for protection, and must evaluate their position in relation to each other. When forced to be self-reliant the groups must assess their relative strength, as other groups could become potential rivals within the unincorporated state sphere. 
Somalia has experienced multiple non-state conflicts, and is a useful example within a weak state capacity framework (Lewis 1994). With the outbreak of civil war and the removal of Barre in 1991, there has been an increasing number of organized and armed groups. With the emerging state anarchy, every major Somali group formed its own militia movement; the Somali Salvation Democratic Front, Somali National Movement, United Somali Congress and Somali Patriotic Movement. These movements became selfgoverning, carving out spheres of influence in the periphery and engaging in conflict with other groups. The armed faction of the group became the providers of security and was often the political representative of the group at large. With the state unable to provide for the people of Somalia, the group became the relevant political community and the armed faction within this group provided protection for the group at large (Vinci 2006).

However, the dissolution of central authority does not in itself necessarily explain why groups take up arms. Many states can be classified as weak without experiencing intergroup fighting. Indeed, without a treatment of group differentiation, which generates this anarchical environment, structural arguments do often not explain conflicts, they merely redescribe them. The rise of a security threat between groups in a weak state is not necessarily a sufficient cause of inter-group violence. Rather, it provides the necessary conditions in which it can take place (Roe 1999). Therefore, I argue that state weakness in combination with economic and political marginalization of groups could further increase the risk of conflict between groups, and that this provides useful insights when trying to explain inter-group violence. While accommodating groups that are relevant for survival, the state is unable to provide for the population at large, leaving other ethnic groups excluded. Disparities in the distribution of economic and political power in a weak state caused by state capture of a specific ethnic group can facilitate violent mobilization of excluded groups to alter distribution asymmetries. Uneven redistribution are transformed into deprivation and security fears through group differentiation. When groups lack welfare and must provide for their own security in a weak state, violent attacks may be directed against rival groups who have a relatively larger share of entitlements in an effort to change the status quo. Simply put, the anarchical environment provides the opportunity to engage in conflict, and the economic and political exclusion of groups provides the motivation. Whereas quantitative studies that focus on economic marginalization and civil war emphasize rebel groups in relation to the state, I argue that economic and political marginalization also can be associated with inter-group conflict. 
Violence to ameliorate any perceived injustice or threat is equally likely to be directed at non-state groups who receive a larger share of economic and political benefits.

The case of Burundi is illustrative when it comes to the combined effect of state neglect and marginalization on group violence. Throughout the post-colonial period, the Burundi state has not been fully in control of its entire territory. Ethnicity has been the central organizing principle, creating policies of differentiation and exclusion of specific groups. Conflicts between groups reflected the contested claims for relevance, representation and security within the state sphere. The Burundi state, then, has not been able to include the complex groupings in society as part of a broader non-ethnic political community. Instead, groups in society are engaging in conflict to secure economic and political privileges. According to Ngaruko and Nkurunziza (2000, 387), the Burundian bureaucracy became an instrument for profit for an ethnically biased elite, where the army played an important role as an actor and guarantor of the mechanism of rent collection and distribution within the elite. Thus, excluded groups are not only responsible for their own security, but are also marginalized by the politicization of ethnicity. The inter-group violence seen in Burundi can to a large extent be related to the predation by the Tutsi elite, and exclusion by the Hutus. Indeed, inter-group conflicts between Hutus and Tutsis erupted in 1997, 2000, 2003 and 2004.

Based on the above discussion I expect that state weakness will increase the risk of nonstate conflict. Furthermore, I expect that if political and economic inequality concur, this should further increase the risk of non-state conflict. I investigate these propositions using large-N analysis, covering all Sub-Saharan countries from 1989 to 2011. The temporal scope reflect limitations in data availability on non-state violence, and the geographical limitation is a choice based on the relative similarity of countries a smaller sample provides, where Sub-Saharan Africa most readily reflects a weak state capacity framework. Also, when focusing on violence between groups, self-conscious group-based structures are important. Group-formation can have many origins, but ethnicity holds a particular importance in organizing collective action, and this is especially the case in Sub-Saharan Africa (Fjelde and Østby 2012; Bates 2008; Fearon 2006; Wimmer 2002). 


\subsection{Core Concepts}

This thesis contains several concepts that are somewhat abstract in nature. I will therefore define their meaning preliminarily, so as to clarify how the concepts are understood and used in my theoretical framework and analysis. The most important concepts used in this thesis are inter-group violence ${ }^{1}$, weak state capacity, and economic and political inequality.

\subsubsection{Inter-group Violence}

To arrive at a definition of non-state conflict that distinguishes it from other types of violence, there are several criteria used. The most important aspect is the lack of governmental involvement in conflict. I only focus on conflicts between two organized groups, where the state is not one of the belligerents. The definition of inter-group violence used in this thesis is taken from the UCDP Non-State Conflict Dataset (Sundberg, Eck and Kreutz 2012a), where non-state violence is understood as a conflict between two formally organized groups, neither of which is the government of a state, causing at least 25 annual battle-related deaths. The emphasis on formally organized groups entails focusing on any non-governmental group having an announced name and using armed force against another similarly organized group, such as between the Niger Delta Defense Force and the Niger Delta Vigilantes in Nigeria. Thus, I focus on groups that are organized to such a degree that they are included in the state-based armed conflict category in the UCDP/PRIO Dataset.

I have chosen to only focus on formally organized groups to get a more unified framework, and to avoid attempting to explain several types of conflicts that can be caused by competing mechanisms. Thus, I do not look at violence between sporadically organized groups or violence during elections. Communal or informally organized groups are not included in the analysis. As I build on a logic where groups residing within a weak state must provide for their own security, is seems more likely that these, or factions of these groups, are permanently organized for combat. By adapting a more narrow focus on the type of violence and organization, I am able to obtain a more coherent theoretical framework, make the assumptions given my framework more clear, and facilitate the interpretation in my analysis.

\footnotetext{
${ }^{1}$ I use the terms inter-group violence, armed conflict between groups and non-state violence interchangeably throughout the thesis.
} 


\subsubsection{Weak State Capacity}

Although important for the study of civil conflict, state capacity is an elusive concept. Indeed, state capacity is a broad term that can entail aspects such as coherence of institutions, economic development, and extractive and repressive capabilities (see e.g. Hegre et al. 2001; Gates et al. 2006; Hendrix 2010; Lichbach 1995; Tilly 1978). I have chosen to focus on state capacity despite its multi-dimensionality, as the quality and capacity of the state is likely to affect the opportunities for groups to exist and organize, and to engage in conflict with each other, either because they are motivated or forced to do so.

Although definitions of state capacity based on military capacity and institutional coherence has proven important for the study of civil conflict, I focus on the state's ability to collect and respond to information and provide services for its population (ICRG nd $a$ ). The reason for this is twofold. First, institutional strength and quality of the bureaucracy is central for acquiring information, as weak states are more sensitive to large changes in public services during governmental change. With a lack of administrative functions, the knowledge of mobilization of groups and eruption of non-state violence is thereby more difficult to hinder. Second, the definition focusing on bureaucratic quality entails state capacity characterized by meritocratic recruitment, insulation from political pressure and the ability to provide services to the population, also during governmental change (DeRouen and Sobek 2004). Thus, the definition used here focuses on aspects of state capacity concerning the incorporation of groups and provision of services in the state sphere. Rather than institutional consistency or military capacity, I will therefore use the definition of state capacity in which state strength is given by the amount of bureaucratic quality and inclusion of the state.

\subsubsection{Economic and Political Inequality}

The study of political and economic inequality has provided a number of mechanisms for how and why conflict between different groups emerge (see e.g. Gurr 1970; Hechter and Levi 1979; Horowitz 1985). Although the motivational role of inequality has often been dismissed in the research of conflict (see e.g. Fearon and Laitin 2003; Collier and Hoeffler 2004), the gap between quantitative and case study research when it comes to motivations as a cause for conflict is large, indicating that the complete dismissal of incentives is uncalled for. When studying inter-group violence, I follow the definition of inequality provided by Stewart (2008), based on 'horizontal inequalities', which she defines as inequalities in economic, social or political dimensions between culturally defined groups. 
Thus, I focus on a group-based definition of inequality, incorporating unequal access to political and economic distribution, rather than interpersonal inequality insensitive to any group based structures or social cleavages in society, and the unequal access to political and economic gains such structures can create.

A group-based definition of inequality can more easily reflect the fact that many postindependent African states were unable to be detached of powerful social interest groups, and not able to provide social benefits to all citizens independent of their ethnic belonging. In weak states where there was no specific majority, many politicians appealed to the same ethnic group, and politics became more ethnically based. Politics turns into a struggle over control of the state between various ethnic groups in weak states, where the control of the state apparatus by one ethnic group comes at the expense of other groups (Cederman, Weidmann and Gleditsch 2011). Thus, to obtain benefits and goods ethnic belonging is important, where excluded groups end up with less resources than included groups. A group based definition of inequality incorporates how economic and political exclusion can be turned into incentives to engage in conflict caused by the relative differences between groups.

\subsection{Main Findings}

In my analysis I find support for my theoretical expectation that weak state capacity leads to unincorporated groups, forcing them to be constantly organized and provide for their own security. This lack of state protection increases the risk of inter-group violence in a weak state. In addition, I find that the presence of not only weak state capacity but also economic inequality further increases the risk of inter-group violence. This finding supports my theoretical proposition that the combined presence of weak state structures and economic inequality provides both opportunities and incentives for groups to engage in non-state conflict. However, I find no evidence that the dual presence of weak state capacity and political exclusion increases the risk of non-state violence. In fact, I find that the larger the excluded population in a weak state, the lower the risk. This can be related to the relative grievance between groups and the potential gains by political inclusion. When it comes to the predictive power of the models, the in-sample predictions indicate that the models are improved when interaction terms are included, and the outof-sample predictions show that the models predict conflict recurrences quite satisfactory, whereas single events by country are poorly predicted. Also, the models tend to predict 
inter-group violence when there is a civil war present, indicating that the more narrow theoretical focus on non-state violence has some limitations.

The relationship between non-state conflicts and state capacity is the most central aspect of this thesis, and provides contributions concerning two aspects; (1) I focus more narrowly on a specific type of conflict, and examine the relationship between inter-group violence and weak state capacity with the use of statistical analysis. (2) I focus on the combined effect of economic and political inequality and weak state capacity, and how this relates to inter-group violence.

\section{$1.3 \quad$ Structure}

This thesis contains eight chapters. In Chapter 2 I review the relevant literature on inter-group violence, which provides some basis for the theoretical framework presented in Chapter 3. First, I focus on the argument of how weak state capacity can increase the risk of inter-group violence. Second, I focus on a combined effect of weak state capacity and economic and political exclusion, and how this interaction can further increase the risk of inter-group violence. In Chapter 4 I present my research design, focusing on logistic and negative binomial regressions. Chapter 5 introduces the data, presenting operationalizations and addressing methodological issues with the measurements used, discussing the potential problems with omitted variable bias, simultaneity, multicollinearity and missing. Chapter 6 contains the analyses, presenting models focusing on the role of weak state capacity, and models focusing on the combined effect of weak state capacity and inequality. Before concluding, I present some robustness tests and additional diagnostics to address the potential problem of biased inferences in Chapter 7 . 


\section{Chapter 2}

\section{Literature Review}

It's a complicated war.

- Finnegan (1992)

In the following I will present relevant literature on inter-group violence. I briefly address some of the literature concerning violence between informal organized groups, such as violence occurring between communal and pastoral groups, before presenting quantitative contributions on organized group violence and its link to the civil war literature. Despite the fact that the case study literature is equally important when investigating the causes for inter-group violence, I have chosen to put main emphasis on the quantitative contributions, as they most closely relate to a theoretical framework based on militarily organized groups within a weak state sphere.

\subsection{Informal Organized Groups}

There exists a substantial qualitative literature on inter-group conflict. Although not directly applicable to the highly organized, armed and politically relevant groups I focus on here, the literature is relevant for the study of non-state violence. Examples of conflicts between more informal groups are violence between communal groups ${ }^{1}$, riots $^{2}$, and land issues between herders and farmers. According to Raleigh $(2010,71)$, much of the findings in the case study literature on intra - and inter-group violence can be understood as a way to access resources in areas with a hostile or sporadic government presence. Thus,

\footnotetext{
${ }^{1}$ According to Sundberg, Eck and Kreutz $(2012 b, 5)$, communal groups can understood as groups that are not permanently organized for combat, but "who at times organize themselves along said lines to engage in fighting".

${ }^{2}$ For contributions within the literature on riots, see e.g. Barron, Kaiser and Pradhan (2004); Varshney (2002, 2001); Wilkinson (2004); Van Klinken (2007).
} 
these findings provide useful insights when trying to explain quantitatively the outbreak of inter-group violence as a consequence of weak state capacity. For example, Obioha (2008) studies violence in Northern Nigeria and note that the actors engaged in conflict are often peasants and herdsmen, where the government becomes involved in the conflict more to settle the dispute than to engage in it. Much of these group conflicts relate to access to arable land and forced migration due to increasingly drought-prone areas (See also Fiki and Lee 2004). More generally, Raleigh (2010) finds that marginalization of groups and accumulating insecurity caused by climate change can cause group conflicts due to both increasing poverty over time and distress migration.

Of the case studies that have addressed armed conflicts between organized groups, Turner (2004) finds that inter-group conflicts in the Sahel region are related to changes in national policy and the corresponding weak local leadership. Conflict in this region is based on relative and not absolute resource availability, erupting when groups attempt to take control of these resources. ${ }^{3}$ Similarly, Bassett (1988) finds that violence between groups in the Northern Ivory Coast erupted as a consequence of national food policies disrupting local land-tenure agreements. Benjaminsen and $\mathrm{Ba}$ (2009) conclude that increased pastoral marginalization in Mali leads to more frequent land use conflicts between herders and farmers. They argue that these conflicts are a result of national policies giving priority to agricultural development at the expense of pastoralism.

Although relating to overlapping mechanisms, these case studies presented here do not focus on permanently armed groups. I therefore proceed to the literature based on large $\mathrm{N}$-studies that mostly focus on militarized rebel groups.

\subsection{Quantitative Studies: The link to the Civil War Literature}

The quantitative literature on inter-group violence is not extensive, and non-state conflict data was only recently introduced, facilitating the study of organized groups in conflict. The most substantial civil war dataset; UCDP/PRIO (Gleditsch et al. 2002), only includes violence where the state is involved, and cases of non-state violence are thereby excluded. Previous research on organized violence tends to focus on interaction with the state, rather than on any interaction between armed non-state actors (see e.g. Fearon

\footnotetext{
${ }^{3}$ See also Turner et al. (2011).
} 
and Laitin 2003; Collier and Hoeffler 2004; Sambanis 2004; Hegre et al. 2001). Hence, for large N-studies the approach has been to emphasize a dyadic interaction between the state and a rebel group, but empirical tests of this relationship have tended to disregard the rebel organizations. While these contributions' focus on state characteristics address the issue of violence within a state, they do not address why the state necessarily is a participant in the organized violence. Arguments concerning deprivation and threat mostly consider when political violence will occur, and do not address whether the state itself is a participant or not. As stated by Fjelde and Østby (2012): "There is arguably a leap in many of the existing accounts from the notion that grievances derive from inter-group comparisons, but violent attempts to redress them are directed against the state, rather than the group who is the target of resentment" (Fjelde and Østby 2012, 5).

The focus on the state in the literature is based on the observation that states control the allocation of resources. However, violence against other groups can be just as likely as violence against the state, as group belonging and political power are often closely aligned. In addition, Cunningham and Lemke (2011) find that the factors used to explain civil war also can be suitable predictors for other forms of violence, such as assassinations, riots and purges. Overlap in findings suggests that theories used to explain civil war onset represent more general mechanisms about the occurrence of violence within states (Nygård and Weintraub 2011). As theories should be tested on a sample that the theory logically applies, there is a need to narrow down theory and use it more directly on a specific type of violence. This is especially relevant if theories on civil war applies to violence in more general terms.

Within the literature on civil war, the non-state side has been categorized as a unitary actor, and the literature has not taken into account the complexity of civil conflicts, where there often are several active rebel groups (Fjelde and Nilsson 2012). Civil conflicts are complex phenomena that rarely consist merely of a military struggle between the state and one rebel group. Kalyvas $(2003,475)$ states that " (. . ) civil wars are not binary conflicts but complex and ambiguous processes that foster an apparently massive, though variable, mix of identities and actions - to such a degree as to be defined by that mix". By treating the rebel side as a unitary actor, much of the dynamics in civil conflict is lost, and the violence between non-state groups are thereby understudied. 
Civil wars are typically understood based on what is perceived to be their overarching dimension: ideological, ethnic, or religious wars. With this unidimensional focus, local dynamics, actors and smaller groupings tend to be dismissed. However, a group's motives are not necessarily driven by an overarching cause and may well be driven by more local or even personal conflicts. Groups and local communities involved in the war can take advantage of the prevailing situation to settle private and local conflicts out of government reach, or are coerced to do so. Hence, the outbreak of civil war creates an additional opportunity factor for groups, and the outbreak of civil war is in itself an indication of state weakness (Hegre et al. 2001). Thus, civil wars can be understood as a condition that provides an opportunity to address unresolved issues within a larger conflict. Civil wars transform societies into anarchies with a breakdown of political order, and when lawlessness is extended to the entire society, violence tends to be a predictable outcome (Kalyvas 2006).

Nevertheless, there are exceptions from an unidimensional focus on civil war. Among the existing studies that have moved beyond the simplifying assumption of the rebel groups as unitary actors are studies that focus on internally divided movements and multiple rebel groups' effect on duration and outcome. According to Cunningham (2011), internally divided movements receive concessions from the state at a much higher rate than unitary actors, and that the more divided movements are the more likely they are to receive concessions. Concessions given by states are strategic acts as states can use concessions to reveal information about preferences of the movement. In the same vein, Cunningham, Bakke and Seymour (2012) focus on the neglected politics of factionalism, and find that factions in more fragmented groups are much more likely to use violence in their struggle against the state, and are more likely to attack one another and co-ethnics. Fjelde and Nilsson (2012) find that violence between groups during civil war is a way to secure material resources and political leverage that could help the group prevail in its conflict against the state. ${ }^{45}$ Also, the literature on secessionism is relevant for intergroup conflict. For example, Brancati (2006) notes that decentralization increases ethnic conflict and secessionism indirectly by encouraging the growth of regional parties. These parties reinforces ethnic and regional identities, introducing legislation that favors specific ethnic groups over others, mobilizing groups to engage in ethnic conflict (see also

\footnotetext{
${ }^{4}$ See also Cunningham, Gleditsch and Salehyan (2009), Nilsson (2008), Shirkey (2012) and Fjelde and Østby (2012).

${ }^{5}$ In addition, there exists research on inter-group conflicts during civil war based on in-depth studies, for example during the civil wars in Sri Lanka and Bosnia (see e.g. Christia 2008; Lilja and Hultman 2011).
} 
Banerjee 1984; Bhatnagar and Kumar 1998; Kumar 1986).

The complexity of the events and numerous actors involved in civil conflicts makes it hard to account for what type of conflict emerges between what actors. I therefore choose to focus on inter-group violence, a specific type of violence that does not include the state, which provides a more consistent focus. The conventional literature on civil conflict places its explanation either at the individual level or more generally at the national level, and says little about the sub-state actors such as organizations or groups. Although there are several contributions on group violence, these are mainly focusing on inter-group violence during civil war, or more in-depth studies with limited generalizability. In the following, I will therefore focus on organized non-state violence both in the absence and presence of civil war, and attempt to apply a more narrowly defined theory based on a security problem between groups in a weak state. There is room for expanding theories on non-state conflicts beyond a more general civil war framework, and for expanding empirical inquiry beyond case and in-depth studies. 


\section{Chapter 3}

\section{Theoretical Framework}

To address the social consequences of a weak state structure, I apply a theory on how weak state institutions can cause security problems between groups, and how these risks might be aggravated by economic and political exclusion. The political topography of African states is seen within the context of ethnic communities, where groups can be understood to be politically included or excluded. The degree of inclusion at the state center is linked to the group's political importance. I rely on a conceptual framework that emphasize the different capabilities and entitlements of groups, and the actors within the political realm are ethno-political groups which are constantly interacting with each other (Raleigh 2010). Hence, this framework assumes the presence of political groups in society. While this is not necessarily always the case, most scholars recognize some form of social belonging or group membership as a given part within the social and political sphere (Fjelde and Østby 2012; Horowitz 1985; Gurr 1993; Stewart 2008).

As a starting point, I follow the conceptualization of groups used by Tajfel and Turner $(1979,40)$, where a group is understood as:

(...) a collection of individuals who perceive themselves to be members of the same social category, share some emotional involvement in this common definition of themselves, and achieve some degree of social consensus about the evaluation of their group and of their membership of it.

However, this definition encompasses a broader approach to group differentiation than I would like to use. Here, the focus is on groups that are defined through aspects such as ethnic or religious belonging, but also has a high degree of organization. The formation of groups can have many sources, such as ethnicity, religion, identity and livelihood. However, ethnicity seems to be a particularly important resource in organizing political 
action, especially so in Sub-Saharan Africa (see e.g. Wimmer, Cederman and Min 2009; Posner 2004; Raleigh 2010). Ethnic cleavages are therefore often the dominant group differentiation in electoral and party opposition, and important social and political units within African states. In addition, I look only at highly organized and armed groups that are permanent fighting organizations, and not groups in society in general. I assume these organized and armed groups have a relation to looser groupings in society, based on Tajfel and Turner (1979) definition of group differentiation. When looking at organized and armed groups, I make no assumption about the underlying preferences of the majority of the population that the group is supposedly representing. Hence, the strong engagement and commitment of a small minority of the organized group is often only a sub-group of a larger ethnic or religious identity, which this organized group claims to represent.

I first present different definitions and understandings of state capacity. Subsequently, I present how weak state capacity can lead to non-state conflict, through lack of control and incorporation of groups. Then, I will present how weak state capacity can cause economic and political exclusion in society, through state capture by specific groups, before illustrating theoretically how this can increase the risk of violence by facilitating mobilization and creating a security problem between groups, providing both opportunities and motivation for non-state conflict.

\subsection{State Capacity}

(...) the most important political distinction among countries concerns not their form of government but their degree of government.

- Huntington (1968, 1)

State capacity's effect on the likelihood of civil conflict has been much debated amongst political scientists. Despite its importance for the study of inter- and intrastate conflict, state capacity remains a concept lacking a precise definition. As stated by Hendrix (2010, 273): "State capacity is a quality conspicuous both in its absence and presence but difficult to define." ${ }^{1}$ State capacity is a multi-dimensional concept that encompasses not only extractive abilities of a state but also economic development and quality of institutions.

\footnotetext{
${ }^{1}$ Given the sparse literature available on inter-group violence, I explicitly draw many of my theoretical assumptions and empirical expectations from the civil war literature.
} 
Despite the variation of definitions of state capacity, previous research show that strong states have a decreased risk of experiencing internal conflict (Sobek 2010). While research based on the greed versus grievances debate focus on the willingness of actors to use violence to alter power relations, there has been less focus on state capacity. The quality and capacity of state institutions are important for the likelihood of conflict, as it affects the opportunities for groups to exist and organize, and to engage in violent conflict with each other.

According to Hegre et al. (2001), states have the ability to absorb the demands of their population in ways that can reduce the potential of political violence, or simply deter resistance through their ability to use physical coercion. While consolidated democracies have institutionalized channels through which subversive groups can be accommodated, authoritarian states experience fewer civil conflicts because potential dissidents are less likely to mobilize when they perceive the repressive capacity of the state to be high (Tilly 1978). Hegre et al. (2001) find that authoritarian states and institutionally consistent democracies experience fewer internal conflicts than intermediate regimes. Semidemocracies are weaker because the regime type possesses inherent contradictions as a result of being open yet somewhat repressive. This is a combination that invites protest, rebellion and other forms of violence. In the same vein, Gates et al. (2006) find that institutionally consistent regimes last longer than inconsistent ones. However, broad distinctions of regime type may simplify institutional heterogeneity of both democratic and authoritarian regimes. It is difficult to decide the institutional structure of an inconsistent regime, other than it is not completely repressive or free, and to assess what the institutional design of an inconsistent regime is (Rød 2012). In addition, although there is evidence linking democracy and bureaucratic capacity, there is little evidence linking institutional coherence to bureaucratic quality (Hendrix 2010).

State capacity can also be defined in relation to a state's ability to use force. This definition has its roots in the Weberian definition of state capacity: "The state is a human community that successfully claims the monopoly of the legitimate use of force within a given territory" (Weber 1946, 212). The strength and size of the military can be seen as the most important element in a state's repressive capabilities, and how this effects the onset and termination of civil conflict. Hence, a smaller and less organized militant group should be less of a threat than a larger and more organized group (Hendrix 2010). Empirically, this implies more internal conflict when states are weak, since weak 
states invite collective dissent (Lichbach 1995). Buhaug (2010) finds that larger militaries are associated with lower risk of conflict onset and shorter war duration, while Fearon and Laitin (2003) stress the importance of a state's repressive capacity, and that the prospects of civil conflict is dependent on the government's military capabilities and the reach of government institutions into rural areas. These areas, where dissident groups exert control, are essential for the group's survival, as they can slowly gain strength through acquiring food and labour from local populations.

However, definitions of state capacity based on military strength may not capture the aspects that are most important for a group to take up arms. State weakness makes it more costly to control an entire country's territory. Yet, the government could transfer an overwhelmingly number of forces to these peripheral areas, and assume control (Holtermann 2012). Fearon and Laitin (2003) argue that if government forces knew who the dissident were and how to find them, they would be easily destroyed, as such groups are relatively weaker than the government in terms of both arms and soldiers. State strength, then, should perhaps rather be measured in a state's ability to collect and respond to information, and provide services for the entire population, than the size of military strength or regime consistency (Hendrix 2010).

The gains of a more bureaucratic-institutional definition is twofold. First, institutional strength and quality of the bureaucracy is central for acquiring and responding to information, as weak states are more sensitive to large changes and interruptions in services during reorganization of government. With a lack of administrative functions and meritocratic expertise the knowledge of potential mobilization of groups can be more difficult to obtain, and thereby also more difficult to hinder. Hence, the decision to engage in violent conflict may be affected more by the bureaucratic quality of the government, than the size of its military and regime characteristics. Second, the definition encompassing bureaucratic quality concerns the state's ability or will to incorporate groups in the state sphere and provide equal concessions to the entire population. Rather than regime consistency or military strength, I will therefore use the definition of state capacity in which state capacity is dependent on the amount of bureaucratic quality in the government, characterized by regular and meritocratic recruitment, insulation from political pressure and the ability to provide services to the population despite government changes (DeRouen and Sobek 2004). Therefore, countries that do not have the strength and expertise to govern without policies being largely altered during government change, is lacking independence 
from political pressure in society, and is largely driven by patrimonialism and lack day-to day administrative functions, are here considered to be states with limited state capacity.

The main features of a weak state are limited reach of state institutions and lack of security within its territory. The state, then, has only limited ability to incorporate all the groups in society within the state sphere, and an increasingly anarchical environment emerges for the excluded groups. The theory of a security dilemma in the presence of anarchy was originally created with interstate relations in mind, ${ }^{2}$ but has in more recent times been used on the intrastate level in an attempt to address the question of ethnic conflict in weak states. Posen (1993) claims that security dilemma within states can occur when conditions are similar to those between states in the international arena. State weakness can therefore be seen as a problem of 'emerging anarchy' in the absence of a central authority, and the various groups are forced to provide for their own security. In the same vein, Kaufmann (1996) points out that if the government cannot effectively control its territory so as to be able to protect its people, while organized groups can, then these groups can acquire sufficient attributes of sovereignty to create a security dilemma. Hence, Kaufmann's approach is similar that of Posen's, where the absence of an effective central authority forces groups to take actions to defend themselves, which again threatens the security of other groups.

With the lack of territorial control and information within the state apparatus, groups can more easily organize themselves militarily and mobilize to engage in conflict. This is especially the case if groups choose to engage in fighting with other groups, who do not have the same amount of military strength and soldiers as the state. Starting a rebellion against the state requires high organizational capacity and resources, which marginalized and excluded groups are not likely to have. Indeed, groups with low military capacity and political irrelevance are not likely to be able to campaign against the government to redress uneven redistribution. Engaging in conflict against other groups, however, requires less military capability and resources, suggesting that inter-group violence is a more likely

\footnotetext{
${ }^{2}$ The term 'security dilemma' was first used by Herz (1951), and was said to occur when two parties, neither wishing to harm the other, end up in a conflict (See also Butterfield 1951; Jervis 1978). The reason for why such a 'tragedy' could occur is uncertainty between the two parties, where the uncertainty produces fear in both parties that the other would want to harm them. At the same time, they are unaware that they themselves are creating feelings of insecurity in the other. This implies that both parties could be secure if they could come to see the nature of the situation they are in. Uncertainty concerning the others' intentions is therefore a central aspect in the security dilemma. Worst-case scenarios may often lead to a spiral between two or several actors. The more one actor increase arms to provide for its own security, the more the other will have to increase the amount of arms so as to maintain the same level of security (Roe 1999).
} 
outcome when groups must be self-reliant. Weak state capacity creates a situation where groups must provide for their own security, and thereby also opens up the opportunity to engage in conflict. Hypothesis $H 1$ summarizes this theoretical expectation:

H1: Weak state capacity increases the risk of inter-group violence.

However, an anarchical environment and the necessity (or opportunity) to provide for ones own security is not necessarily enough to cause inter-group violence. It is possible to reside within a weak state, and have an opportunity to engage in fighting, without taking up arms. There is not a deterministic relationship between an anarchical state and intergroup violence, since states with anarchical features do not necessarily see inter-group violence. Rather, it is a precondition for violence between groups to emerge. Hence, I hypothesize that two additional features within a weak state might help explain the emergence of non state conflict, by incorporating specific incentives in addition to the opportunity structures provided by a weak state; economic and political marginalization.

\subsection{Economic and Political Exclusion in a Weak State}

Ethnic contests for power serve mainly to perpetuate disproportional government representation.

- Raleigh (2010, 74)

Political and economic inequality has been a central part of the literature on violent conflict, and has provided a number of mechanisms for how and why ethnicity contributes to conflict. Gurr (1970) focused on state-imposed disadvantages and discrimination of groups, and presented the theory of relative deprivation, which argued that different types of inequality increase the risk of internal conflict as a reaction to frustrations stemming from unfulfilled aspirations. ${ }^{3}$ Some argue that ethnicity causes violence through emotions, resentment of other groups than one's own, or the protection of one's group survival based on fear (see e.g. Kaplan 1993; Petersen 2002; Posen 1993; Lake and Rothchild 1996). According to Toft (2003), ethnic conflicts are more likely to occur when ethnic groups are territorially concentrated in an area considered their homeland.

\footnotetext{
${ }^{3}$ See also Hechter and Levi (1979), Russett (1964), Davies (1962) and Horowitz (1985).
} 
The motivational role of inequality has often been dismissed in the research of conflict on the basis that grievances are abstract phenomena (see e.g. Fearon and Laitin 2003; Collier and Hoeffler 2004). These contributions have focused more on opportunity structures emerging for potential insurgents, while giving incentives a less prominent role (Buhaug et al. 2011). These studies have found no link between inequality and conflict. Using interpersonal income inequality, these studies have been criticized for using individual level measures of income distribution, such as the Gini-coefficient, that are insensitive to social cleavages and group structures. Stewart (2008) emphasizes the importance of 'horizontal inequalities', ${ }^{4}$ which she defines as inequalities in economic, social or political dimensions between culturally defined groups. Based on case studies, she finds that horizontal inequality is associated with armed conflict. Also more recent large-N studies focus on how distributional asymmetries affect conflict behavior, and finds that countries with a more unequal distribution of wealth and political benefits are more exposed to various forms of violence (see e.g. Buhaug, Cederman and Rød 2008; Cederman, Weidmann and Gleditsch 2011; Hegre, Østby and Raleigh 2009; Østby 2008). These contributions, among others, stress the need to focus on group-based measures of unequal access to political and economic distribution, and find evidence for a link between group inequality and conflict.

I follow the definition of horizontal inequalities (HI) provided by Stewart (2008) to theorize group differentiation, focusing on the political and economic dimension of horizontal inequalities. Although these two aspects can be claimed to be interrelated, I will treat them as two separate components. It is emphasized that different types of deprivation can exist simultaneously, and that one type of exclusion may be present whereas the other is not (Raleigh 2010). Economic inequality is not simply and artifact of political inequality, and vice versa (see e.g. Cederman, Weidmann and Gleditsch 2011). I therefore choose to include both marginalization aspects in my analysis. ${ }^{5}$

African political regimes tend to be dominated by the intensity of the competition that divides their political actors, and competition between political entrepreneurs accounts for much of the institutional instability in Sub-Saharan Africa (Bayart 2003). The amount of inequality in many Sub-Saharan African states tend to be related to the structure

\footnotetext{
${ }^{4}$ As opposed to vertical inequalities, that measures inequality between individuals rather than groups.

${ }^{5}$ The definition provided by Stewart (2008) also include social and cultural inequalities. These aspects are expected to be equally important for the study of civil conflict, but these mechanisms are outside the scope and aim of the theoretical framework presented here.
} 
of states, where African governments do not have easy access or authority within the entire country. The emergence of nation-states in post-colonial Africa provided changes in the principles of political legitimacy, and group relations took on new dynamics when interacting with the state. The elites of the nationalizing states were not able to include and integrate the vast majority of the population into the planned community of the nation. This was especially the case for states where institutions were limited and the civil society weak, leaving the elites to rely on ethnic ties for support and legitimation (see e.g. Wimmer 2002; Buhaug, Cederman and Rød 2008). Hence, the state was not strong enough to be independent of powerful social interest groups and dominant elites, and was unable to provide social benefits to all citizens independent of their ethnic belonging. In weak states where there is no specific majority and no ethnic group that can be viewed as the "state's people", political leaders might appeal to members of the same ethnic or regional group, so that ethnic distinctions become politicized.

The ethnicisation of the bureaucracy can occur through the formation of client groups, and provides the opportunity to legitimize governmental power through benefits, which again assures support from the receiving group (Migdal 1988). Ethnicity becomes a tool for private patronage and public goods provision between the ruling elite and local communities, where governments seek legitimacy by favoring co-ethnics in the distribution of goods (Fjelde and Østby 2012). Hence, the state is not a neutral agent, but is rather captured to different degrees by representatives of a specific ethnic group (Cederman, Wimmer and Min 2010). The charging of ethnic differences is connected with the struggle for the resources of legal security, financial redistribution, political relevance and economic infrastructure (Wimmer 1997), where political relations between groups is based on uneven political representation and interests (Raleigh 2010). Thus, resources provided by the ethnic elite that has control of the state apparatus do not seem to be public benefits, but rather collective goods available to those who belong to the ethnic group in power. As stated by Wimmer $(1997,631)^{6}$ :

(...) the politicization of ethnicity is to be interpreted as a central aspect of modern state-building. For only when 'people' and state are mutually related within the ideal of a legitimate order does the question arise for which ethnic group the state has to act, who is regarded as its legitimate owner, and who is entitled to have access to its services.

\footnotetext{
${ }^{6}$ For a full overview of Wimmer's theory on the exclusion of non-members in society, see Wimmer (2002).
} 
Politics becomes a struggle over control of the state between various ethnic groups, and this is especially the case in weak states as it is more easily captured by a specific ethnic elite and its constituencies (Cederman, Wimmer and Min 2010). It follows that to obtain material benefits, ethnic belonging is crucial. Those who lose out in the struggle for state power are less likely to obtain favorable concessions from the state, leaving the excluded groups with less resources than the included groups. As different groups in society make claims on behalf of their collective interests against the state or other groups, the state also may make such claims in the name of the dominant ethnic group (Gurr and Moore 1997). Mobutu's faction in Zaire, for example, is mainly made up of the Ngbandi from the Equateur province, and the Kinois in D.R. Congo have a close relationship with those in power, highlighting the privileged relationship some groups can enjoy with the central authority (Bayart 2003).

Inequalities between groups are often large in Sub-Saharan African societies (Kanbur and Venables 2005), where the state neglects more peripheral groups. When social identities are politicized and the groups make social comparison through in-group and out-group categories, large differences between groups might create antagonistic inter-group relations (Tajfel and Turner 1979; Buhaug et al. 2009). The self-identification within the group can provide motivation and incentive to engage in conflict. Groups that are nonprivileged in the distribution of goods share both a common deprivation and a common identity that facilitate collective action to assert groups interests (see e.g. Wimmer 2002; Fjelde and Østby 2012; Gurr 1993). Thus, opposing group interests when attempting to obtain scarce resources promote competition and facilitates cooperation within the group, and inter-group competition can enhance intragroup morale, cooperation and cohesiveness. Particularly unequal distribution of universally sought goods such as equality and rights will have a potential to create feelings of anger and resentment (Kalyvas 2006). This suggests that group variation matters for the motivation for conflict not just in terms of the local conditions, but that the relative size of differences may also have influence. Because ethnic status is given at birth and therefore cannot be changed, the struggle for group prestige in ethnically heterogeneous societies may ameliorate collective action problems as soon as processes of uneven development foster rivalry between groups.

Ethnonationalist motivation may also be facilitated by historical experiences. Competition over relevance creates historical patterns of perception and definition of the 'other'. According to Smith (1992), the polarization of group belonging can easily be 
transformed into motivation for conflict if the members feel politically threatened. The members, then, reconstruct a new set of ideas from their common history and revive them through their reinterpretations (Smith 1995). The emergence of group motivation may be especially easy if the group has past violent experiences with another group, where a discourse based on encounters with a rival group is created, either through glorifying own achievements or characterizing the rival group with negative attributes. Hence, in the words of Tajfel and Turner $(1979,33) ;$ " ( . . . ) the real conflicts of group interests not only create antagonistic inter-group relations but also heighten identification with, and positive attachment to, the in-group." Exclusion along ethnic lines can lead to political mobilization of counter-elites, where conflict erupts because of demands of inclusion at the center of power, for example the ANC in South Africa, or the creation of a separate state or self-determination in which the ethnic group would be dominant, for example in the Angolan exclave of Cabinda (Buhaug et al. 2011).

The existing literature provides strong implications for how uneven distribution and anarchical features within the state can lead to a polarization of group belonging. However, just as there are many weak states with lacking security that have not seen any non-state violence, there are many aggrieved groups within countries that do not choose to engage in conflict. "It is a profound and repeated finding that the mere facts of poverty and inequality or even increases in these conditions do not lead to political and ethnic violence" (Goldstone 2002, 8). For mobilization to occur, there must be opportunities available for the aggrieved groups to do so, and it is therefore important to identify structures that make it both possible and likely for groups to take up arms. And it is exactly here that the combination of limited state security and the state capture of a specific group becomes relevant. As a weak state is more likely to be controlled by a specific ethnic group, and cannot provide economic and political security for the remaining ethnic groups, the excluded groups are more inclined to engage in conflict. State weakness in combination with economic and political marginalization of groups could cause security problems by creating both opportunities and incentives to engage in conflict, as inequality in economic and political relevance can facilitate violent mobilization to alter resource asymmetries when uneven redistribution are transformed into fear of survival and a sense of deprivation through group comparison.

Violence between groups can be seen as a product of self-governing (Raleigh 2010), where the political exclusion of groups exacerbates conflict over political and economic resources 
when inclusion is a function of group belonging. Inter-group violence is a way of addressing imbalanced access to relevance critical for group survival within a weak state sphere which is controlled by a different ethnic group. When weaker groups must provide for their own security in a weak state, violent attacks may be directed against rival groups who have a relatively larger share of entitlements in an effort to change the status quo. Indeed, when the distribution of power is limited to a specific group in society and the non-privileged groups are excluded from political competition of power, the subordination of the excluded group is permanently fixed. Change can be brought about only through the means of force (Horowitz 1985). Thus, unequal distribution of resources are likely to intensify group violence between privileged and non-priveleged groups.

However, it is not necessarily only the weaker group who decides to take up arms. The lack of reach of state institutions may also provide opportunity structures for stronger groups to attack a weaker, so as to take control of an even larger share of resources. Stronger groups can have incentives to exploit such divisions to engage in conflict, by portraying weaker groups as a threat to their economic and political privileges (Fjelde and Østby 2012). Previous studies have found that social inequalities can shape nationalism beyond the basis of marginalization, where more affluent groups seek toward separatism. Gourevitch (1979), for example, noted that groups in economically richer areas felt undermined by poorer regions, seeking independence for ones own group.

In practice, many Sub-Saharan African governments do not have effective sovereignty across their full territories. This lack of capacity affects the ability (or will) of states to provide basic services, and the geographical control of the government is quite varied, creating spaces of non-governance that are unincorporated. Economic and political exclusion creates high variation in government services, where political representation and economic accommodation is lower for marginalized groups (Peet and Watts 1996; Coast 2002). Thus, the question of economic and political survival and relevance becomes important in an anarchical state, and the emergence of a security problem between groups may manifest itself in two ways: First, the anarchical structure provides an opportunity for a stronger group to attack a weaker to secure an even larger share of wealth and political relevance, and second, a weaker group attacks a stronger group because of security fears and deprivation. Hence, the groups deliberately take up arms in the anarchical state because of an uneven distribution of economic and political privileges, and unintentionality cannot be assumed. The security dilemma emerging within an anarchy is a 
spiral model where intentions on both parts are benign, and neither side wishes to harm the other. ${ }^{7}$ However, I assume that groups deliberately take up arms to change the status quo within the anarchical structure, where one group attempts to make its situation better by arming itself to deter another group. Also, the security dilemma sees state participation as completely absent, whereas I focus on the consequences when the central authority is weak and politicized. I therefore see the relationship between groups with different amounts of economic entitlements as a security problem, rather than a security dilemma, where groups are intentionally aggressive. This security problem emerges when the groups included in the legitimate base of support of the government are accommodated, whereas excluded groups in the periphery are not (Raleigh 2010). The exclusion of groups within a weak state sphere creates both opportunities and incentives to alter the status quo, making non-state conflict more likely. The hypotheses summarize these theoretical expectations:

H1a: Economic marginalization in a weak state further increases the risk of inter-group violence.

H1b: Political marginalization in a weak state further increases the risk of inter-group violence.

Given that the state is such a significant actor for the allocation of power and resources, existing literature has focused on conflicts where the state is involved. However, because group belonging and political power is so closely linked in many Sub-Saharan states, the feeling of deprivation and fear of group survival is likely to be directed at the members of the group that occupies the state. When the state is functioning in defense of particular group interests, attacking the group that is receiving privileges from the government is also an attack on the state as such (Fjelde and Østby 2012). Hence, inter-group violence

\footnotetext{
${ }^{7}$ Both Kaufmann and Posen's argument seems to indicate that group identities, historical record and rhetoric are equally important for threats between groups as by anarchy itself. Although I do agree that conflict between groups may be driven by some additional factor than an anarchical environment, I do not view these factors necessarily as creating a security dilemma. As stated by Tang (2011), three aspects of the security dilemma are essential: anarchy, lack of malign intention on both sides, and some accumulation of power. As a consequence, Posen's use of the former Yugoslavia as case is contradictory to the security dilemma, as he claims there were plenty of signals of malign intent (Posen 1993, 37). Therefore, it is not given whether the situation is best described as a security dilemma, or as a security problem. Kaufmann's use of the concept is also at odds with the definition provided by Butterfield (1951), as he claims that elite-led violence will eventually create a security dilemma. Kaufmann's structural security dilemma, then, has occurred after the outbreak of violence, and he disregards the unintentional origin of the security dilemma.
} 
is a result of a struggle over the control of economic and political resources where groups must provide for their own well-being and security.

\subsection{Summary}

The most central question in this thesis is why do non-state groups engage in conflict with each other? In an attempt to answer this question I rely on a weak state capacity framework, where the lack of state incorporation of the entire population forces excluded groups to provide for their own security. The lack of territorial control and ability to gather information creates opportunity structures for groups to exist and organize militarily, and to engage in conflict with each other. Based on these expectations, I argue that weak state capacity increases the risk of inter-group violence.

Although weak state capacity can be seen as a necessary condition for inter-group violence, it is not an exhaustive explanation. Indeed, a state can be categorized as weak without experiencing inter-group violence. Therefore, I argue that opportunity structures created by a weak state in combination with incentives based on group inequality can further increase the risk of inter-group violence. As a weak state is more likely to be controlled by a specific ethnic group with a limited ability to equally incorporate all groups in society, the groups excluded from political and economic benefits are more inclined to engage in conflict. Thus, state weakness in combination with economic and political inequality increases the risk for inter-group violence by creating both opportunities and motivation to engage in conflict. Inequality between groups can facilitate violent mobilization to change uneven redistribution as excluded groups receive a relatively smaller share of public goods than included groups, and must provide for their own security within a weak state. 


\section{Chapter 4}

\section{Research Design}

Essentially, all models are wrong, but some are useful.

- Box and Draper (1987, 424)

In this chapter I present a research design that allows for a quantitative assessment of whether a weak state increases the probability of inter-group violence. First, I will briefly present why I explore the relationship between weak state and inter-group violence using a quantitative approach. Second, I will present the estimation techniques used in the regression analyses, logistic regression and negative binomial regression, before presenting the statistical model.

\subsection{Why Quantitative Analysis?}

Scientific research is supposed to test assumptions and draw causal conclusions on the basis of empirical information (King, Keohane and Verba 1994). As the styles of quantitative and qualitative research is very different, there are gains and drawbacks inherent in both methods. Whereas the literature on the violence including the state is vast, the literature on inter-group violence is dominated by research focusing on individual cases (see e.g. Christia 2008; Duquet 2009; Lilja and Hultman 2011; Barron, Kaiser and Pradhan 2004; Magdalena 1977). The most central reason for choosing a quantitative design in this thesis is that I am seeking to explain a more general pattern of inter-group violence over time and space, and how weak state institutions and group inequality is related to this type of violence. In case studies the generalizability is somewhat limited, and a statistical analysis allows for more structured and coherent approach, incorporating multiple cases. Quantitative research also has limitations such as confirmation bias, 
lack of direct application to specific situations, and imposing too simple logic on diverse events. Although being aware of limitations of the quantitative research design, I choose a quantitative approach to answer my hypotheses more systematically, in an attempt to contribute to the relatively limited quantitative tradition of inter-group violence research.

\subsection{The Models}

When investigating the relationship between weak state capacity and inter-group violence, there are several ways to conduct the analysis. The data at hand holds information both on discrete outcomes, and the number of non-state conflicts per country year. Thus, the analysis can be conceptualized using a dependent variable measuring both a discrete outcome, and the number of non-state conflict events. Therefore, I will in the following present the two estimation techniques that I have chosen for my analysis; logistic and negative binomial regression. ${ }^{1}$ I choose two estimation models to assess consistency in the findings, but also because they answer slightly different questions. Whereas the logistic approach indicates whether there occurred a non-state conflict event or not, the negative binomial also gives information about how many conflicts occurred. The logit models report the probability of experiencing inter-group violence, whereas the count models report the probability of distribution of counts.

\subsubsection{Logistic Regression}

The logit model is developed in terms of the regression of a nonlinear model relating the $x$ 's to the probability of an event, here inter-group violence. Measuring a discrete outcome implies that when the conflict reaches a certain intensity threshold, the observed variable is 1, 0 otherwise. A logit model can be derived by transforming $\operatorname{Pr}(y=1 \mid x)$ into a function that ranges from $-\infty$ to $\infty$ (Long 1997). The probability is first transformed into odds:

$$
\frac{\operatorname{Pr}(y=1 \mid x)}{\operatorname{Pr}(y=0 \mid x)}=\frac{\operatorname{Pr}(y=1 \mid x)}{1-\operatorname{Pr}(y=1 \mid x)}
$$

The odds indicate how often something happens, for example how often $y=1$, and range from 0 when $\operatorname{Pr}(y=1 \mid x)=0$ to $\infty$ when $\operatorname{Pr}(y=1 \mid x)=1$. The logit, or log of the odds, ranges from $-\infty$ to $\infty$. Hence, the model is linear in the logit:

\footnotetext{
${ }^{1}$ For the estimations I use both R Version 2.15.0 and Stata 12.
} 


$$
\ln \left[\frac{\operatorname{Pr}(y=1 \mid x)}{1-\operatorname{Pr}(y=1 \mid x)}\right]=\chi \beta
$$

The logit models are symmetric. At point $\operatorname{Pr}(y=1 \mid x)=0.7$ on the probability curve, increasing $\chi$ by any given amount $\delta$ changes the probability by the same amount as if $\chi$ is decreased by $\delta$. However, a unit change in logit does not give an intuitive understanding of what this change means. A transformation of the $\beta$ 's in the logit model indicates a factor change in the odds for an event occurring:

$$
\Omega(\chi)=\chi \beta
$$

As the interpretation of odds is more intuitive, I will report all my results in odds ratios. The interpretation is that an odds ratio greater than 1 increases the chances of an outcome happening relative to the previous value of variable $\chi$, while an odds ratio below 1 decreases the chances (ibid).

\subsubsection{Negative Binomial Model}

The UCDP Non-State Conflict Dataset provides information on how many conflict there are within a country in a given year. The logit estimation model presented above is only able to give us information on whether there was a non-state conflict in a given year or not, and not how many. Hence, although there were 4 inter-group conflicts in Sudan in 1997, this is only coded as one event in the logistic regression. To be able to account for the number of conflict events in a country in a specific year, I also include a count model in my analysis.

Counting how many times something has happened is quite common in the social sciences. Count variables are often treated as continuous in quantitative analysis and linear regression is applied. However, the preponderance of zeros, the low values, and the clearly discrete nature of the dependent variable suggests that the usage of linear regression models for count outcomes can lead to inconsistent and biased estimates (Greene 2003). Figure 4.1 shows the frequency of counts of non-state violence. It is apparent here that the normal distribution assumption in OLS is not met, as the values clearly are skewed to the right, displaying that low values are far more frequent than higher values. Thus, the use of OLS is not viewed as suitable for my analysis. 
Figure 4.1: Distribution of Non-State Conflicts: 1989-2011

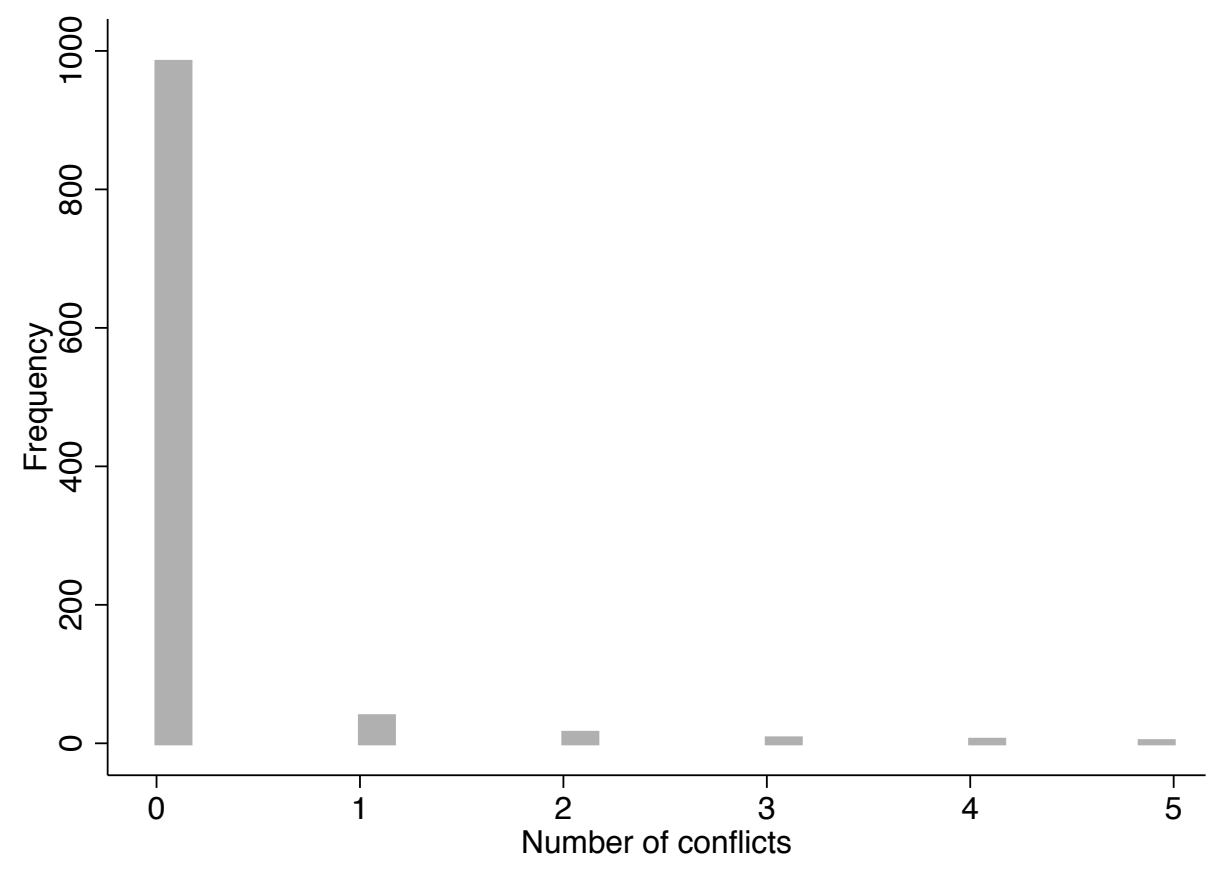

Source: UCDP Non-State Conflict Dataset (Sundberg, Eck and Kreutz $2012 a)$

The Poisson regression is the most basic regression method for count data. With a Poisson the probability of a count is determined by the Poisson distribution, where the mean of the distribution is a function of the independent variables - the conditional mean of the results is equal to the variance. The classical Poisson regression model for count data is often of limited use because empirical count datasets typically exhibit overdispersion, indicating that a Poisson distribution is not met (Zeileis, Kleiber and Jackman 2007). Poisson regression can be tested with a poisson goodness-of-fit. A large value for chi-square in the goodness-of-fit indicates that the poisson model is inappropriate. In a poisson regression model with controls the value is 1117.372 , and is significant (Prb > chi2 $(949)=0.0001)$, indicating that the Poisson model is inappropriate.

The problem of overdispersion can be addressed by extending the basic model by allowing the variance to exceed the mean in a negative binominal model. The mean $\mu$ is replaced with the random variable $\tilde{\mu}$ :

$$
\tilde{\mu}=\exp \left(x_{i} \beta+\varepsilon_{i}\right)
$$

$\varepsilon$ is a random error that is assumed to be uncorrelated with $x$. Thus, the variation in $\tilde{\mu}$ is due to both variation in $x$ among observations but also unobserved heterogeneity 
introduced by $\varepsilon$ (Long 1997).

The negative binomial distribution is a probability distribution of the number of trials before an event occurs. For example, for my analysis, the occurrence of a non-state conflict event is 1 , whereas all non-events are zero. Hence, the amount of zeros needed to obtain, say, four non-state conflict events will be negative binomial. However, the negative binominal is not always well suited for modeling excess zeros. Figure 4.1 shows that zero counts make up the majority of the data, representing 93 percent alone, indicating that a negative binomial could lead to underprediction of zeros. As conflict events are rare in general, and especially when only looking at a specific type of violence, it is important to take zero counts into account. Zero-augmented models can address this issue by explicitly modeling the production of zero counts. Zero modified models allow for the possibility of some units never obtaining a count, meaning never experiencing an intergroup conflict, by increasing the conditional variance and the probability of zero counts. However, although zero inflation is useful when estimating models with excessive zeros, the limited amount of observations in my analysis and the number of variables included have the potential of introducing instability when estimating zero inflated models (Staub and Winkelmann 2010). Therefore, I have chosen not to use this estimation technique for my main analysis, as zero inflated model is often not well suited in small samples (Hall and Shen 2010). I will therefore focus on negative binomial regression in my main analysis. As a robustness test, I will also estimate a zero inflated model and a rare event logistic model to see if the results are consistent, or driven by the estimation technique used.

\subsubsection{Regression Models}

To be able to determine whether there is an effect of weak state capacity on inter-group violence, both alone and in combination with economic and political inequality, I will run several regression analyses. For the logistic and negative binomial regression with control variables I run four regression models:

$$
\begin{aligned}
& Y(\text { Inter-group Violence })=\beta_{0}+\beta_{1}(\text { Weak State })+\beta_{2}(\text { Economic Inequality }) \\
& +\beta_{3} \ln \left(\text { Largest Excluded Group }+\beta_{4}(\text { Civil War })+\beta_{5} \ln (\text { Population })\right. \\
& +\beta_{6} \ln (\text { Infant mortality rate })+\beta_{7}(\text { Number of groups })+\beta_{8}(\text { Peace years })+\varepsilon
\end{aligned}
$$




$$
\begin{aligned}
& Y(\text { Inter-group Violence })=\beta_{0}+\beta_{1}(\text { Weak State })+\beta_{2}(\text { Economic Inequality }) \\
& +\beta_{3} \ln (\text { Excluded Population })+\beta_{4}(\text { Civil War })+\beta_{5} \ln (\text { Population }) \\
& +\beta_{6} \ln (\text { Infant mortality rate })+\beta_{7}(\text { Number of groups })+\beta_{8}(\text { Peace years })+\varepsilon
\end{aligned}
$$

$Y($ Inter-group Violence $)=\beta_{0}+\beta_{1}($ Weak State $)+\beta_{2}($ Poorest group $)+\beta_{3}$ (Richest group $)$

$+\beta_{4} \ln ($ Largest Excluded Group $)+\beta_{5}($ Civil War $)+\beta_{6} \ln ($ Population $)$

$+\beta_{7} \ln ($ Infant mortality rate $)+\beta_{8}$ (Number of groups $)+\beta_{8}($ Peace years $)+\varepsilon$

$Y($ Inter-group Violence $)=\beta_{0}+\beta_{1}($ Weak State $)+\beta_{2}($ Poorest group $)+\beta_{3}$ (Richest group $)$ $+\beta_{4} \ln ($ Excluded Population $)+\beta_{5}($ Civil War $)+\beta_{6} \ln ($ Population $)$

$+\beta_{7} \ln ($ Infant mortality rate $)+\beta_{8}$ (Number of groups $)+\beta_{8}($ Peace years $)+\varepsilon$

\subsection{Summary}

To test my theoretical assumptions concerning inter-group violence, I have chosen a quantitative design to enable generalizability over time and space, and to apply a more systematic approach to how weak state institutions and group inequality is related to non-state violence. When investigating the relationship between weak state capacity and inter-group violence I will use both logistic and negative binomial regression, and report all results in odds ratios. I use the two estimation models to assess the consistency in the findings, applying a dichotomous indicator to evaluate the likelihood of inter-group violence, and a count indicator to make use of the frequency of conflicts within a country year. In the next section I present the indicators chosen for my analysis. 


\section{Chapter 5}

\section{Data and Unit of Analysis}

In this chapter I focus on the data used in the regression analyses. First, I will make the case for limiting the study to Sub-Saharan Africa, and why I use country years as the unit of analysis. Second, operationalizations of the main concepts will be presented and discussed, with an emphasis on non-state violence, weak state, and economic and political marginalization. I also present the control variables, which are drawn from the more general civil war literature. These control variables will be included in all models when assessing the performance of weak state capacity, and economic and political marginalization. Third, I discuss methodological challenges with a main focus on missing data.

\subsection{Regional and Temporal Scope}

The observations included in the regression models are limited to Sub-Saharan Africa, as this region is most closely applicable to the weak state framework put forth in the thesis, and the geographical area is a context that unites a relatively similar group of countries. By doing this, I avoid regressing a global sample on a regional theory, providing the global mean effect of non-state violence. A global analysis is relevant to the entire world, but it is perhaps not feasible to compare all the countries included in the sample. For example, in the sample there are non-state violent events in Canada between motorcycle clubs. Although these are clearly cases of inter-group violence, it is questionable to compare this type of group mechanisms with conflicts between ethnic groups in Sub-Saharan Africa, as it is arguably related to different dynamics than weak state capacity. Rather, I seek to perform a theoretically informed sub-global analysis of relatively similar countries where violence can be explained by overlapping mechanisms. Also, when focusing on violence 
between groups, group-based structures in society are important. As group belonging based on ethnicity holds a particular importance in organizing collective action in SubSaharan Africa, it seems reasonable to focus on this region in my analysis concerning conflicts between groups (Fjelde and Østby 2012; Bates 2008).

The analysis is based on country years, and the main observation of interest is whether an instance of inter-group violence occurred that year between groups who are permanently organized for combat. The country years in the dataset go from January 1st to December 31st from 1989 until 2011, and a non-state conflict enters the dataset if it reaches the 25 battle-death threshold in one calendar year. There are potential weaknesses when the unit of analysis is at the country level, as I seek to explain mechanisms that more readily relate to local conflict dynamics of non-state violence. It would be optimal to have more local data to base the analysis on. Unfortunately, accurate information regarding the location, political influence and wealth of the non-state groups who engage in fighting is currently unavailable. The models in the analysis are therefore based on country-level characteristics, as a more disaggregated analysis is not possible to conduct. This can lead to a conceptual problem, since local features and characteristics may vary considerably within countries. Conflict is most often a localized phenomenon, that does not include the entire country, but normally takes place in particular regions in the periphery (Buhaug and Lujala 2005; Buhaug et al. 2009). However, despite the fact that I cannot say whether it is a wealthy group that attacks a poorer group, or vice versa, I can confirm or revoke that the presence of economic and political inequality within a weak state increases the likelihood of violence between groups. In addition, country years is the most used unit of analysis in the civil war literature, and as the focus of this thesis is the effect of limited state capacity, it is important to take country-level dynamics into account.

\subsection{Operationalizing Concepts}

A central objective when operationalizing concepts is to ensure that the indicators chosen reflect the concept one attempts to capture (Adcock and Collier 2001). Operationalizing the theoretical concepts presented in this thesis is challenging due to the elusiveness of indicators such as state capacity, bureaucratic quality and inequality. I therefore present and discuss advantages and drawbacks with the measurements used, and the degree to which they reflect the theoretical constructs. 


\subsubsection{Dependent Variable: Non-State Violence}

It is difficult to arrive at an operational definition of civil conflict without adopting some ad hoc way of distinguishing it from other types of violence, and there are several ways to measure organized non-state conflict. The first issue is where to set the death threshold for inter-group violence. Within the civil war literature, Small and Singer (1982) distinguished war from other types of violence by the requirement that state participation and violence should be sustained and that the conflict exceeds a threshold of more than a 1000 deaths, based on an annual-death criterion. This death threshold might be helpful as civil war is distinguished from other forms of violence given that it causes large-scale destruction. However, a strict application of the threshold can lead to exclusion of several cases that satisfy all other characteristics of civil war (Sambanis 2004).

The Uppsala dataset on armed conflict has two thresholds, where a 1000 battle-related deaths in a year is coded as a major war, whereas 25 battle-related deaths is coded as a minor war. This lower threshold is viewed as the most reasonable threshold in this analysis on inter-group violence for several reasons. First of all, with a higher threshold of a 1000 deaths, several conflicts that can be said to be typical cases of non-state violence are excluded. In fact, with a threshold of a 1000 deaths, only five conflict years would be included; Liberia in 1996, Somalia in 1992, and Sudan in 1991, 1992 and 1993. Hence, such a threshold would exclude well-known incidents of inter-group conflict. Also, there is a statistical reason for why a lower threshold would be more useful. With a quantitative approach, there is not enough non-state conflicts to conduct statistical analyses for the relatively short time period from 1989 to 2011, which my sample is limited to. Lowering the threshold for conflict inclusion will amount to more conflicts and therefore more flexibility (Gleditsch et al. 2002).

A more general issue with all conflict coding is the use of a numerical threshold of deaths to identify conflicts, as it is difficult to handle the problem of unreliable reporting and incomplete data. This is perhaps especially an issue in Sub-Saharan Africa, where data is generally more difficult to collect. An unbalanced data collection over time is likely to introduce a bias in the data. Being aware of this issue, the UCDP Non-state Conflict Dataset is the most thorough and extensive dataset available on inter-group violence. The lack of complete and unbiased information is rare in social inquiry, and important topics are worth studying even as only limited information is available (King, Keohane and Verba 1994). Figure 5.1 shows the number of fatalities for the entire period from 1989 
Figure 5.1: Number of Non-State Fatalities in Thousands: 1989-2011

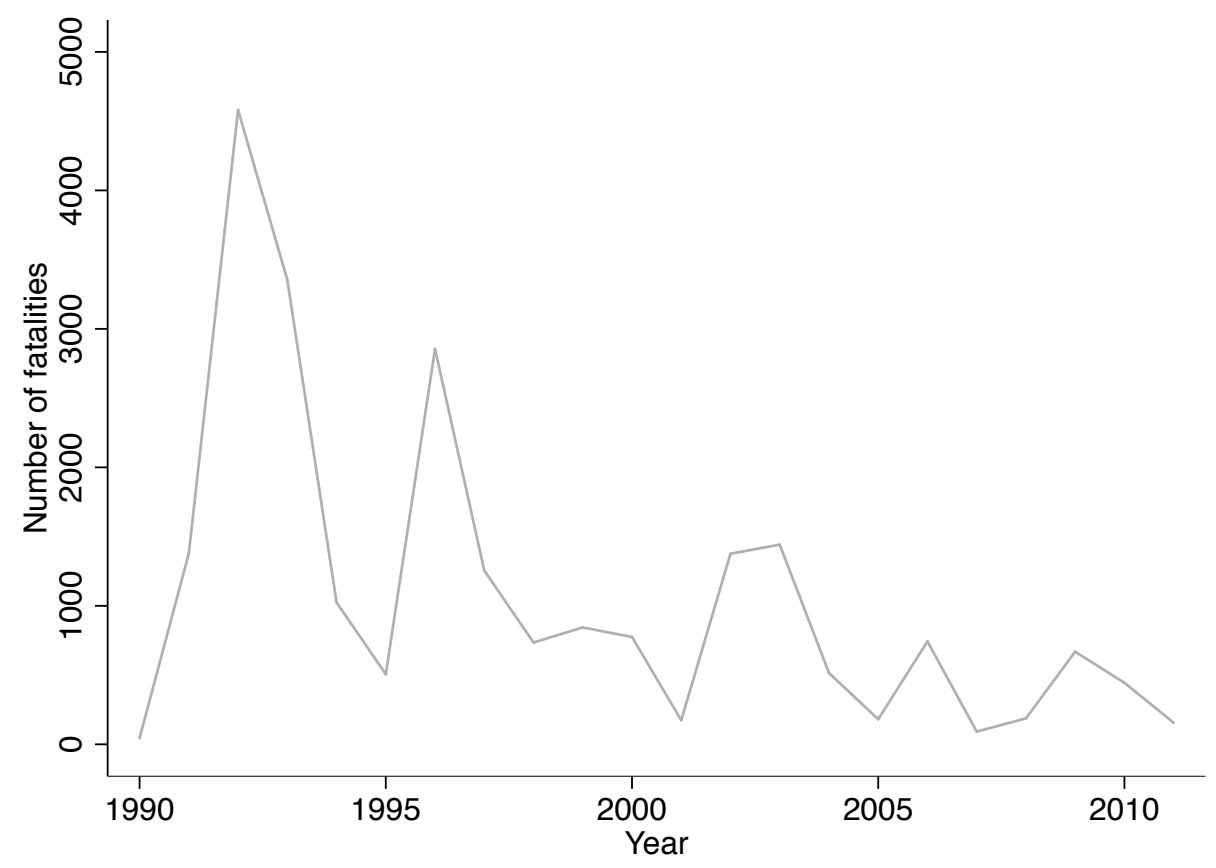

Source: UCDP Non-State Conflict Dataset (Sundberg, Eck and Kreutz 2012a)

to 2011, where there is a peak in 1992 mainly due to large conflicts in Sudan, Somalia and Liberia. The graph shows that the number of fatalities was highest during the 90s, before steadily declining. Since 2000, the number has been below 2000, compared to the peak of 4500 in 1992, and just below 3000 in 1996.

The second issue with an operational definition is to separate non-state conflict from other types of violence, such as intra - and interstate conflicts. The exclusion of government involvement is essential here. The whole concept of organized group violence is that the state is not involved. However, it is important to note that an organized group can be involved in a non-state conflict with another group, and be part of a conflict against the state at the same time. Hence, there can be ongoing non-state conflicts during a civil war. In fact, this is often the case. We see examples of this in countries such as Burundi, Nigeria and Mali. Related to this issue is the degree of organization required for the parties to be distinguished as actors in a non-state conflict, and not other forms of violence. I have here chosen to only focus on formally organized groups. This means that informally organized groups and communal groups are excluded from the analysis. There are three main reasons for the choice to only analyze formally organized groups. First, as I apply theoretical assumptions from the civil war literature about the relationship 
between groups and the consequences of weak state capacity, it seems more reasonable for my theoretical framework to focus on groups that resemble (and in fact sometimes are) rebel groups in their form of organization and level of activity, without fighting the state. Second, to focus on a high level of organization is more consistent with the idea of only looking on the specific type of violence that reflects the theoretical aim put forth in the thesis. Third, when attempting to explain why violence occurs when ethnicity is politicized in a weak state, the continuity of group activity is important. In the context of a civil war, the group is given, the rebels already exist to challenge the state. However, outside the context of a civil war, the groups themselves are part of the outcome that needs to be explained. As I try to do this by applying a scenario where a security threat exists between groups, it seems more plausible to look at organized groups as the weak state forces the groups to provide for their own protection, and are therefore likely to be permanently organized for combat.

Violence between more informally organized groups, typically related to elections and political parties, is also relevant for the study of non-state conflict. However, these informal groups are not permanently organized for combat, and only occasionally use their looser organizational structures for such purposes. Examples of inter-group violence between more loosely organized groups are Christians and Muslims in Nigeria, and between the Kikuyu and Maasai in Kenya (Sundberg, Eck and Kreutz 2012b). More informal groups tend to share a common identification along ethnic or religious lines, but this type of violence is more related to communal conflicts, and is not directly reflecting the theoretical framework presented here. To be included in the analysis, the group must have a high enough level of organization so as to be included in the state-based armed conflict category provided by the UCDP/PRIO Dataset to be included in the analysis (Sundberg, Eck and Kreutz 2012a). Thus, instead of estimating models on overly diverse observations that include several types of violence and level of organization, I try to keep the models as coherent as possible, focusing only on groups who are permanently armed and organized. This will make the assumptions about the theoretical framework and models more clear, and facilitate the interpretation of the results. Table 5.1 shows a random sample of some of the conflicts in the dataset. The sample shows the conflict ID, the name of the groups involved in conflict, year and number of fatalities. It is clear from the table that the conflicts included in the dataset represent a wide variety of armed groups, organized on the basis of factors such as ethnicity, separatism, rebel activities and political affiliation. 
Table 5.1: Sample of Inter-group Conflicts in Sub-Saharan Africa: 1989-2011

\begin{tabular}{llllll}
\hline ID & Side A & Side B & Statename & Year & Deaths \\
\hline 393 & Defense of Democracy & Liberation of the Hutu & Burundi & 1997 & 224 \\
291 & Habar Gidir clan & Marehan subclan & Somalia & 1995 & 31 \\
22 & Arrow Boys & Lord's Resistance Army & Uganda & 2003 & 71 \\
209 & ANC 'Green' faction & ANC 'Red' faction & South Africa & 1993 & 30 \\
10 & Ahlu Sunna Waljamaca & Al-Shabaab & Somalia & 2010 & 202 \\
246 & Naparama & Renamo & Mozambique & 1991 & 63 \\
243 & Islamic Front Azawad & Azawad Movement & Mali & 1994 & 30 \\
123 & Niger Delta Force & Niger Delta Vigilantes & Nigeria & 2004 & 63 \\
240 & National Patriotic Front & ULIMO & Liberia & 1991 & 313 \\
121 & Moorland Defence & Sabaot Defence & Kenya & 2008 & 32 \\
363 & Al-Shabaab & Ogaden NLF & Ethiopia & 2007 & 40 \\
135 & Mayi Mayi & Rally for Democracy & DR Congo & 2002 & 375 \\
329 & SPLM/A & South Sudan Defence Force & Sudan & 1993 & 2732 \\
303 & Rahanweyn Army & Somali National Alliance & Somalia & 1997 & 41 \\
451 & Patriots for Justice & Democratic Forces & C. A. Republic & 2011 & 60 \\
183 & Hunde & Hutu & DR Congo & 1996 & 119 \\
118 & MDFC, Dim faction & MDFC, Sadio faction & Senegal & 2006 & 124 \\
92 & Janjaweed & SPLM/A & Sudan & 2005 & 30 \\
25 & Bangadi Militia & Lord's Resistance Army & DR Congo & 2008 & 27 \\
\hline
\end{tabular}

Source: UCDP Non-State Conflict Dataset (Sundberg, Eck and Kreutz 2012a)

The non-state conflict dataset records conflicts between formally or informally organized groups. If a group uses violence against civilians who are not organized, this would be recorded in the one-sided violence category of the UCDP dataset. Hence, organized groups are not coded as participants in non-state conflicts if the levels of organization differ. Violence by groups against civilians of a different ethnicity or identity is seen as one-sided violence, even if the group's ethnic brethren are simultaneously involved in a non-state conflict with the rivaling group (Sundberg, Eck and Kreutz 2012b). For example, even if the Naparama is involved in a conflict with Renamo in Mozambique, and are at the same time killing unarmed civilians from the other group, the violence against the civilians caused by Renamo is considered as one-sided violence, and is not included in the analysis.

It should also be noted that inter-group violence is not necessarily only between different ethnic or religious groups, but also split factions from a originally unified group. This is especially the case during civil war, where the groups are organized as rebels. One example of this is during the civil war in Liberia in 1999, where group violence broke out between ULIMO Alhaji Kromah faction and the faction of Roosevelt Johnson, 
and in Somalia in 1992 between USC/SNA and the faction of Osman Atto (Sundberg, Eck and Kreutz 2012a). Perhaps the most frequent inter-group violence events in SubSaharan Africa between factions has occurred in Sudan. The master cleavage in the second Sudanese civil war from 1989 to 2005 was between the Sudanese People's Liberation Movement/Army and the government. However, additional rebel groups announced their arrival, such as Sudanese Liberation Army (SLA), the Justice and Equality Movement (JEM) and Southern Sudan Defense Force (SSDF). These groups, perhaps with the exception of JEM, was marked by divisions at the top and constantly shifting allegiances lower down, and military command and control was disrupted as rebel groups such as the SLA split along ethnic lines. The SLA was never more than a looser alliance between two tribal components, between the factions of Abdel Wahid and Minni Minawi, and fighting between them erupted as Minni Minawi sought to gain control of the entire rebel group to be better positioned when facing government forces (Flint 2007). Hence, in addition to fighting with other groups during the civil war, such as the Janjaweed and the Lord Resistance Army (LRA), conflicts between factions within the same group also emerged.

The definition of inter-group violence is derived from the UCDP Non-State Conflict Dataset (Sundberg, Eck and Kreutz 2012a). Inter-group violence can be understood as a conflict between two organized groups, neither of which is the government of a state, that results in at least 25 annual battle-related deaths per year. I focus on formally organized groups, which includes any non-governmental group of people having an announced name for their group (as well as military factions) and using armed force against another similarly organized group, such as between Al-Shabaab and the Ogaden National Liberation Front (ONLF) in Ethiopia.

For the logistic regressions, the dependent variable Inter-Group Violence takes the value 1 if there is a non-state conflict event in a country year, 0 otherwise. In order to deal with the problem of multiple inter-group conflicts in a country year, I code one case of inter-group violence if there were multiple cases in a country year. This implies that the number of conflicts recorded are reduced, as the focus is aggregated from group to country level. For example, in 1995 there were five inter-group conflicts in Somalia, but these are collapsed into one observation in the logistic regressions. This makes the results somewhat conservative. For the count models, Inter-group Violence is a count dependent variable, measuring the sum of inter-group conflicts in a country year. The logistic dependent variable includes 69 conflict events, the count dependent variable includes 125 . 
As the count measure includes more variation and has a higher number of conflicts than the binary dependent variable, the main focus in the analysis will be on the count models.

\subsubsection{Main Independent Variable: Weak State}

The literature on how best to define African states is vast, and the words to describe them equally so; quasi-states, patrimonial states, 'Big Man' states, failed states, fragile states, dysfunctional states, and postcolonial states, to name a few (see e.g. Clapham 1998, 1996; Bates 2008; Migdal 1988; Herbst 2000; Helmke and Levitsky 2004; Kitschelt and Wilkinson 2007; Reno 1995). With these overlapping terms and definitions, it can be difficult to capture the essence of the type of state I would like to focus on in the thesis, and which I have based my theoretical implications on; the lack of welfare and security for the entire population, and the state capture of an specific ethnic group. The choice of indicator used for measurement of state capacity can often affect the results of a statistical analysis (Sobek 2010), and it is therefore important to find a satisfactory indicator.

To best be able to define a weak state, it is perhaps more fruitful to first describe what a weak state is not. A strong or well-functioning state is here understood as a bureaucratic organization with a rational character and impersonal authority structure, efficient administration on the basis of rules, well-functioning infrastructure and welfare, nonviolable and legitimate state sovereignty, and the monopoly over means of force. A weak state, then, is a state not fulfilling these criteria, and can be defined as having persistent difficulties with revenue collection, questionable legitimacy within its boundaries, lack of administrative capacity, and limited national cohesion (see e.g. Jackson 1990; Herbst 2000; Young 1994; Mamdani 1996).

There are several ways of measuring state capacity, but the usual operationalizations are based on military capacity, bureaucratic or administrative capacity, and institutional coherence. Military capacity is often operationalized as military personnel per capita ${ }^{1}$, where larger militaries are associated with lower likelihood of conflict. Fearon and Laitin (2003) proxy state capacity with GDP per capita, which they hold as a measure for military and administrative capacity of the state. Others use (in)coherence of political institutions as a proxy for state capacity, where known measures are the polity scale and SIP (see e.g. Gates et al. 2006; Hegre et al. 2001). Although having inherent qualities,

\footnotetext{
${ }^{1}$ See e.g. Wayman, Singer and Goertz (1983); Jones, Bremer and Singer (1996); DeRouen and Sobek (2004).
} 
these measures are not considered to capture the essence of state capacity sought after in this thesis. The focus here is the state's ability to manage and include the entire population, and to have information and provide service equally for all members. Hence, the focus is not on degree of a specific regime type, or the ability to deploy large number of troops, but the extent of bureaucratic quality, and the ability to accommodate needs and be representative for all groups in society.

The main concern is the degree to which measures proxy the theoretical construct, and allows one to discriminate between competing causal mechanisms (Hendrix 2010). To best proxy weak state capacity, I use a measure for state capacity based on bureaucratic quality, taken from the International Country Risk Guide (ICRG nd $b$ ). The variable is measured on a $0-4$ scale and uses expert assessments on the quality of a country's bureaucracy. High scores are given to countries where the bureaucracy has the strength and expertise to govern without drastic changes in government services. In stronger states the bureaucracy tends to be autonomous from political pressure and to have an established mechanism for recruitment. Countries that lack a strong bureaucracy receive low points because a change in government tends to be severe in terms of policy formulation and administrative capabilities (ICRG nd $a$ ). The bureaucratic quality indicator is based on three conditions.

The first condition is regular, meritocratic recruitment and advancement processes. The usage of formal institutions in Burundi is a useful example where this criteria is not met, where state offices are being captured by a small elite that provides jobs and services to co-ethnics. The politicization of identities has become central in Burundi, where the political leaders currently in power provide representation and secure recruitment of coethnics (Daley 2006).

The second is insulation from political pressure. This entails being able to put funds and government revenues where the bureaucratic administration sees fit. Nigeria can provide an example where this is not the case, where public funds are channeled to specific groups in society. The bureaucracy functions predominantly through clientelism, where benefits are measured in cash values and services provided by the state in return for support. Revenues are thereby distributed to groups that are relevant for political survival, and the bureaucracy becomes a politicizing instead of a neutralizing agent (Ifeka 2001). 
The last condition is the ability to provide services and expertise to govern without drastic changes in policy. Here Zambia provides an interesting case when it comes to the relationship between political change and patronage. Since independence, the country has had three constitutions with changes from one-party to multi-party state several times. Constitutional change has resulted in political crises because of policy alteration, where groups compete over state power to manage patronage relations to preferred groups (Szeftel 2000). A closer look at the 1053 country years in the analysis show that the bureaucratic quality measure has a mean for all the Sub-Saharan countries at 1.31, where South Africa in the early 1990s is the only country receiving a 4 point score ${ }^{2}$, indicating a low average of bureaucratic quality for the continent in general. ${ }^{3}$

It is important to note here that I only focus on state strength, and do not distinguish between regime types. Most of the literature on civil conflict has focused on the form of government and not the degree of government (Sobek 2010). While not denying that the type of government can be important when explaining conflict, it is the degree of government's effect on the risk of a violent event that is of interest here. Hence, in the definition one country can be autocratic and another democratic, and both be considered weak. However, although several states can have low scores on some of the indicators, they are not necessarily weak. I have therefore recoded the measure so that intermediate regimes will not be included in the measure of weak state capacity. This is perhaps even more relevant as several Sub-Saharan countries do not attain high values on the bureaucratic quality measure in general, making it more difficult to separate between the weak and the intermediary countries. Therefore, all countries obtaining a score below 1 on the bureaucratic quality scale is considered weak, leaving countries like Liberia, Somalia and Sierra Leone categorized as weak states, wheres countries like Botswana, South Africa and Mauritius are categorized as strong, which is according to the expected separation of these countries. A dichotomy of state capacity is an easily traceable and clear way of separating weak states from intermediate and strong. A weak state, then, is any state not fulfilling any of the bureaucratic quality criteria; there is a lack of meritocratic recruitment, a high degree of political pressure, and the lack of ability to provide public

\footnotetext{
${ }^{2}$ That South Africa during apartheid was characterized as a state bureaucracy led by meritocratic recruitment and advancement processes does not provide face validity, and the score seems to be more related to potential risks of investment, than the quality and capacity of state. However, I choose to use the measure despite this limitation, given the indicator's strength as a proxy for state capacity in more general terms.

${ }^{3}$ The world average for the bureaucratic quality measure is 2.13 .
} 
services for their citizens.

Using bureaucratic quality as a proxy for state weakness have both empirical and theoretical advantages. First of all, when it comes to face validity, it most closely captures the components of the theoretical construct of bureaucratic capacity such as meritocracy, policy continuation and providing public goods. Second, it is a satisfying measure from the perspective of construct validity, as it is, in the words of Hendrix $(2010,283)$, " (...) difficult to imagine a theoretical link between bureaucratic quality and civil conflict that does not operate through the state capacity causal channel". Third, the coding is based on the political stability of countries where risk points are given by experts who asses the country's current situation. This entails that the coders have thorough and comprehensive knowledge about the country at hand, where political information are converted into risk points on the basis of a predictable pattern of evaluation. Fourth, the measure is consistent both between countries and over time, as points are assigned by expert editors on the basis of pre-set questions for each risk component (ICRG nd $a$ ). This contributes to the prevention of measurement errors, and makes comparison between countries more well-founded. Fifth, bureaucratic quality is highly collinear with other operationalizations of state capacity, such as institutional coherence and economic development, indicating that the measure is overlapping with other well-known measures of state capacity (Hegre and Nygård 2012).

There are also noteworthy limitations with the bureaucratic quality measure presented here. ${ }^{4}$ The fact that bureaucratic quality is based on expert assessments create challenges as it is a subjective measure. This has two implications. First, the expert must process, analyze and interpret a country's given situation, and is therefore not based on objective measures such as GDP per capita or infant mortality rate (Henisz 2000). Second, the expert can only perceive or report a problem or change in quality when it becomes public knowledge, and the score obtained by countries can sometimes lag the events it is supposed to predict (Linder and Santiso 2002). Hence, it can be questioned whether the bureaucratic quality indicator sometimes functions as a lagging indicator rather than a leading indicator of conflict. However, with the use of cross-sectional time-series this potential problem should not overly influence the results, as the indicator is picking up these political trends over time.

\footnotetext{
${ }^{4}$ I will return to the problem of endogeneity in section 5.3.
} 
One related challenge with this point, however, is that changes in bureaucracy relevant to this indicator are not necessarily identified. A change in bureaucratic functioning can be blurred by lack of information or access to state agencies, and potential rumors or exaggerated facts leaked by the opposition to alter the distribution of power. Also, it seems intuitively reasonable to assume that the country experts and survey respondents perceptions are affected by more recent events, and the subjective manner in which scores are given may overstate the potential risk.

In many Sub-Saharan African countries the political institutions are best defined within a grey area between dictatorship and democracy. There are several versions between these two end-points, where a mixture of authoritarian and liberal institutions determine a state's strength (Hegre et al. 2001). With these multiple types of regimes at hand a more narrow 5 point scale may not be able to pick up the diversity that the continent represents. Therefore, it is perhaps fruitful to extend the risk rating to include more categories, so as to be able to capture the mixture of hybrid regimes that have emerged in Sub-Saharan Africa since independence. Although this is especially relevant for a more limited scale, I hope to be able to create a sharper distinction and more readily identify the weakest types of regimes by focusing on countries that have received a score below 1 . Being aware of these potential drawbacks and challenges with the state capacity measure chosen for this thesis, I find bureaucratic quality as the most suitable indicator for the analysis given my theoretical framework. However, it is important to be aware of these limitations in my analysis.

The variable Weak State is a dummy variable coded 1 if bureaucratic quality is below 1, 0 otherwise. This measure will be used to assess hypothesis $H 1$, whether weak state capacity increases the risk of inter-group violence. The variable is limited to the years from 1989 to 2010 in Sub-Saharan Africa in the original dataset, and has 671 observations from 46 countries. As I wish to conduct the analysis on the years which correspond with my dependent variable, from 1989 to 2011, the timeseries must be extended. To be able to increase the number of observation I use multiple imputation as presented by Honaker and King (2010), described in more detail in section 5.3.4. The observations are extended both in time and across space in an attempt to maximize the coverage. Although not a perfect solution, removing the 11 countries without coverage and not extending the timeseries to 2011 leads to a loss of 10 (14.5 percent) conflict onsets. As the sample as a starting point only has 69 conflict events, a removal of this magnitude 
would limit the analysis. The countries without coverage on the state capacity measure in the sample seems to be random, as countries usually lacking data, such as Somalia and D.R. Congo, are included. The countries with completely missing include, amongst others, Benin, Comoros, Mauritius, and the Central African Republic, which indicates that the missingness does not readily introduce a bias, considering the variation of these countries. An overview of the countries in question is provided in Appendix B, table B.1.

\subsubsection{Independent Variables: Economic and Political Inequality}

Many attempts have been made to measure economic inequality's effect on civil conflict, relying both on statistical and qualitative methods. The statistical contributions have a mixed record when it comes to empirical evidence, lacking conclusive findings. In fact, virtually all possible causal mechanisms have been presented; negative, positive, curvilinear and none (Lichbach 1989; Cederman, Weidmann and Gleditsch 2011). In addition, there is a major gap between the recent non-findings in statistical contributions, whereas case studies repeatedly point at economic inequality as an explanation for civil conflict. It therefore seems that the results of statistical analyses are to a large degree dependent on the choice of measurement.

Contemporary statistical studies have found a limited effect of economic and political inequality on conflict onset (see e.g. Collier and Hoeffler 2004; Fearon and Laitin 2003). Fearon and Laitin (2003) find that the factors that explain which countries experience civil war are not their ethnic or religious characteristics, but conditions that favors insurgency. More important than exclusion and ethnic identity are material incentives and organizational opportunities to start a rebellion against the state. In the same vein, Collier and Hoeffler (2004) find that conflicts occur because they are feasible, rather than a consequence of motivated actors who are marginalized. Others find that ethnic heterogeneity has a link to internal conflicts, as separatist wars, ethnic cleansing, or ethnic nepotism breeding conflict (see e.g. Vanhanen 1999; Gellner 1991; Sambanis 2001). However, the degree to which some of the measures used to assess the relationship between conflict and inequality are hitting the operationalized target can be questioned.

First of all, these studies have often used economic inequality indicators such as the Gini coefficient, which measures the income distribution among individuals, arguing that ethnic grievances are too common to explain the rare event of civil conflict. These studies have largely dismissed the role of economic inequality. However, other scholars argue 
that vertical measures such as the Gini coefficient is a highly aggregated proxy that do not capture the structural inequality between groups, and their relation to the state (see e.g. Østby 2008; Buhaug et al. 2011). In addition, the Gini measure has limited coverage, especially when it comes to Sub-Saharan countries. The data is also constructed from different sources, making the information more difficult to compare, and contain observations based on expenditure and income, on net and gross income, and per capita surveys. These different data sources may affect the coherence of the inequality measure. For example, because of income redistribution, the observations based on gross income should indicate more inequality than those based on net income (Houle 2009).

Second, most quantitative tests of whether political exclusion of groups leads to conflict, whether belonging to the greed and opportunity school or diversity breeding conflict school, rely on the same type of ethnic heterogeneity measurement (Wimmer, Cederman and Min 2009). However, demographic measures such as linguistic or ethnic fractionalization indexes can be problematic when modeling exclusion of groups. First, not all ethnic groups are relevant for politics. Second, demographic measures describe the degree of ethnic diversity in a country, which is not necessarily related to the constellation of power at the state center (Cederman, Wimmer and Min 2010). Hence, the demographic measures tend to be reflecting ethnic diversity that is not necessarily related to the dynamics of ethnic politics. Several in-depth studies on ethnic conflict show that cases where the state is not an ethnically neutral agent, but actively excluding specific groups, help explain the onset of internal conflict. Hence, the individual-level measures can be said to miss their theoretical target (Cederman, Wimmer and Min 2010; Cederman, Weidmann and Gleditsch 2011). In the same vein, Sambanis (2005) argues that wars should be measured according to group-based inequality, rather than by interpersonal inequality. As this thesis seeks to capture the economic inequality between groups, and their degree of inclusion at the state centre, the Gini coefficient and ethnic heterogeneity based measures are not viewed as satisfactory.

The Minorities at Risk (MAR) dataset builds on the work in the relative deprivation tradition, and has long been the most prominent measure for discrimination and exclusion of groups (Gurr 1993). This dataset focus on the relationship between ethnicity and conflict on the group level, rather than on the state level. Gurr (1993) find that ethnic minorities are more likely to rebel when there is widespread communal grievance. However, this data only focus on minorities, holding the state as a neutral agent, excluding 
the dynamics of ethnic power struggles at the center. In addition, the MAR data ignores groups in power from systematic consideration, which can reduce the comparative abilities of the data and make it more challenging to capture the effects of political exclusion over time. Shifts in power constellations may change the political status of a specific group, a political dynamic that can be central when trying to explain conflicts between groups. A group could go from being excluded in one period to being included in the next, and it is therefore important to treat access to power as a variable in change, rather than as a constant (Cederman, Wimmer and Min 2010).

To better capture the systematic economic inequality between groups, I use a groupbased measure of inequality presented by Stewart (2002). This measure differs from more individually or vertically based measures, as it focuses on horizontal inequalities (HI) between groups. To answer H1a, that economic inequality in a weak state further increases the risk of inter-group violence, I apply a measure from Cederman, Weidmann and Gleditsch (2011), lineq, where the variable defines inequality as the square of the logarithmized ratio between the GDP per capita of the ethnic group, and the average GDP per capita of all groups in the country:

$$
\operatorname{lineq}=[\log (g / G)]
$$

This measure captures deviations from the country average and is zero for groups at the country average. I also use two asymmetric variables of economic inequality that corresponds with groups that are wealthier or poorer than the country average:

$$
\begin{aligned}
\text { low ratio } & =\frac{G}{g} \text { if } g<G, 0 \text { otherwise } \\
\text { high ratio } & =\frac{g}{G} \text { if } g>G, 0 \text { otherwise }
\end{aligned}
$$

These two measures guarantees that deviations from the country mean always are positive numbers greater than one. This means that a group that is twice as wealthy as the average has low ratio $=0$, and high ratio $=2$, for example. The measure is based on the G-Econ data (Nordhaus 2006), which is one of the few broadly available cross-national data on variation in wealth within countries. The database covers Sub-Saharan Africa up to 2005, but the specific methodologies differ and some countries are lacking due to limited data availability, and I will therefore use multiple imputation. 
To be able to analyze the economic data on the country level, I have constructed three measures based on lineq, low ratio and high ratio. Economic Inequality is the maximum value that lineq has in country x in year x, and Poorest Group and Richest Group contains the maximum value that low ratio and high ratio has in country $\mathrm{x}$ in year $\mathrm{x}$, respectively. This will provide information about how poor/wealthy the poorest/wealthiest group is compared to the average. While I am able to capture the discrepancies between the richest and poorest group to the average, I am not able to measure whether it is the poorest or richest groups who engage in conflict. I am, however, able to say something about the level of inequality between groups, and how this might affect group violence. Hence, the inequality measures used as proxies cannot distinguish between the groups. Being aware of the limitations I choose to use the measure, as it is the best available data on economic distribution between groups within countries. Moreover, to be able to say something more specific on how wealthy the groups are in relation to each other provides the analysis with more information than simply using average per capita income for a country. More general national income measures will be dominated by more populated areas, and mask internal variations of group wealth that could be relevant for group conflicts. Indeed, at the country level that my analysis is based on, the likelihood of conflict should depend on the level of poverty and wealth of the most extreme groups, rather than on national average income of population weighted GDP per capita (Buhaug et al. 2011). The economic measures have a scope limited to a single year, 1990, leaving the level of economic inequality to be constant. Although not ideal, the relative inequality is often characterized as consistent over time, as opposed to absolute wealth. In addition, I am not interested in the long-run change in economic inequality, but the effects of having a certain level of economic inequality over time, and the measure should therefore be satisfactory.

To answer hypothesis $H 1 b$, whether political inequality in a weak state further increases the risk of non-state conflict, I include two political exclusion variables, taken from the Ethnic Power Relations dataset (EPR) (Cederman, Wimmer and Min 2010), which draws on a institutionalist approach to ethnic politics. This measure is chosen in an attempt to capture how ethnicity relates to the state, the role of the state as a politicized agent in society, and the capture of central authority to different degrees by representatives from a particular ethnic group. This data records all politically relevant ethnic groups in a country, and their degree of access to state power. The EPR dataset defines ethnicity as a subjectively experienced sense of commonality, based on a belief in common ancestry 
and shared culture (Wimmer, Cederman and Min 2009). These ethnic categories included in the data may be hierarchically nested and comprise of multiple levels, where not all groups are politically relevant at a given time. An ethnic group is seen as politically relevant if " (.. ) at least one significant political actor claims to represent the interests of that group in the national political arena, or if members of an ethnic category are systematically and intentionally discriminated against in the domain of public politics" (Wimmer, Cederman and Min 2009, 325). All politically relevant groups are categorized according to (1) whether those who claimed to represent its interest held full control of the executive branch with no participation by members of any other group, (2) whether they divided power with other groups through power-sharing, or (3) whether they were completely excluded from the decision making process at the state center (Cederman, Wimmer and Min 2010). As this thesis focuses on the exclusion of ethnic groups, I will only use the third category of political relevance. I will use an exclusion variable based on the sum of the population of excluded groups in the country. To be able to get a more normalized measure that gives information about the relative amount of group exclusion, I have constructed a variable, In(Excluded Population), which is the excluded population as a fraction of the total population, and $\ln$ (Largest Excluded Group), which the size of the largest excluded group in the country, as a fraction of the total population. Both political exclusion measures are log-transformed with the expectation of a declining marginal effect of exclusion on non-state conflict risk.

The EPR dataset includes all politically relevant ethnic groups and their degree of power at the state center, and this has several gains. The EPR data takes into account that not all ethnic groups are necessarily relevant for state politics, which is a more precise approach than conventional demographic measures that captures only the degree of ethnic diversity in a country. Also, the EPR data focuses on included and majority groups in addition to excluded groups, and how the inclusion and exclusion of groups change over time, and is thereby able to capture the dynamics of ethnic politics at the state center. The EPR data covers the years from 1989 to 2009, and lacks four Sub-Saharan countries; Cape Verde, Equatorial Guinea, Comoros and Mauritius, and I will use multiple imputation to handle this issue.

\subsubsection{Making the Case for Interactions}

If it is true that a weak state creates anarchical structures between groups, this should increase the likelihood of inter-group violence. For my theoretical framework, also the 
additional effects of economic and political inequality within a weak state are essential. Hence, it is important to not only look at weak state per se, but also the effect of the state's role in the exclusion of groups. It could perhaps be claimed that Sub-Saharan Africa is in itself an interaction term, keeping in mind the relatively large amount of weak states on the continent. However, as several countries, such as South Africa, Namibia, Botswana, Ghana and Kenya, have recieved scores above 3 on bureaucratic quality indicator, I do not consider this a problem. Sandbrook (1986) warns about assuming too high a degree of uniformity in Africa, and claims that there " (..) is indeed variation in the degree of state capacity" (Sandbrook 1986, 327). It is important to note, however, that the concept of "strong" can be relative in the African context.

The criticism of including interaction terms in multiplicative regression models have been, amongst other factors, increased difficulty with interpretation, large standard errors, and results with less substantive meaning. However, a model that includes interaction terms provides coefficients that give a more detailed description of the relationship between the dependent variable and the independent variables than without. An interactive model enables an assessment of the possibility that relationships between variables change with changes in other variables (see e.g. Friedrich 1982; Brambor, Clark and Golder 2005). This is especially relevant for my analysis, as the whole idea of weak state capacity's effect on inter-group violence is dependent on some third aspect, here economic and political inequality.

\subsubsection{Control Variables}

When it comes to my control variables, I seek to balance two considerations. First, I attempt to avoid overspecifying my models by the inclusion of irrelevant variables, following what Achen $(2002,424)$ warns about in much contemporary statistical modeling ${ }^{5}$;

Even at the most quantitative end of the profession, much contemporary empirical work has little long-term scientific value. 'Theoretical models' are too often long lists of independent variables from social psychology, sociology, or just casual empiricism, tossed helter-skelter into canned linear regression packages.

Second, I seek to reduce the risk of excluding important explanatory factors in my analysis. Thus, I have tried to avoid a model specification including variables with no partial effect on $y$ and omitted variable bias (Wooldridge 2009). The control variables chosen

\footnotetext{
${ }^{5}$ See also Schrodt (2010), Achen (2005) and Ward, Greenhill and Bakke (2010).
} 
have previously demonstrated predictive power in the civil conflict literature, and I include controls for civil war, infant mortality rate, population, politically relevant groups

and peace years. I run several robustness checks to make sure that the results in the models presented are robust and not driven by the choice of indicators.

\section{Civil War}

Non-state violence during peace, and non-state violence during civil war belongs to two different contexts that both induce and hinder violence in different ways. The security threat between groups in a weak state is perhaps more apparent in the context of civil war, but through different mechanisms, as the government is also involved in the conflict. I follow Kalyvas (2006), and view civil war as a complicated and interactive phenomenon, where there are additional conflicts during civil war than that between the state and a rebel group. Indeed, national-level discourse have often little in common with subnational conflicts, where conflicts on the ground tend to be related to local issues rather than the master cleavage that drives the civil war on the national level. In other words, " (...) the fusion and interaction between dynamics at the center and the periphery is fundamental rather than incidental to civil war, a matter of essence rather than noise" (Kalyvas 2006, 365). Thus, the outbreak of violence at the national level between a government and one or several rebel groups can also influence the risk of inter-group violence at the local level, and it is important to account for whether civil war affect the likelihood of violence between groups.

The civil war data included in this thesis is taken from the widely used UCDP/PRIO Armed Conflict Dataset, which includes both major and minor conflicts (Gleditsch et al. 2002). An armed conflict is defined as an incompatibility that concerns government or territory or both, where the use of force between two warring parties results in at least 25 battle-related deaths. Of these two parties, at least one has to be the government of state. Minor conflict records conflicts that reaches at least 25 battle-related deaths in a year, while major conflicts are those who pass the 1000 annual deaths threshold. While the original dataset separates between minor and major conflict, I have constructed a new variable for my analysis. The variable Civil War, taken from Hegre et al. (forthcoming), combines minor and major war. Hence, the variable takes on the value 1 if there was a civil war, either minor or major, in a given country in a given year, 0 otherwise. I have chosen to combine the two as I am most interested in the presence or absence, and not the quantity, of violence in a country. Also, as with inter-group violence, a lower threshold 
results in more conflicts in the data, making the statistical analysis more well-founded and robust. The civil war variable has full coverage of all Sub-Saharan African countries from 1989 to 2011.

\section{Infant Mortality Rate}

The most common proxy for economic development is income level. It is a robust measure within the literature of civil conflict, where lower level of GDP per capita affects the risk of conflict onset and duration, through factors such as recruitment costs and feasibility (Collier and Hoeffler 2004; Collier, Hoeffler and Söderbom 2004), infrastructure (Fearon and Laitin 2003), and asset specificity (Boix 2008). However, infant mortality rate (IMR) has been promoted as an alternative measure of level of development, capturing a broader set of developmental factors than the standard measure of income levels such as GDP per capita. Several studies have reported a strong effect of infant mortality on conflict (see e.g. Esty et al. 1998; Urdal 2005; Abouharb and Kimball 2007). I include the variable $\ln$ (Infant Mortality Rate), which is the natural logarithm of infant mortality rate. The measure has been log-transformed following an expectation of a declining marginal effect on conflict risk with increasing infant mortality. Infant mortality is defined as the probability of dying between birth and exact age 1, expressed as the number of infant deaths per 1000 live births. The variable is taken from Hegre et al. (forthcoming), and has complete coverage of all Sub-Saharan African in the sample.

\section{Population}

While many explanatory factors in the civil war literature are not robust or replicable across analyses, population size is a variable proven to be robust in different statistical studies studies, where larger populations are associated with increased conflict risk in the civil conflict literature (see e.g. Raleigh and Hegre 2009; Gleditsch, Hegre and Strand 2009; Hegre and Sambanis 2006; Fjelde 2010). The variable $\ln$ (Population) is taken from the World Population Prospects 2006 constructed by the United Nations Population Divisions (United Nations 2007). The data provides estimates on demographic indicators for all Sub-Saharan countries from 1989 to 2011. Total population is defined as the actual size of the population in thousands as of July 1st of the given year. This measure has also been log-transformed, with the expectation of a declining effect of increasing population size on conflict risk. This measure has complete coverage of all Sub-Saharan countries included in the analysis from 1989 to 2011. 


\section{Number of Groups}

Following Cederman, Weidmann and Gleditsch (2011), I have included a variable to control for the number of groups in a country. Cederman, Weidmann and Gleditsch (2011) assume that the number of groups has a negative impact on conflict probability, as governments facing many ethnic groups fear domino effects and will therefore be less willing to make concessions to a single group. Although this negative relationship may be useful when studying civil war, it is not directly transferable to inter-group violence. In fact, I expect the exact opposite than Cederman, Weidmann and Gleditsch (2011), that an increase in number of excluded groups in a country also increase the risk of inter-group violence. This is simply based on the assumption that more excluded groups also leads to an increase in the number of potential conflict dyads between groups. The variable Relevant groups is a count variable indicating the total number of politically relevant groups in a country, as defined by EPR (Cederman, Wimmer and Min 2010). The variable is taken from the GROWup data (GROWup nd), and has the same coverage as $\ln$ (Largest Excluded Group) and $\ln$ (Excluded Population).

\section{Peace Years}

When using cross-section time-series it is important to account for interdependence among the observations. The logistic regression model assumes that observations are independent of each other, meaning that the risk of inter-group violence in D.R. Congo next year is taken to be independent of an inter-group conflict this year. However, this is an inappropriate assumption, and ignoring interdependence may lead to biased results. The incorrect assumption of temporal independence leads to both inaccurate statistical analyses and loss of information in the data (Beck, Katz and Tucker 1998; Beck and Gleditsch 2003). One option to account for time dependence is to include a series of dummy variables to the model specification. These variables mark the number of years since the previous occurrence of an event (Box-Steffensmeier and Jones 2004). $K_{t-t 0}$ can be understood as baseline hazards, giving the probability of a failure in each time interval when all the explanatory variables are zero. However, to be able to create a smoother baseline hazard rate that changes relatively slowly over time, I choose to include natural cubic splines instead of temporal dummies (Carter and Signorino 2010), that avoids hazard rates jumping around from year to year. Natural cubic splines make it possible to specify points in $t$ where the relationship with $y$ changes, usually referred to as knots. These knots determines the location where the dependent variable and $t$ can change significantly. I include the variable peace years with three cubic splines, and use a similar 
logic in the selection of knots as Beck, Katz and Tucker (1998), but with the inclusion of an additional knot, placing knots at $t=1,3,7,15$ years in peace. ${ }^{6}$

Green, Kim and Yoon (2001) stress the need to account for unobserved differences between units that change over units but not over time (Green, Kim and Yoon 2001). Although fixed effects control for omitted variables, there are two reasons why I have not chosen to apply this method in my analysis. First, using fixed effects to address time-dependence can have harmful affects when using a binary dependent variable, as many countries in the dataset will always have the value zero, and hence having no impact on the parameter estimates, causing misleading results when assessing the impact of important independent variables (Beck and Katz 2001). Without variation on the dependent variable, fixed effects models do not contribute to the explanation as change in the dependent variable is a necessary precondition to be able to draw inferences in a fixed effects regression. Second, Sub-Saharan countries can be claimed to be quite similar, at least compared to European or Latin American countries, leaving the sample with little variation over units.

\subsection{Methodological Challenges}

I focus on four methodological challenges which may produce false inferences concerning the relationship between inter-group violence and weak state, and economic and political exclusion. In the following I present the features of omitted variable bias, simultaneity, multicollinearity and missing data in an attempt to best handle these issues in my analysis.

\subsubsection{Omitted Variable Bias}

As already mentioned in section 5.2.5, the amount of control variables chosen for the models are limited to avoid overspecification. Yet, more restricted models have an increased risk of excluding variables that both affect inter-group violence and the main independent variables included in the analysis, making biased results more likely (Greene 2003, 148). For example, the results could be distorted if the length of peace years are not taken into account in the models, as a recent conflict may affect the likelihood of groups resorting

\footnotetext{
${ }^{6}$ The number of knots were chosen after several regression analyses, where changes in both number and placement of the knots had very limited impact on the results. I chose an additional knot after 15 years as it seems intuitively reasonable to assume that the hazard rate to some extent flattens out after 15 consecutive years without conflict.
} 
to violence, especially if the groups previously have engaged in fighting with each other. A recent conflict will most likely also affect the capacity of any government, making the bureaucracy and infrastructure weaker than before conflict onset. Hence, previous conflicts may affect both the strength of a state and the probability of inter-group violence. To try to account for potential omitted variable bias, I run several robustness checks with alternative measures for state capacity, and also include other control variables.

\subsubsection{Reverse Causality}

Simultaneity refers to the possibility that not only $x$ has an impact on $y$, but at the same time $y$ has an impact on $x$. Thus, the causal impact is uncertain when both $x$ and $y$ is simultaneously determined, and it is difficult to specify which of them is having an effect on the other (Verbeek 2008, 138). Hence, inter-group violence may well cause state weakness, and vice versa. The best solution to deal with simultaneity is according to Hendrix (2010) to either choose which variables to include based on theoretical rather than empirical reasons, or to use instrumental variables analysis. However, good instrumental variables are difficult to find, and another potential solution to reduce the threat of reversed causality is to use lagged variables. Therefore, I lag all my independent variables in the analysis. Also, I expect some of the simultaneity problem to be ameliorated with the usage of peace years in the models, as the time variable accounts for some of the effect violence has on state capacity.

\subsubsection{Multicollinearity}

A high correlation between two variables can introduce biased results in the analysis. A multicollinearity problem emerges when there is high correlation between two or more explanatory variables in the model. This indicates that the two explanatory factors have a tendency to be present at the same time. Hence, if one of the explanatory factors is present, so will the other, and vice versa. This implies that it can be difficult to decide the relative effect of the two variables. Multicollinearity can introduce statistical problems, for example that small changes in the data produce wide swings in the estimates, or that the coefficients have very high standard errors and low significance levels (Greene 2003, 56). Collinearity is usually not a problem below 0.8 , but above this threshold the standard error would become increasingly large. 
Table 5.2: Cross-Correlation Table for Interactions

\begin{tabular}{|c|c|c|c|}
\hline Variables & Weak State & Economic Inequality & Weak State ${ }^{*}$ Ec. inequality \\
\hline Weak State & 1.000 & & \\
\hline Economic Inequality & -0.123 & 1.000 & \\
\hline Weak State $*$ Ec. Inequality & 0.480 & 0.173 & 1.000 \\
\hline Variables & Weak state & Poorest group & Weak State ${ }^{*}$ Poorest \\
\hline Weak State & 1.000 & & \\
\hline Poorest & -0.091 & 1.000 & \\
\hline Weak * Poorest & 0.973 & 0.007 & 1.000 \\
\hline Variables & Weak state & Richest group & Weak State * Richest \\
\hline Weak State & 1.000 & & \\
\hline Richest group & -0.108 & 1.000 & \\
\hline Weak State * Richest & 0.946 & -0.008 & 1.000 \\
\hline Variables & Weak state & Largest Excl. Group & Weak State ${ }^{*}$ Largest Excl. Group \\
\hline Weak State & 1.000 & & \\
\hline Largest Excl. Group & 0.034 & 1.000 & \\
\hline Weak * Largest Excl. Group & -0.896 & 0.213 & 1.000 \\
\hline Variables & Weak state & Excl. Population & Weak State ${ }^{*}$ Excl. Population \\
\hline Weak State & 1.000 & & \\
\hline Excl. Population & 0.011 & 1.000 & \\
\hline Weak * Excl. Population & -0.835 & 0.276 & 1.000 \\
\hline
\end{tabular}

Source: ICRG (ndb), Cederman, Weidmann and Gleditsch (2011), (Hegre et al. forthcoming)

Table 5.2 shows the bivariate correlation between the independent variables included in the interaction terms in the analysis. The instances where the variables have a higher correlation than 0.8 are in bold, which are all the interaction terms included in the models. That the variables have a high degree of correlation between them is perhaps not surprising, as the interaction terms are functions of the original variables. However, this will lead to an increase in the standard errors, and can make the relationships in the analysis non-significant. ${ }^{7}$ I have chosen to include the interaction terms despite high correlation, as not including the interaction terms would following my theoretical framework lead to omitted variable bias, which is arguably a more severe bias than multicollinearity. Nonetheless, the variables containing high correlation should be interpreted with caution.

\subsubsection{Missing and Multiple Imputation}

Missing data is common in the literature on armed conflict, and this thesis is no exeption. Factors considered to be of importance when explaining conflict incidence, such as demographic and socio-economic indicators, are in many countries scarce or non-existent. Some of the variables I use in the analysis contain missing from the original datasets ${ }^{8}$, and missing data is a central challenge for my analysis. Two of the three main explanatory variables, weak state and economic inequality, have completely missing on countries

\footnotetext{
${ }^{7}$ None of the control variables have a higher correlation than 0.5 .

${ }^{8}$ See Appendix B for missingness map.
} 
like the Central African Republic, Burundi and Somalia, accounting for 25 inter-group conflict outbreaks alone. Hence, it is important to find the most satisfactory approach to handle missing data.

The most common way of dealing with missing data in quantitative studies is to carry out "listwise deletion". This method entails limiting the analysis to those units which have complete data coverage, and deleting everyone else (Little and Rubin 2002). When the data is missing completely at random (MCAR), the only consequence of listwise deletion is loss of efficiency, indicating that the probability of type 2 errors increases. This procedure does not add any new information to the units, but reduces the models predictive ability. There are two relevant problems with this method. First, the assumption of MCAR is often not met in quantitative studies, i.e. that the missingness depends only on the missing value generating mechanism, and not on the dependent variable. Hence, whether a country was in conflict or not would not give any indication about the probability of an observation being missing, which is often not the case. In fact, it is often the countries that have missing that sees the most conflict outbreaks in the first place (Høyland and Nygård 2012). King et al. (2001) show that using listwise deletion under the most optimistic assumptions causes the estimates to be about a standard error farther from the truth. Second, I seek to obtain an as complete dataset as possible, and deleting units which have missing observation would obstruct the usage of all information available. As the dataset contains several units with one or more missing observations, I would lose much valuable information by deleting an entire country at time $t$. Data may well be missing at random (MAR), which entails that the probability of an observation being missing depends and can therefore be explained by other non-missing values. However, listwise deletion would still give biased results if the missing sample is not representative of the full sample (Høyland and Nygård 2012).

Linear imputation techniques are also common tools for handling missing data. Linear interpolation entails filling in missing data between observed time points from time $t$ to time $t_{+1}$ linearly. Filling in missing points for one year if you have data for 2003 and 2005, for example, is not problematic. However, when the time periods between the observed data points increase, the linear imputation becomes increasingly problematic as the uncertainty of the true value increases. With economic inequality measures included in the analysis, for example, there is no information from 2005 to 2011, making the linear imputation more difficult to complete accurately. Also, the analysis includes countries 
that have complete missing on certain variables, making the linear imputation techniques less suitable. Clearly imputed values are not known, and since they are imputed they are not observed meaningfully either (Høyland and Nygård 2012). Hence, unless one is able to fill in the holes with the true values of the data that are missing, the statistical analysis assumes that the data have more observations than are actually observed, which leads to exaggerated certainty in the results, and biased confidence intervals and standard errors (Honaker and King 2010). Of course, imputed values are by definition guesses, but under single imputation techniques they are not treated as such, but as data points with the same precision as observed values without any associated uncertainty. Uncertainty concerning the missing data is hard to take into account under single imputation, which leads to under-coverage. Multiple imputation techniques, however, explicitly take imputational uncertainty into account (Høyland and Nygård 2012).

Normal imputation models assume that missing values are linear functions of other observed variables, that observations are independent conditional on the remaining observed units, and that all the observations are not organized hierarchically. These assumptions do not work well for panel data, as there is a tendency for variables to move smoothly over time, to jump sharply between units like countries, and to jump less between countries that are adjacent (Honaker and King 2010). Time-series often differs across countries, and it is important to take this into account. Multiple imputation handles missing by filling in the holes in the data using a predictive model that includes all available information in the observed data together with any prior knowledge. Multiple completed datasets are created where the observed data remains the same, but the missing data are filled in with imputations. The expected value for any missing observation is the mean of the imputed values across these different datasets, and the uncertainty in the model is represented by the variation across the multiple imputations for each missing value. Hence, this removes the under-coverage and overconfidence that results from a single analysis, by incorporating the variation across the estimates from each completed dataset into the standard errors (Honaker, King and Blackwell 2011). ${ }^{9}$ Although not a flawless approach, the estimates are presented with uncertainty when using multiple imputation, represented in the variation between the different imputations for the missing

\footnotetext{
${ }^{9}$ Despite the advantages of using multiple imputation, there will be uncertainty in the data given the amount of missing in my sample. Also, imputation of missing data can fail when a discrete variable has missing values. Multiple imputation techniques often rely on continuous distributional assumptions, and this can produce illogical imputations and spuriously low standard errors (Cranmer and Gill 2012). However, I view the use of multiple imputation as a more suitable option than alternatives such as listwise deletion and linear interpolation. Also, given that I do not have missing on any of my dummy variables in my analysis, I do not consider this point a direct challenge.
} 
values. This uncertainty will be modeled in my analysis by running regressions on all the imputed datasets.

To perform multiple imputation I use Amelia II, which is a general-purpose approach to data with missing values. As we are only able to observe $D^{\text {obs }}$, and not the entirety of $\mathrm{D}$, Amelia makes an assumption in multiple imputation that the data is MAR. This assumptions means that the pattern of missingness only depends on the observed data $D^{o b s}$, and not on the unobserved data $D^{m i s}$, which is a less strict assumption than MCAR applied by listwise deletion. Multiple imputation has to assume that the missing observations are MAR, as the model conditions on the observed data when drawing values for the missing cells (Høyland and Nygård 2012). After multiple imputation, I run the analyses on the imputed datasets, and the coefficients and standard errors of the results are combined over the D estimations. By combining the results I am able to create an inference that validly reflects the sampling variability caused by the missing values. Thus, uncertainty about the correct model is apparent by the variation in the results across the models (Little and Rubin 2002). Another option is to average the values for the variables in the different imputed dataset. I have chosen not to do so, as this would simply create a single imputed dataset with the uncertainty of the different imputations lost, not reflecting sampling variability.

In my imputation model I allow all ordinals to be treated as continuous variables, as recommended by Honaker and King (2010). This indicates that the bureaucratic quality measure taking on integers from 0 to 4 , is allowed to take on values in between the integers in the imputed dataset. This simply means that a country obtaining a score of 1.26, for example, has a lower bureaucratic quality than a country obtaining a score of 1.27. By treating ordinals as continuous more uncertainty is included in the model, and the non-integer provides more information about the underlying distribution than would be the case if I forced the imputation to be integers. To account for the fact that trends over time are likely to differ between units, I include a third order polynomial of time to let trends vary between cross-sections. I also include lags and leads to account for autocorrelation. Both past and future values of a variable are likely to be correlated with the current value, and an inclusion of both leads and lags should therefore improve the model. I have also included logical bounds for minimum and maximum values on the main variables, and thereby avoiding that bureaucratic quality, for example, has values below 0 and above 4 , which is the given range of this variable. As my data contains a 
high degree of missing, I include a ridge prior to speed up the convergence by increasing numerical stability by shrinking the covariances among the variables, without changing the overall mean or variance (ibid). The goal is to reduce variance to increase efficiency without introducing bias in the data, and I hope to achieve this by setting the ridge prior at .001 percent. Such a small prior is able to achieve efficiency gains, and is at the same time unlikely to introduce a bias. I have imputed ten datasets in total.

When using multiple imputation to handle missing data, it is important to check the distribution of the imputed values (Honaker, King and Blackwell 2011). It is often held that the quality of multiple imputation and its underlying assumptions cannot be tested from observed data. However, imputations that have unexpected distributions or are far from the observed data may indicate that the imputation model did not perform well. Thus, the distribution of the completed data as a whole can be checked to see whether they are plausible in the context of the topic being studied. I have therefore run imputation diagnostics to test the imputation model's fit.

First, although it is impossible to test the MAR assumption given the model since the information to perform such a test is by definition unavailable, there can be indirect evidence of problems relating to the missing data assumptions. A way to do this is to compare the empirical distribution of the observed and imputed data by using the Kolmogorov-Smirnov (KS) test, as recommended by Abayomi, Gelman and Levy (2008). When applied to the main independent variables in my analysis, there is evidence for statistically significant differences between the observed and imputed data. However, the distribution of missing can differ from the observed data, and still be missing at random (ibid). Figure B.2 in Appendix B shows a kernel density plot, and is in a sense a visual representation of the KS test. It can be seen that the difference between observed and imputed values are more divergent at higher density levels. The total consequence of this for the analysis is difficult to assess, but a skewed sample towards the mean and right, may underestimate the effects of inequality in the analysis. The two bottom panels have quite different distribution than the observed values, which can be a consequence of economic inequality being missing at different rates.

Second, I make use of overimputation. ${ }^{10}$ Figure B.3 runs this procedure through all

\footnotetext{
${ }^{10}$ Overimputation involves treating each of the observed values as if they had been missing. It is then possible to graphically inspect whether my observed data tends to fall within the range where it would have been imputed had it been missing.
} 
the observed values for weak state and poorest group. It is not a perfect imputation model, especially for the higher levels of weak state. However, as the majority of imputation falls within the range of the observed value, I consider the test for overimputation as satisfactory.

Third, I inspect the imputed variables visually in scatterpots. ${ }^{11}$ After imputation I check whether the prediction and imputation seems reasonable in comparison to other countries with similar values on variables such as GDP, governance, population and infant mortality rate. The scatterplots in figure B.4 show that the imputed values are to a large degree in line with the trend in the observed data, although with a higher level of uncertainty. This uncertainty simply reflects the true uncertainty of the imputation. Despite the fact that the KS test showed significantly different trends of the imputed and observed values in the data, the Kernel density plot, overimputation and scatterplots give me reason to believe that the imputation model is sufficiently accurate to base my analysis on. Nonetheless, it is important to be aware of potential weaknesses when making inferences, as the data with completely missing is based on prediction, and not on previously observed values.

\subsection{Summary: The Dataset}

I construct a dataset consisting of 1053 observations, with 69 inter-group conflict events from 1989 to 2011. The time period is according to the data available on non-state conflicts, and I have limited the independent and control variables to all begin in 1989 . The data covers 46 Sub-Saharan countries. ${ }^{12}$ All variables in the analysis are lagged to reduce the risk of reversed causality. I include robust standard error to account for heteroskedasticity by reporting more restricted standard errors (Long and Freese 2006). Also, I cluster by country to account for correlation between the error terms for consecutive observations for the same unit of analysis, also known as autocorrelation or serial correlation. Clustered standard errors accounts for the assumption in the model that all the observations are independent of each other.

\footnotetext{
${ }^{11}$ For countries with completely missing on a variable, I have chosen a hybrid between a "hot deck" approach and predicting values, mainly because the amount of transparency and overview of the data at hand seems more present, than with simply imputing where there is no correlation to draw on from previous or consecutive years. When predicting values for missing observations, I set the missing independent variable as dependent variable, and include variables in the model that can help explain, for example, economic inequality, and predict values for economic inequality in countries with completely missing.

${ }^{12}$ See table A.2 in Appendix A for an overview of countries included in the analysis.
} 
The data on inter-group violence is provided by Sundberg, Eck and Kreutz (2012a), as part of the Uppsala Conflict Data Program (UCDP). The data on state capacity is taken from ICRG (nd $a$ ), while the political and economic exclusion measures are EPR data derived from Cederman, Weidmann and Gleditsch (2011) and Cederman, Wimmer and Min (2010). The data on civil war, population and infant mortality rate is taken from Hegre et al. (forthcoming). Descriptive statistics for the non-imputed dataset can be found in Appendix A, table A.1.

Table 5.3: Descriptive Statistics: Imputed data

\begin{tabular}{lccccc}
\hline \multicolumn{1}{c}{ Variable } & Mean & Std. Dev. & Min. & Max. & N \\
\hline Inter-group Violence, logit & 0.065 & 0.247 & 0 & 1 & 1053 \\
Inter-group Violence, count & 0.119 & 0.536 & 0 & 5 & 1053 \\
Weak State & 0.205 & 0.404 & 0 & 1 & 1053 \\
Economic Inequality & 0.237 & 0.417 & 0 & 2.445 & 1053 \\
Poorest Group & 1.231 & 0.304 & 0.673 & 2.434 & 1053 \\
Richest Group & 1.365 & 0.653 & 0.865 & 4.776 & 1053 \\
Civil War & 0.212 & 0.408 & 0 & 1 & 1053 \\
$\ln ($ Largest excluded group) & -2.151 & 1.329 & -8.502 & -0.092 & 1053 \\
$\ln$ (Excluded population) & -1.818 & 1.369 & -8.502 & -0.084 & 1053 \\
$\ln$ (Population) & 8.777 & 1.377 & 5.810 & 11.994 & 1053 \\
$\ln$ (Infant Mortality Rate) & 4.457 & 0.440 & 2.557 & 5.232 & 1053 \\
Relevant Groups & 4.649 & 3.387 & 0 & 16 & 1053 \\
\hline Source: UCDP Non-State Conflict Dataset (Sundberg, Eck and Kreutz 2012a), & \multicolumn{5}{c}{ Cederman, Weidmann and Gleditsch (2011), Hegre et al. (forthcoming) }
\end{tabular}




\section{Chapter 6}

\section{Analysis}

The theoretical expectations in this thesis is that being a weak state increases the risk of inter-group violence, and that this risk is further increased by the presence of economic and political marginalization. The objective of the analyses in this chapter is to assess this potential relationship, and to examine whether the level of state capacity is important when trying to explain inter-group violence. I start off by presenting some descriptive statistics, to take a closer look at the tendencies in the data. Second, I present my multivariate regression analyses, where I begin with a logit and count model with control variables, before presenting interaction terms for economic and political inequality. Lastly, I assess the performance of the models. ${ }^{1}$

\subsection{Descriptive Statistics}

Figure 6.1 shows the frequency of non-state conflicts in Sub-Saharan Africa between 1989 and 2011. The graph shows that inter-group conflicts were more frequent during the 1990s, followed by a peak in 2003, whereafter the number of conflicts was reduced. The peak in 2003 is based on 11 inter-group conflicts in 5 different countries; 5 conflicts in D. R. Congo, 1 in Uganda, Burundi and Sudan, and 3 in Somalia. The period 1989 to 1991 has relatively few non-state conflicts, whereas the number fluctuates after 1994 . The fluctuation in the number of conflicts can perhaps be due to organizational characteristics, where rebel groups have a more continuous mobilized base of support, whereas organized groups solely focused on attacking other groups may have a more volatile support base and access to funding (Sundberg, Eck and Kreutz 2012a).

\footnotetext{
${ }^{1}$ A baseline model can be found in Appendix C, table C.1.
} 
Figure 6.1: Number of Non-State Conflicts, 1989-2011: Count dependent variable

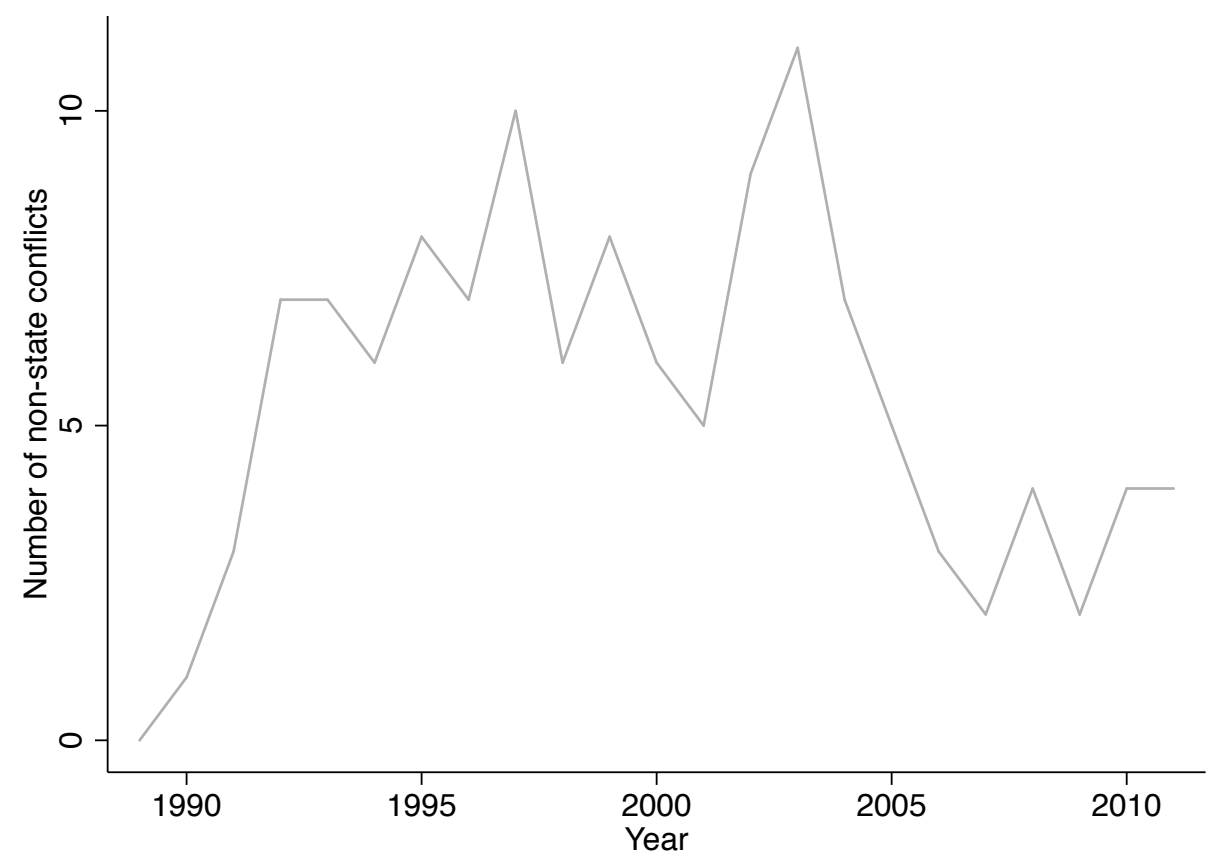

Source: UCDP Non-State Conflict Dataset (Sundberg, Eck and Kreutz 2012a)

Table 6.1 provides some preliminary evidence for $H 1$, that states with weak state capacity experience more inter-group violence than strong states. Of all the inter-group conflicts in Sub-Saharan Africa between 1989 and 2011, 61 percent were in weak states, whereas 39 percent were in stronger. This supports what previously have been stated by scholars such as Lichbach (1995), Herbst (2000) and Fjelde and de Soysa (2009), where weak states tend to lack the ability to accommodate grievances and hinder collective dissent.

Table 6.1: Inter-group Conflicts by Regime Strength

\begin{tabular}{lcc}
\hline \multicolumn{1}{c}{ State Capacity } & Inter-group Violence & N \\
\hline Weak State Capacity & 42 & 227 \\
Strong State Capacity & 27 & 826 \\
Total & 69 & 1053 \\
\hline Source: UCDP Non-State Conflict Dataset (Sundberg, Eck and \\
Kreutz 2012a), Cederman, Weidmann and Gleditsch (2011)
\end{tabular}

Table 6.2 shows the number of conflicts for countries with economic exclusion above and below the mean. 1.27 is the mean value of economic exclusion for the whole sample. The table shows that the majority of inter-group conflicts have occurred in countries where the amount of economic exclusion is above the mean, compared to countries below 
this threshold. This provides some preliminary evidence that the the degree of economic inequality is relevant for non-state conflict.

Table 6.2: Inter-group Conflicts by Amount of Economic Exclusion

\begin{tabular}{lcccc}
\hline Size of ec. exclusion & Inter-group Conflicts & Mean & Std. Dev & N \\
\hline$<1.27$ & 28 & 1.086 & 0.153 & 646 \\
$>1.27$ & 41 & 1.553 & 0.316 & 407 \\
Total & 69 & 1.267 & 0.307 & 1053 \\
\hline
\end{tabular}

Source: UCDP Non-State Conflict Dataset (Sundberg, Eck and Kreutz 2012a), Cederman,

Weidmann and Gleditsch (2011)

Table 6.3 shows the frequency of inter-group violence according to the size of the largest excluded group, below and above the mean. In contrast to table 6.2, there is no clear tendency of more inter-group violence when the size of the excluded group is large. ${ }^{2}$ There is an approximately equal share of inter-group violence in both cases, displaying no preliminary trends for political exclusion and non-state conflict.

Table 6.3: Inter-group Conflicts by Size of Largest Excluded Group

\begin{tabular}{lcccc}
\hline Status & Inter-group Conflicts & Mean & Std. Dev & $\mathbf{N}$ \\
\hline$<.15$ & 36 & 0.023 & 0.039 & 639 \\
$>.15$ & 33 & 0.359 & 0.189 & 414 \\
Total & 69 & 0.212 & 0.408 & 1053 \\
\hline
\end{tabular}

Source: UCDP Non-State Conflict Dataset (Sundberg, Eck and Kreutz 2012a), Cederman, Weidmann and Gleditsch (2011)

Table 6.4 shows the frequency of inter-group conflicts within countries in the sample. The first column shows that 1 ongoing conflict within a country is the most frequent number both in weak and strong states, with 22 and 18 conflict events. For 2, 3, 4 and 5 ongoing conflicts in a country year, the amount is higher throughout for weak state capacity. The three country years that saw five ongoing conflicts was D.R Congo in 2003, and Somalia in 1995 and 1999. The interesting case of 4 ongoing conflicts in a strong state was in Sudan in 1997, during the civil war. Thus, the preliminary evidence shows some support for hypothesis $H 1$ and $H 1 a$, but the picture is less clear when it comes to the effect of political exclusion in hypothesis $H 1 b$.

\footnotetext{
${ }^{2}$ The tendency is the same with the measure for amount of excluded population.
} 
Table 6.4: Conflict Events within States

\begin{tabular}{lccc}
\hline N Conflicts & Weak State & Strong State & N \\
\hline 1 & 22 & 18 & 40 \\
2 & 9 & 6 & 15 \\
3 & 4 & 2 & 6 \\
4 & 4 & 1 & 5 \\
5 & 3 & 0 & 3 \\
\hline Total & 88 & 37 & 69 \\
\hline \multicolumn{2}{l}{ Source: UCDP Non-State Conflict Dataset (Sundberg, Eck } \\
and Kreutz 2012a)
\end{tabular}

\subsection{Multivariate Regression Results}

I begin by evaluating my first hypothesis in models 1 to $8, H 1$, that suggests a relationship between weak state capacity and the occurrence of inter-group violence. Second, I present the results in models 9 to 12 evaluating $H 1 a$, whether economic inequality in a weak state increases the risk of non-state violence. Third, I present the results from model 13 to 16 to assess $H 1 b$, whether political inequality in a weak state increases the risk of inter-group violence. All models include control variables for size of population, infant mortality rate, number of groups and peace years. The analysis is based on a time-series cross-sectional dataset of 47 countries from 1989 to $2011 .^{3}$ All the independent variables are lagged with one year.

\subsubsection{Weak State Capacity}

Table 6.5 reports the results from eight multinomial regressions. Models termed logit are based on logistic regression, while models termed count are based on negative binomial regression. The results in the table suggests that states with limited capacity are more likely to experience inter-group violence, and provides support for $H 1$. In all models the odds ratio for weak state are above 1 and significant at the 0.01 level. The degree of capacity in a given state thus has explanatory power when it comes to the variation in non-state conflicts between units.

According to the theoretical framework, weak states lack territorial control and information within the state apparatus, and groups therefore end up providing for their own

\footnotetext{
${ }^{3}$ See Appendix A, table A.2 for an overview of the countries included in the analysis. I follow the same threshold as Cederman, Weidmann and Gleditsch (2011), including countries with a population above 500.000 in the analysis.
} 
Table 6.5: Logistic and Count Regressions: Estimated odds and incidence odds of intergroup violence in Sub-Saharan Africa, 1989-2011

\begin{tabular}{|c|c|c|c|c|c|c|c|c|}
\hline & $\begin{array}{c}(1) \\
\text { Logit }\end{array}$ & $\begin{array}{c}(2) \\
\text { Count }\end{array}$ & $\begin{array}{c}(3) \\
\text { Logit }\end{array}$ & $\begin{array}{c}(4) \\
\text { Count }\end{array}$ & $\begin{array}{c}(5) \\
\text { Logit }\end{array}$ & $\begin{array}{c}(6) \\
\text { Count }\end{array}$ & $\begin{array}{c}(7) \\
\text { Logit }\end{array}$ & $\begin{array}{c}(8) \\
\text { Count }\end{array}$ \\
\hline Weak State & $\begin{array}{l}4.024^{* *} \\
(2.095)\end{array}$ & $\begin{array}{l}3.297^{* *} \\
(1.360)\end{array}$ & $\begin{array}{l}4.491^{* *} \\
(2.353)\end{array}$ & $\begin{array}{l}3.767^{* *} \\
(1.528)\end{array}$ & $\begin{array}{l}4.288^{* *} \\
(2.164)\end{array}$ & $\begin{array}{l}3.786^{* *} \\
(1.571)\end{array}$ & $\begin{array}{l}4.820^{* *} \\
(2.503)\end{array}$ & $\begin{array}{c}4.361^{* * *} \\
(1.816)\end{array}$ \\
\hline Economic Inequality & $\begin{array}{l}2.239^{+} \\
(1.088)\end{array}$ & $\begin{array}{l}2.530^{*} \\
(1.107)\end{array}$ & $\begin{array}{l}2.319^{+} \\
(1.166)\end{array}$ & $\begin{array}{l}2.659^{*} \\
(1.226)\end{array}$ & & & & \\
\hline Poorest Group & & & & & $\begin{array}{l}9.790^{* *} \\
(7.286)\end{array}$ & $\begin{array}{c}8.597^{* * *} \\
(4.346)\end{array}$ & $\begin{array}{l}9.282^{* *} \\
(6.968)\end{array}$ & $\begin{array}{c}8.303^{* * *} \\
(4.457)\end{array}$ \\
\hline Richest Group & & & & & $\begin{array}{c}1.195 \\
(0.337)\end{array}$ & $\begin{array}{c}1.278 \\
(0.361)\end{array}$ & $\begin{array}{c}1.239 \\
(0.367)\end{array}$ & $\begin{array}{c}1.339 \\
(0.394)\end{array}$ \\
\hline $\ln$ (Largest Excluded Group) & $\begin{array}{c}0.544 \\
(0.217)\end{array}$ & $\begin{array}{l}0.593^{+} \\
(0.173)\end{array}$ & & & $\begin{array}{c}0.554 \\
(0.209)\end{array}$ & $\begin{array}{l}0.575^{+} \\
(0.174)\end{array}$ & & \\
\hline $\ln$ (Excluded Population) & & & $\begin{array}{c}0.799 \\
(0.194)\end{array}$ & $\begin{array}{c}0.854 \\
(0.146)\end{array}$ & & & $\begin{array}{c}0.828 \\
(0.193)\end{array}$ & $\begin{array}{c}0.843 \\
(0.143)\end{array}$ \\
\hline Civil War & $\begin{array}{c}5.924^{* * *} \\
(2.490)\end{array}$ & $\begin{array}{l}3.373^{* *} \\
(1.283)\end{array}$ & $\begin{array}{c}5.393^{* * *} \\
(2.219)\end{array}$ & $\begin{array}{l}3.226^{* *} \\
(1.161)\end{array}$ & $\begin{array}{c}4.366^{* * *} \\
(1.777)\end{array}$ & $\begin{array}{l}2.254^{*} \\
(0.852)\end{array}$ & $\begin{array}{c}3.942^{* * *} \\
(1.585)\end{array}$ & $\begin{array}{l}2.163^{*} \\
(0.769)\end{array}$ \\
\hline $\ln$ (Population) & $\begin{array}{l}1.355^{+} \\
(0.234)\end{array}$ & $\begin{array}{l}1.365^{*} \\
(0.214)\end{array}$ & $\begin{array}{c}1.321 \\
(0.232)\end{array}$ & $\begin{array}{l}1.332^{+} \\
(0.211)\end{array}$ & $\begin{array}{l}1.426^{+} \\
(0.264)\end{array}$ & $\begin{array}{l}1.466^{*} \\
(0.222)\end{array}$ & $\begin{array}{l}1.363^{+} \\
(0.243)\end{array}$ & $\begin{array}{l}1.401^{*} \\
(0.211)\end{array}$ \\
\hline $\ln$ (Infant Mortality Rate) & $\begin{array}{c}1.944 \\
(1.806)\end{array}$ & $\begin{array}{c}2.376 \\
(1.387)\end{array}$ & $\begin{array}{c}1.676 \\
(1.424)\end{array}$ & $\begin{array}{c}2.092 \\
(1.207)\end{array}$ & $\begin{array}{c}5.711 \\
(6.297)\end{array}$ & $\begin{array}{l}8.684^{* *} \\
(6.062)\end{array}$ & $\begin{array}{c}4.816 \\
(4.911)\end{array}$ & $\begin{array}{l}7.350^{* *} \\
(5.100)\end{array}$ \\
\hline Relevant Groups & $\begin{array}{c}1.085 \\
(0.102)\end{array}$ & $\begin{array}{c}1.054 \\
(0.055)\end{array}$ & $\begin{array}{c}1.077 \\
(0.100)\end{array}$ & $\begin{array}{c}1.042 \\
(0.056)\end{array}$ & $\begin{array}{l}1.020 \\
(0.101)\end{array}$ & $\begin{array}{c}1.011 \\
(0.053)\end{array}$ & $\begin{array}{c}1.016 \\
(0.093)\end{array}$ & $\begin{array}{c}1.003 \\
(0.052)\end{array}$ \\
\hline Peace Years & $\begin{array}{c}0.866^{*} \\
(0.056)\end{array}$ & $\begin{array}{c}0.857^{*} \\
(0.052)\end{array}$ & $\begin{array}{l}0.856^{*} \\
(0.057)\end{array}$ & $\begin{array}{l}0.846^{* *} \\
(0.052)\end{array}$ & $\begin{array}{l}0.844^{*} \\
(0.058)\end{array}$ & $\begin{array}{l}0.841^{* *} \\
(0.048)\end{array}$ & $\begin{array}{l}0.833^{* *} \\
(0.059)\end{array}$ & $\begin{array}{l}0.830^{* *} \\
(0.048)\end{array}$ \\
\hline Spline 1 & $\begin{array}{l}0.456^{* *} \\
(0.124)\end{array}$ & $\begin{array}{c}0.512^{* * *} \\
(0.100)\end{array}$ & $\begin{array}{l}0.461^{* *} \\
(0.123)\end{array}$ & $\begin{array}{c}0.515^{* * *} \\
(0.103)\end{array}$ & $\begin{array}{l}0.513^{* *} \\
(0.122)\end{array}$ & $\begin{array}{l}0.580^{* *} \\
(0.101)\end{array}$ & $\begin{array}{l}0.519^{* *} \\
(0.121)\end{array}$ & $\begin{array}{l}0.583^{* *} \\
(0.105)\end{array}$ \\
\hline Spline 2 & $\begin{array}{l}241.024^{*} \\
(599.004)\end{array}$ & $\begin{array}{c}81.864^{* *} \\
(131.197)\end{array}$ & $\begin{array}{l}213.413^{*} \\
(518.279)\end{array}$ & $\begin{array}{c}77.304^{* *} \\
(125.751)\end{array}$ & $\begin{array}{l}125.535^{*} \\
(284.419)\end{array}$ & $\begin{array}{l}40.268^{*} \\
(62.508)\end{array}$ & $\begin{array}{l}112.070^{*} \\
(248.233)\end{array}$ & $\begin{array}{c}38.087^{*} \\
(59.906)\end{array}$ \\
\hline Spline 3 & $\begin{array}{c}0.000^{*} \\
(0.001)\end{array}$ & $\begin{array}{l}0.001^{*} \\
(0.004)\end{array}$ & $\begin{array}{l}0.000^{*} \\
(0.001)\end{array}$ & $\begin{array}{c}0.002^{*} \\
(0.004)\end{array}$ & $\begin{array}{l}0.001^{+} \\
(0.003)\end{array}$ & $\begin{array}{c}0.004^{*} \\
(0.012)\end{array}$ & $\begin{array}{l}0.001^{+} \\
(0.003)\end{array}$ & $\begin{array}{l}0.005^{*} \\
(0.013)\end{array}$ \\
\hline Observations & 961 & 961 & 961 & 961 & 961 & 961 & 961 & 961 \\
\hline $\mathrm{AIC}$ & 293.903 & 454.663 & 296.580 & 457.566 & 282.977 & 436.758 & 285.886 & 440.433 \\
\hline LL_0 & -245.631 & -331.929 & -245.631 & -331.929 & -245.631 & -331.929 & -245.631 & -331.929 \\
\hline LL & -134.951 & -214.331 & -136.290 & -215.783 & -128.487 & -204.379 & -129.943 & -206.217 \\
\hline
\end{tabular}


security. This lack of cohesion also implies that groups can more easily organize themselves militarily and mobilize to engage in conflict. This is the case especially if groups choose to engage in fighting with other groups, who have less military strength than the state. Engaging in conflict against other groups, then, is both a forced result of a security threat between groups within the anarchical state structure, but also an opportunity for groups to engage in fighting, suggesting that inter-group violence is a more likely when groups must be self-reliant. The results presented in table 6.5 are in line with this argument.

It is important to remember that odds and incidence odds do not tell us the marginal effect of change in the $x$ variable on $y$. We can only interpret the direction and the significance of the coefficients, and not the substantive significance or size of the relationship. The nonlinearity of generalized linear models means that the relationship between a change in the value of an independent variable and the change in the probability of a count cannot be directly discerned from the variables' coefficient. This magnitude depends on the size of change in the independent variable, the variable's starting values, and the values of all other independent variables (Zelner 2009). As it can prove difficult to interpret the substantial meaning of odds ratios and incidence odds, CLARIFY can provide quantities of substantial interest in a reader-friendly manner, including reasonable measures of uncertainty attached to those estimates (King, Tomz and Wittenberg 2000). ${ }^{4}$ With the independent variables at their means in model 6 , the probability of inter-group violence is 3 percent in a weak state, while it is 1 percent in a strong.

To show the simulation of $H 1$ graphically, I present the probability of inter-group violence in figure 6.2 and 6.3. The figures show box plots of the simulated probabilities of inter-group violence in a weak and strong state for dichotomous and count dependent variables. The range of the vertical scales show the minimum and maximum value of the observations, and the boxes are the 25 th and the 75 th percentile. The line in the middle of the box is the median, and the whiskers represent the lowest and highest value of the lower and upper quartile. The data that is not between these whiskers, here presented as dots, are extreme values. The graph illustrates that the probability of inter-group

\footnotetext{
${ }^{4}$ CLARIFY uses simulation to compute quantities of interest and account for uncertainty. To capture uncertainty, CLARIFY draws a given number of parameters from the sampling distribution. I have set the simulation algorithm to 10000, producing 10000 predicted values and thereby approaching the entire probability distribution of $y$. From these simulations I am able to present average predicted values of my dependent variable and its corresponding uncertainty. Thus, I apply CLARIFY in an attempt to make the results more informative and transparent.
} 
Figure 6.2: Model 5, Logistic Regression: Box plot of simulated probability of inter-group violence in strong and weak states.

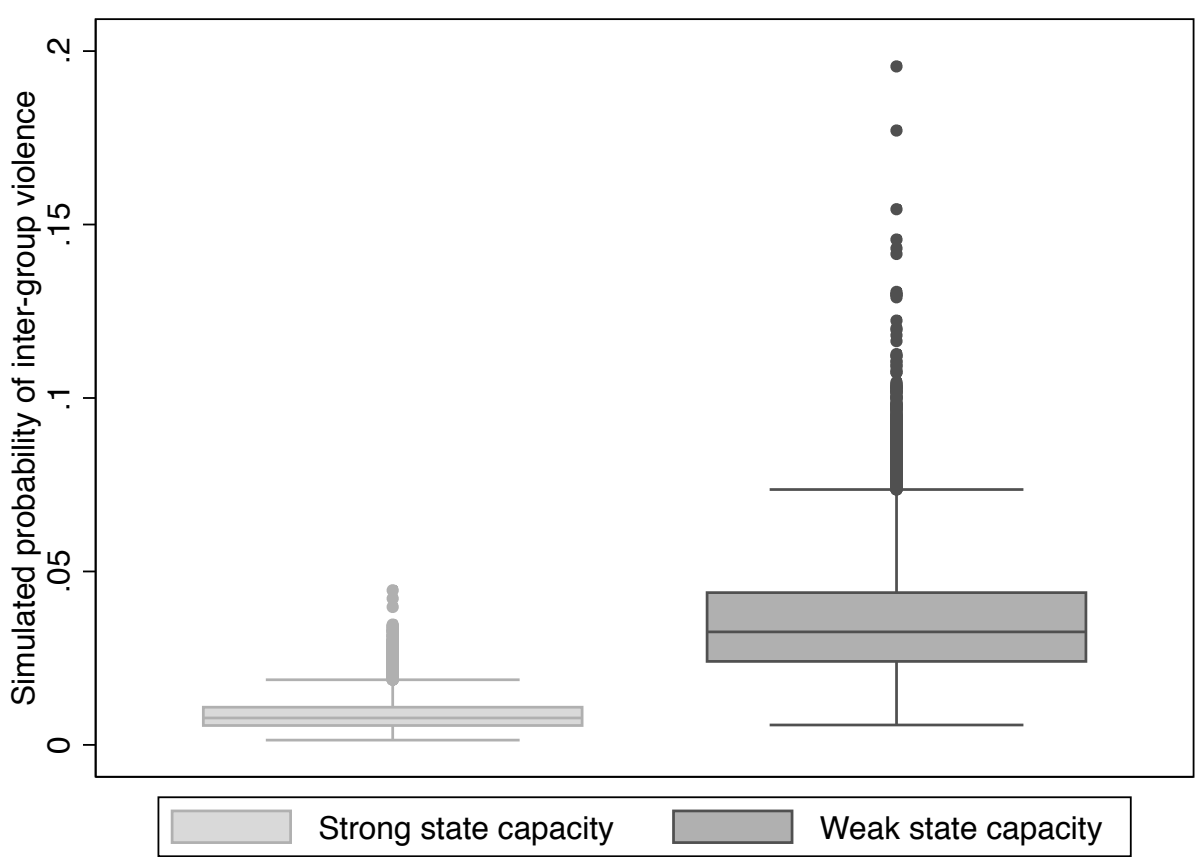

violence is higher in weaker states than in strong. The extreme values predicted for intergroup violence in a strong state is below the average probability of inter-group violence in a weak state. In addition, the predicted probabilities for non-state violence are less spread out than for weaker states, which range from 1 to 19 percent in figure 6.2, and 3 to 12 percent in figure 6.3. As the boxes in both figures do not overlap, the two scenarios are significantly different from each other.

The results from table 6.5 also show that the measures for economic inequality and poorest group are significant and has explanatory power. This is perhaps not surprising, given the distribution non-state conflict events in countries with high economic inequality, presented in section 6.1. Indeed, with sufficient strength and equipment of a group, it can challenge other groups based on economic marginalization even with some degree of governmental strength. The variables for political exclusion are insignificant in all models, except for size of the largest excluded group in model two and six, which is significant only at the 10 percent level. The variable is also not in the expected direction, indicating that the incidence odds of inter-group violence decreases at higher levels of political exclusion. 
Figure 6.3: Model 6, Negative Binomial Regression: Box plot of simulated probability of inter-group violence in strong and weak states

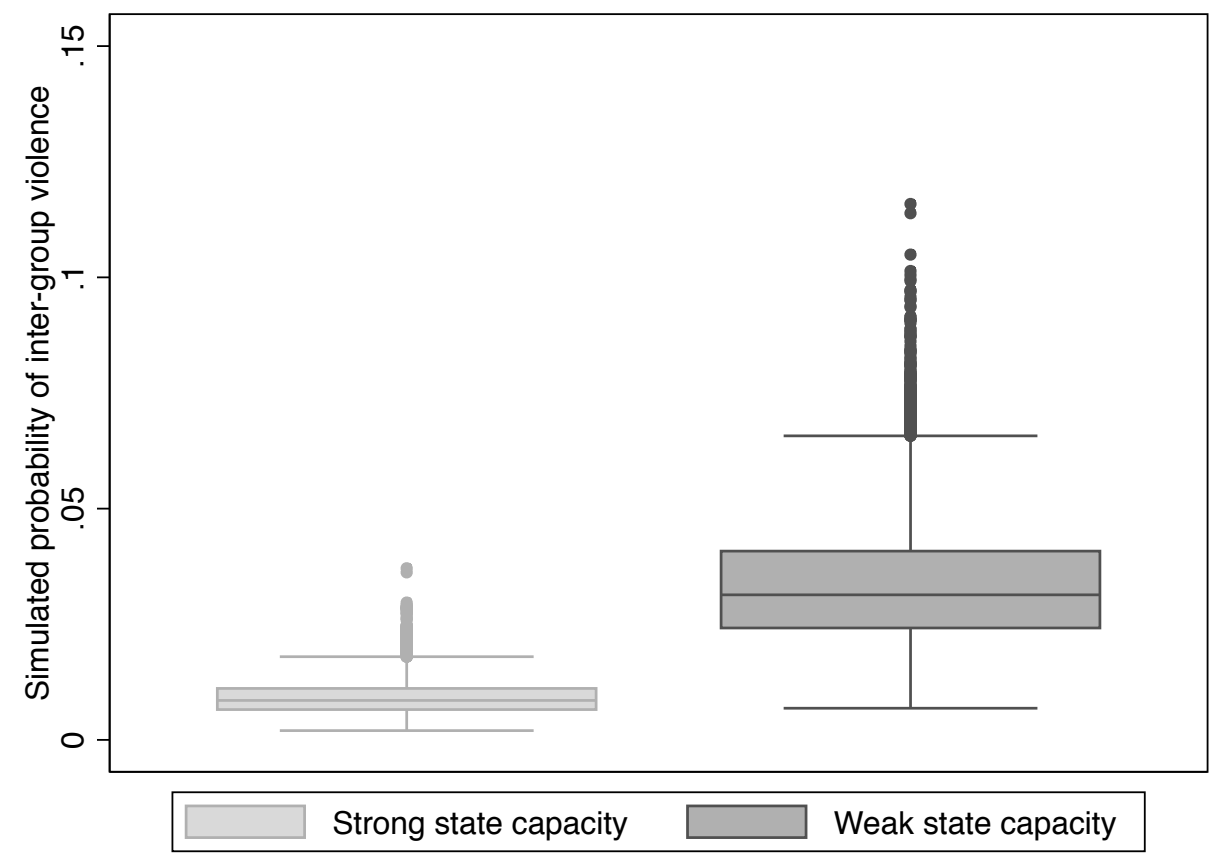

When it comes to the control variables, civil war is significant and positive in all models in table 6.5. Moreover, with the presence of civil war, the simulated probability of intergroup violence in model 6 is 2 and 6 percent in a strong and weak state, respectively. Thus, the presence of civil war severely increases the risk of non-state violence. In line with Kalyvas (2006), this increased risk of inter-group violence during civil war can be related to alternative group motivations than the overarching cause at the national level. Thus, groups involved in the war can take advantage of the prevailing situation, or are forced to do so, to settle local conflicts out of government reach. Under circumstances where the state had more information and capacity, these conflicts could be regulated and not necessarily result in violent conflict between groups. However, when the government has limited strength, it is more difficult to handle more local issues between groups. Civil wars can be understood as a condition that opens for a variety of grievances to be realized within the space of a larger conflict, and this is especially so for the use of violence in a weak state (Kalyvas 2006). Of the total of 69 non-state conflict events between 1989 and 2011, 68 percent took place during a civil war, indicating that the amount of non-state conflicts in war time and peace are substantially different. Peace years is significant and in the expected negative direction, demonstrating that longer peace spells reduce the 
risk of inter-group violence. Thus, there are reasons to believe that previous events of inter-group violence increase the risk of conflict recurrence.

\subsubsection{Weak State in Combination with Economic and Political Inequality}

As the negative binomial regressions inhabits more variation on the dependent variable than the logistic regressions, I apply the interaction terms only in the negative binomial models. Table 6.6 assess hypotheses $H 1 a$ and $H 1 b$, which concern whether the combined effect of weak state capacity and economic and political inequality increases the risk of inter-group violence. ${ }^{5}$ The table presents models 9 to 12 where the symmetric and asymmetric measures for economic inequality are interacted with weak state capacity. Models 13 to 16 include the interaction terms for the two political exclusion measures combined with weak state. As the models 9 to 16 all include interaction terms, the models cannot be interpreted as the unconditional or average effect of a independent variable on the dependent variable. This is because multiplicative interaction models make the effect of the independent variable $x$ on the dependent variable $y$ depend on a third variable $z$, in my case the variables for economic inequality and political inequality (Brambor, Clark and Golder 2005). In model 9, for example, the coefficient of weak state only capture the effect of weak state when economic inequality is zero. Similarly, the coefficient for economic inequality only captures the effect of economic inequality when weak state is zero, meaning when the state is strong. Before presenting more intuitive plots of this conditional relationship between economic and political inequality and weak state capacity, I briefly comment on the results in table 6.6.

The inclusion of interaction terms in the regression models provides insights into the combined effect of weak state capacity and economic inequality on inter-group violence. The conjunction of weak state capacity and economic inequality contributes to an insignificant effect of weak state capacity. When all indicators for economic inequality is zero, state incapacity explains little of the variation of inter-group violence. Thus, this indicates that for the models not including interaction terms, weak state is to some extent driven by the effect of economic inequality.

\footnotetext{
${ }^{5}$ I have chosen to not include all interaction terms in the same model, to avoid including too many variables in the regressions, as I have results based on only 46 countries and 1053 observations. Models with all the interaction terms for both economic and political exclusion are included in Appendix C, table C.2, and the results are consistent.
} 
Table 6.6: Count Regressions with Interactions: Estimated incidence odds of inter-group violence in Sub-Saharan Africa, 1989-2011

\begin{tabular}{|c|c|c|c|c|c|c|c|c|}
\hline & \multicolumn{4}{|c|}{ Economic Inequality } & \multicolumn{4}{|c|}{ Political Inequality } \\
\hline & $(9)$ & $(10)$ & $(11)$ & $(12)$ & $(13)$ & $(14)$ & $(15)$ & $(16)$ \\
\hline Weak State & $\begin{array}{c}1.624 \\
(0.700)\end{array}$ & $\begin{array}{c}1.891 \\
(0.762)\end{array}$ & $\begin{array}{c}3.562 \\
(4.338)\end{array}$ & $\begin{array}{c}5.053 \\
(6.268)\end{array}$ & $\begin{array}{l}0.116^{*} \\
(0.111)\end{array}$ & $\begin{array}{c}1.086 \\
(0.283)\end{array}$ & $\begin{array}{c}0.273 \\
(0.244)\end{array}$ & $\begin{array}{c}1.599 \\
(0.485)\end{array}$ \\
\hline Economic Inequality & $\begin{array}{c}1.490 \\
(0.556)\end{array}$ & $\begin{array}{l}1.553 \\
(0.605)\end{array}$ & & & $\begin{array}{l}2.392^{+} \\
(1.080)\end{array}$ & $\begin{array}{l}2.371^{+} \\
(1.151)\end{array}$ & & \\
\hline Weak State $*$ Ec. Inequality & $\begin{array}{l}9.661^{* *} \\
(6.757)\end{array}$ & $\begin{array}{l}9.517^{* *} \\
(7.082)\end{array}$ & & & & & & \\
\hline Poorest Group & & & $\begin{array}{c}9.740^{* * *} \\
(5.911)\end{array}$ & $\begin{array}{c}10.303^{* * *} \\
(6.589)\end{array}$ & & & $\begin{array}{c}6.183^{* * *} \\
(3.328)\end{array}$ & $\begin{array}{l}5.497^{\text {** }} \\
(3.072)\end{array}$ \\
\hline Weak State ${ }^{*}$ Poorest & & & $\begin{array}{c}0.197^{*} \\
(0.161)\end{array}$ & $\begin{array}{l}0.159^{*} \\
(0.134)\end{array}$ & & & & \\
\hline Richest Group & & & $\begin{array}{c}0.909 \\
(0.238)\end{array}$ & $\begin{array}{c}0.929 \\
(0.254)\end{array}$ & & & $\begin{array}{c}1.245 \\
(0.365)\end{array}$ & $\begin{array}{c}1.268 \\
(0.387)\end{array}$ \\
\hline Weak State $*$ Richest & & & $\begin{array}{l}4.840^{* *} \\
(2.544)\end{array}$ & $\begin{array}{l}5.154^{* *} \\
(2.838)\end{array}$ & & & & \\
\hline $\ln$ (Largest Excluded Group) & $\begin{array}{l}0.559^{+} \\
(0.181)\end{array}$ & & $\begin{array}{c}0.648 \\
(0.192)\end{array}$ & & $\begin{array}{c}1.849 \\
(0.723)\end{array}$ & & $\begin{array}{c}1.433 \\
(0.549)\end{array}$ & \\
\hline Weak State * Largest Excl. Group & & & & & $\begin{array}{c}0.098^{* * *} \\
(0.069)\end{array}$ & & $\begin{array}{l}0.162^{* *} \\
(0.104)\end{array}$ & \\
\hline $\ln$ (Excluded Population) & & $\begin{array}{c}0.808 \\
(0.149)\end{array}$ & & $\begin{array}{c}0.921 \\
(0.161)\end{array}$ & & $\begin{array}{l}1.918^{+} \\
(0.653)\end{array}$ & & $\begin{array}{l}1.558^{+} \\
(0.409)\end{array}$ \\
\hline Weak State * Excl. Population & & & & & & $\begin{array}{c}0.245^{* * *} \\
(0.090)\end{array}$ & & $\begin{array}{c}0.341^{* * *} \\
(0.104)\end{array}$ \\
\hline Civil War & $\begin{array}{l}3.171^{* *} \\
(1.280)\end{array}$ & $\begin{array}{l}3.062^{* *} \\
(1.169)\end{array}$ & $\begin{array}{l}2.222^{*} \\
(0.888)\end{array}$ & $\begin{array}{l}2.116^{*} \\
(0.805)\end{array}$ & $\begin{array}{l}2.656^{* *} \\
(0.943)\end{array}$ & $\begin{array}{l}2.404^{* *} \\
(0.799)\end{array}$ & $\begin{array}{l}2.016^{*} \\
(0.718)\end{array}$ & $\begin{array}{l}1.889^{+} \\
(0.632)\end{array}$ \\
\hline $\ln$ (Population) & $\begin{array}{l}1.240^{+} \\
(0.155)\end{array}$ & $\begin{array}{c}1.210 \\
(0.156)\end{array}$ & $\begin{array}{c}1.311 \\
(0.219)\end{array}$ & $\begin{array}{c}1.245 \\
(0.207)\end{array}$ & $\begin{array}{l}1.372^{*} \\
(0.200)\end{array}$ & $\begin{array}{l}1.364^{*} \\
(0.204)\end{array}$ & $\begin{array}{l}1.529^{*} \\
(0.260)\end{array}$ & $\begin{array}{l}1.507^{*} \\
(0.262)\end{array}$ \\
\hline $\ln$ (Infant Mortality Rate) & $\begin{array}{l}3.496^{*} \\
(2.138)\end{array}$ & $\begin{array}{l}3.000^{+} \\
(1.789)\end{array}$ & $\begin{array}{l}8.388^{* *} \\
(5.574)\end{array}$ & $\begin{array}{l}7.235^{* *} \\
(4.711)\end{array}$ & $\begin{array}{c}2.212 \\
(1.335)\end{array}$ & $\begin{array}{c}2.380 \\
(1.462)\end{array}$ & $\begin{array}{l}7.312^{* *} \\
(5.531)\end{array}$ & $\begin{array}{l}7.005^{* *} \\
(5.113)\end{array}$ \\
\hline Relevant Groups & $\begin{array}{l}1.104^{*} \\
(0.052)\end{array}$ & $\begin{array}{l}1.095^{+} \\
(0.055)\end{array}$ & $\begin{array}{c}1.035 \\
(0.049)\end{array}$ & $\begin{array}{c}1.022 \\
(0.048)\end{array}$ & $\begin{array}{l}1.128^{*} \\
(0.058)\end{array}$ & $\begin{array}{l}1.098^{+} \\
(0.054)\end{array}$ & $\begin{array}{c}1.069 \\
(0.057)\end{array}$ & $\begin{array}{c}1.047 \\
(0.056)\end{array}$ \\
\hline Peace Years & $\begin{array}{l}0.847^{* *} \\
(0.050)\end{array}$ & $\begin{array}{l}0.838^{* *} \\
(0.050)\end{array}$ & $\begin{array}{l}0.825^{* *} \\
(0.052)\end{array}$ & $\begin{array}{l}0.814^{* *} \\
(0.052)\end{array}$ & $\begin{array}{c}0.871^{*} \\
(0.051)\end{array}$ & $\begin{array}{l}0.856^{* *} \\
(0.051)\end{array}$ & $\begin{array}{l}0.858^{* *} \\
(0.049)\end{array}$ & $\begin{array}{l}0.843^{* *} \\
(0.047)\end{array}$ \\
\hline Spline 1 & $\begin{array}{l}0.542^{* *} \\
(0.113)\end{array}$ & $\begin{array}{l}0.544^{* *} \\
(0.116)\end{array}$ & $\begin{array}{l}0.635^{* *} \\
(0.106)\end{array}$ & $\begin{array}{l}0.643^{* *} \\
(0.109)\end{array}$ & $\begin{array}{c}0.562^{* * *} \\
(0.090)\end{array}$ & $\begin{array}{c}0.571^{* * *} \\
(0.092)\end{array}$ & $\begin{array}{l}0.609^{* *} \\
(0.092)\end{array}$ & $\begin{array}{l}0.613^{* *} \\
(0.094)\end{array}$ \\
\hline Spline 2 & $\begin{array}{l}39.696^{+} \\
(76.389)\end{array}$ & $\begin{array}{l}37.393^{+} \\
(73.536)\end{array}$ & $\begin{array}{c}12.826 \\
(22.012)\end{array}$ & $\begin{array}{c}10.725 \\
(18.865)\end{array}$ & $\begin{array}{c}36.173^{*} \\
(52.068)\end{array}$ & $\begin{array}{c}31.517^{*} \\
(46.824)\end{array}$ & $\begin{array}{l}26.134^{*} \\
(37.269)\end{array}$ & $\begin{array}{c}22.913^{*} \\
(33.642)\end{array}$ \\
\hline Spline 3 & $\begin{array}{c}0.005 \\
(0.017) \\
\end{array}$ & $\begin{array}{c}0.006 \\
(0.019)\end{array}$ & $\begin{array}{c}0.032 \\
(0.095) \\
\end{array}$ & $\begin{array}{c}0.045 \\
(0.135) \\
\end{array}$ & $\begin{array}{l}0.005^{*} \\
(0.013)\end{array}$ & $\begin{array}{l}0.007^{*} \\
(0.018) \\
\end{array}$ & $\begin{array}{l}0.009^{+} \\
(0.021)\end{array}$ & $\begin{array}{l}0.011^{+} \\
(0.028)\end{array}$ \\
\hline Observations & 961 & 961 & 961 & 961 & 961 & 961 & 961 & 961 \\
\hline AIC & 447.439 & 450.837 & 431.891 & 434.245 & 431.433 & 434.847 & 423.154 & 428.051 \\
\hline LL_0 & -331.929 & -331.929 & -331.929 & -331.929 & -331.929 & -331.929 & -331.929 & -331.929 \\
\hline LL & -209.720 & -211.419 & -199.945 & -201.123 & -201.716 & -203.424 & -196.577 & -199.025 \\
\hline
\end{tabular}

Exponentiated coefficients; Clustered and robust standard errors in parentheses.

AIC, LL_0 and LL are averaged values for the ten imputed datasets.

$+p<0.10,{ }^{*} p<0.05,{ }^{* *} p<0.01,{ }^{* * *} p<0.001$ 
The incidence odds ratio for weak state*economic inequality is in the expected positive direction and significant at the 1 percent level in both model 9 and 10. Both weak state and economic inequality is insignificant when the other variable is zero. This is in line with the argument provided by Fjelde and Østby (2012), who find that socio-economic inequality increases the risk of armed conflict between groups. Thus, when groups must provide for their own well-being, and there are large discrepancies between the amount of resources that the groups control, the risk of inter-group violence increases. The results therefore seem consistent with the theoretical expectations that the combined effect of weak state structures and economic inequality is influential in shaping the risk of violence through its impact on both incentives and opportunities for mobilization.

Poorest group is significant at the 0.1 percent level in model 11 and 12 , demonstrating that how poor the poorest group in a country is has strong explanatory power for inter-group violence, even when the state is strong. ${ }^{6}$ Despite being engaged in civil war, Sudan has been characterized as a stronger state than for example Somalia and D.R. Congo. Still, there has been several instances of inter-group violence. ${ }^{7}$ Darfurians dissatisfied with Islamist leaders distributed the Black Book: Imbalance of Power and Wealth in Sudan in 2000, which describes where political and economic power in Sudan lies and has lain since independence; in the hands of a small elite from the three tribes north of Karthoum: the Shaygiyya, Ja'aliyiin and Dangala (Flint 2007). The same group established the JEM, and took up arms in Darfur shortly after (de Waal 2007). Many leading figures in the country's armed conflicts have claimed to be fighting to remedy the exploitation of the peripheries by the center and their ethnic kins. ${ }^{8}$

The asymmetric measure for richest group interacted with weak state capacity is significant at the 1 percent level and in the expected direction in model 11 and 12. Thus, how rich the richest group in a country is helps explain the variation of inter-group conflicts. de Soysa (2002) highlights how valuable resources can be a "honey pot" and attract violent efforts to gain control over resources of wealth. This risk can be especially large

\footnotetext{
${ }^{6}$ As the interaction term for weak state* ${ }^{*}$ poorest group is insignificant in the model where all interaction terms are included, I do not present these results in the interaction plots. Although the incidence odds ratios for poorest group is below one, the marginal effect is still positive, only less so than when the state is strong.

${ }^{7} \mathrm{~A}$ crude dichotomization of state capacity does not capture the different levels of state strength, as Sudan surely is not viewed as a strong state within a global context. However, within the Sub-Saharan African context, this categorization seems more justifiable.

${ }^{8}$ Among this group of revolutionaries are Ahmed Diraige, Taisir Ahmed, Malik Agar and Sharif Harir.
} 
in developing countries, fueling further dissatisfaction. In the same vein, Buhaug et al. (2011) find that local income matters more than national income, and that pockets of relative wealth within poor countries are more likely to see conflict outbreaks. Although higher income in general means lower conflict risk, an area with substantially higher GDP than other areas have a higher risk to engage in conflict. As group and territory or area tends to be closely linked in many Sub-Saharan African countries (Toft 2003), these results can be said to relate to overlapping mechanisms. In more substantive terms, with all variables set to their mean and the interaction terms for economic inequality set to 0.5 in model 9, the simulated probability for inter-group violence is 7 percent in a weak state and 2 percent in a strong. Similarly, with the interaction terms for poorest and richest group set to 2 in model 11, the simulated probability of inter-group violence is 11 percent in a weak state and 4 percent in a strong. The simulated probability was 3 percent in model 6 , indicating that the combined effect of weak state capacity and economic inequality further increases the risk of inter-group violence with 4 and 9 percent for the inequality measures.

When it comes to the control variables, the indicator for civil war is positive and significant also here. With the presence of civil war and inequality set to 2 in model 11, the simulated probability of non-state conflict is 7 in a strong state, and 19 in a weak. Moreover, with all variables set to their mean, infant mortality rate set to its maximum value and inequality set to 2 in model 12 , the simulated probability for inter-group violence is 16 percent in a strong state, while it is 27 (!) percent in a weak. This indicates that poorer countries have a higher risk of inter-group conflicts in general. Thus, models 9 to 13 in table 6.6 confirm hypothesis $H 1 a$, that the combined effect of weak state capacity and economic inequality increases the risk of inter-group violence.

In table 6.6, models 13 to 16 show the results for the negative binomial regressions to assess hypothesis $H 1 b$, that the combined effect of weak state capacity and political exclusion increase the risk of inter-group violence. The two measures for political exclusion, largest excluded group and excluded population, are interacted with weak state capacity. The interaction between weak state capacity and largest excluded group is significant at the 0.1 percent level in model 13, and at the 1 percent level in model 15, but not in the expected direction. In other words, the combined effect of political exclusion and weak state decreases the risk of inter-group violence, and the simulated probability for intergroup violence in model 15 is lower for weak states, at 0.4 percent, while it is 1 percent in strong states. In model 15 and 16 the incidence odds for inter-group violence in a strong 
state is positive, but only significant at the ten percent level. This finding is directly opposite of the expectations presented in my theoretical framework. However, it is in line with preliminary evidence presented in Section 6.1. Where there was a clear pattern with economic inequality, where inequalities above the mean provided some preliminary evidence for more inter-group violence, no such pattern revealed itself when it came to political exclusion.

A closer look at the data shows that countries such as D.R. Congo, Somalia and Uganda have low scores on political exclusion, whereas countries that have not experienced largescale inter-group violence such as Angola, Ethiopia, Rwanda and Togo have high scores on both political exclusion measures. Take for example Angola, a country characterized as a strong state where around 40 percent of the population was politically excluded in 2009. Despite the relatively large amount of exclusion, there have been no instances of inter-group violence, but a long lasting civil war. Thus, the politically excluded groups who engage in fighting, do not necessarily attack other groups, but choose to target the state to address political asymmetries. This can be relevant for the perception that political exclusion is more salient in a strong state, where the group potentially have more to gain by inclusion, and thereby more aggrieved by exclusion. Also, the positive relationship between political exclusion and strong state capacity in model 14 and 16 can be related to excessive state strength. If the groups seek to change political asymmetries, it requires less organizational capabilities and equipment to attack representatives of the group occupying the state, than attacking the state as such. However, these results are only significant at the ten percent level, leaving the confidence in the findings more tentative.

A related point is that a high degree of state weakness can make it of limited value for excluded groups to try to be politically included, and groups may even choose to be outside the state structure. Examples of this are separatist movements who seek to establish an independent state, for example in Cote dIvoire and Somalia. Hence, the negative effect of political exclusion on inter-group violence in weak states may reflect the relative grievance that groups have in relation to other groups. If a majority of the different groups are unincorporated within the state, these are perhaps more concerned with grievances related to economic well-being, rather than any political presentation within a weak state structure. When large segments of the population are unincorporated, the relative grievance for one politically unincorporated group is low, and the potential gains 
for increased political representation equally so. Economic differences between groups, on the other hand, are more visible through material well-being, access to land and resources, and may be more important than political inclusion and more easily addressed at the local level, without engaging the state. However, in a state where most groups are included within the state sphere, whereas one group is not, for example the Hutus in Burundi in the 1990s, the relative grievance is much higher. Instead of being one of many, you are the only or one of few groups who are politically excluded. Thus, the incentive to engage in fighting with other groups is higher. The limited value of political inclusion in weak states and the low relative grievance when large segments of the population are excluded can perhaps help explain why there is a signicantly negative effect of political exclusion on inter-group violence in a weak state.

As the interpretation of several included interaction terms in one model can make the interpretation intricate, I present the marginal effect of the interaction terms in a plot. Following Brambor, Clark and Golder (2005), interactions can only be interpreted meaningfully when accounting for the combined effects of the interacted variables. Thus, I will consider the interaction by presenting the marginal effect of economic and political inequality at different levels of state capacity; strong and weak. The uncertainty in these estimates is also included, and the marginal effects are presented in figure 6.4. The figure shows the estimated incidence odds for richest group, economic inequality, excluded population and largest excluded group at different levels of state capacity. The interaction plots are based on model 9, 11, 15 and 16 .

Figure 6.4 shows the estimated incidence odds associated with political and economic inequality changes with the level of state capacity, and that the effect is statistically different for strong and weak states. For economic inequality, being in a weak state increases the incidence odds for non-state violence when state capacity is weak, and the effect is statistically significant. However, being in a weak state with the presence of political inequality significantly decreases the incidence ratio when state capacity is weak. ${ }^{9}$

Some of the odds ratios in the models are relatively high, perhaps especially for weak states and poorest group, that have ratios ranging from 3.297 to 4.820 , and 8.303 to 9.790, respectively, in table 6.5. These high estimates are most likely due to the small sample, where a limited amount of countries are driving the results. For example, of the

\footnotetext{
${ }^{9}$ For a basic coefficient plot for the interaction terms in table 6.6, see Appendix C, figure C.2.
} 
Figure 6.4: Interactions: Estimated incidence odds for inter-group violence in SubSaharan Africa with the presence of economic and political inequality in weak and strong states, based on model 9, 11, 15 and 16, 1989-2011.
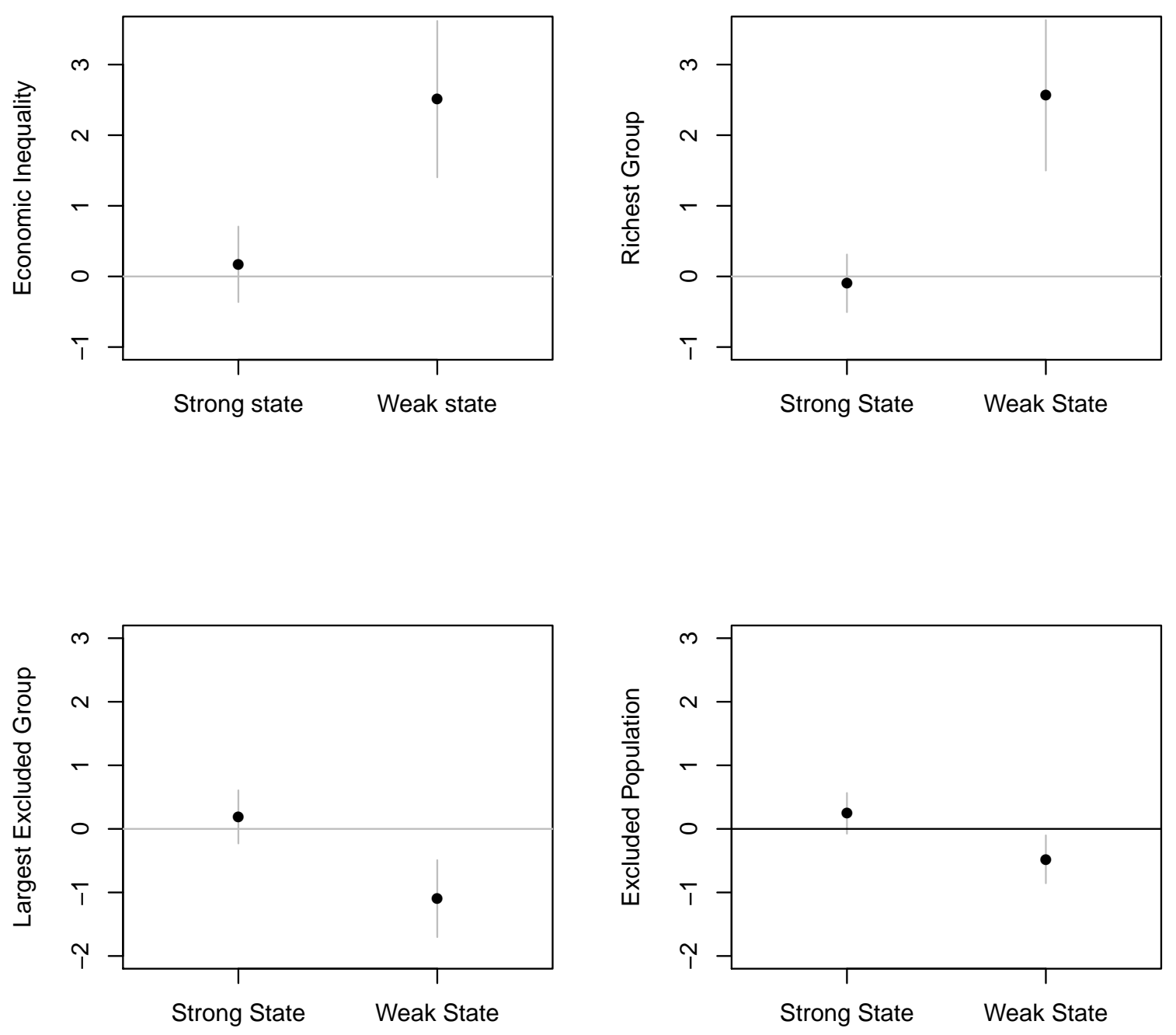
69 conflict events per country year, 30 of them were in Somalia and D. R. Congo. Hence, the values on the independent variables for these countries have a substantial impact on the results. However, that inter-group conflicts reoccur in the same countries is expected, and the inclusion of peace years is an attempt to account for this. It would be preferable with more diversity in the data, but there are few options for correcting this limitation. In chapter $7 \mathrm{I}$ will use alternative specifications to see whether the results are affected and how robust the findings are.

\subsubsection{Scenarios}

The use of CLARFY provides several advantages when trying to present the results in a more meaningful manner (King, Tomz and Wittenberg 2000). Although the use of CLARIFY can give more substance to the results, to assume that both strong and weak states have the same mean values on variables such as infant mortality rate and years since last conflict seems unlikely. Indeed, the mean infant mortality rate in strong states is 4.35 , while it is 4.85 in weak. Similarly, the average value for peace years is 9 in strong states, while it is 6 in weak, indicating more frequent conflict relapses in states with limited capacity. Also, there is great variation in values on the different indicators included in the analysis, making it difficult to say something more specific about a given scenario.

Table 6.7: Overview of the eight scenarios used for simulation

\begin{tabular}{lccccccc}
\hline \multicolumn{1}{c}{ Value } & N & State & Capacity & From & To & Civil War & Peace Years \\
\hline Economic & 1 & Liberia & Weak & Low & High & 0 & 9 \\
Inequality & 2 & South Africa & Strong & Low & High & 0 & 9 \\
& 3 & Burundi & Weak & Low & High & 1 & 1 \\
& 4 & Nigeria & Strong & Low & High & 1 & 4 \\
\hline Political & 5 & Somalia & Weak & Low & High & 0 & 0 \\
Exclusion & 6 & Senegal & Strong & Low & High & 0 & 5 \\
& 7 & D.R. Congo & Weak & Low & High & 0 & 0 \\
& 8 & Ethiopia & Strong & Low & High & 0 & 3 \\
\hline
\end{tabular}

To get a better overview of the probability weak and strong states have for inter-group violence, I construct several scenarios. First, I present the mean values for weak and strong states in a simulation plot, where I change the level of economic inequality and political exclusion, to investigate the effect inequality has on non-state conflict events. By changing the level of economic and political inequality, while keeping the other variables constant, I am able to isolate the effect of inequality on non-state violence. The 
Figure 6.5: Simulated probability of inter-group violence in Sub-Saharan Africa over increasing levels of economic and political inequality in weak and strong states, based on model 9 and 13, 1989-2011.
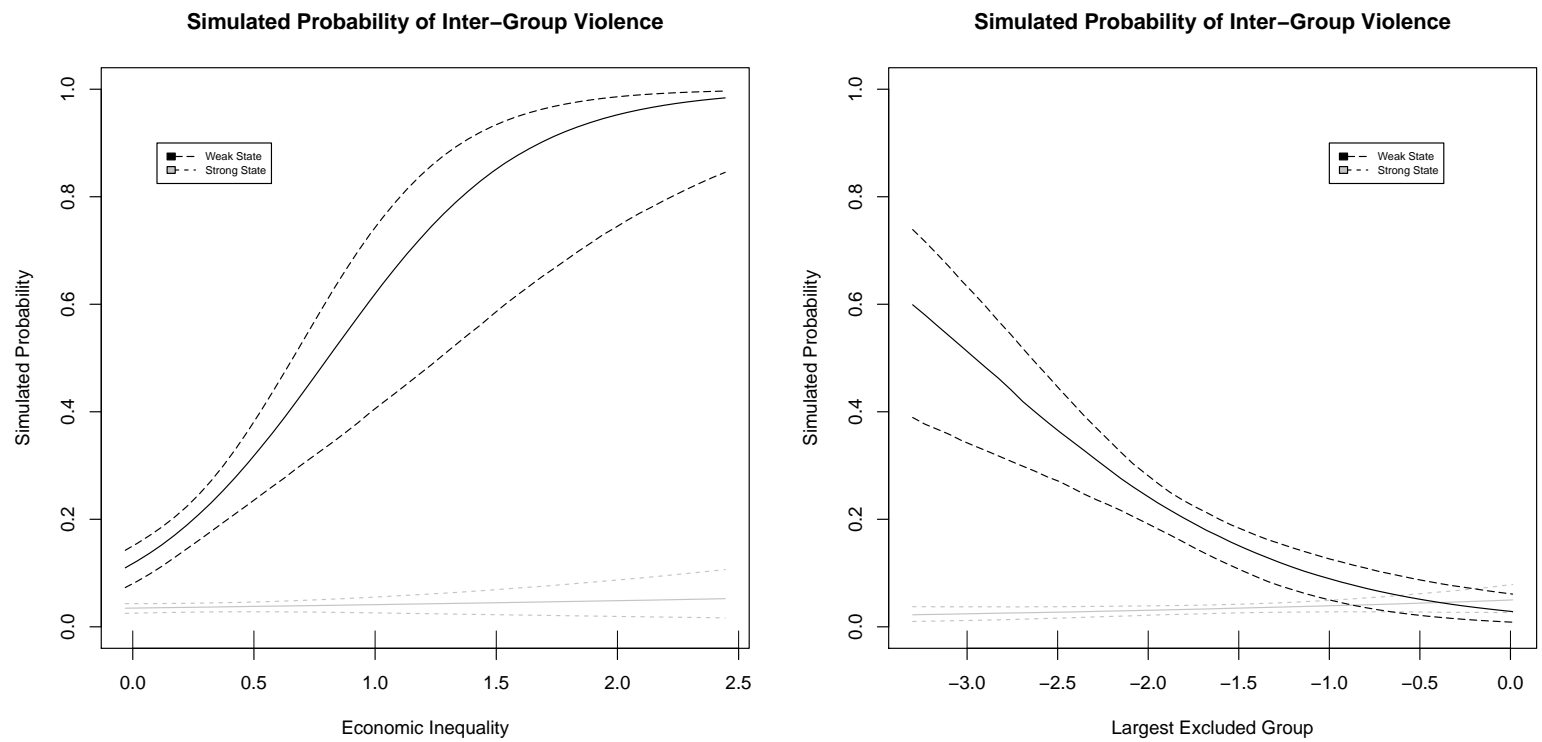

scenario for averaged values for weak and strong states is illustrated in figure 6.5. Second, I have chosen eight countries to illustrate the effect of different levels of inequality on non-state violence given specific state characteristics; South Africa, Liberia, Burundi, Nigeria, Senegal, Somalia, D.R. Congo and Ethiopia. I have chosen these eight countries as they inhabit different values on my main independent variables weak state capacity, economic inequality and political exclusion. I have also taken into account the presence of civil war and time since last non-state conflict, to illustrate some of the variation in non-state conflict risk. In each simulation plot I have compared the simulated probability of inter-group violence of a strong and weak state, with the corresponding values of the other independent variables in a given year. The scenarios for the eight Sub-Saharan African countries are presented in figure 6.6.

Figure 6.5 shows the effect of increasing levels of economic and political inequality on the probability of inter-group violence in weak and strong states, and the corresponding uncertainty. The simulation is based on averaged values for the two levels of state capacity. As already illustrated with the use of CLARIFY, the simulated probability of inter-group violence increases with higher levels of economic inequality, shown in the plot 
to the left. With no economic inequality the simulated probability of inter-group violence is 9 percent, while it is 1 percent in stronger states. The risk increases rapidly for weak states, where the simulated probability for non-state violence is above 50 percent after the level of economic inequality passes 1 . The probability for strong states, however, is almost constant, with confidence intervals increasing somewhat at higher levels of economic inequality. When it comes to political exclusion in the plot to the right, the effect is directly opposite, showing that higher levels of political exclusion leads to decreasing probability of a non-state conflict event. The effect becomes insignificant, however, at higher levels of political exclusion, where the confidence intervals overlaps with strong state capacity.

The upper-left panel in figure 6.6 shows the simulated probability of inter-group violence in Liberia and South Africa in 2005. As seen in table 6.7, the two countries have the same values for peace years and civil war. The main difference between the countries for the variables included in the regression analysis is state capacity, where Liberia is considered weak, and the infant mortality rate, where Liberia had 1086 more child deaths than South Africa in 2005, which is quite substantial. We can see that although having the same duration of peace spells, South Africa has a flat line of simulated probability with increasing confidence intervals at larger values of economic exclusion, showing similar tendencies as strong state capacity in figure 6.5. Liberia, on the other hand, has a significantly higher simulated probability for inter-group violence. Liberia had a long record of political stability before the civil war broke out in 1989, which caused largescale violence and a great variance in types of political violence during the war. Most contributions from the case study literature sees the violence in Liberia as a consequence of security concerns, while economic motivations were of less importance (see e.g. Pugel 2007; Bøås and Hatløy 2008). However, the simulation of economic inequality in Liberia indicates that larger levels of economic inequality increase the risk of inter-group violence in a weak state. Thus, it is not necessarily a trade-off between security concerns due to governmental weakness and economic motivations for conflict. The presence of both weak state capacity and economic inequality can increase the risk of inter-goup violence, also after the civil war ended. This is in line with Hegre, Østby and Raleigh (2009), who find that the Liberian government had very limited control outside the capital during the 1990s, meaning that groups were able to target potential locations more freely, and that both aggrieved and greedy groups had an incentive to target more wealthy regions where 
hostilities would pay off. ${ }^{10}$

The upper-right panel shows the probability of non-state violence in Burundi and Nigeria in 2008. Burundi is here representing weak state capacity, although both Burundi and Nigeria experienced civil war in 2008. The presence of civil war increases the probability of inter-group violence in both cases. Whereas the probability started at 3 percent in Liberia, the probability starts at 40 percent with the presence of civil war in Burundi. Thus, the probability of a non-state conflict event is higher than a non-event in Burundi in 2008, with the presence of both civil war and economic inequality above 1 . The probability for non-state violence is higher also in Nigeria with the presence of civil war, although at a lower level and marginal effect than weak state capacity. The confidence intervals are also quite large, reflecting the large amount of uncertainty for the simulated probability. The high risk of inter-group violence despite Nigeria's categorization as a stronger state can perhaps be best understood as a consequence of the dynamics, the interplay and consequences of high stake rentier politics in the reproduction and persistence of the oil conflict in Nigeria and its corresponding security issues. In the words of Omeje $(2006,2)$ :

The perfusion of violent conflicts of varying intensities in many oil exporting economies of the south, coupled with the increasing inability of beleaguered states to provide security (...), suggest that the questions of who provides security or who should provide security, for whom security is provided, in what issue areas, under what conditions and using what methods, are recurrent problems (...).

Thus, the risk of inter-group violence is relatively high in Nigeria despite a higher level of state capacity than Burundi, as the conflict has severe consequences both on the national and sub-regional level. The persistent conflict on the national level creates a deteriorating cycle of conflicts which also effects the probability of non-state violence at the local level.

The bottom-left panel in figure 6.6 shows the simulated probability of non-state conflict over political exclusion in Senegal and Somalia in 2010, where Somalia had a non-state conflict event the year before, and Senegal had a peace spell of five years. In the dataset, Somalia is coded as having no excluded groups, as the country is a clan-based society, and no politically relevant ethnic groups apply. Thus, it is interesting to see whether the introduction of political exclusion increase the risk of inter-group violence. The results from the panel indicate that this is not the case, showing the same tendencies as the right

\footnotetext{
${ }^{10}$ See also Bøås (2005).
} 
Figure 6.6: Simulated probability of inter-group violence in Sub-Saharan Africa over increasing levels of economic and political inequality in eight scenarios, based on model 9, 10, 13 and 14, 1989-2011.
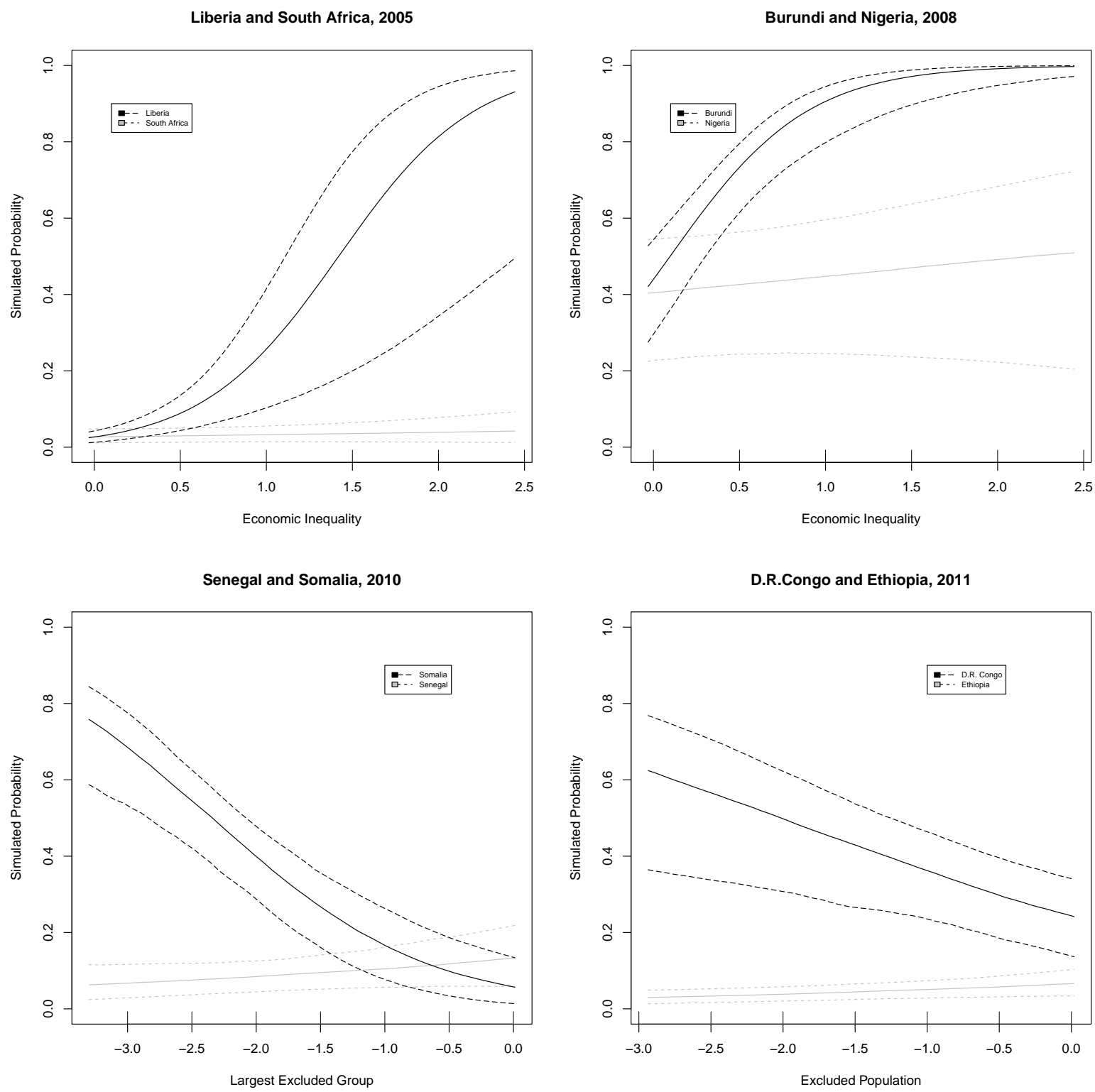
hand panel in figure 6.5. Thus, although with frequent incidence of non-state violence and a high infant mortality rate, the introduction of political exclusion decreases the risk of inter-group violence. The predicted probability is highest when there are no excluded groups. The effect becomes insignificant at higher levels of political exclusion, with confidence intervals overlapping with Senegal at -1.5. For Senegal, representing stronger state capacity, the predicted probability of inter-group violence increases somewhat at higher levels of political exclusion. This can be related to politically excluded groups choosing to target other groups in stronger states, because the state is too strong to be challenged. Also, as already mentioned, it could be that there is much more to gain by political incorporation in a strong state, whereas there is less incentive to be included in a weaker state structure.

The bottom-right panel in figure 6.6 shows the same tendencies as the bottom-left panel for political exclusion in D.R. Congo and Ethiopia. As with Somalia, D.R. Congo has had several instances of inter-group violence, but the predicted probability of non-state violence decreases as political exclusion increases. In contrast to the bottom-left panel, the confidence intervals of D.R. Congo and Ethiopia do not overlap at the highest levels of political exclusion. The probability for inter-group violence barely increases at higher levels of political exclusion in Ethiopia, indicating a minimal higher risk of inter-group violence in 2011. In D.R. Congo, however, when political exclusion is at its minimum level, the predicted probability is just above 60 percent in 2011, decreasing continuously to 20 percent at the highest level of political exclusion. The negative effect of increased political exclusion in weak states such as D.R. Congo can be related to so-called 'non-state' politics, where the disruption of state capacity has not led to a fundamental political transformation. The excluded groups have not sought to be included in the extremely weak formal state structures, as there is not much to gain by inclusion. Instead, in areas such as in North Kivu, there has been a reconfiguration of political power at the local level. Indeed, the armed group named Rassemblement Congolais pour la Démocratie (RCD) is increasingly resembling a state bureaucracy, and Tull $(2003,435)$ provides many examples of this:

The movement has made important efforts to display the formal attributes of a state administration. For example, it has transformed Kinshasas decentralized government units into its own ministries (départements). It also celebrates national holidays, displays its own flag and letter-heads, undertakes formal promotions of its administrative and political staff, regulates travel, customs or markets, receives and sends diplomatic missions and so on. In short, the RCD vigorously displays 
the state symbols and trademarks in the manner of any other state.

Thus, instead of fighting other groups to get incorporated in the state structure, RCD simply created a state within the state. Political exclusion was therefore not an incentive to engage in inter-group fighting. The picture was somewhat different, however, when it came to economic aspects. The central government made use of the traditional leaders in the postcolonial era to extend authority in peripheral areas in return for benefits. Although the local chiefs benefited from state-sponsored clientelism, it also undermined their legitimacy from within, as they used their control over land to distribute portions to party state officials. The patron-client relationship between chiefs and the locals therefore eroded, as the land as a social resource became a private asset. This change lead to increasing economic exclusion of large parts of the population, and ethnic conflicts between local groups erupted in the early 1990s (ibid). Thus, the example in D.R. Congo might help explain how political exclusion can have negative effects on group violence, whereas economic exclusion has a positive effect.

\subsubsection{Model Performance}

In the multivariate regression analysis, both estimation techniques provided significant results. However, when making inferences it is also important to account for the models' predictive power. To test the predictive performance of state capacity on inter-group violence, I first estimate a ROC curve for the logistic regressions based on in-sample predictions. Second, I address the log-likelihood and AIC for the nested and non-nested models to assess model performance, and third, perform out-of-sample predictions for the negative binomial models.

Following Ward, Greenhill and Bakke (2010), I include a ROC plot for the logistic regressions, and out-of-sample predictions for the negative binomial models. A ROC plot illustrates the relationship between false positives (defined as the number of incorrectly predicted events of non-state violence divided by the total number of cases where intergroup violence did not occur) and the rate of true positives (defined as the number of correctly predicted conflict events divided on the total number of cases where inter-group violence did occur). In an ideal case, then, a perfectly predictive model will identify all actual cases of inter-group violence and never generate false positives. The predictive power of a model can be assessed by the size of the area between the x-axis and the ROC curve, called the AUC, where better models have curves that cover more than a minimum of 0.5 , where the predictive power is no better than chance, to 1.0, where the model predicts 
Figure 6.7: ROC-curve: Model 1, 3, 5 and 7. The plot is based on averaged values for the ten imputed datasets.

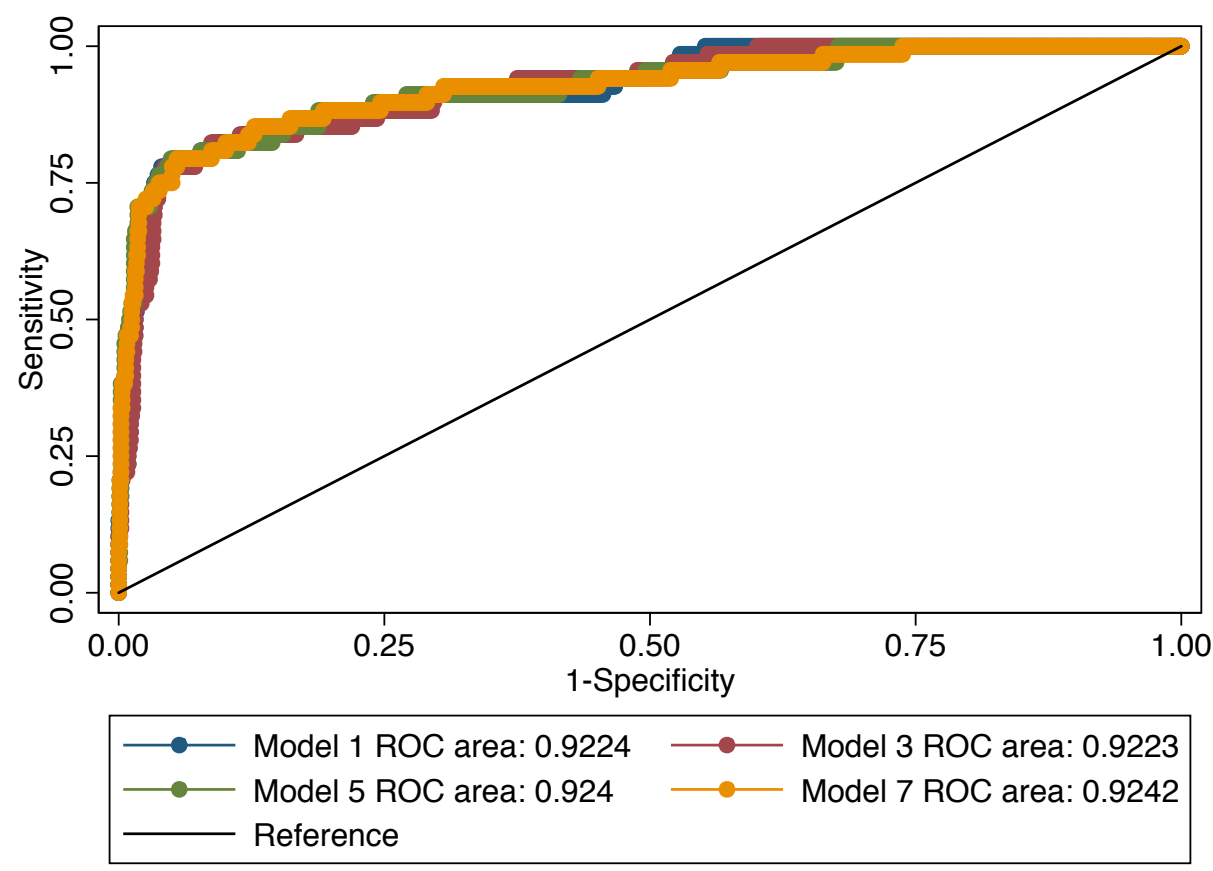

perfectly. Figure 6.7 shows the ROC curve for model 1, 3, 5 and 7, where the AUC for all four models is above 0.9 , indicating a satisfying predictive power of the logistic models.

To assess in-sample predictive capability I have included log likelihood and Akaike's Information Criterion (AIC) in all the models. ${ }^{11}$ It is clear from the estimations in the analysis that the inclusion of control variables in table 6.5 improves the AIC relative to the baseline models in Appendix C. Also, the AIC is lower in table 6.6 than in table 6.5, indicating that the inclusion of the interaction terms for economic and political inequality improves the predictive power of the models for the negative binomial regression. When it comes to log likelihood, the trend is the same for all tables, where the last model included has the lowest log likelihood, showing that the asymmetric economic measures for inequality improves the models, and that this is also relevant for the models addressing political exclusion in models 13 to 16 .

\footnotetext{
${ }^{11}$ The AIC is an approach to model selection based on non-nested hypothesis tests (Greene 2003). The test is useful when assessing the within-sample fit for prediction of the dependent variable. A common statistical test is $\mathrm{R}^{2}$, which measures proportion of the sample variation in $y_{i}$ that is explained by variation in $x_{i}$. However, the $\mathrm{R}^{2}$ does not punish the inclusion of many variables, which can lead to inaccurate estimations, as the inclusion of additional variables would always improve the model. Therefore, to account for both goodness-of-fit and the number of variables included in the model, I apply log likelihood for the nested models, and AIC for the non-nested.
} 
Testing models for performance not only in sample but also outside of sample is important to see whether the models perform well beyond the data used for the analysis. As model 11 and 12 for economic inequality and model 15 and 16 for political inequality have the lowest AIC scores and lowest log likelihood when comparing the full models in table 6.6, I use these models for the out-of sample predictions. Since I do not have any other data source outside the sample used in my analysis, I split my dataset in two equal parts. Then, I estimate model 11, 12, 15 and 16 on one half of the data, and test the predictive power on the other half. I do this procedure five times for the avergaed ten imputed datasets, to make sure that the predictions are not biased of particular features of the data. The highest predicted probability for model 11 and 12 is 36 and 33 percent, and for model 15 and 16 it is 31 and 36 percent. As the events in the data are rare, the low probability level is not unexpected.

To give a more complete picture of the models' predictive performance I create three thresholds for probabilities, on the 10, 20 and 30 percent level, and am thereby able to say how well the model predicts on different probability levels. When choosing how to split the dataset, I could also have used a division based on time, for example estimating with a division before and after 1999. Also, it is possible to divide the dataset in several parts. However, as I already have relatively few observations in general, and few conflict events in particular, I have chosen to divide them in two equal parts. Also, I have dismissed temporal separation because inter-group violence events tend to occur in the same country during short time periods. Thus, when an inter-group conflict occurs, other conflicts between groups also break out. An example of this is DR Congo, which saw multiple inter-group conflict events from 1996 to 2004. Thus, a divide of complete country years should make the out-of-sample prediction more restricted than a temporal divide, as the predictions in the models cannot make as much use of conflict relapses.

The results listed in table 6.8 are averaged values of the five out-of-sample predictions for the ten imputed datasets of inter-group violence events, compared with observed events. "False positives" reports how many times the model predicted an inter-group conflict event when no such event occurred, while "true positives" report the number of accurately predicted non-state conflicts of all observed events. "Negatives" report the number of correctly predicted non-events in the models, of all observed non-events. The results show that the percentage of correctly classified negatives are higher over all thresholds in 
Table 6.8: Out-of-Sample Predictions: Model 11, 12, 15 and 16

\begin{tabular}{lccc} 
& \% False Positives & \% True Positives & \% Negatives \\
\hline Modell 11 & & & \\
\hline Predicted prob $>.1$ & 11.92 & 64.25 & 94.83 \\
Predicted prob $>.2$ & 6.56 & 62.33 & 94.68 \\
Predicted prob $>.3$ & 4.28 & 50.66 & 94.06 \\
\hline Model 12 & & 66.94 & 98.20 \\
\hline Predicted prob $>.1$ & 11.37 & 56.75 & 97.32 \\
Predicted prob $>.2$ & 7.14 & 32.13 & 96.39 \\
Predicted prob $>.3$ & 5.12 & & \\
\hline Model 15 & & 72.85 & 95.32 \\
\hline Predicted prob $>.1$ & 8.01 & 54.91 & 93.89 \\
Predicted prob $>.2$ & 5.58 & 47.05 & 93.54 \\
Predicted prob $>.3$ & 3.80 & & \\
\hline Model 16 & & 67.57 & 97.20 \\
\hline Predicted prob $>.1$ & 11.57 & 54.53 & 96.32 \\
Predicted prob $>.2$ & 8.87 & 36.61 & 94.91 \\
Predicted prob $>.3$ & 6.06 & & \\
\hline
\end{tabular}

model 12, while the number of false positives is highest in model 11 . The amount of true positives is highest in model 15 , but the model predicts worst at the 30 percent threshold.

Among the non-state conflict events that the models predicted poorly at the ten percent level are Comoros in 1997, Uganda in 2002, Senegal in 2005 and Kenya in 2007. The aspect all these non-state conflict events have in common is only occurring once between 1989 and 2011, making it harder for the models to predict them accurately. Thus, for countries that have had multiple non-state events, such as Somalia, Sudan and D.R. Congo, the models' predictive capability is quite satisfactory, as the models anticipate an increased risk of conflict recurrence. However, when peace spells are long, the models are not able to pick up unexpected events. In addition, all these countries are considered as strong states, and the concept of non-state violence within a weak state capacity framework is therefore absent. At the other end, Angola is predicted to have non-state conflicts from 1989 to 2002, when there was none. This can be due to the ongoing civil war in the same period, increasing the predicted probability for violence in general. Hence, the out-of-sample predictions show that the models predict conflict quite satisfactory in countries that have had multiple events, whereas single events within countries are poorly predicted. Also, the models tend to predict inter-group violence when there is a civil war present, indicating that the more narrow theoretical focus on non-state violence has some 
weaknesses. Despite some variation, the results are quite similar for all models, and there is no apparent model that predicts more accurately on all thresholds. Generally, the results show that the models have predictive power out of sample, and the predictive capabilities of the four models are quite even.

\subsection{Summary}

With the use of both preliminary evidence from the descriptive statistics and multivariate regression analyses I have assessed the relationship between inter-group violence and weak state capacity. There are three distinctive patterns that emerge from the results. First, the results lend support to hypothesis $H 1$, that weak state capacity increases the risk of inter-group violence. This finding is in line with the theoretical implications presented in chapter 3.1, where weak state capacity forces groups to provide for their own safety. This implies that the groups can more easily organize themselves militarily and engage in conflict with each other.

Second, I find that the combined presence of weak state capacity and economic inequality further increases the risk of inter-group violence, providing support for hypothesis H1a. The presence of weak state capacity is a necessary condition for inter-group violence to take place, but an anarchical environment in itself might not be a sufficient explanation for inter-group violence. Hence, I have argued that the combination of limited state security and the state capture of a specific group can be relevant when trying to explain inter-group violence. As a weak state tends to be controlled by a single ethnic group, and is not able or willing to provide economic and political security for the remaining ethnic groups, they are more likely to engage in conflict. State weakness in combination with economic and political marginalization of groups could create security fears between groups, as inequality in the distribution of economic and political goods can facilitate violent mobilization through group comparison to change the status quo. When weaker groups must provide for their own security in a weak state, violent attacks may be directed against rival groups who receive larger shares of collective goods. Thus, the combined effect of weak state capacity and economic inequality provides groups with both opportunities and incentives to engage in non-state conflict.

Third, the results lend no support to the proposition that the conjunction of weak state capacity and political exclusion increases the risk of inter-group violence. In fact, the 
results show a negative relationship, indicating that the larger share of the population being excluded, the lower the risk of inter-group violence in a weak state. Thus, the results falsify my last hypothesis, $H 1 b$. This negative effect can be related to the relative grievance of groups and the potential gains of state inclusion. If a larger share of groups are excluded from a state with weak capacity, the negative effect of political exclusion can be related to two mechanisms. First, if the majority of the groups are unincorporated, the relative grievance for one excluded group is low. The economic differences between groups, however, are important given any type of state, and also more easily addressed at the local level. Second, if a state is weak to such a degree that it is unable to provide for the majority of its population, the potential gains for political representation is limited. However, if the state is able to provide for most groups within the state, and only a few groups are excluded from political relevance, the relative grievance is higher. Also, when the state is stronger the potential gains from political inclusion are more present, and the degree of state capacity can make it more difficult to challenge the state, indicating that conflicts between groups are more likely.

When assessing model performance, the ROC-plot for the logistic regression was satisfactory, showing AUC's above .9 in all models. Also, the inclusion of the interaction terms improved the AIC and log likelihood in all models in table 6.6, indicating that the interaction terms for economic and political inequality improve the predictive power of the models. Also, when conducting out-of-sample predictions the results were quite similar for the four models chosen, although single non-state conflict events were not predicted satisfactory. This is due to the lack of continuity in the observations, as countries that have experienced several non-state conflicts are predicted more accurately. This indicates that the models recognize conflict recurrences successfully, or conflict traps (Collier et al. 2003), and that the length of peace spells are important for the degree of adequate predictions. 


\section{Chapter 7}

\section{Model Robustness and Diagnostics}

To enable an assessment of whether the results presented in the main models are consistent and accurate, it is important to account for non-independence, influential observations, possible omitted variables, and alternative operationalizations and estimation methods. I therefore perform model robustness tests and diagnostics to assess whether certain model specifications or aspects of the research design are having an effect on the results. The models presented in the analysis provides evidence of an effect of weak state capacity, both by itself and in combination with marginalization, on the risk of a nonstate conflict event. Still, it is important to conduct alternative model specifications to detect and account for any errors in the models I have chosen.

\subsection{Non-Independent Observations}

The negative binomial estimation used in section 6.2 is based on a simple stochastic process, where the outcome is the number of occurrences per unit of time. Thus, how many 0 counts are needed to obtain a 1. A critical assumption of this Poisson distribution is that the events are independent. Thus, when inter-group violence occurs, this does not affect the probability of the event occurring in the future (Long 1997). However, observations in the data share similarities that could violate the assumption of independent observations, leading to incorrect standard errors. For example, when inter-group violence occurs in a country, it tends to reoccur in subsequent years. Hence, it may well be that groups choose to engage in conflict with each other because of previous conflicts or because of other inter-group violence events occurring in the same year. For example, the conflict between the Independent National Patriotic Front of Liberia (INPFL) and National Patriotic Front of Liberia (NPFL) in 1990 may have affected the outbreak of the subsequent 
non-state conflict in 1991 between NPFL and ULIMO in 1991. This implies that there may well be time dependence in the data, and not necessarily spatial dependence.

To account for alternative forms of dependence, I have estimated the models in section 6.2 with standard errors clustered on year. However, there is also a possibility for other types of dependency, such of that between dyads, or between regions within countries. It seems reasonable to assume that the choice of one group to engage in fighting with another affects its likelihood of engaging in yet an additional conflict, or that war prone regions are more likely to see non-state conflicts. However, given the nature of my data I am not able to to account for these possible dependencies. Therefore, I have tried to account for potential forms of non-independence by using unclustered sandwich robust standard errors, as robust standard errors can correct for possible violations of the assumptions in the model (ibid). This is an advantage when it is difficult to identify the type of clustering in the data. Thus, to account for non-independent observations beyond clustering on country, I run model 5 to 8 and 11, 12, 15 and 16 with standard errors clustered on year, and unclustered robust sandwich standard errors. ${ }^{1}$

Table D.1 assesses the robustness of $H 1$, while table D.2 assesses the robustness of $H 1 a$ and $H 1 b$ in Appendix D. The results show that the results remain consistent over alternative clustering options. All the significant results remain significant when I cluster on year and use only the robust standard error specification. Also the AIC and log-likelihood remain similar, indicating that the results do not show a high degree of dependence, spatial, temporal or other.

\subsection{Residuals and Influence}

An important assessment of the model fit of a regression model is to examine the residuals and potential outliers. Residuals can be understood as the difference between a model's predicted and observed outcome for all observations. Cases that are poorly predicted lies far from the regression line, and are known as outliers. When these observations have a large effect on the estimated parameters, they are said to be influential (Long and Freese 2006). To take a closer look at the residuals is especially important for my analysis, as a handful of countries have experienced the majority of instances of non-state conflicts. If some of these observations are poorly predicted, it can have an impact on the results.

\footnotetext{
${ }^{1}$ As several specification options are place consuming, I present the different clustering options on estimations with lowest AIC and log likelihood.
} 
Thus, I investigate the residuals in my analysis for both logistic and negative binomial regression. ${ }^{2}$

When deciding on the threshold for what characterizes as a large residual, there is no given rule. Indeed, Hosmer and Lemeshow (2000) claim that it is impossible to provide any absolute standard, as the assessment of what is too large must be based on the particular set of data being analyzed. Given my residual plot from the logistic regressions using Cook's distance (Pregibon 1981), it seems reasonable to categorize residuals above 1 as influential cases, which leaves me with 6 outliers (Menard 2010). ${ }^{3}$ Thus, the model has not predicted a non-state conflict event satisfactory in these instances. These observations were in South Africa in 1992, Comoros in 1997, Uganda in 2002, Burundi 1996, and D.R. Congo in 1995 and 1996. In addition to another non-state conflict event between two taxi organizations in 1995, South Africa has not seen additional inter-group conflict events. Equally, Comoros and Uganda have only had one non-state conflict event in the sample. Thus, states who have had limited continuity in non-state violence have been predicted less accurately, which is not surprising given the unexpected occurrence of these events. Burundi had the first non-state conflict event in 1996, which is predicted poorly, whereas the subsequent events have smaller residuals. The more unexpected large residuals concerns D. R. Congo, which have had several instances of inter-group violence. This can be related to the fact that the country was categorized as a strong state when the non-state conflict events occurred, which can explain why the model predicted the events poorly. The country is not coded as weak until 1998, while the country saw the first instance of inter-group violence in 1996. When the coding changes in 1998 to a weak state, the model predicts non-state conflicts more satisfactory. Hence, it is interesting to note that the models are better able to pick up non-state conflicts within the weak state capacity context, indicating that the models are to some degree able to pick up the features of state strength and inter-group violence.

To see whether the six observations classified as influential are effecting the results, I

\footnotetext{
${ }^{2}$ All statistics concerning the residuals and influential observations are based on averaged values of the variables in the dataset, and not the coefficients. This is simply because commands such as dbeta and countfit are not possible to conduct using mi estimate in Stata. Thus, the results from this section is based on one averaged dataset, and the uncertainty of the estimates is therefore lost. However, when conducting the regressions and residual plots on the different datasets, the results are similar, indicating that the statistics presented here should not be too divergent from the results if more post estimation options had been available.

${ }^{3}$ See Appendix D, figure D.1 for the residual plot for model 5. The residual plots for model 1, 3 and 7 show similar results.
} 
Figure 7.1: Predicted versus Observed Values: Model 15. Positive deviations display underpredictions.

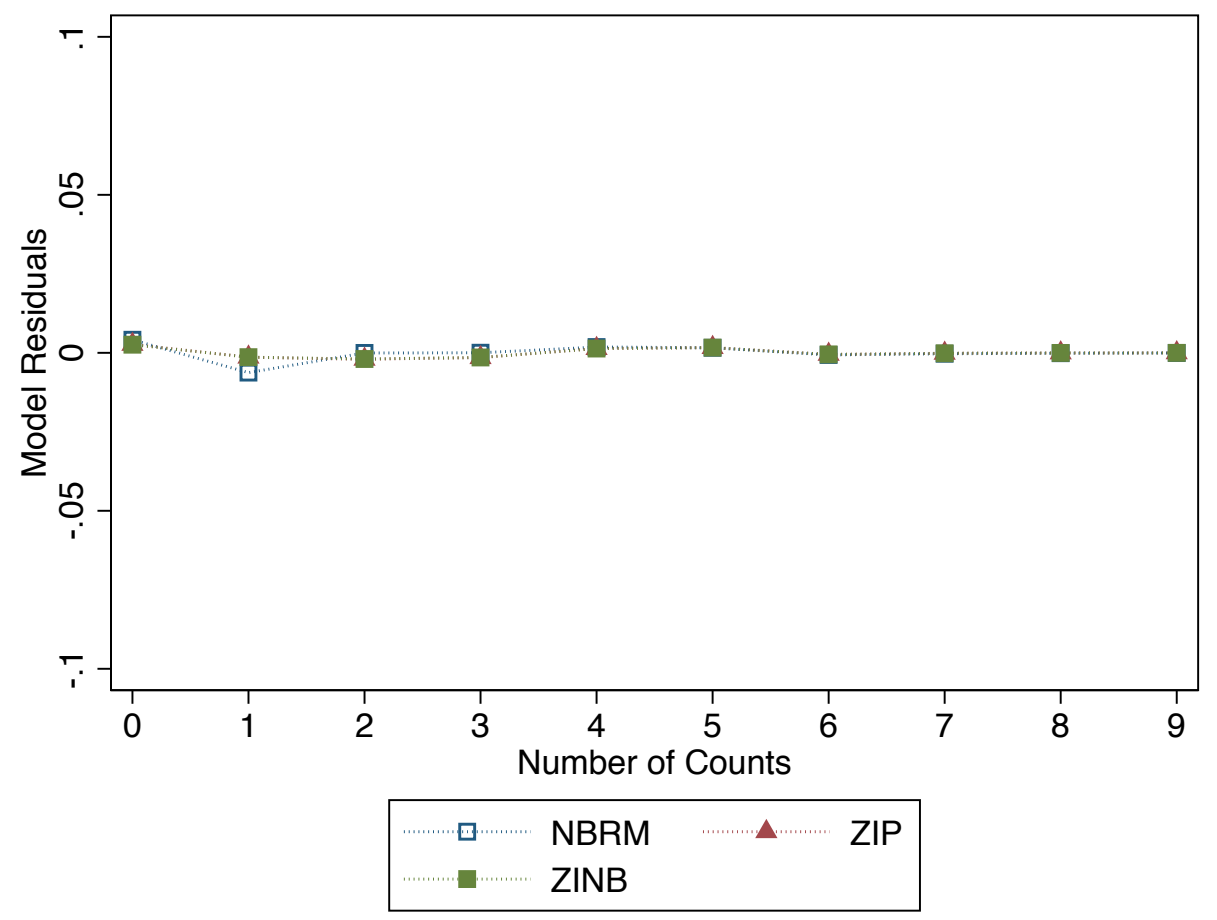

exclude them from the sample, and run the logistic regressions without these observations. The results are not altered when the influential cases are omitted in the logistic regressions.

When using count regression models, I am not able to apply a similar logic as with Cook's statistic. Hence, I am not able to point out cases that the models predict poorly. However, I am able to compare model residuals for different count estimation methods, which enables me to say something about how well the negative binomial regression performs compared to other count estimation techniques. Figure 7.1 shows a plot of the residuals from a negative binomial model, zero inflated negative binomial model and zero inflated poisson model estimated for model $15 .{ }^{4}$ Small residuals are indicative of a well-fitted model, meaning values close to zero. It is evident that the three models perform very similarly for all counts, and that all three differ most from observed values at zero and one counts. The plots shows that the negative binomial model overpredicts somewhat at one counts, but the difference between the models are very limited.

\footnotetext{
${ }^{4}$ I chose model 15 as it has the lowest $\log$ likelihood and AIC. The results were similar for the other negative binomial regression models.
} 
Table 7.1: Fit Statistics

Summary Comparisons

\begin{tabular}{llllll}
\hline NBRM & $\mathrm{BIC}=-6100.536$ & $\mathrm{AIC}=0.449$ & Prefer & Over & Evidence \\
\hline vs ZIP & $\mathrm{BIC}=-6093.165$ & $\mathrm{dif}=-7.374$ & NBRM & ZIP & Strong \\
& $\mathrm{AIC}=0.436$ & $\mathrm{dif}=0.013$ & ZIP & NBRM & \\
\hline \multirow{2}{*}{ vs ZINB } & $\mathrm{BIC}=-6087.149$ & $\mathrm{dif}=-13.390$ & NBRM & ZINB & Very Strong \\
& $\mathrm{AIC}=0.438$ & $\mathrm{dif}=0.011$ & ZINB & NBRM & \\
& Vuong $=2.674$ & $\mathrm{prob}=0.004$ & ZINB & NBRM & $\mathrm{P}=0.004$ \\
\hline
\end{tabular}

Table 7.1 suggests the preferred model and the strength of confidence in this preference. ${ }^{5}$ When comparing the three models using BIC and AIC, the negative binomial is preferred over both the zero inflated poisson and the zero inflate negative binomial. However, the Vuong test prefers the zero inflated negative binomial model at a statistically significant level. Nonetheless, as both the AIC and BIC support a negative binomial model, and since the predictions are almost identical in figure 7.1, I conclude that the negative binomial is a suitable mode for my analysis.

\subsection{Omitted Variables}

Although the models in the analysis include five independent variables with their corresponding interaction terms, I have only included four control variables. Hence, the choice of control variables have been made at the expense of other possible explanatory factors. If a relevant variable is left out, this can alter the results as the analysis is biased because of an specification error due to the omitted variable (Greene 2003). In this section I will take possible omitted variable bias into account by including four additional variables; Education, ethnic fractionalization, size of youth population and oil. ${ }^{6}$

First, several studies have found a pacifying effect of education on armed conflict (see

\footnotetext{
${ }^{5}$ I obtained these numbers and fit statistics by using the countfit command in Stata.

${ }^{6} \mathrm{GDP}$ per caita income is among the most robust predictors of civil conflict. The variable is assosciated with both the onset and duration of civil war (Hegre and Sambanis 2006; Collier, Hoeffler and Söderbom 2004; Collier and Hoeffler 2004; Fearon and Laitin 2003). However, I have chosen not to include this measure as infant mortality rate is viewed as a more accurate proxy for economic development, and also because both infant mortality rate and education can be said to explain much of the variation a GDP per capita measure would capture (Hegre et al. forthcoming).
} 
e.g. Collier and Hoeffler 2004; Collier, Hoeffler and Söderbom 2004). ${ }^{7}$ Thus, education may decrease the risk of inter-group violence. I therefore control for education, and the measure used is taken from Hegre et al. (forthcoming), which is orignially from Lutz et al. (2007). As Hegre et al. (forthcoming), I use a measure of male secondary education, defined as the proportion of males aged between 20 and 24 years with secondary or higher education of all males within the same age range.

Second, as I have chosen to not include linguistic measures for ethnic diversity in my analysis, I include an alternative measure for ethnic groupings as a robustness test. Although it is viewed as a less accurate measure than EPR, significance on variables with a more demographic nature would lend additional support for my findings. I include a measure on ethnic fractionalization from Fearon (2003), which is defined as the probability for two randomly selected individuals in a country being from different ethnic groups.

Third, I include a demographic measure for youth bulges. Several scholars have addressed the relationship between the proportion of young people and armed conflict (see e.g. Hegre et al. forthcoming; Collier, Hoeffler and Söderbom 2004; Fearon and Laitin 2003), where the effect of youth bulges on civil conflict has been both confirmed and rejected. I use an age specific measure taken from Hegre et al. (forthcoming), which is originally from the United Nations (2007). The variable is measured as the percentage of the population aged 15 to 24 of all adults aged 15 years and up.

Fourth, I apply a measure for primary commodities. The effect of oil on armed conflict has been much debated in the conflict literature. Some studies find that oil or diamond wealth can be tied to the onset or duration of civil war (see e.g. de Soysa 2002; Ross 2006; Humphreys 2005; Reynal-Querol 2002; Lujala, Gleditsch and Gilmore 2003), whereas others have found no such effect (see e.g. Elbadawi and Sambanis 2002; Regan and Norton 2005). The measure for oil is taken from Hegre et al. (forthcoming), originally from the Fearon and Laitin dataset (Fearon and Laitin 2003), coded 1 if the country obtains one third of its export revenues from oil or gas.

In Appendix D, table D.4 and table D.5 show that the main findings are robust with the inclusion of additional variables. All the variables have significance and are in the

\footnotetext{
${ }^{7}$ Collier (2000) claims that a strong education system decreases the likelihood of insurgency because it decreases the incentive that potential rebels would have to challenge the state, and Thyne (2006) find that secondary enrollment and literacy rates decrease the probability of war.
} 
same direction as the models in table 6.5 and table 6.6. Nonetheless, there are some divergence. Weak state has lower significance levels throughout in table D.4 compared to table 6.5. In table D.5 the variable for economic inequality is significant at the ten percent level in model 9 and 10, which is insignificant in table 6.6. Also, the coefficients for weak state*economic inequality and poorest group have larger coefficients. The interaction term for weak state and richest group is now significant on the five percent level, indicating weaker confidence in the results with the inclusion of additional variables. None of the added variables are significant in the model, except from youth bulges in model 11, 12 and 15, indicating that larger share of a younger population increase the risk of inter-group violence. This result, however, is somewhat tentative with significance levels only at the five and ten percent level.

Models 13 to 16 show the same tendencies, with lower significance levels for economic inequality and richest group, and the coefficients are stronger also here. The interaction terms for political inequality have similar significance level and direction as models 13 to 16 in table 6.6, and the coefficients are quite similar in strength. None of the additional variables included are significant. Thus, although with somewhat lower confidence in the findings, $H 1$ and $H 1 a$ are still supported, while $H 1 b$ is rejected also in the robustness tests for potential omitted variables.

\subsection{Alternative Operationalizations and Estimation Methods}

When assessing the degree of robustness of the main findings, it is important to use alternative operationalizations to make sure that the results are consistent. As there is no alternative measure with equally broad coverage and specificity as the dependent variable used, I focus on an alternative measure for weak state capacity, as state capacity is my main independent variable, and included in all interaction terms. Also, I use two additional estimation techniques, zero inflated negative binomial and rare event logistic regression. If there is an effect of weak state capacity in inter-group violence, the results should not be altered in substantive ways with alternative operationalizations of state strength and estimation methods.

I use Polity as an alternative measure for state strength. The Combined Polity Score is a unified polity scale that ranges from +10 (strongly democratic) for countries such 
as Mauritius between 1989 and 2007, to -10 (strongly autocratic), for countries such as Swaziland between 1989 and 1992. As the Polity focus on the degree of a specific type of regime, and not directly on state strength, I have dichotomized the variable to try to capture those states that can be considered as weak. As the variable on state capacity taken from the ICRG is based on 20 percent of the variable range ( 0 to 4 , where below 1 is characterized as weak), I apply the same logic with my alternative measure. I follow the argument on how inconsistent political regimes invite collective action and political contestation among competing forces, and that this leads to higher level of state incapacity (see e.g. Fjelde and Nilsson 2012). I recode the Polity measure, where -2 to 2 is coded 1, 0 otherwise. I hereby base the measure on a dichotomization, where one fifth is considered as weak, ensuring that only the states considered most inconsistent around 0 is included. With this division I am able to follow the same logic as ICRG, where weak states make up one fifth of the range. I can thereby test the robustness of my findings with an alternative measure picking up other aspects of state capacity than the ICRG, with a similar categorization. Thus, for my findings to be consistent, the results should be fairly similar using a different but theoretically corresponding measure.

Also, as discussed in section 4.2.2, negative binomial regression is not always suited when dealing with large amount of zeros on the dependent variable. As the amount of zeros in my data is extensive, the negative binomial model can lead to underprediction (Long 1997). To try to account for this, I include a zero-augemented model that allows for the possibility that some units will never obtain a count. In relation to the amount of zeroes in the data, I also include rare event logistic regression, an estimation method that corrects for small samples and rare events by generating lower-variance estimates (King and Zeng 2001).

Table D.6 and table D.7 in Appendix D show the results for estimations with Polity as an alternative measure for state capacity. The overall picture is that the variables that are significant using ICRG are also significant when using the Polity measure, and the estimates have the same direction. Table D.6 shows that the incidence odds for weak state capacity pulls in the same direction as anticipated, and are all significant. The interaction term for weak state and economic inequality in table D.7 is positive and highly significant in both P9 and P10. In P11 and P12, the interaction for poorest group is insignificant, while weak state interacted with richest group is positively significant, but only at the 10 percent level, indicating a weaker confidence for the interaction term when using the 
alternative measure. When it comes to political inequality, the interaction terms in P13 to P16 are less robust using Polity. Although in the same direction, the interactions have lower significance, and the interaction term in model P16 is insignificant. This leaves the results for political exclusion more uncertain. Thus, the estimates concerning state capacity and economic inequality from my full models in section 6.2 show the same tendencies and point in the same direction when I use an alternative measure for state capacity. The results are also overall significant, although with a lower level of significance for the asymmetric economic inequality measures and the political exclusion measures.

When it comes to alternative estimation methods, table D.8 shows that the effect of weak state capacity on inter-group violence is still positive and significant, both using rare event logistic and zero inflated negative binomial regressions. Table D.9 shows the results for estimations including the interaction terms using rare event logistic regressions. The results support the finding that the combination of economic inequality and weak state capacity increases the risk of inter-group violence, while the combined effect of political exclusion and weak state capacity has a negative effect on non-state conflict risk. However, although the estimates for economic and political inequality are in the same direction as the main analysis, the findings have lower levels of significance throughout. While being significant at the 1 percent level using negative binomial regression, weak state*economic inequality is only significant at the ten percent level using rare event logistic regression. The interaction between weak state and richest group is insignificant in both model 3 and 4 . This leaves the finding of an interaction effect of economic exclusion and weak state structure more tentative. Nonetheless, the core findings are quite robust using alternative estimations, as the direction is the same for all indicators and the results show some degree of significance. Also, weak state*richest group is insignificant, but barely so, with significance levels at 10.6 percent in model 3, and 11 percent in model 4. Furthermore, table D.10 report the results of a zero inflated negative binomial regression with interaction terms included, and I find that also here most of the indicators are significant and in the same direction as table 6.6. As the estimates for both alternative operationalization of weak state capacity and alternative estimation methods show similar results in direction and significance, I conclude that my findings in section 6.2 are quite robust to alternative specifications. 


\subsection{Summary}

The alternative operationalizations and specifications used in this chapter render the results from my analysis robust and consistent. When using alternative clustering options to account for dependence in the data, the results were not altered, and the removal of outliers did not substantially effect the results. When comparing the model fit of different count estimation techniques, the results were quite similar and satisfactory, indicating that the negative binomial regression is appropriate. The inclusion of the additional variables education, ethnic diversity, oil and youth bulges shows that the main findings are robust. However, the models including interaction terms for weak state and economic inequality rendered the results with lower certainty. The inclusion of Polity as an alternative measure and the usage of rare event and zero inflated models show that the results are overall significant and in the same direction as in the main analysis, although with lower levels of significance. This is especially the case for the asymmetric economic inequality measures and political exclusion. Thus, although the results are more tentative given the changes in significance, I consider the robustness tests as supportive of the findings in my analysis. 


\section{Chapter 8}

\section{Conclusion}

The main emphasis in this thesis has been to investigate the relationship between weak state capacity and inter-group violence. I have argued that the strength and quality of state institutions is important when trying to explain the variation in non-state conflict occurrences. When central authority is weak and unable to maintain full authority within the state sphere, groups must provide for their own protection. This situation of selfgovernance could create risks between groups, as other groups could become potential rivals when the state is unable to assure group security. Thus, a weak state sphere creates opportunities for groups to engage in conflict. Although weak state institutions is a necessary condition for the emergence of inter-group violence, it is not necessarily a sufficient explanation. I therefore argued that the interaction between weak state capacity and economic and political marginalization further increases the risk of inter-group violence, as such an interplay creates both opportunities and incentives to engage in conflict. Within many African states, the central authority does not have full authority within the state sphere. While relying on ethnic politics for support and accommodating groups that are relevant for survival, the state is unable to incorporate the entire population, leaving other ethnic groups excluded. Through a process of group comparison, I have argued that the capture of the state by an ethnic group at the expense of others can facilitate mobilization and increases incentives to engage in conflict.

In the following I will present some implications and limitations of the thesis, alongside some ideas for ways to improve the analysis. 


\subsection{The Scope of the Theory}

Previous research on non-state violence has mostly consisted of case studies. Although relating to the same mechanisms, these studies are not directly comparable with the type of conflict focused on in this thesis, which has been on more informally organized groups. Most quantitative studies on conflict, on the other hand, have focused on armed conflicts with the state as one of the belligerents, paying limited attention to the non-state side. While these contributions are highly relevant for the study of civil conflict, it is not clear from the theories why the state necessarily has to be a participant in the conflict. Indeed, arguments concerning incentives and opportunities for violence mostly consider whether violence will occur or not, and not who might participate in it. When accounting for grievances within a state, these incentives are usually related to other groups in society. When theorizing the emergence of conflict, however, the efforts to address these grievances are related to the state. Despite the fact that the state controls the allocation of resources, I argued that groups are just as likely to attack other groups, as which ethnic group you belong to is closely related to whether you receive concessions from the state. Thus, I have tried to avoid the construction of a theoretical framework that can be applied to violence in more general terms. Although the theoretical scope presented here has its limitations, the predictive power of the models are quite satisfactory. Moreover, it is important to specify more clearly what type of violence one seeks to explain, as conflicts often open for multiple grievances to be addressed, which are not necessarily explained by the same mechanisms. In order to account for why conflict occurs, then, it seems reasonable to focus on a more specific type of conflict. I have therefore used a more narrow theory relating to the protection and entitlements of groups, seeking to test the theory on a sample to which the theory logically applies.

\subsection{Implications}

In conducting the quantitative analysis, there were both rejections and confirmations of my three hypotheses. Hypothesis $H 1$ was confirmed, which implies that the strength and capacity of a state is relevant when attempting to explain and predict non-state violence. A theoretical interpretation of this is that groups engage in conflict with each other as a consequence of the opportunity structures that a weak state provides. Without the presence of state authority, groups can more easily mobilize militarily and engage in conflict with each other, or are forced to do so. I also find support for hypothesis H1a, that the combined effect of weak state capacity and economic inequality increases the risk of 
inter-group violence. As a weak state tends to be controlled by a single ethnic group, and is not able or willing to provide economic and political security for the remaining ethnic groups, economically excluded groups are more likely to engage in conflict to alter uneven distribution. As the structure of inequality is group based, mobilization and collective action within excluded groups is more easily achieved through group comparison. The results do not, however, lend support for hypothesis H1b. This indicates that the interaction between political exclusion and weak state capacity renders non-state violence less likely. Although this result can be related to several and overlapping mechanisms, I have tried to explain the negative relationship through the attributes and features of a weak state. This negative effect implies that the relative exclusion of groups is important for non-state violence, and the degree to which controlling the state provides potential gains. I relate this to two mechanisms. First, if the majority of groups are excluded from the state apparatus, the relative grievance of exclusion is low. Second, if the capacity of a state is so limited that it cannot provide for its population, the potential gains, and thereby incentives, for state inclusion is low. However, with a more capable state able to accommodate the majority of inhabitants, the relative grievance of exclusion is higher. Also, a stronger state provides higher incentives and potential gains by inclusion, and can be more difficult to challenge directly. This implies that group violence caused by political exclusion is less likely within weaker states.

The interplay between non-state violence and weak state capacity is the central focus of this thesis, and provides contributions concerning two aspects. First, I focus on a specific type of violence, and examine the link between inter-group conflict and state capacity with a quantitative approach. Second, I focus on the combined effect of economic and political exclusion and weak state capacity, and how this conjunction relates to intergroup violence. Moreover, the findings can also be relevant for policy implications. If it is the case that state capacity both by itself and in combination with economic inequality affect the likelihood of group conflict in Sub-Saharan African states, attempts to improve bureaucratic quality and more even redistribution of public goods must be made. The state capture of an ethnic group at the expense of others leave the excluded groups more vulnerable and insecure, making political representation that reflects the size and needs of the different ethnic groups essential to hinder non-state conflicts. In addition, to avoid the outbreak of conflict between groups caused by weak state capacity and exclusion is important for the future risk of inter-group fighting, as conflict relapse is a clear pattern in non-state violence. 


\subsection{Moving Further}

This study is relevant for several research traditions. First of all, it is relevant for the study of violence between factions that does not involve the state. Indeed, this is perhaps the main contribution of this thesis given the few quantitative studies on the topic. In addition, it is relevant for the study of horizontal inequalities, where group mobilization and in- and out-group categories are relevant for conflict, and it is also relevant for the literature focusing on opportunity structures that weak state capacity provides. When looking closer at non-state violence, I made a choice about the size of the sample, limiting the study to Sub-Saharan Africa. This choice was made based on theoretical considerations, where the structure and strength of many Sub-Saharan African states seemed to be most relevant for a weak state capacity framework. For example, in the complete sample, there are cases of inter-group violence between drug cartels in Mexico and Columbia, and between motorcycle gangs such as Hells Angels and Rock Machine in Canada. Although clear examples of inter-group violence, these cases are not directly relevant nor applicable to the concept of weak state capacity. However, although this study has only focused on inter-group violence in Sub-Saharan Africa, it is interesting to consider whether the approach used here is also applicable to other regions with similar characteristics, and in Asia, countries such as Afghanistan, Iraq, and Bangladesh would perhaps fit within such a framework. Thus, the relevance and applicability of this study might not be limited solely to Sub-Saharan Africa, but also to other countries in different regions with the combined presence of limited capacity and the marginalization of groups.

Although the analysis has presented some relevant trends and implications for the study of non-state violence, it also has its limitations. Before concluding, I would like to present and discuss some of them. First of all, a clear limitation of the study is that the excluded groups and the groups who engage in conflict are not matched. Although I can confirm that the presence of economic inequality increases the risk of inter-group violence, I cannot say whether it is the poorest or richest group who engage in conflict, or assess the relative income and political access available for the groups. With more time and resources, it would have been fruitful to match the two data sources used on groups, to be able to draw on more information in the analysis. Second, for further research, it is perhaps useful to disaggregate the measure on weak state capacity, as a simple dichotomization of weak and strong state is a crude division. Although this thesis sought to capture only the weakest states, which was to a large degree accomplished with this dichotomization, it would have been interesting to see what institutions, specifically, that induced inter- 
group violence. This should contribute to a more accurate assessment of what aspects of weak state capacity that increase conflict risks between groups. Third, despite the fact that economic differences tend to change slowly over time, it would have been optimal to have a dynamic economic inequality measure. The inequality measure used here is based on inequality levels from 1990, making the analysis static when it comes to economic aspects of non-state violence. Creating measures that reflect the changes in the economic status of groups is important for future research on inequality and non-state violence. Fourth, it would have been constructive to include information on the role of neighboring states. Given that the groups who engage in fighting are economically excluded, it would be interesting to assess how and why groups receive funding, and how they are able to withhold their highly organizational nature. Factors such as foreign support and ties to the same ethnic group over borders could be a possible advancement of this study. Also, a related point to this is to map whether the groups fight for inclusion or secession. With such information it would be possible to assess whether excluded groups fight for increased relevance or for independence. With more data on non-state violence, and further advancement in information available, such studies would be a step forward for this type of analysis.

\subsection{Concluding Remarks}

This thesis has provided insights on the relationship between state capacity and non-state violence, suggesting that weak state structures increase the risk of inter-group conflict. Moreover, the combined effect of weak state capacity and economic marginalization further increases this risk. The results imply that it is important to look at characteristics of states when studying group violence, and the interaction between specific state structures and the exclusion of groups. When addressing non-state violence, it is constructive to not only focus on an individual or distinct type of explanation, but the combined effect weak state capacity can have with other explanations for civil conflict. Thus, instead of focusing solely on opportunity or motivation at the expense of the other, the interplay between these two factors proves relevant in the study of non-state conflict. 


\section{Chapter 9}

\section{Bibliography}

Abayomi, Kobi, Andrew Gelman and Marc Levy. 2008. "Diagnostics for Multivariate Imputations." Applied Statistics 57(3):273-291.

Abouharb, M. Rodwan and Anessa L. Kimball. 2007. "A New Dataset on Infant Mortality Rates, 1816-2002." Journal of Peace Research 44(6):743-754.

Achen, Christopher H. 2002. "Toward a New Political Methodology: Microfoundations and ART." Annual Review of Political Science 5:423-450.

Achen, Christopher H. 2005. "Let's Put Garbage-Can Regressions and Garbage-Can Probits Where They Belong." Conflict Management and Peace Science 22(4):327-339.

Adcock, Robert and David Collier. 2001. "Measurement Validity: A Shared Standard for Qualitative and Quantitative Research." American Political Science Review 95(3):529546.

Banerjee, Kishalay. 1984. Regional Political Parties. New Dehli: B. R. Publishing.

Barron, Patrick, Kai Kaiser and Menno Pradhan. 2004. "Local Conflict in Indonesia. Measuring Incidence and Identifying Patterns." World Bank Policy Research Working Paper 3384, August 2004.

Bassett, Thomas. 1988. "The Political Ecology of Peasant-Herder Conflicts in the Northern Ivory Coast." Annuals of the Association of American Geographers 78(3):453-472.

Bates, Robert. 2008. When Things Fell Apart. State Failure in Late-Century Africa. New York: Cambridge University Press. 
Bayart, Jean F. 2003. The State. In Readings in African Politics, ed. Tom Young. Oxford: James Currey Ltd pp. 40-45.

Beck, Nathaniel, Jonathan N. Katz and Richard Tucker. 1998. "Taking Time Seriously: Time-Series-Cross-Section Analysis with a Binary Dependent Variable." American Journal of Political Science 42(4):1260-1288.

Beck, Nathaniel and Kristian S. Gleditsch. 2003. "Space is More than Geography." Workshop on Geography, Conflict and Cooperation, Joint Session of the European Consortium of Political Research (ECPR).

URL: http://polmeth.wustl.edu/media/Paper/beck03.pdf

Beck, Nathaniel and N. Katz, Jonathan. 2001. "Throwing out the Baby with the Bath Water: A Comment on Green, Kim, and Yoon." International Organization 55(2):187195.

Benjaminsen, Tor A. and Boubacar Ba. 2009. "Farmer-Herder Conflicts, Pastoral Marginalization and Corruption: A Case Study from the Inland Niger Delta of Mali." The Geographical Journal 175(1):71-81.

Bhatnagar, Satyavan and Pradeep Kumar. 1998. Regional Political Parties in India. New Dehli: Ess Ess Publications.

Bøås, Morten. 2005. "The Liberian Civil War: New War/Old War?" Global Society $19(1): 73-88$.

Bøås, Morten and Anne Hatløy. 2008. "Getting in, Getting Out": Militia Membership and Prospects for Re-Integration in Post-War Liberia." Journal of Modern African Studies 46(1):33-55.

Boix, Carles. 2008. "Economic Roots of Civil Wars and Revolutions in the Contemporary World." World Politics 60(3):390-437.

Box, George E. P. and Norman R. Draper. 1987. Empirical Model-Building and Response Surfaces: Wiley Series in Probability and Mathematical Statistics. Oxford: John Wiley and Sons.

Box-Steffensmeier, Janet M. and Bradford S. Jones. 2004. Event History Modeling: A Guide to Social Scientists. Cambridge: Cambridge University Press. 
Brambor, Thomas, William R. Clark and Matt Golder. 2005. "Understanding Interaction Models: Improving Empirical Analysis." Political Analysis 14(1):63-82.

Brancati, Dawn. 2006. "Decentralization: Fueling the Fire or Dampening the Flames of Ethnic Conflict and Secessionism?" International Organization 60(3):651-685.

Buhaug, H., K. S. Gleditsch, H. Holtermann, G. Østby and A. F. Tollefsen. 2009. "Revolt of the Paupers or the Aspiring? Geographic Wealth Dispersion and Conflict." Unpublished manuscript. Centre for the Study of Civil War, The Peace Research Institute Oslo (PRIO).

URL: http://www.imtlucca.it/_kbase/seminar_paper/006527_000253_pdf

Buhaug, Halvard. 2010. "Dude, Where's My Conflict? LSG, Relative Strength, and the Location of Civil War'." Conflict Management and Peace Science 27(2):107-128.

Buhaug, Halvard, Kristian S. Gleditsch, Helge Holtermann, Andreas F. Tollefsen and Gudrun Østby. 2011. "It's the Local Economy, Stupid! Geographic Wealth Dispersion and Conflict Outbreak Location." Journal of Conflict Resolution 55(5):814-840.

Buhaug, Halvard, Lars-Erik Cederman and Jan K. Rød. 2008. "Disaggregating EthnoNationalist Civil Wars: A Dyadic Test of Exclusion Theory." International Organization 62(3):531-551.

Buhaug, Halvard and Päivi Lujala. 2005. "Accounting for Scale: Measuring Geography in Quantitative Studies of Civil War." Political Geography 24(4):399-418.

Butterfield, Herbert. 1951. History and Human Relations. London: Collins.

Carter, David B. and Curtis. S. Signorino. 2010. "Back to the Future: Modeling Time Dependence in Binary Data." Political Analysis 18(3):271-292.

Cederman, Lars-Erik, Andreas Wimmer and Brian Min. 2010. "Why do ethnic groups rebel? New data and analysis." World Politics 62(1):87-119.

Cederman, Lars-Erik, Nils B. Weidmann and Kristian S. Gleditsch. 2011. "Horizontal Inequalities and Ethnonationalist Civil War: A Global Comparison." American Political Science Review 105(3):478-495.

Christia, Fotini. 2008. "Following the Money: Muslim versus Muslim in Bosnia's Civil War." Comparative Politics 43(2):461-480. 
Clapham, Christopher. 1996. "Governmentality and Economic Policy in Sub-Saharan Africa." Third World Quarterly 17(4):809-824.

Clapham, Christopher. 1998. "Degrees of Statehood." Review of International Studies 24:143-157.

Coast, Elaine. 2002. "Maasai Socioeconomic Conditions: A Coss Border Comparison." Human Ecology 30(1):79-105.

Collier, Paul. 2000. "Economic Causes of Civil Conflict and Their Implications for Policy." World Bank Development Research Group.

URL: $\quad$ Uttp://reliefweb.int/report/world/economic-causes-civil-conflict-and-theirimplications-policy

Collier, Paul and Anke Hoeffler. 2004. "Greed and Grievance in Civil War." Oxford Economic Papers 56(4):563-595.

Collier, Paul, Anke Hoeffler and Måns Söderbom. 2004. "On the Duration of Civil War." Journal of Peace Research 41(3):253-273.

Collier, Paul, Lani Elliot, Håvard Hegre, Anke Hoeffler, Marta Reynal-Querol and Nicholas Sambanis. 2003. Breaking the Conflict Trap. Civil War and Development Policy. Oxford: Oxford University Press.

Cranmer, Skyler J. and Jeff Gill. 2012. "We Have to Be Discrete About This: A NonParametric Imputation Technique for Missing Categorical Data." British Journal of Political Science 43(2):425-449.

Cunningham, David E and Douglas Lemke. 2011. "Beyond Civil War: A Quantitative Analysis of Sub-state Violence." Paper presented at the annual meeting of the American Political Science Association, Seattle, WA.

Cunningham, David E., Kristian S. Gleditsch and Idean. Salehyan. 2009. "It Takes Two: A Dyadic Analysis of Civil War Duration and Outcome." Journal of Conflict Resolution 53(4):570-597.

Cunningham, Kathleen Gallagher. 2011. "Divide and Conquer or Divide and Concede: How Do States Respond to Internally Divided Separatists." American Political Science Review 105(2). 
Cunningham, Kathleen Gallagher, Kristin M. Bakke and Lee J. M. Seymour. 2012. "Shirts Today, Skins Tomorrow: Dual Contests and the Effects of Fragmentation in Self-Determination Disputes." Journal of Conflict Resolution 56(1):67-93.

Daley, Patricia. 2006. "Ethnicity and Political Violence in Africa: The Challenge to the Burundi State." Political Geography 25(6):657-679.

Davies, James C. 1962. "Towards a Theory of Revolution." American Sociological Review $27(1): 5-19$.

de Soysa, Indra. 2002. "Paradise is a Bazaar? Greed, Creed, and Governance in Civil War, 1989-99." Journal of Peace Research 39(4):395-416.

de Waal, Alex. 2007. Sudan: The Turbulent State. In War in Darfur and the Search for Peace, ed. Alex de Waal. Harvard: Harvard Univeristy Press pp. 1-38.

DeRouen, Karl and David Sobek. 2004. "The Dynamics of Civil War Duration and Outcome." Journal of Peace Research 41(3):303-320.

Duquet, Nils. 2009. "Arms Acquisition Patterns and the Dynamics of Armed Conflict: Lessons from the Niger Delta." International Studies Perspectives 10(2):169-185.

Elbadawi, Ibrahim A. and Nicholas Sambanis. 2002. "How Much War Will We See? Explaining the Prevalence of Civil War." Journal of Conflict Resolution 46(3):307334.

Esty, Daniel C., Jack A. Goldstone, Ted R. Gurr, Barbara Harff, Marc Levy, Geoffrey Dabelko, Pamela T. Surko and Alan N. Unger. 1998. State Failure Task Force Report: Phase II Findings. McLean, VA: Science Applications International, for State Failure Task Force.

Fearon, James D. 2003. "Ethnic and Cultural Diversity by Country." Journal of Economic Growth 8:195-222.

Fearon, James D. 2006. Ethnic Mobilization and Ethnic Violence. In Oxford Handbook of Political Economy, ed. Barry Weingast and Donald Wittman. Oxford: Oxford University Press.

Fearon, James D. and David D. Laitin. 2003. "Ethnicity, Insurgency, and Civil War." American Political Science Review 97(1):75-90. 
Fiki, OC and Bill Lee. 2004. "Conflict Generation Conflict Management and SelfOrganizing Capabilities in Drought-Prone Rural Communities in North-Eastern Nigeria: A Case Study." Journal of Social Development in Africa 19(2):25-48.

Finnegan, William. 1992. A Complicated War: The Harrowing of Mozambique. Berkeley: University of Calefornia Press.

Fjelde, Hanne. 2010. "Generals, Dictators, and Kings: Authoritarian Regimes and Civil Conflict, 1973-2004." Conflict Management and Peace Science 27(3):195-218.

Fjelde, Hanne and Desiree Nilsson. 2012. "Rebels Against Rebels: Explaining Violence Between Rebel Groups." Journal of Conflict Resolution 56(4):604-628.

Fjelde, Hanne and Gudrun Østby. 2012. "Economic Inequality and Inter-group Conflicts in Africa." Paper prepared for presentation at the Democracy as Idea and Practice conference, Oslo, January 12-13, 2012.

Fjelde, Hanne and Indra de Soysa. 2009. "Coercion, Co-optation or Cooperation? State Capacity and the Risk of Civil War, 1961-2004." Conflict Management and Peace Science 26(1):5-25.

Flint, Julie. 2007. Darfur's Armed Movements. In War in Darfur and the Search for Peace, ed. Alex de Waal. Harvard: Harvard University Press.

Friedrich, Robert J. 1982. "In Defense of Multiplicative Terms in Multiple Regression Equations." American Journal of Political Science 26(4):797-833.

Gates, Scott, Håvard Hegre, Mark P. Jones and Håvard Strand. 2006. "Institutional Inconsistency and Political Instability: Polity Duration, 1800-2000." American Journal of Political Science 50(4):893-908.

Gellner, Ernest. 1991. "Nationalism and Politics in Eastern Europe." New Left Review 189(1):127-143.

Gleditsch, Nils Petter, Håvard Hegre and Håvard Strand. 2009. Democracy and Civil War. In Handbook of War Studies III, ed. Manus Midlarsky. Ann Arbor, MI: University of Michigan Press pp. 155-192.

Gleditsch, Nils Petter, Peter Wallensteen, Mikael Eriksson, Margareta Sollenberg and Håvard Strand. 2002. "Armed Conflict 1946-2001: A New Dataset." Journal of Peace Research 39(5):615-637. 
Goldstone, Jack. 2002. "Population and Security: How Demographic Change can Lead to Violent Conflict." Journal of International Affairs 56(1):3-21.

Gourevitch, Peter. 1979. "The Re-emergence of 'Peripheral Nationalism': Some Comparative Speculations on the Spatial Distribution of Political Leadership and Economic Growth." Comparative Studies in Society and History 21(2):303-322.

Green, Donald P., Soo Yeon Kim and David Yoon. 2001. "Dirty Pool." International Organization 55(2):441-468.

Greene, William H. 2003. Econometric Analysis. 5th Edition. Upper Saddle River: Prentice-Hall.

GROWup. nd. "Codebook, GROWup Research Front-End." Swiss Federal Institute of Technology, Zurich: The GROWup Research Front-End.

URL: http://growup.ethz.ch/rfe/

Gurr, Ted Robert. 1970. Why Men Rebel. Princeton, NJ: Princeton University Press.

Gurr, Ted Robert. 1993. "Why Minorities Rebel: A Global Analysis of Communal Mobilization and Conflict Since 1945." International Political Science Review 14(2):161-201.

Gurr, Ted Robert and Will H. Moore. 1997. "Ethnopolitical Rebellion: A Cross-Section Analysis of the 1980s with Risk Assessments for the 1990s." American Journal of Political Science 41(4):1079-1103.

Hall, Daniel B. and Jing Shen. 2010. "Robust Estimation for Zero-Inflated Poisson Regression." Scandinavian Journal of Statistics 37(2):237-252.

Hechter, M and M. Levi. 1979. "The Comparative Analysis of Ethnoregional Movements." Ethnic and Racial Studies 2(3):260-274.

Hegre, Håvard, Gudrun Østby and Clionadh Raleigh. 2009. "Poverty and Civil War Events: A Disaggregated Study of Liberia." Journal of Conflict Resolution 53(4):598623.

Hegre, Håvard and Håvard Nygård. 2012. "Governance and Conflict Relapse." Paper presented at the International Studies Association Annual Convention, San Diego.

Hegre, Håvard, Joakim Karlsen, Håvard Mokleiv Nygård, Håvard Strand and Henrik Urdal. forthcoming. "Predicting Armed Conflict 2010-2050." International Studies Quarterly 2013. 
Hegre, Håvard and Nicholas Sambanis. 2006. "Sensitivity Analysis of Empirical Results on Civil War Onset." Journal of Conflict Resolution 50(4):508-535.

Hegre, Håvard, Tanja Ellingsen, Scott Gates and Nils Petter Gleditsch. 2001. "Toward a Democratic Civil Peace? Democracy, Political Change, and Civil War, 1816-1992." American Political Science Review 95(1):33-48.

Helmke, Gretchen and Steven Levitsky. 2004. "Informal Institutions and Comparative Politics: A Research Agenda." Perspectives on Politics 2(4):725-740.

Hendrix, Cullen S. 2010. "Measuring State Capacity: Theoretical and Emperical Implication for the Study of Civil Conflict." Journal of Peace Research 47(3):271-285.

Henisz, Witold J. 2000. "The Institutional Environment for Economic Growth." Economics and Politics 12(1):1-31.

Herbst, Jeffrey. 2000. States and Power in Africa: Comparative Lessons in Authority and Control. Princeton NJ: Princeton University Press.

Herz, John. 1951. Political Realism and Political Idealism. Chicago, IL: Chicago University Press.

Holtermann, Helge. 2012. "Power Theory and the Growth of Weak Rebel Groups: Lessons from Nepal." Unpublished manuscript. Centre for the Study of Civil War, The Peace Research Institute Oslo (PRIO).

Honaker, James and Gary King. 2010. "What to Do about Missing Values in Time-Series Cross-Section Data." American Journal of Political Science 54(2):561-581.

Honaker, James, Gary King and Michael Blackwell. 2011. "Amelia II: A Program for Missing Data." Journal of Statistical Software 45(7):1-47.

Horowitz, Donald L. 1985. Ethnic groups in conflict. Berkeley, CA: University of California Press.

Hosmer, David W and Stanley Lemeshow. 2000. Applied Logistic Regression. Second Edititon. New York, NY: Wiley.

Houle, Christian. 2009. "Inequality and Democracy: Why Inequality Harms Consolidation but Does Not Affect Democratization." World Politics 61(4):589-622. 
Høyland, Bjørn and Håvard Mokleiv Nygård. 2012. "Non Random Missing Data in the Study of Political Violence." Paper presented to the General Conference of the European Political Science Association, Berlin, June 2012.

Humphreys, Macartan. 2005. "Natural Resources, Conflict, and Conflict Resolution: Uncovering the Mechanisms." Journal of Conflict Resolution 49(4):538-562.

Huntington, Samuel P. 1968. Political Order in Changing Societies. New Haven, CT and London: Yale University Press.

ICRG. nda. "Codebook, the International Country Risk Guide (ICRG)." East Syracuse, NY: The PRS Group.

URL: http://www.prsgroup.com/icrg.aspx

ICRG. nd $b$. "The Political Risk Rating." East Syracuse, NY: The PRS Group.

URL: http://www.prsgroup.com/ICRG_Methodology.aspx

Ifeka, Caroline. 2001. "Playing Civil Society Tunes: Corruption and Misunderstanding in Nigeria's 'Real' Political Institutions." Review of African Political Economy 28(89):461-465.

Jackson, Robert H. 1990. Quasi-States: Sovereignty, International Relations and the Third World. Cambridge: Cambridge University Press.

Jervis, Robert. 1978. "Cooperation under the Security Dilemma." World Politics 30:167174.

Jones, Daniel M., Stuart A. Bremer and J. David Singer. 1996. "Militarized Interstate Disputes, 1816-1992: Rationale, Coding Rules, and Empirical Patterns." Conflict Management and Peace Science 15(2):163-213.

Kalyvas, Stathis. 2003. "The Ontology of "Political Violence": Action and Identity in Civil Wars." Perspectives on Politics 1(3):475-494.

Kalyvas, Stathis N. 2006. The Logic of Violence in Civil War. Cambridge: Cambridge University Press.

Kanbur, Ravi and Tony Venables. 2005. "Introduction: Spatial Inequality and Development." Journal of Economic Geography 5(1):1-2.

Kaplan, Robert D. 1993. Balkan Ghosts: A Journey Through History. New York: Vintage Books. 
Kaufmann, Chaim. 1996. "Possible and Impossible Solutions to Ethnic Civil Wars." International Security 20(4):136-175.

King, Gary, James Honaker, Anne Joseph and Kenneth Scheve. 2001. "Analyzing Incomplete Political Science Data: An Alternative Algorithm for Multiple Imputation." American Political Science Review 95(1):49-69.

King, Gary and Langche Zeng. 2001. "Logistic Regression in Rare Events Data." Political Analysis 9:137-163.

King, Gary, Michael Tomz and Jason Wittenberg. 2000. "Making the Most of Statistical Analyses: Improving Interpretation and Presentation." American Journal of Political Science 44(2):347-361.

King, Gary, Robert O. Keohane and Sidney Verba. 1994. Designing Social Inquiry. Scientific Inference in Qualitative Research. Princeton, NJ: Princeton University Press.

Kitschelt, Herbert and Steven I. Wilkinson. 2007. Patrons, Clients and Policies: Patterns of Democratic Accountability and Political Competition. Cambridge: Cambridge University Press.

Kumar, Gopa G. 1986. Regional Political Parties and State Politics. New Dehli: Deep and Deep Publications.

Lake, David A. and Donald Rothchild. 1996. "Containing Fear. The Origins and Management of Ethnic Conflict." International Security 21(2):41-75.

Lewis, Ioan M. 1994. Blood and Bone: The Call of Kinship in Somali Society. New Jersey: The Red Sea Press.

Lichbach, Mark Irving. 1989. "An Evaluation of 'Does Economic Inequality breed Political Conflict?' Studies." World Politics 41(4):431-470.

Lichbach, Mark Irving. 1995. The Rebel's Dilemma. Ann Arbor, MI: University of Michigan Press.

Lilja, Jannie and Lisa Hultman. 2011. "Intra-Ethnic Dominance and Control: Violence against Co-Ethnics in the Early Sri Lankan Civil War." Security Studies 20(2):171-197.

Linder, Anja and Carlos Santiso. 2002. "Assessing the Predictive Power of Country Risk Rating and Governance Indicators." John Hopkins University, School of Advanced International Studies (SAIS) Working Paper Series. 
Little, Roderick, J. A. and Donald B. Rubin. 2002. Statistical Analysis With Missing Data. 2nd ed. Hoboken, NJ: Wiley.

Long, J. Scott. 1997. Regression Models for Categorical and Limited Dependent Variables. Advanced Quantitative Techniques in the Social Sciences London: Sage Publications.

Long, J. Scott and Jeremy Freese. 2006. Regression Models for Categorical Dependent Variables Using Stata. Texas: 2nd ed. Stata Press.

Lujala, Pøivi, Nils Petter Gleditsch and Elisabeth Gilmore. 2003. "Diamonds in Civil War: A New Dataset and a First Test." Conference on Political Violence and Primary Commodities, Montreal.

Lutz, Wolfgang, Anne Goujon, Samir K.C. and Warren Sanderson. 2007. Reconstruction of Population by Age, Sex and Level of Educational Attainment for 120 Countries 1970-2000. Laxenburg, Austria: IIASA.

Magdalena, Federico V. 1977. "Intergroup Conflict in the Southern Philippines: An Empirical Analysis." Journal of Peace Research 14(4):299-313.

Mamdani, Mahmood. 1996. Citizen and Subject: Contemporary Africa and the Legacy of Late Colonialism. Princeton: Princeton University Press.

Menard, Scott. 2010. Logistic Regression: From Introductory to Advanced Concepts and Applications. London: SAGE Publications Ltd.

Migdal, Joel S. 1988. Strong Societies and Weak States. Princeton: Princeton Univeristy Press.

Ngaruko, Floribert and Janvier D. Nkurunziza. 2000. "An Economic Interpretation of Conflict in Burundi." Journal of African Economies 9(3):370-409.

Nilsson, Desiree. 2008. "Partial Peace: Rebel Groups Inside and Outside Civil War Settlements." Journal of Peace Research 45(4):479-495.

Nordhaus, William D. 2006. "Geography and Macroeconomics: New Data and New Findings." Proceedings of the National Academy of Science of the United States of America 103(10):3510-3517.

Nygård, Håvard, M. and Michael Weintraub. 2011. "Bargaining Between Rebel Groups and the Outside Option of Violence." Unpublished manuscript.

URL: http://folk.uio.no/haavarmn/BargainingRebels.pdf 
Obioha, Emeka E. 2008. "Climate Change, Population Drift and Violent Conflict over Land Resources in North Eastern Nigeria." Journal of Human Ecology 23(4):311-324.

Omeje, Kenneth. 2006. High Stakes and Stakeholders: Oil Conflict and Security in Nigeria. Hampshire: Ashgate Publishing Ltd.

Østby, Gudrun. 2008. "Polarization, Horizontal Inequalities and Violent Civil Conflict." Journal of Peace Research 45(2):143-162.

Peet, Richard and Michael Watts. 1996. Liberation Ecology: Development, Sustainability and Environment in an Age of Market Triumphalism. In Liberation Ecologies, ed. Richard Peet and Michael Watts. London: Routledge.

Petersen, Roger Dale. 2002. Understanding Ethnic Violence: Fear, Hatred, and Resentment in Twentieth-Century Eastern Europe. Cambridge studies in comparative politics Cambridge: Cambridge University Press.

Posen, Barry. 1993. "The Security Dilemma and Ethnic Conflict." Survival 35(1):27-47.

Posner, Eric. 2004. "The Political Salience of Cultural Difference: Why Chewas and Tumbukas are Allies in Zambia and Adversaries in Malawi." American Political Science Review 98(4):529-545.

Pregibon, Daryl. 1981. "Logistic Regression Diagnostics." The Annals of Statistics $9(4): 705-724$.

Pugel, James. 2007. "What the fighters Say: A survey of ex-combatants in Liberia." United Nations Development Programme.

URL: http://www.lr.undp.org/UNDPwhatFightersSayLiberia-2006.pdf

Raleigh, Clionadh. 2010. "Political Marginalization, Climate Change, and Conflict in African Sahel States." International Studies Review 12:69-86.

Raleigh, Clionadh and Håvard Hegre. 2009. "Population, Size, and Civil War. A Geographically Disaggregated Analysis." Political Geography 28(4):224-238.

Regan, Patrick. M. and Daniel Norton. 2005. "Greed, Grivance and Mobilization in Civil Wars." Journal of Conflict Resolution 49(3):319-336.

Reno, William. 1995. "Reinvention of an African Patrimonial State: Charles Taylor's Liberia." Third World Quarterly 16(1):109-120. 
Reynal-Querol, Marta. 2002. "Ethnicity, Political Systems, and Civil Wars." Journal of Conflict Resolution 46(1):29-54.

Rød, Espen Geelmuyden. 2012. Institutions Under Authoritarianism and Coup Attempts: 1950-2008. Master's thesis Department of Political Science, University of Oslo. URL: http://folk.uio.no/hahegre/MasterTheses/GeelmuydenRod\%20MasterThesis.pdf

Roe, Paul. 1999. "The Intrastate Security Dilemma: Ethnic Conflict as a 'Tragedy'?" Journal of Peace Research 36(2):183-202.

Ross, Michael. 2006. "A Closer Look at Oil, Diamonds and Civil War." Annual Review of Political Science 9(9):265-300.

Russett, Bruce M. 1964. "Inequality and Intability: The Relation of Land Tenure to Politics." World Politics 16(3):442-454.

Sambanis, Nicholas. 2001. "Do Ethnic and Nonethnic Civil Wars Have the Same Causes? A Theoretical and Empirical Inquiry (Part 1)." Journal of Conflict Resolution 45(3):259-282.

Sambanis, Nicholas. 2004. "What Is Civil War? Conceptual and Empirical Complexities of an Operational Definition." Journal of Conflict Resolution 48(6):814-858.

Sambanis, Nicholas. 2005. Conclusion: Using Case Studies to Refine and Expand the Theory of Civil War. In Understanding Civil War: Evidence and Analysis, ed. Paul Collier and Nicholas Sambanis. Washington, DC: World Bank pp. 299-330.

Sandbrook, Richard. 1986. "The State and Economic Stagnation in Tropical Africa." World Development 14(3):319-332.

Schrodt, Philip A. 2010. "Seven Deadly Sins of Contemporary Quantitative Political Analysis." American Political Science Association 2010 Annual Meeting .

URL: http://papers.ssrn.com/sol3/papers.cfm?abstract_id=1661045

Shirkey, Zachary C. 2012. "When and How Many: The Effects of Third Party Joining on Casualties and Duration in Interstate Wars." Journal of Peace Research 49(2):321-334.

Small, Melvin and J. David Singer. 1982. Resort to Arms: International and Civil Wars, 1816-1980. Beverly Hills, CA: Sage.

Smith, Anthony D. 1992. "Chosen Peoples: Why Ethnic Groups Survive." Ethnic and Racial Studies 15(3):436-456. 
Smith, Anthony D. 1995. "Gastronomy or Geology? The Role of Nationalism in the Reconstruction of Nations." Nations and Nationalism 1(1):3-24.

Sobek, David. 2010. "Masters of their Domains; The Role of State Capacity in Civil Wars." Journal of Peace Research 47(3):267-271.

Staub, Kevin E. and Rainer Winkelmann. 2010. "Quasi-Likelihood Estimation of ZeroInflated Count Models." Univeristy of Zurich, Department of Economics.

URL: http://www.sgvs.ch/congress10/upload/p_24-802533.pdf

Stewart, Frances. 2002. Horizontal Inequalities: A Neglected Dimension of Development. QEH Working Paper 81 Queen Elisabeth House, University of Oxford.

URL: http://www3.qeh.ox.ac.uk/pdf/qehwp/qehwps81.pdf

Stewart, Frances. 2008. Horizontal Inequalities and Conflict: Understanding Group Violence in Multiethnic Societies. Basingstoke: Palgrave Macmillan.

Sundberg, Ralph, Kristine Eck and Joakim Kreutz. 2012a. "Introducing the UCDP NonState Conflict Dataset." Journal of Peace Research 49(2):351-362.

Sundberg, Ralph, Kristine Eck and Joakim Kreutz. 2012b. "UCDP Non-State Conflict Codebook Version 2.4." Uppsala Conflict Data Program, Department of Peace and Conflict Research, Uppsala University.

URL: http://www.pcr.uu.se/research/ucdp/datasets/ucdp_non-state_conflict_dataset_/

Szeftel, Morris. 2000. "Eat With Us: Managing Corruption and Patronage Under Zambia's Three Republics." Journal of Contemporary African Studies 18(2):207-224.

Tajfel, Henri and John C. Turner. 1979. An Integrative Theory of Intergroup Conflict. In The Social Psychology of Intergroup Relations, ed. W. G. Austin and S. Worchel. Monterey, CA: Brooks/Cole pp. 33-47.

Tang, Shiping. 2011. "The Security Dilemma and Ethnic Conflict: Toward a Dynamic and Integrative Theory of Ethnic Conflict." Review of International Studies 37(2):511-536.

Thyne, Clayton. 2006. “ABC's, 123's, and the Golden Rule: The Pacifying Effect of Education on Civil War, 1980-1999." International Studies Quarterly 50(4):733-754.

Tilly, Charles. 1978. From Mobilization to Revolution. Reading, MA: Addison-Wesley.

Toft, Monica D. 2003. The Geography of Ethnic Violence: Identity, Interests, and the Indivisibility of Territory. Princeton: Princeton University Press. 
Tull, Denis M. 2003. "A Reconfiguration of Political Order? The State of the State in Noth Kivu (DR Congo)." African Affairs 102:429-446.

Turner, Matthew D. 2004. "Political Ecology and the Moral Dimension of 'Resource CoConflicts The Case of Farmer-Herder Conflicts in the Sahel." Political Geography 23(7):863-889.

Turner, Matthew D, Augustine Ayantunde, Kristen Patterson and Daniel E. Patterson. 2011. "Livelihood Transitions and the Changing Nature of Farmer-Herder Conflict in Sahelian West Africa." Journal of Development Studies 47(2):183-206.

United Nations. 2007. World Population Prospects. The 2006 Revision. New York: UN.

Urdal, Henrik. 2005. "People vs. Malthus: Population Pressure, Environmental Degradation and Armed Conflict Revisited." Journal of Peace Research 42(4):417-434.

Van Klinken, Gerry. 2007. Communal Violence and Democratization in Indonesia. Abingdon: Routledge.

Vanhanen, Tatu. 1999. "Domestic Ethnic Conflict and Ethnic Nepotism." Journal of Peace Research 36(1):55-79.

Varshney, Ashutosh. 2001. "Ethnic Conflict and Civil Society: India and Beyond." World Politics 53(3):362-398.

Varshney, Ashutosh. 2002. Ethnic Conflict and Civic Life: Hindus and Muslims in India. New Haven CT: Yale University Press.

Verbeek, Marno. 2008. A Guide to Modern Econometrics. West Sussex: John Wiley and Sons, Ltd.

Vinci, Anthony. 2006. "An Analysis and Comparison of Armed Groups in Somalia." African Security Review 15(1):75-90.

Ward, Michael D., Brian D. Greenhill and Kristin M. Bakke. 2010. "The Perils of Policy by P-Value: Predicting Civil Conflicts." Journal of Peace Research 47(4):363-375.

Wayman, Frank W., David J. Singer and Gary Goertz. 1983. "Capabilities, Allocation, and Success in Militarized Disputes and Wars, 1816-1976." International Studies Quarterly 27(2):497-515. 
Weber, Max. 1946. Politics as a Vocation. In From Max Weber: Essays in Sociology, ed. Hans H. Gerth and Charles Wright (trans.) Mills. New York: Oxford University Press.

Wilkinson, Steven I. 2004. Votes and Violence: Electoral Competition and Ethnic Riots in India. Cambridge University Press.

Wimmer, Andreas. 1997. "Who Owns the State? Understanding Ethnic Conflict in Post-Colonial Societies." Nations and Nationalism 3(4):631-665.

Wimmer, Andreas. 2002. Nationalist Exclusion and Ethnic Conflict: Shadows of Modernity. Cambridge: Cambridge Univeristy Press.

Wimmer, Andreas, Lars-Erik Cederman and Brian Min. 2009. "Ethnic Politics and Armed Conflict: A Configurational Analysis of a New Global Data Set." American Sociological Review 74(2):316-337.

Wooldridge, Jeffrey M. 2009. Introductory Econometrics: A Modern Approach. Ohio: South-Western.

Young, Crawford. 1994. The African Colonial State in Comparative Perspective. Yale: Yale University Press.

Zeileis, Achim, Christian Kleiber and Simon Jackman. 2007. "Regression Models for Count Data in R." Research Report Series, Department of Statistics and Mathematics, University of Economics and Business, Vienna.

Zelner, Bennet A. 2009. "Using Simulation to Interpret Results from Logit, Probit, and Other Nonlinear Models." Strategic Management Journal 30(12):1335-1348. 


\section{Appendix A}

\section{Descriptives}

Table A.1: Descriptive Statistics: Non-imputed data

\begin{tabular}{lccccc}
\hline \multicolumn{1}{c}{ Variable } & Mean & Std. Dev. & Min. & Max. & N \\
\hline Inter-group Violence, logit & 0.066 & 0.248 & 0 & 1 & 1053 \\
Inter-group Violence, count & 0.119 & 0.536 & 0 & 5 & 1053 \\
Weak State & 0.209 & 0.407 & 0 & 1 & 685 \\
Economic Inequality & 0.247 & 0.490 & 0 & 2.445 & 544 \\
Poorest Group & 1.266 & 0.347 & 0.898 & 2.434 & 544 \\
Richest Group & 1.383 & 0.757 & 0.958 & 4.776 & 544 \\
Civil War & 0.212 & 0.409 & 0 & 1 & 1053 \\
$\ln$ (Largest Excluded Group) & -1.963 & 1.631 & -8.502 & -0.092 & 495 \\
$\ln$ (Excluded Population) & -1.52 & 1.656 & -8.502 & -0.084 & 495 \\
$\ln$ (Population) & 8.777 & 1.378 & 5.811 & 11.994 & 1053 \\
$\ln$ (Infant Mortality Rate) & 4.457 & 0.441 & 2.557 & 5.232 & 1053 \\
Relevant Groups & 4.563 & 3.494 & 0 & 16 & 877 \\
\hline Source: UCDP Non-State Conflict Dataset (Sundberg, Eck and Kreutz 2012a), EPR, \\
Hegre et al. (forthcoming)
\end{tabular}


Table A.2: Countries Included in the Analysis

\begin{tabular}{|lll|}
\hline Countries & & \\
\hline Angola & Benin & Botswana \\
Burkina Faso & Burundi & Cameroon \\
Cape Verde & Central African Republic & Chad \\
Comoros & Congo & D.R. Congo \\
Cote D'Ivoire & Djibouti & Equatorial Guinea \\
Eritrea & Ethiopia & Gabon \\
Gambia & Ghana & Guinea \\
Guinea-Bissau & Kenya & Lesotho \\
Liberia & Madagascar & Malawi \\
Mali & Mauritania & Mauritius \\
Mozambique & Namibia & Niger \\
Nigeria & Rwanda & Senegal \\
Sierra Leone & Somalia & South Africa \\
Sudan & Swaziland & Tanzania \\
Togo & Uganda & Zambia \\
Zimbabwe & & \\
\hline
\end{tabular}




\section{Appendix B}

\section{Missing}

Table B.1: Countries with Completely Missing

\begin{tabular}{|c|c|c|c|c|c|c|}
\hline Statename & Ec. inequality & Poorest & Richest & Excl. group & Excl. pop & Weak state \\
\hline Cape Verde & $\mathrm{X}$ & $\mathrm{X}$ & $\mathrm{X}$ & $\mathrm{X}$ & $\mathrm{X}$ & $\mathrm{X}$ \\
\hline Equatorial Guinea & $\mathrm{X}$ & $\mathrm{X}$ & $\mathrm{X}$ & $\mathrm{X}$ & $\mathrm{X}$ & $\mathrm{X}$ \\
\hline Swaziland & $\mathrm{X}$ & $\mathrm{X}$ & $\mathrm{X}$ & & & $\mathrm{X}$ \\
\hline Comoros & $\mathrm{X}$ & $\mathrm{X}$ & $\mathrm{X}$ & $\mathrm{X}$ & $\mathrm{X}$ & $\mathrm{X}$ \\
\hline Mauritius & $\mathrm{X}$ & $\mathrm{X}$ & $\mathrm{X}$ & $\mathrm{X}$ & $\mathrm{X}$ & $\mathrm{X}$ \\
\hline Benin & & & & & & $\mathrm{X}$ \\
\hline Burkina Faso & $\mathrm{X}$ & $\mathrm{X}$ & $\mathrm{X}$ & & & \\
\hline CAR & & & & & & $\mathrm{X}$ \\
\hline Burundi & $\mathrm{X}$ & $\mathrm{X}$ & $\mathrm{X}$ & & & $\mathrm{X}$ \\
\hline Tanzania & $\mathrm{X}$ & $\mathrm{X}$ & $\mathrm{X}$ & & & \\
\hline Rwanda & $\mathrm{X}$ & $\mathrm{X}$ & $\mathrm{X}$ & & & $\mathrm{X}$ \\
\hline Somalia & $\mathrm{X}$ & $\mathrm{X}$ & $\mathrm{X}$ & & & \\
\hline Djibouti & $\mathrm{X}$ & $\mathrm{X}$ & $\mathrm{X}$ & & & \\
\hline Eritrea & & & & & & $\mathrm{X}$ \\
\hline Lesotho & $\mathrm{X}$ & $\mathrm{X}$ & $\mathrm{X}$ & & & $\mathrm{X}$ \\
\hline
\end{tabular}


Figure B.1: Missingness Map

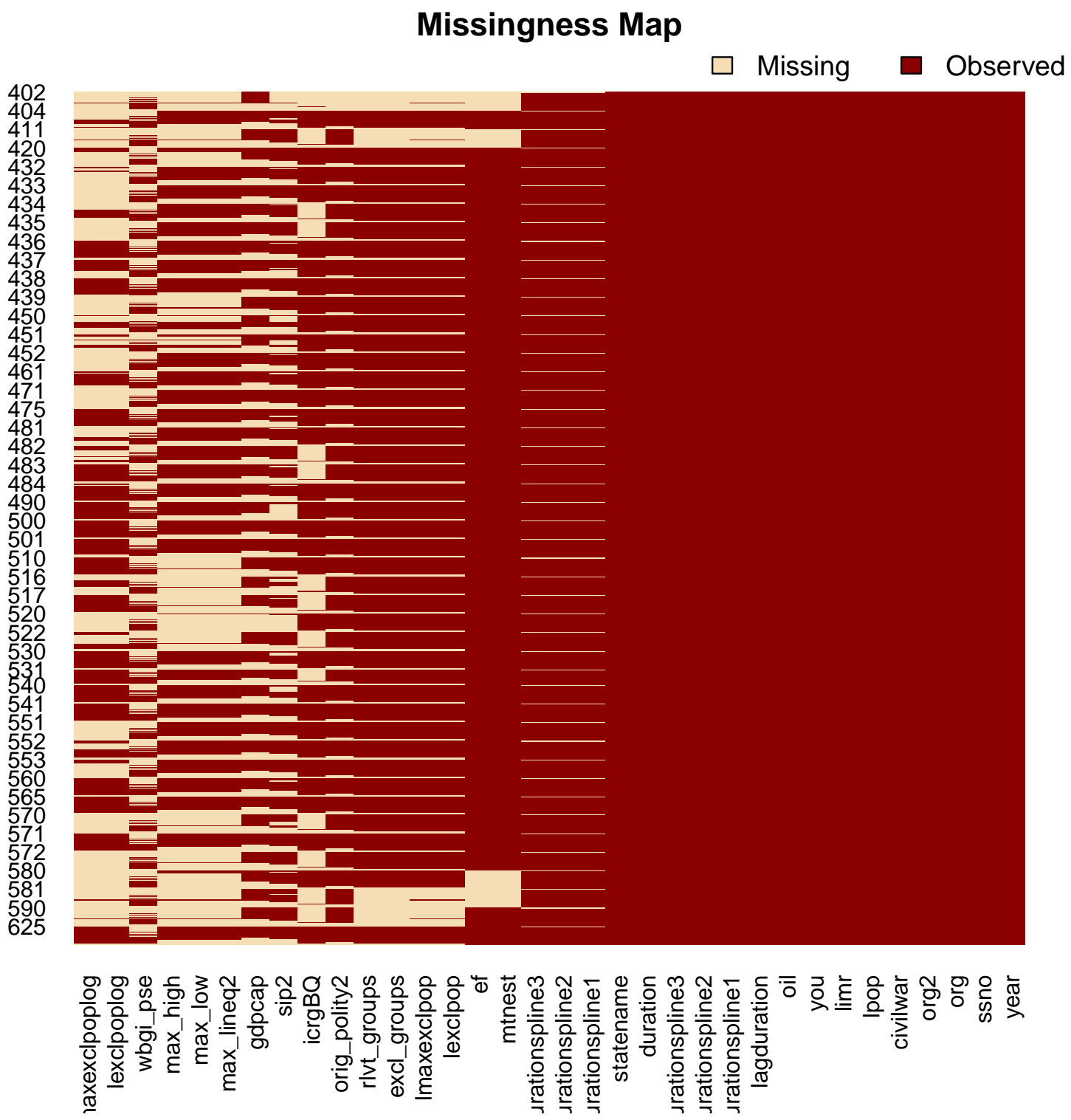


Figure B.2: Testing the Missing at Random Assumption: Kernel density plot. The red line represents the imputed values, whereas the black represents the observed values.

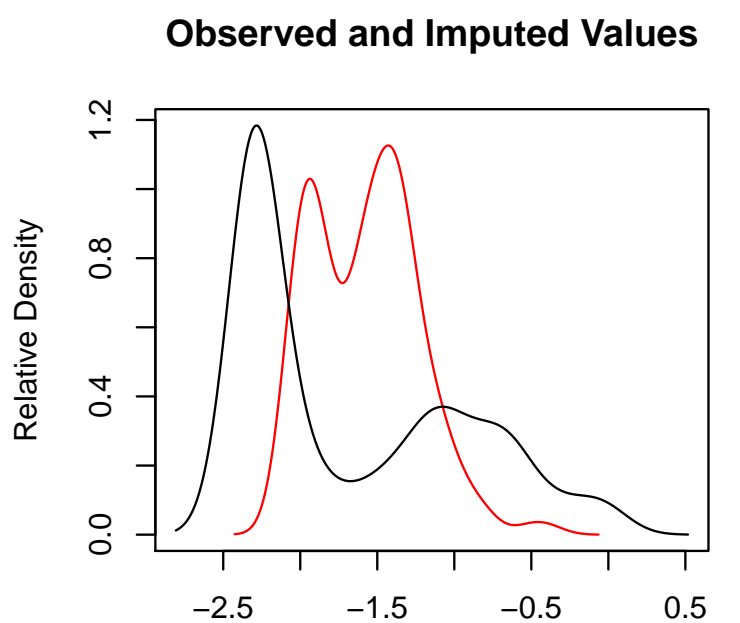

Largest Excluded Group - Fraction Missing: 0.163

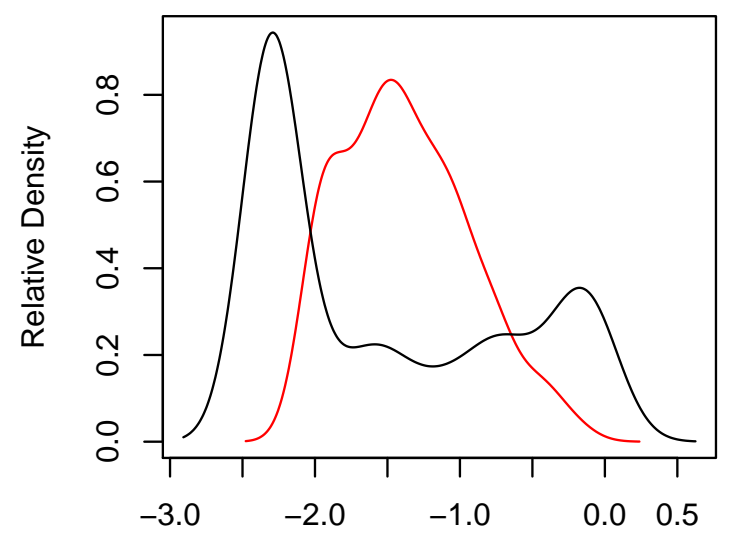

Excluded Population - Fraction Missing: 0.163
Observed and Imputed Values

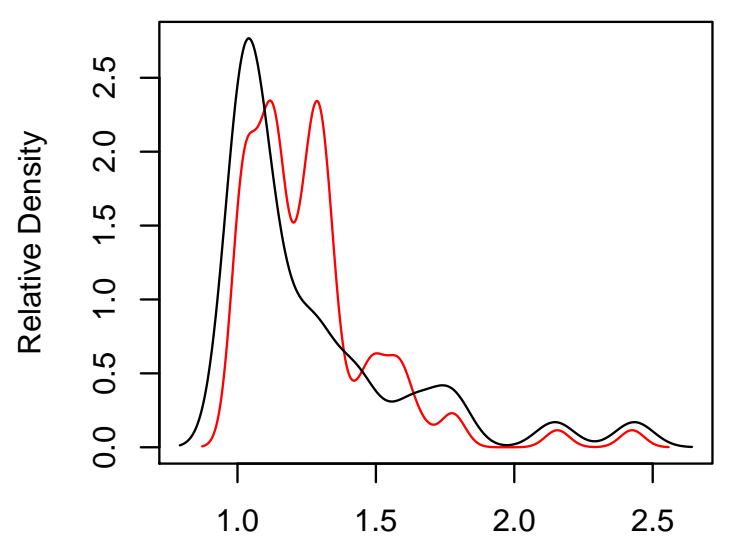

Poorest Group - Fraction Missing: 0.454

\section{Observed and Imputed Values}

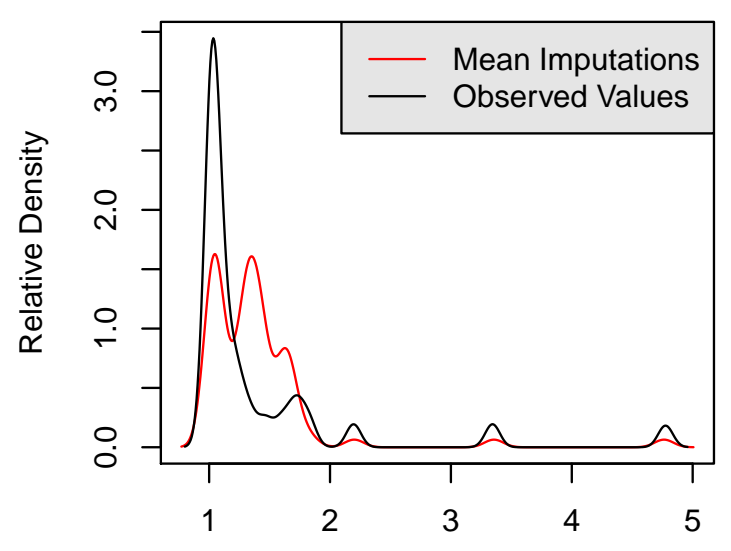

Richest Group - Fraction Missing: 0.454 
Figure B.3: Overimputation: The graphs illustrate the estimates of each observation against the true values of the observations, where $y=x$ line indicates the line of perfect prediction, where all the imputations would fall on this line. The 90 percent confidence intervals shows where the observed values would have been imputed had it been missing from the dataset, given the imputation model. The dots represent the mean imputation, and the colored line represent the fraction of missing observations in the pattern of missingness for that observation.

\section{Observed versus Imputed Values, State Capacity}

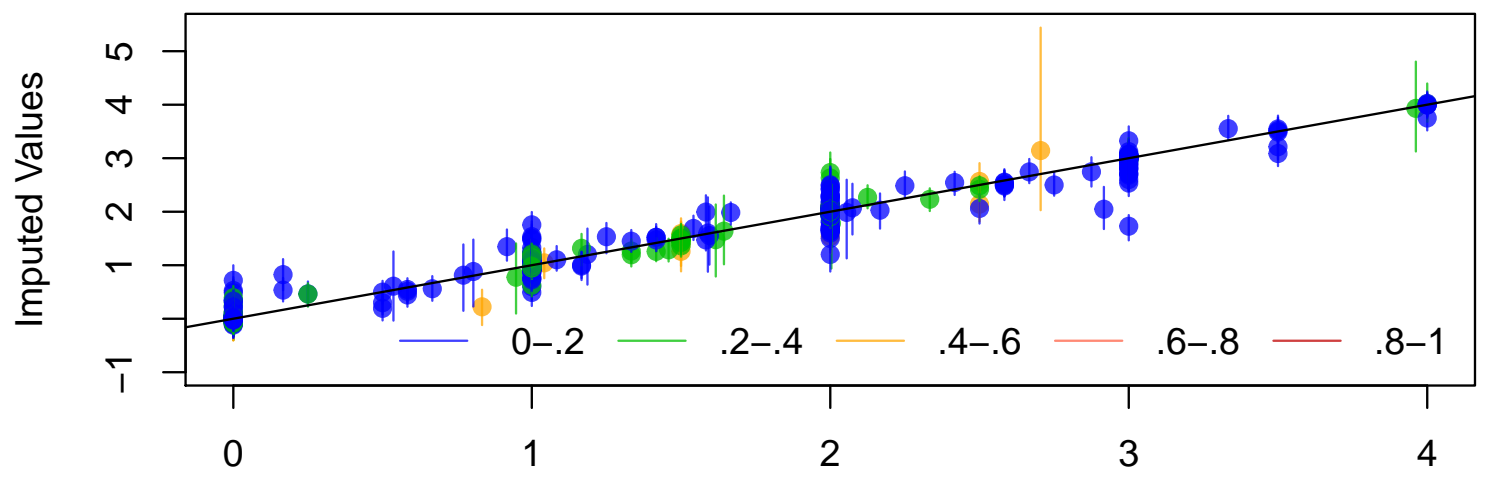

Observed Values

\section{Observed versus Imputed Values, Poorest Group}

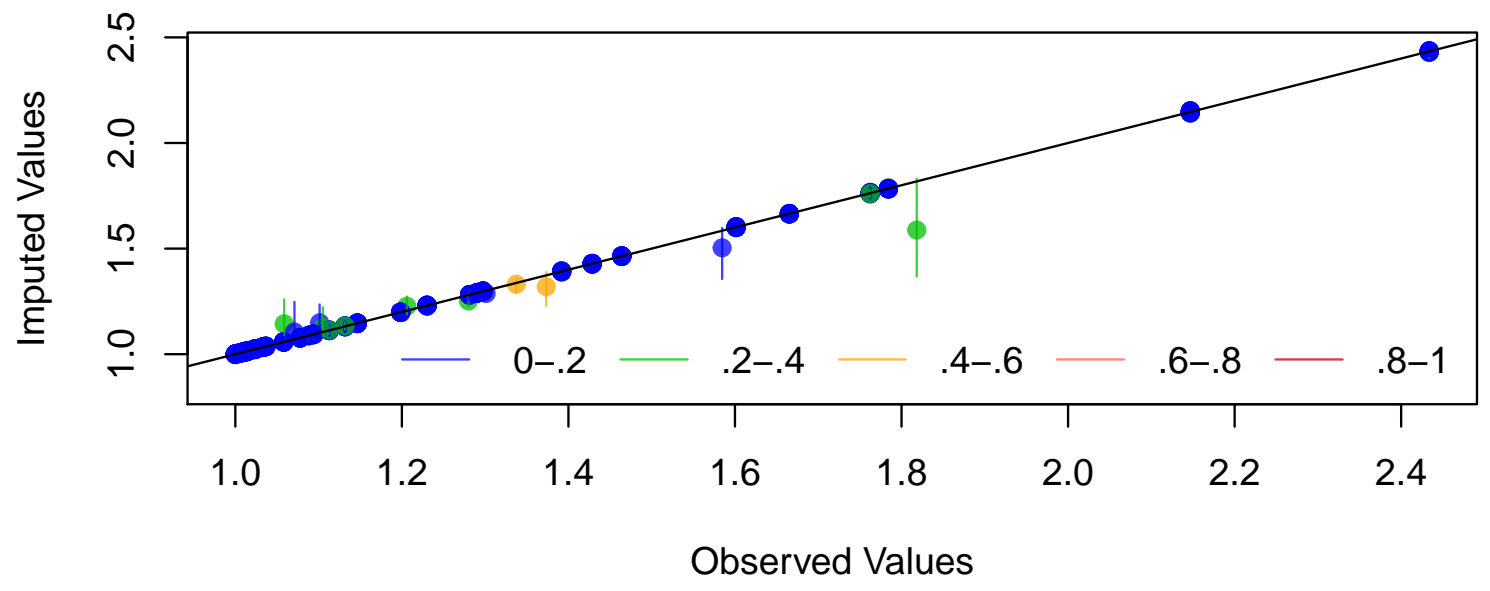


Figure B.4: Scatterplot: Missing: The plots illustrate values for imputed and observed, and imputed and predicted values. The red dots are imputed values, the black are observed.

Kenya

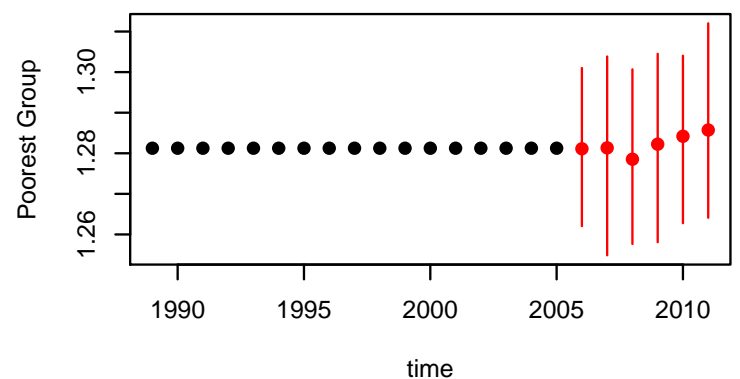

Ethiopia

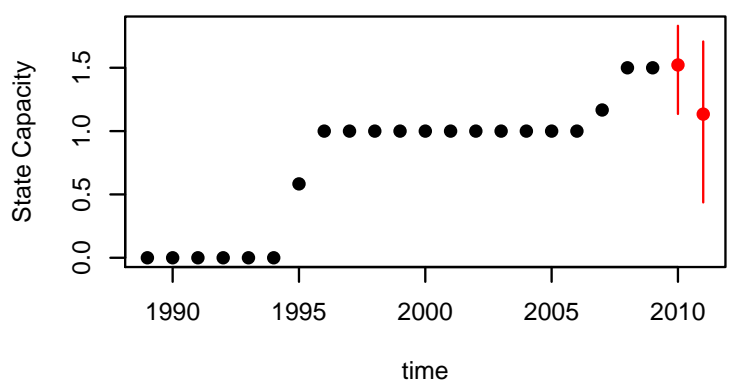

Namibia

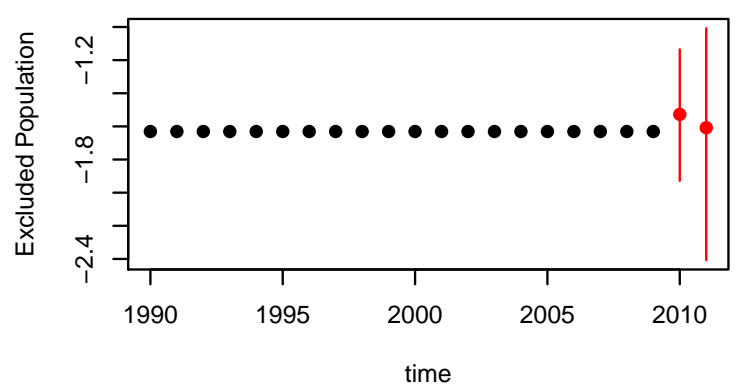

Burkina Faso

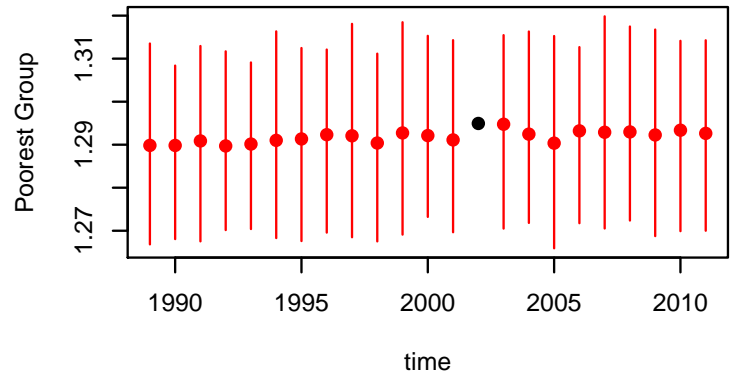

Eritrea

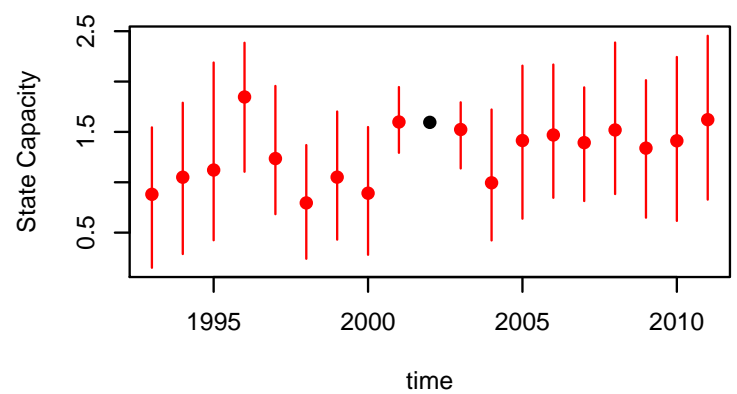

Mauritius

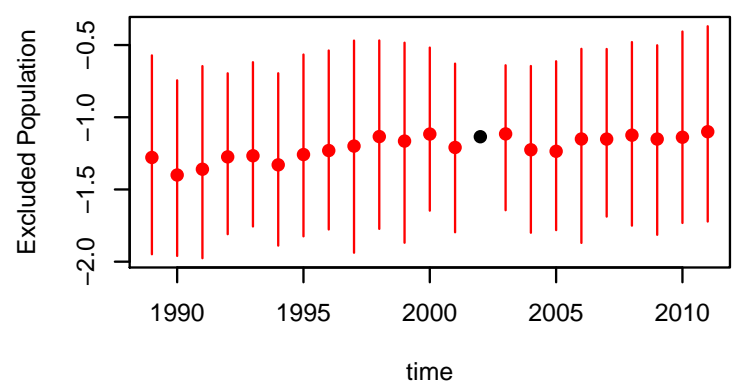




\section{Appendix C}

\section{Additional Regressions and Diagnostics}

Table C.1: Logistic and Count Regressions: Baseline models, 1989-2011

\begin{tabular}{|c|c|c|c|c|c|c|c|c|}
\hline & $\begin{array}{c}\text { (Base 1) } \\
\text { Logit }\end{array}$ & $\begin{array}{c}\text { (Base 2) } \\
\text { Count }\end{array}$ & $\begin{array}{c}\text { (Base 3) } \\
\text { Logit }\end{array}$ & $\begin{array}{c}\text { (Base 4) } \\
\text { Count }\end{array}$ & $\begin{array}{c}\text { (Base 5) } \\
\text { Logit }\end{array}$ & $\begin{array}{c}\text { (Base 6) } \\
\text { Count }\end{array}$ & $\begin{array}{c}\text { (Base 7) } \\
\text { Logit }\end{array}$ & $\begin{array}{c}\text { (Base 8) } \\
\text { Count }\end{array}$ \\
\hline Weak State & $\begin{array}{l}8.280^{* *} \\
(5.958)\end{array}$ & $\begin{array}{c}11.555^{* * *} \\
(6.155)\end{array}$ & $\begin{array}{l}8.465^{* *} \\
(5.969)\end{array}$ & $\begin{array}{c}15.591^{* * *} \\
(8.413)\end{array}$ & $\begin{array}{c}11.057^{* * *} \\
(7.897)\end{array}$ & $\begin{array}{c}20.238^{* * *} \\
(11.236)\end{array}$ & $\begin{array}{c}10.899^{* * *} \\
(7.725)\end{array}$ & $\begin{array}{c}22.834^{* * *} \\
(14.010)\end{array}$ \\
\hline Economic Inequality & $\begin{array}{c}2.143 \\
(0.993)\end{array}$ & $\begin{array}{c}3.993 \\
(5.169)\end{array}$ & $\begin{array}{l}2.157^{+} \\
(1.006)\end{array}$ & $\begin{array}{c}3.757 \\
(3.968)\end{array}$ & & & & \\
\hline Poorest Group & & & & & $\begin{array}{c}10.140^{* *} \\
(8.662)\end{array}$ & $\begin{array}{l}20.055^{* *} \\
(19.715)\end{array}$ & $\begin{array}{l}9.160^{* *} \\
(6.872)\end{array}$ & $\begin{array}{l}15.230^{* *} \\
(13.000)\end{array}$ \\
\hline Richest Group & & & & & $\begin{array}{c}1.088 \\
(0.358)\end{array}$ & $\begin{array}{c}1.155 \\
(0.474)\end{array}$ & $\begin{array}{c}1.113 \\
(0.370)\end{array}$ & $\begin{array}{c}1.229 \\
(0.496)\end{array}$ \\
\hline $\ln$ (Largest Excluded Group) & $\begin{array}{c}1.009 \\
(0.477)\end{array}$ & $\begin{array}{c}1.484 \\
(0.765)\end{array}$ & & & $\begin{array}{c}0.900 \\
(0.405)\end{array}$ & $\begin{array}{c}0.970 \\
(0.449)\end{array}$ & & \\
\hline $\ln$ (Excluded Population) & & & $\begin{array}{c}1.522 \\
(0.813)\end{array}$ & $\begin{array}{l}1.964^{+} \\
(0.755)\end{array}$ & & & $\begin{array}{c}1.372 \\
(0.645)\end{array}$ & $\begin{array}{c}1.391 \\
(0.472)\end{array}$ \\
\hline Observations & 1007 & 1007 & 1007 & 1007 & 1007 & 1007 & 1007 & 1007 \\
\hline $\mathrm{AIC}$ & 436.006 & 611.584 & 427.450 & 594.963 & 399.573 & 562.746 & 394.924 & 557.010 \\
\hline LL_0 & -251.543 & -338.355 & -251.543 & -338.335 & -251.543 & -388.335 & -251.543 & -338.335 \\
\hline LL & -214.003 & -300.792 & -209.725 & -292.482 & -194.787 & -275.375 & -192.462 & -271.505 \\
\hline
\end{tabular}

Exponentiated coefficients; Clustered and robust standard errors in parentheses.

AIC, LL_0 and LL are averaged values for the ten imputed datasets.

${ }^{+} p<0.10,{ }^{*} p<0.05,{ }^{* *} p<0.01,{ }^{* * *} p<0.001$ 
Table C.2: Count Regressions with All Interactions: Estimated incidence odds for intergroup violence in Sub-Saharan Africa, 1989-2011

\begin{tabular}{|c|c|c|c|c|}
\hline & $(1)$ & $(2)$ & $(3)$ & $(14)$ \\
\hline Weak State & $\begin{array}{l}0.043^{* *} \\
(0.048)\end{array}$ & $\begin{array}{c}0.493^{+} \\
(0.184)\end{array}$ & $\begin{array}{c}0.048 \\
(0.103)\end{array}$ & $\begin{array}{c}0.272 \\
(0.338)\end{array}$ \\
\hline Economic Inequality & $\begin{array}{c}1.115 \\
(0.396)\end{array}$ & $\begin{array}{c}1.074 \\
(0.365)\end{array}$ & & \\
\hline Weak State ${ }^{*}$ Ec. inequality & $\begin{array}{c}11.514^{* * *} \\
(7.624)\end{array}$ & $\begin{array}{c}10.112^{* * *} \\
(6.294)\end{array}$ & & \\
\hline Poorest Group & & & $\begin{array}{c}4.982^{*} \\
(3.180)\end{array}$ & $\begin{array}{c}4.637^{*} \\
(2.800)\end{array}$ \\
\hline Weak State ${ }^{*}$ Poorest & & & $\begin{array}{c}0.480 \\
(0.416)\end{array}$ & $\begin{array}{c}0.481 \\
(0.401)\end{array}$ \\
\hline Richest Group & & & $\begin{array}{c}0.718 \\
(0.198)\end{array}$ & $\begin{array}{c}0.650 \\
(0.209)\end{array}$ \\
\hline Weak State ${ }^{*}$ Richest & & & $\begin{array}{l}5.420^{* *} \\
(3.523)\end{array}$ & $\begin{array}{c}5.924^{*} \\
(4.235)\end{array}$ \\
\hline ln(Largest Excluded Group) & $\begin{array}{c}1.608 \\
(0.631)\end{array}$ & & $\begin{array}{c}1.481 \\
(0.568)\end{array}$ & \\
\hline Weak State ${ }^{*}$ Largest Excl. Group & $\begin{array}{c}0.091^{* * *} \\
(0.063)\end{array}$ & & $\begin{array}{c}0.149^{*} \\
(0.113)\end{array}$ & \\
\hline $\ln ($ Excluded Population $)$ & & $\begin{array}{l}1.742^{+} \\
(0.524)\end{array}$ & & $\begin{array}{l}1.657^{+} \\
(0.450)\end{array}$ \\
\hline Weak State ${ }^{*}$ Excl. Population & & $\begin{array}{c}0.246^{* * *} \\
(0.081)\end{array}$ & & $\begin{array}{c}0.320^{* * *} \\
(0.111)\end{array}$ \\
\hline Civil War & $\begin{array}{c}2.407^{*} \\
(0.898)\end{array}$ & $\begin{array}{c}2.265^{*} \\
(0.779)\end{array}$ & $\begin{array}{l}2.013^{+} \\
(0.737)\end{array}$ & $\begin{array}{c}1.897^{+} \\
(0.655)\end{array}$ \\
\hline $\ln$ (Population) & $\begin{array}{l}1.269^{+} \\
(0.167)\end{array}$ & $\begin{array}{l}1.270^{+} \\
(0.175)\end{array}$ & $\begin{array}{l}1.400^{+} \\
(0.273)\end{array}$ & $\begin{array}{l}1.383^{+} \\
(0.268)\end{array}$ \\
\hline $\ln ($ Infant Mortality Rate) & $\begin{array}{l}3.595^{+} \\
(2.362)\end{array}$ & $\begin{array}{c}3.590^{*} \\
(2.186)\end{array}$ & $\begin{array}{l}7.347^{* *} \\
(5.229)\end{array}$ & $\begin{array}{l}7.094^{* *} \\
(4.725)\end{array}$ \\
\hline Relevant Groups & $\begin{array}{l}1.193^{* *} \\
(0.067)\end{array}$ & $\begin{array}{l}1.155^{* *} \\
(0.056)\end{array}$ & $\begin{array}{l}1.109^{+} \\
(0.069)\end{array}$ & $\begin{array}{c}1.080 \\
(0.060)\end{array}$ \\
\hline Peace Years & $\begin{array}{l}0.858^{* *} \\
(0.050)\end{array}$ & $\begin{array}{l}0.845^{* *} \\
(0.049)\end{array}$ & $\begin{array}{l}0.844^{* *} \\
(0.052)\end{array}$ & $\begin{array}{l}0.830^{* *} \\
(0.050)\end{array}$ \\
\hline Spline 1 & $\begin{array}{l}0.599^{* *} \\
(0.099)\end{array}$ & $\begin{array}{l}0.602^{* *} \\
(0.098)\end{array}$ & $\begin{array}{l}0.649^{* *} \\
(0.105)\end{array}$ & $\begin{array}{c}0.655^{*} \\
(0.109)\end{array}$ \\
\hline Spline 2 & $\begin{array}{l}16.999^{+} \\
(28.107)\end{array}$ & $\begin{array}{c}14.789 \\
(25.285)\end{array}$ & $\begin{array}{c}11.234 \\
(19.079)\end{array}$ & $\begin{array}{c}8.971 \\
(16.046)\end{array}$ \\
\hline Spline 3 & $\begin{array}{c}0.020 \\
(0.056)\end{array}$ & $\begin{array}{c}0.026 \\
(0.076)\end{array}$ & $\begin{array}{c}0.037 \\
(0.109)\end{array}$ & $\begin{array}{c}0.057 \\
(0.176)\end{array}$ \\
\hline Observations & 961 & 961 & 961 & 961 \\
\hline $\mathrm{AIC}$ & 422.462 & 427.039 & 418.395 & 422.674 \\
\hline LL_0 & -331.929 & -331.929 & -331.929 & -331.929 \\
\hline LL & -196.231 & -198.519 & -192.197 & -194.337 \\
\hline
\end{tabular}


Figure C.1: All Interactions Included: Estimated incidence odds for inter-group violence in Sub-Saharan Africa with the presence of economic and political inequality in weak and strong states, 1989-2011.
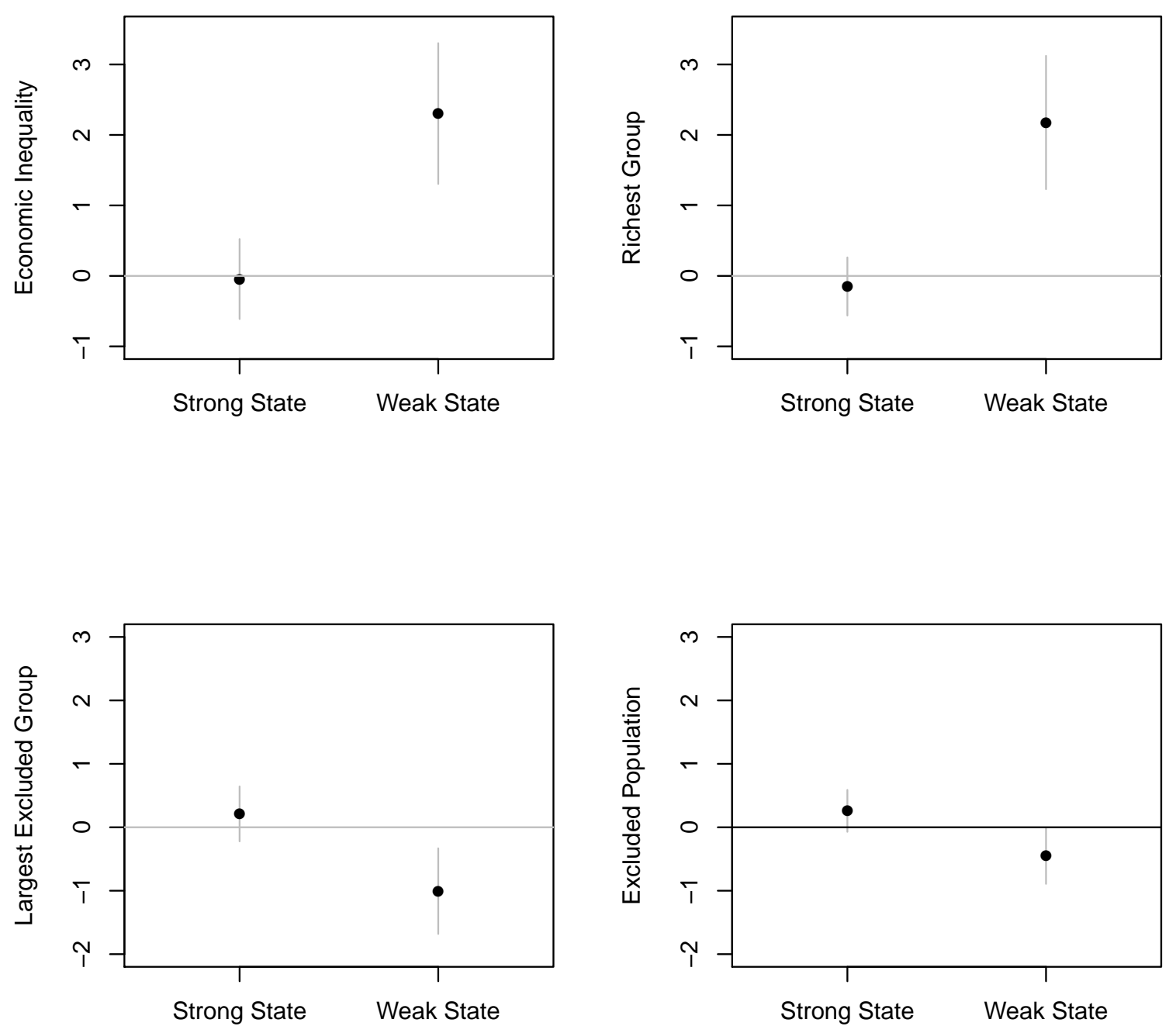
Figure C.2: Coefficient Plot: The effect of inequality conditioned on state capacity in Sub-Saharan Africa, based on model 9, 11, 13 and 15, 1989-2011. The plot shows the change in log odds for non-state violence in weak and strong states given the value for political and economic exclusion. All other variables are held constant on their median value for numeric values, and most common category for factors. The plot is based on averaged values for the ten imputed datasets.
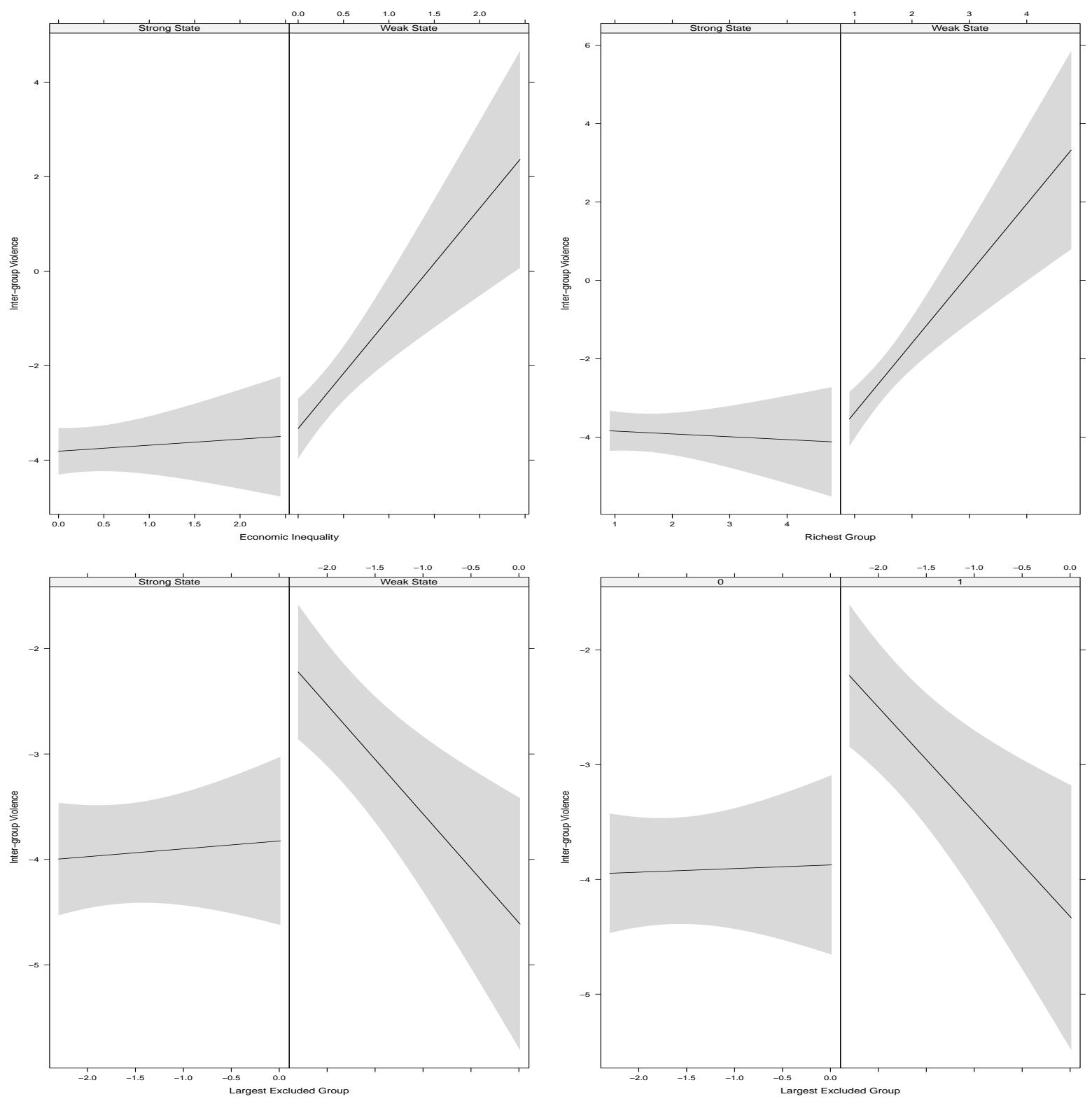
Appendix D

Robustness 
Table D.1: Logistic and Count Regressions: Clustered on year and unclustered, 1989-2011

\begin{tabular}{|c|c|c|c|c|c|c|c|c|}
\hline & \multicolumn{2}{|c|}{ Model 5} & \multicolumn{2}{|c|}{ Model 6} & \multicolumn{2}{|c|}{ Model 7} & \multicolumn{2}{|c|}{ Model 8} \\
\hline & $(1)$ & $(2)$ & (3) & (4) & $(5)$ & (6) & (7) & $(8)$ \\
\hline & Cluster & Unclustered & Cluster & Unclustered & Cluster & Unclustered & Cluster & Unclustered \\
\hline Weak State & $\begin{array}{l}4.288^{* *} \\
(1.930)\end{array}$ & $\begin{array}{c}4.288^{* * *} \\
(1.871)\end{array}$ & $\begin{array}{c}4.820^{* * *} \\
(2.151)\end{array}$ & $\begin{array}{c}4.820^{* * *} \\
(2.102)\end{array}$ & $\begin{array}{c}3.786^{* * *} \\
(1.114)\end{array}$ & $\begin{array}{c}3.786^{* * *} \\
(1.194)\end{array}$ & $\begin{array}{c}4.361^{* * *} \\
(1.293)\end{array}$ & $\begin{array}{c}4.361^{* * *} \\
(1.370)\end{array}$ \\
\hline Poorest Group & $\begin{array}{c}9.790^{* * *} \\
(6.623)\end{array}$ & $\begin{array}{c}9.790^{* * *} \\
(6.692)\end{array}$ & $\begin{array}{c}9.282^{* * *} \\
(6.204)\end{array}$ & $\begin{array}{c}9.282^{* * *} \\
(6.283)\end{array}$ & $\begin{array}{c}8.597^{* * *} \\
(4.025)\end{array}$ & $\begin{array}{c}8.597^{* * *} \\
(4.156)\end{array}$ & $\begin{array}{c}8.303^{* * *} \\
(3.867)\end{array}$ & $\begin{array}{c}8.303^{* * *} \\
(4.075)\end{array}$ \\
\hline Richest Group & $\begin{array}{c}1.195 \\
(0.303)\end{array}$ & $\begin{array}{c}1.195 \\
(0.330)\end{array}$ & $\begin{array}{l}1.239 \\
(0.307)\end{array}$ & $\begin{array}{c}1.239 \\
(0.339)\end{array}$ & $\begin{array}{c}1.278 \\
(0.225)\end{array}$ & $\begin{array}{c}1.278 \\
(0.262)\end{array}$ & $\begin{array}{c}1.339 \\
(0.238)\end{array}$ & $\begin{array}{c}1.339 \\
(0.277)\end{array}$ \\
\hline $\ln$ (Largest Excluded Group) & $\begin{array}{c}0.554 \\
(0.203)\end{array}$ & $\begin{array}{l}0.554^{+} \\
(0.187)\end{array}$ & & & $\begin{array}{l}0.575^{+} \\
(0.163)\end{array}$ & $\begin{array}{l}0.575^{*} \\
(0.149)\end{array}$ & & \\
\hline $\ln$ (Excluded Population) & & & $\begin{array}{c}0.828 \\
(0.229)\end{array}$ & $\begin{array}{c}0.828 \\
(0.202)\end{array}$ & & & $\begin{array}{c}0.843 \\
(0.185)\end{array}$ & $\begin{array}{c}0.843 \\
(0.155)\end{array}$ \\
\hline Civil War & $\begin{array}{c}4.366^{* * *} \\
(1.303)\end{array}$ & $\begin{array}{c}4.366^{* * *} \\
(1.646)\end{array}$ & $\begin{array}{c}3.942^{* * *} \\
(1.107)\end{array}$ & $\begin{array}{c}3.942^{* * *} \\
(1.472)\end{array}$ & $\begin{array}{l}2.254^{* *} \\
(0.624)\end{array}$ & $\begin{array}{l}2.254^{* *} \\
(0.698)\end{array}$ & $\begin{array}{l}2.163^{* *} \\
(0.584)\end{array}$ & $\begin{array}{l}2.163^{*} \\
(0.662)\end{array}$ \\
\hline $\ln$ (Population) & $\begin{array}{l}1.426^{+} \\
(0.305)\end{array}$ & $\begin{array}{l}1.426^{+} \\
(0.307)\end{array}$ & $\begin{array}{c}1.363 \\
(0.284)\end{array}$ & $\begin{array}{c}1.363 \\
(0.285)\end{array}$ & $\begin{array}{l}1.466^{* *} \\
(0.217)\end{array}$ & $\begin{array}{l}1.466^{*} \\
(0.226)\end{array}$ & $\begin{array}{l}1.401^{*} \\
(0.195)\end{array}$ & $\begin{array}{l}1.401^{*} \\
(0.211)\end{array}$ \\
\hline $\ln$ (Infant Mortality Rate) & $\begin{array}{l}5.711^{+} \\
(5.413)\end{array}$ & $\begin{array}{l}5.711^{+} \\
(6.016)\end{array}$ & $\begin{array}{l}4.816^{+} \\
(4.549)\end{array}$ & $\begin{array}{c}4.816 \\
(4.881)\end{array}$ & $\begin{array}{c}8.684^{* * *} \\
(4.771)\end{array}$ & $\begin{array}{l}8.684^{* *} \\
(6.570)\end{array}$ & $\begin{array}{c}7.350^{* * *} \\
(4.120)\end{array}$ & $\begin{array}{l}7.350^{* *} \\
(5.445)\end{array}$ \\
\hline Relevant Groups & $\begin{array}{l}1.020 \\
(0.057)\end{array}$ & $\begin{array}{l}1.020 \\
(0.068)\end{array}$ & $\begin{array}{l}1.016 \\
(0.065)\end{array}$ & $\begin{array}{l}1.016 \\
(0.067)\end{array}$ & $\begin{array}{c}1.011 \\
(0.034)\end{array}$ & $\begin{array}{c}1.011 \\
(0.042)\end{array}$ & $\begin{array}{c}1.003 \\
(0.040)\end{array}$ & $\begin{array}{l}1.003 \\
(0.043)\end{array}$ \\
\hline Peace Years & $\begin{array}{l}0.844^{* *} \\
(0.050)\end{array}$ & $\begin{array}{l}0.844^{*} \\
(0.056)\end{array}$ & $\begin{array}{l}0.833^{* *} \\
(0.051)\end{array}$ & $\begin{array}{l}0.833^{* *} \\
(0.057)\end{array}$ & $\begin{array}{c}0.841^{* * *} \\
(0.042)\end{array}$ & $\begin{array}{c}0.841^{* * *} \\
(0.043)\end{array}$ & $\begin{array}{c}0.830^{* * *} \\
(0.043)\end{array}$ & $\begin{array}{c}0.830^{* * *} \\
(0.044)\end{array}$ \\
\hline Spline 1 & $\begin{array}{c}0.513^{* * *} \\
(0.104)\end{array}$ & $\begin{array}{l}0.513^{* *} \\
(0.110)\end{array}$ & $\begin{array}{l}0.519^{* *} \\
(0.108)\end{array}$ & $\begin{array}{l}0.519^{* *} \\
(0.111)\end{array}$ & $\begin{array}{c}0.580^{* * *} \\
(0.085)\end{array}$ & $\begin{array}{c}0.580^{* * *} \\
(0.093)\end{array}$ & $\begin{array}{c}0.583^{* * *} \\
(0.092)\end{array}$ & $\begin{array}{l}0.583^{* *} \\
(0.096)\end{array}$ \\
\hline Spline 2 & $\begin{array}{l}125.535^{* *} \\
(230.130)\end{array}$ & $\begin{array}{c}125.535^{*} \\
(267.762)\end{array}$ & $\begin{array}{l}112.070^{*} \\
(207.881)\end{array}$ & $\begin{array}{c}112.070^{*} \\
(238.219)\end{array}$ & $\begin{array}{l}40.268^{*} \\
(58.804)\end{array}$ & $\begin{array}{l}40.268^{*} \\
(67.557)\end{array}$ & $\begin{array}{l}38.087^{*} \\
(57.617)\end{array}$ & $\begin{array}{c}38.087^{*} \\
(65.172)\end{array}$ \\
\hline Spline 3 & $\begin{array}{l}0.001^{*} \\
(0.002)\end{array}$ & $\begin{array}{l}0.001^{*} \\
(0.003)\end{array}$ & $\begin{array}{l}0.001^{*} \\
(0.003)\end{array}$ & $\begin{array}{l}0.001^{*} \\
(0.003)\end{array}$ & $\begin{array}{l}0.004^{*} \\
(0.011)\end{array}$ & $\begin{array}{l}0.004^{+} \\
(0.013)\end{array}$ & $\begin{array}{l}0.005^{*} \\
(0.013)\end{array}$ & $\begin{array}{l}0.005^{+} \\
(0.014)\end{array}$ \\
\hline Observations & 961 & 961 & 961 & 961 & 961 & 961 & 961 & 961 \\
\hline AIC & 282.977 & 282.977 & 285.886 & 285.886 & 436.758 & 436.758 & 440.433 & 440.433 \\
\hline LL_0 & -245.631 & -245.631 & -245.631 & -245.631 & -331.929 & -331.929 & -331.292 & -331.292 \\
\hline LL & -128.489 & -128.489 & -129.943 & -129.943 & -204.379 & -204.379 & -206.217 & -206.217 \\
\hline
\end{tabular}

Exponentiated coefficients; Standard errors in parentheses.

AIC, LL_0 and LL are averaged values for the ten imputed datasets.

${ }^{+} p<0.10,{ }^{*} p<0.05,{ }^{* *} p<0.01,{ }^{* * *} p<0.001$ 
Table D.2: Count Regressions with Interactions: Clustered on year and unclustered, 1989-2011

\begin{tabular}{|c|c|c|c|c|c|c|c|c|}
\hline & \multicolumn{2}{|c|}{ Model 11} & \multicolumn{2}{|c|}{ Model 12} & \multicolumn{2}{|c|}{ Model 15} & \multicolumn{2}{|c|}{ Model 16} \\
\hline & (1) & $(2)$ & (3) & (4) & (5) & $(6)$ & (7) & (8) \\
\hline & Cluster & Unclustered & Cluster & Unclustered & Cluster & Unclustered & Cluster & Unclustered \\
\hline Weak State & $\begin{array}{c}3.562 \\
(4.826)\end{array}$ & $\begin{array}{c}3.562 \\
(4.234)\end{array}$ & $\begin{array}{c}5.053 \\
(6.779)\end{array}$ & $\begin{array}{c}5.053 \\
(5.943)\end{array}$ & $\begin{array}{c}0.273 \\
(0.253)\end{array}$ & $\begin{array}{c}0.273 \\
(0.261)\end{array}$ & $\begin{array}{c}1.599 \\
(0.542)\end{array}$ & $\begin{array}{c}1.599 \\
(0.654)\end{array}$ \\
\hline Poorest Group & $\begin{array}{c}9.740^{* * *} \\
(5.926)\end{array}$ & $\begin{array}{c}9.740^{* * *} \\
(5.636)\end{array}$ & $\begin{array}{c}10.303^{* * *} \\
(6.301)\end{array}$ & $\begin{array}{c}10.303^{* * *} \\
(6.085)\end{array}$ & $\begin{array}{c}6.183^{* * *} \\
(3.146)\end{array}$ & $\begin{array}{c}6.183^{* * *} \\
(3.244)\end{array}$ & $\begin{array}{c}5.497^{* * *} \\
(2.828)\end{array}$ & $\begin{array}{l}5.497^{* *} \\
(2.902)\end{array}$ \\
\hline Weak State * Poorest & $\begin{array}{l}0.197^{*} \\
(0.161)\end{array}$ & $\begin{array}{l}0.197^{*} \\
(0.142)\end{array}$ & $\begin{array}{c}0.159^{*} \\
(0.133)\end{array}$ & $\begin{array}{c}0.159^{*} \\
(0.115)\end{array}$ & & & & \\
\hline Richest Group & $\begin{array}{c}0.909 \\
(0.296)\end{array}$ & $\begin{array}{c}0.909 \\
(0.303)\end{array}$ & $\begin{array}{c}0.929 \\
(0.315)\end{array}$ & $\begin{array}{c}0.929 \\
(0.320)\end{array}$ & $\begin{array}{c}1.245 \\
(0.246)\end{array}$ & $\begin{array}{c}1.245 \\
(0.280)\end{array}$ & $\begin{array}{c}1.268 \\
(0.256)\end{array}$ & $\begin{array}{c}1.268 \\
(0.299)\end{array}$ \\
\hline Weak State ${ }^{*}$ Richest & $\begin{array}{l}4.840^{*} \\
(3.103)\end{array}$ & $\begin{array}{l}4.840^{* *} \\
(2.863)\end{array}$ & $\begin{array}{l}5.154^{*} \\
(3.406)\end{array}$ & $\begin{array}{l}5.154^{* *} \\
(3.120)\end{array}$ & & & & \\
\hline ln(Largest Excluded Group) & $\begin{array}{l}0.648^{+} \\
(0.164)\end{array}$ & $\begin{array}{l}0.648^{+} \\
(0.167)\end{array}$ & & & $\begin{array}{c}1.433 \\
(0.627)\end{array}$ & $\begin{array}{c}1.433 \\
(0.617)\end{array}$ & & \\
\hline Weak State ${ }^{*}$ Largest Excl. Group & & & & & $\begin{array}{l}0.162^{* *} \\
(0.109)\end{array}$ & $\begin{array}{l}0.162^{* *} \\
(0.106)\end{array}$ & & \\
\hline $\ln$ (Excluded Population) & & & $\begin{array}{c}0.921 \\
(0.181)\end{array}$ & $\begin{array}{c}0.921 \\
(0.167)\end{array}$ & & & $\begin{array}{c}1.558 \\
(0.538)\end{array}$ & $\begin{array}{c}1.558 \\
(0.522)\end{array}$ \\
\hline Weak State ${ }^{*}$ Excl. Population & & & & & & & $\begin{array}{l}0.341^{* *} \\
(0.118)\end{array}$ & $\begin{array}{l}0.341^{* *} \\
(0.124)\end{array}$ \\
\hline Civil War & $\begin{array}{l}2.222^{* *} \\
(0.623)\end{array}$ & $\begin{array}{l}2.222^{*} \\
(0.703)\end{array}$ & $\begin{array}{l}2.116^{* *} \\
(0.580)\end{array}$ & $\begin{array}{l}2.116^{*} \\
(0.667)\end{array}$ & $\begin{array}{l}2.016^{*} \\
(0.571)\end{array}$ & $\begin{array}{l}2.016^{*} \\
(0.612)\end{array}$ & $\begin{array}{c}1.889^{*} \\
(0.513)\end{array}$ & $\begin{array}{c}1.889^{*} \\
(0.577)\end{array}$ \\
\hline $\ln$ (Population) & $\begin{array}{c}1.311 \\
(0.246)\end{array}$ & $\begin{array}{c}1.311 \\
(0.242)\end{array}$ & $\begin{array}{c}1.245 \\
(0.227)\end{array}$ & $\begin{array}{c}1.245 \\
(0.226)\end{array}$ & $\begin{array}{l}1.529^{*} \\
(0.258)\end{array}$ & $\begin{array}{c}1.529^{*} \\
(0.274)\end{array}$ & $\begin{array}{l}1.507^{*} \\
(0.241)\end{array}$ & $\begin{array}{l}1.507^{*} \\
(0.271)\end{array}$ \\
\hline $\ln ($ Infant Mortality Rate) & $\begin{array}{c}8.388^{* * *} \\
(4.551)\end{array}$ & $\begin{array}{l}8.388^{* *} \\
(6.105)\end{array}$ & $\begin{array}{c}7.235^{* * *} \\
(3.938)\end{array}$ & $\begin{array}{l}7.235^{* *} \\
(5.127)\end{array}$ & $\begin{array}{l}7.312^{* *} \\
(4.423)\end{array}$ & $\begin{array}{l}7.312^{*} \\
(5.957)\end{array}$ & $\begin{array}{l}7.005^{* *} \\
(4.308)\end{array}$ & $\begin{array}{l}7.005^{*} \\
(5.657)\end{array}$ \\
\hline Relevant Groups & $\begin{array}{c}1.035 \\
(0.039)\end{array}$ & $\begin{array}{c}1.035 \\
(0.046)\end{array}$ & $\begin{array}{c}1.022 \\
(0.041)\end{array}$ & $\begin{array}{c}1.022 \\
(0.045)\end{array}$ & $\begin{array}{c}1.069 \\
(0.045)\end{array}$ & $\begin{array}{c}1.069 \\
(0.048)\end{array}$ & $\begin{array}{c}1.047 \\
(0.051)\end{array}$ & $\begin{array}{c}1.047 \\
(0.048)\end{array}$ \\
\hline Peace Years & $\begin{array}{c}0.825^{* * *} \\
(0.044)\end{array}$ & $\begin{array}{c}0.825^{* * *} \\
(0.043)\end{array}$ & $\begin{array}{c}0.814^{* * *} \\
(0.045)\end{array}$ & $\begin{array}{c}0.814^{* * *} \\
(0.044)\end{array}$ & $\begin{array}{l}0.858^{* *} \\
(0.042)\end{array}$ & $\begin{array}{l}0.858^{* *} \\
(0.042)\end{array}$ & $\begin{array}{c}0.843^{* * *} \\
(0.042)\end{array}$ & $\begin{array}{c}0.843^{* * *} \\
(0.042)\end{array}$ \\
\hline Spline 1 & $\begin{array}{l}0.635^{* *} \\
(0.097)\end{array}$ & $\begin{array}{l}0.635^{* *} \\
(0.105)\end{array}$ & $\begin{array}{l}0.643^{* *} \\
(0.103)\end{array}$ & $\begin{array}{l}0.643^{* *} \\
(0.108)\end{array}$ & $\begin{array}{c}0.609^{* * *} \\
(0.084)\end{array}$ & $\begin{array}{l}0.609^{* *} \\
(0.097)\end{array}$ & $\begin{array}{c}0.613^{* * *} \\
(0.089)\end{array}$ & $\begin{array}{l}0.613^{* *} \\
(0.099)\end{array}$ \\
\hline Spline 2 & $\begin{array}{c}12.826 \\
(22.164)\end{array}$ & $\begin{array}{c}12.826 \\
(24.560)\end{array}$ & $\begin{array}{c}10.725 \\
(19.102)\end{array}$ & $\begin{array}{c}10.725 \\
(21.135)\end{array}$ & $\begin{array}{l}26.134^{*} \\
(37.854)\end{array}$ & $\begin{array}{l}26.134^{+} \\
(44.174)\end{array}$ & $\begin{array}{l}22.913^{*} \\
(32.914)\end{array}$ & $\begin{array}{l}22.913^{+} \\
(39.268)\end{array}$ \\
\hline Spline 3 & $\begin{array}{c}0.032 \\
(0.097)\end{array}$ & $\begin{array}{c}0.032 \\
(0.106)\end{array}$ & $\begin{array}{c}0.045 \\
(0.138) \\
\end{array}$ & $\begin{array}{c}0.045 \\
(0.151)\end{array}$ & $\begin{array}{l}0.009^{+} \\
(0.022)\end{array}$ & $\begin{array}{l}0.009^{+} \\
(0.025)\end{array}$ & $\begin{array}{l}0.011^{+} \\
(0.027)\end{array}$ & $\begin{array}{c}0.011 \\
(0.033)\end{array}$ \\
\hline Observations & 961 & 961 & 961 & 961 & 961 & 961 & 961 & 961 \\
\hline $\mathrm{AIC}$ & 431.891 & 431.891 & 434.245 & 434.245 & 423.154 & 423.154 & 428.051 & 428.051 \\
\hline LL_0 & -331.929 & -331.929 & -331.929 & -331.929 & -331.929 & -331.929 & -331.929 & -331.929 \\
\hline LL & -199.945 & -199.945 & -201.123 & -201.123 & -196.577 & -196.577 & -199.025 & -199.025 \\
\hline
\end{tabular}


Table D.3: Logistic Regressions: Influential observations removed, 1989-2011

\begin{tabular}{|c|c|c|c|c|}
\hline & $(1)$ & (3) & $(5)$ & $(7)$ \\
\hline Weak State & $\begin{array}{c}6.904^{* * *} \\
(3.913)\end{array}$ & $\begin{array}{c}8.452^{* * *} \\
(4.719)\end{array}$ & $\begin{array}{c}9.303^{* * *} \\
(5.765)\end{array}$ & $\begin{array}{c}11.613^{* * *} \\
(7.391)\end{array}$ \\
\hline Economic Inequality & $\begin{array}{c}3.233^{*} \\
(1.518)\end{array}$ & $\begin{array}{c}3.338^{*} \\
(1.643)\end{array}$ & & \\
\hline Poorest Group & & & $\begin{array}{l}20.862^{* *} \\
(20.285)\end{array}$ & $\begin{array}{l}19.431^{* *} \\
(19.927)\end{array}$ \\
\hline Richest Group & & & $\begin{array}{c}1.540 \\
(0.406)\end{array}$ & $\begin{array}{l}1.644^{+} \\
(0.451)\end{array}$ \\
\hline $\ln$ (Largest Excluded Group) & $\begin{array}{l}0.318^{*} \\
(0.149)\end{array}$ & & $\begin{array}{l}0.340^{*} \\
(0.157)\end{array}$ & \\
\hline $\ln$ (Excluded Population) & & $\begin{array}{c}0.531^{*} \\
(0.152)\end{array}$ & & $\begin{array}{c}0.574^{*} \\
(0.153)\end{array}$ \\
\hline Civil War & $\begin{array}{c}7.424^{* * *} \\
(3.816)\end{array}$ & $\begin{array}{c}6.773^{* * *} \\
(3.293)\end{array}$ & $\begin{array}{l}4.747^{* *} \\
(2.290)\end{array}$ & $\begin{array}{l}4.315^{* *} \\
(1.975)\end{array}$ \\
\hline $\ln ($ Population $)$ & $\begin{array}{l}1.477^{*} \\
(0.243)\end{array}$ & $\begin{array}{l}1.411^{*} \\
(0.233)\end{array}$ & $\begin{array}{l}1.632^{* *} \\
(0.264)\end{array}$ & $\begin{array}{l}1.508^{* *} \\
(0.209)\end{array}$ \\
\hline $\ln$ (Infant Mortality Rate) & $\begin{array}{c}2.797 \\
(2.421)\end{array}$ & $\begin{array}{c}2.368 \\
(1.892)\end{array}$ & $\begin{array}{c}12.353^{*} \\
(14.331)\end{array}$ & $\begin{array}{c}10.076^{*} \\
(10.626)\end{array}$ \\
\hline Relevant Groups & $\begin{array}{c}1.128 \\
(0.098)\end{array}$ & $\begin{array}{c}1.145 \\
(0.103)\end{array}$ & $\begin{array}{c}1.038 \\
(0.079)\end{array}$ & $\begin{array}{l}1.056 \\
(0.084)\end{array}$ \\
\hline Peace Years & $\begin{array}{l}0.877^{+} \\
(0.063)\end{array}$ & $\begin{array}{c}0.866^{*} \\
(0.063)\end{array}$ & $\begin{array}{c}0.846^{*} \\
(0.071)\end{array}$ & $\begin{array}{l}0.831^{*} \\
(0.072)\end{array}$ \\
\hline Spline 1 & $\begin{array}{c}0.334^{* * *} \\
(0.107)\end{array}$ & $\begin{array}{c}0.342^{* * *} \\
(0.103)\end{array}$ & $\begin{array}{l}0.397^{* *} \\
(0.124)\end{array}$ & $\begin{array}{l}0.409^{* *} \\
(0.120)\end{array}$ \\
\hline Spline 2 & $\begin{array}{c}601.191^{+} \\
(2032.197)\end{array}$ & $\begin{array}{c}486.638^{+} \\
(1597.069)\end{array}$ & $\begin{array}{c}216.549 \\
(740.393)\end{array}$ & $\begin{array}{c}159.978 \\
(530.814)\end{array}$ \\
\hline Spline 3 & $\begin{array}{c}0.000 \\
(0.001)\end{array}$ & $\begin{array}{c}0.000 \\
(0.001)\end{array}$ & $\begin{array}{c}0.001 \\
(0.003)\end{array}$ & $\begin{array}{c}0.001 \\
(0.005)\end{array}$ \\
\hline Observations & 955 & 955 & 955 & 955 \\
\hline $\mathrm{AIC}$ & 234.259 & 238.616 & 221.428 & 225.988 \\
\hline LL_0 & -229.486 & -229.486 & -229.486 & -229.486 \\
\hline LL & -105.129 & -107.308 & -97.714 & -99.994 \\
\hline
\end{tabular}


Table D.4: Logistic and Count Regressions: Education, ethnic diveristy, youth bulges and oil added, 1989-2011

\begin{tabular}{|c|c|c|c|c|c|c|c|c|}
\hline & $\begin{array}{c}(1) \\
\text { Logit }\end{array}$ & $\begin{array}{c}(2) \\
\text { Count } \\
\end{array}$ & $\begin{array}{c}(3) \\
\text { Logit }\end{array}$ & $\begin{array}{c}(4) \\
\text { Count } \\
\end{array}$ & $\begin{array}{c}(5) \\
\text { Logit }\end{array}$ & $\begin{array}{c}(6) \\
\text { Count } \\
\end{array}$ & $\begin{array}{c}(7) \\
\text { Logit }\end{array}$ & $\begin{array}{c}(8) \\
\text { Count } \\
\end{array}$ \\
\hline Weak State & $\begin{array}{l}2.858^{+} \\
(1.652)\end{array}$ & $\begin{array}{l}2.271^{+} \\
(0.970)\end{array}$ & $\begin{array}{l}3.001^{+} \\
(1.758)\end{array}$ & $\begin{array}{l}2.439^{*} \\
(1.051)\end{array}$ & $\begin{array}{l}3.080^{+} \\
(1.883)\end{array}$ & $\begin{array}{l}2.563^{*} \\
(1.192)\end{array}$ & $\begin{array}{l}3.197^{+} \\
(1.975)\end{array}$ & $\begin{array}{l}2.743^{*} \\
(1.290)\end{array}$ \\
\hline Economic Inequality & $\begin{array}{c}4.172 \\
(3.678)\end{array}$ & $\begin{array}{l}5.307^{*} \\
(3.952)\end{array}$ & $\begin{array}{l}4.706^{+} \\
(4.270)\end{array}$ & $\begin{array}{l}6.100^{*} \\
(4.646)\end{array}$ & & & & \\
\hline Poorest Group & & & & & $\begin{array}{c}15.024^{* * *} \\
(11.040)\end{array}$ & $\begin{array}{c}10.625^{* * *} \\
(4.588)\end{array}$ & $\begin{array}{c}13.960^{* * * *} \\
(10.337)\end{array}$ & $\begin{array}{c}10.195^{* * *} \\
(4.473)\end{array}$ \\
\hline Richest Group & & & & & $\begin{array}{c}1.601 \\
(0.931)\end{array}$ & $\begin{array}{l}2.228^{+} \\
(1.050)\end{array}$ & $\begin{array}{c}1.739 \\
(1.011)\end{array}$ & $\begin{array}{l}2.391^{+} \\
(1.102)\end{array}$ \\
\hline $\ln$ (Largest Excluded Group) & $\begin{array}{c}0.661 \\
(0.247)\end{array}$ & $\begin{array}{c}0.697 \\
(0.203)\end{array}$ & & & $\begin{array}{c}0.631 \\
(0.218)\end{array}$ & $\begin{array}{c}0.689 \\
(0.173)\end{array}$ & & \\
\hline $\ln$ (Excluded Population) & & & $\begin{array}{c}0.947 \\
(0.209)\end{array}$ & $\begin{array}{l}1.001 \\
(0.155)\end{array}$ & & & $\begin{array}{c}0.906 \\
(0.181)\end{array}$ & $\begin{array}{c}0.955 \\
(0.131)\end{array}$ \\
\hline Civil War & $\begin{array}{c}6.459^{* * *} \\
(3.130)\end{array}$ & $\begin{array}{l}3.126^{*} \\
(1.430)\end{array}$ & $\begin{array}{c}6.175^{* * *} \\
(2.983)\end{array}$ & $\begin{array}{l}3.087^{*} \\
(1.379)\end{array}$ & $\begin{array}{c}5.558^{* * *} \\
(2.471)\end{array}$ & $\begin{array}{l}2.554^{*} \\
(1.092)\end{array}$ & $\begin{array}{c}5.264^{* * *} \\
(2.300)\end{array}$ & $\begin{array}{l}2.528^{*} \\
(1.041)\end{array}$ \\
\hline $\ln$ (Population) & $\begin{array}{l}1.596 \\
(0.476)\end{array}$ & $\begin{array}{l}1.771^{*} \\
(0.445)\end{array}$ & $\begin{array}{c}1.571 \\
(0.470)\end{array}$ & $\begin{array}{l}1.731^{*} \\
(0.437)\end{array}$ & $\begin{array}{l}1.470 \\
(0.413)\end{array}$ & $\begin{array}{l}1.679^{*} \\
(0.397)\end{array}$ & $\begin{array}{l}1.424 \\
(0.401)\end{array}$ & $\begin{array}{l}1.613^{*} \\
(0.378)\end{array}$ \\
\hline $\ln$ (Infant Mortality Rate) & $\begin{array}{c}2.850 \\
(3.390)\end{array}$ & $\begin{array}{l}4.290 \\
(3.833)\end{array}$ & $\begin{array}{c}2.631 \\
(3.099)\end{array}$ & $\begin{array}{c}3.833 \\
(3.493)\end{array}$ & $\begin{array}{c}6.947 \\
(9.292)\end{array}$ & $\begin{array}{l}9.261^{*} \\
(8.419)\end{array}$ & $\begin{array}{c}6.372 \\
(8.414)\end{array}$ & $\begin{array}{l}8.215^{*} \\
(7.454)\end{array}$ \\
\hline Relevant Groups & $\begin{array}{c}1.005 \\
(0.110)\end{array}$ & $\begin{array}{c}0.991 \\
(0.065)\end{array}$ & $\begin{array}{c}0.981 \\
(0.099)\end{array}$ & $\begin{array}{c}0.961 \\
(0.059)\end{array}$ & $\begin{array}{c}0.955 \\
(0.083)\end{array}$ & $\begin{array}{c}0.937 \\
(0.050)\end{array}$ & $\begin{array}{c}0.942 \\
(0.077)\end{array}$ & $\begin{array}{c}0.920 \\
(0.048)\end{array}$ \\
\hline Education & $\begin{array}{c}3.794 \\
(7.877)\end{array}$ & $\begin{array}{c}1.369 \\
(2.270)\end{array}$ & $\begin{array}{c}4.991 \\
(10.485)\end{array}$ & $\begin{array}{l}1.780 \\
(2.858)\end{array}$ & $\begin{array}{l}5.275 \\
(9.500)\end{array}$ & $\begin{array}{l}3.997 \\
(5.591)\end{array}$ & $\begin{array}{c}6.409 \\
(11.593)\end{array}$ & $\begin{array}{c}4.329 \\
(5.852)\end{array}$ \\
\hline Ethnic Diversity & $\begin{array}{c}2.637 \\
(3.108)\end{array}$ & $\begin{array}{c}2.263 \\
(1.948)\end{array}$ & $\begin{array}{c}3.271 \\
(3.960)\end{array}$ & $\begin{array}{l}2.859 \\
(2.572)\end{array}$ & $\begin{array}{l}4.466 \\
(5.411)\end{array}$ & $\begin{array}{c}3.286 \\
(3.297)\end{array}$ & $\begin{array}{c}5.424 \\
(6.760)\end{array}$ & $\begin{array}{c}4.063 \\
(4.177)\end{array}$ \\
\hline Youth Bulges & $\begin{array}{l}1.009 \\
(0.077)\end{array}$ & $\begin{array}{c}0.997 \\
(0.059)\end{array}$ & $\begin{array}{l}1.013 \\
(0.075)\end{array}$ & $\begin{array}{l}1.005 \\
(0.058)\end{array}$ & $\begin{array}{l}1.180^{+} \\
(0.106)\end{array}$ & $\begin{array}{l}1.133^{+} \\
(0.081)\end{array}$ & $\begin{array}{l}1.183^{*} \\
(0.100)\end{array}$ & $\begin{array}{l}1.140^{+} \\
(0.078)\end{array}$ \\
\hline Oil & $\begin{array}{c}0.099 \\
(0.242)\end{array}$ & $\begin{array}{c}0.050 \\
(0.113)\end{array}$ & $\begin{array}{l}0.078 \\
(0.194)\end{array}$ & $\begin{array}{c}0.039 \\
(0.089)\end{array}$ & $\begin{array}{c}0.242 \\
(0.566)\end{array}$ & $\begin{array}{c}0.069 \\
(0.155)\end{array}$ & $\begin{array}{c}0.195 \\
(0.453)\end{array}$ & $\begin{array}{c}0.061 \\
(0.132)\end{array}$ \\
\hline Peace Years & $\begin{array}{l}0.869^{*} \\
(0.055)\end{array}$ & $\begin{array}{l}0.856^{* *} \\
(0.050) \\
\end{array}$ & $\begin{array}{l}0.862^{*} \\
(0.055) \\
\end{array}$ & $\begin{array}{l}0.848^{* *} \\
(0.050)\end{array}$ & $\begin{array}{l}0.852^{*} \\
(0.056)\end{array}$ & $\begin{array}{l}0.840^{\text {** }} \\
(0.048)\end{array}$ & $\begin{array}{l}0.845^{*} \\
(0.056) \\
\end{array}$ & $\begin{array}{l}0.832^{* *} \\
(0.047)\end{array}$ \\
\hline Observations & 961 & 961 & 961 & 961 & 961 & 961 & 961 & 961 \\
\hline $\mathrm{AIC}$ & 297.932 & 453.314 & 299.473 & 454.978 & 286.125 & 435.72 & 288.130 & 437.793 \\
\hline LL_0 & -245.631 & -331.929 & -245.631 & -331.929 & -245.631 & -331.929 & -245.631 & -331.929 \\
\hline LL & -132.966 & -209.657 & -133.737 & -210.489 & -126.062 & -199.86 & -127.050 & -200.900 \\
\hline
\end{tabular}


Table D.5: Count Regressions with Interactions: Education, ethnic diveristy, youth bulges and oil added, 1989-2011

\begin{tabular}{|c|c|c|c|c|c|c|c|c|}
\hline & & Economic & Inequality & & & Political I & nequality & \\
\hline & $(9)$ & $(10)$ & $(11)$ & $(12)$ & $(13)$ & $(14)$ & $(15)$ & $(16)$ \\
\hline Weak State & $\begin{array}{c}1.096 \\
(0.541)\end{array}$ & $\begin{array}{c}1.158 \\
(0.570)\end{array}$ & $\begin{array}{c}2.830 \\
(3.192)\end{array}$ & $\begin{array}{c}3.341 \\
(3.772)\end{array}$ & $\begin{array}{c}0.063^{*} \\
(0.080)\end{array}$ & $\begin{array}{c}0.544 \\
(0.262)\end{array}$ & $\begin{array}{l}0.136^{+} \\
(0.158)\end{array}$ & $\begin{array}{c}0.797 \\
(0.374)\end{array}$ \\
\hline Economic Inequality & $\begin{array}{l}3.283^{+} \\
(2.243)\end{array}$ & $\begin{array}{l}3.771^{+} \\
(2.620)\end{array}$ & & & $\begin{array}{l}5.941^{*} \\
(4.688)\end{array}$ & $\begin{array}{c}7.932^{*} \\
(6.989)\end{array}$ & & \\
\hline Weak State $*$ Ec. Inequality & $\begin{array}{c}11.236^{* *} \\
(8.692)\end{array}$ & $\begin{array}{c}11.472^{* *} \\
(8.992)\end{array}$ & & & & & & \\
\hline Poorest Group & & & $\begin{array}{c}10.974^{* * *} \\
(5.421)\end{array}$ & $\begin{array}{c}11.038^{* * *} \\
(5.422)\end{array}$ & & & $\begin{array}{c}8.017^{* * *} \\
(3.658)\end{array}$ & $\begin{array}{c}7.385^{* * *} \\
(3.145)\end{array}$ \\
\hline Weak State $*$ Poorest & & & $\begin{array}{c}0.188^{*} \\
(0.139)\end{array}$ & $\begin{array}{c}0.163^{*} \\
(0.127)\end{array}$ & & & & \\
\hline Richest Group & & & $\begin{array}{c}1.574 \\
(0.723)\end{array}$ & $\begin{array}{c}1.661 \\
(0.737)\end{array}$ & & & $\begin{array}{l}2.248^{+} \\
(1.083)\end{array}$ & $\begin{array}{l}2.520^{+} \\
(1.278)\end{array}$ \\
\hline Weak State $*$ Richest & & & $\begin{array}{l}4.912^{*} \\
(3.120)\end{array}$ & $\begin{array}{l}5.261^{*} \\
(3.509)\end{array}$ & & & & \\
\hline ln(Largest Excluded Group) & $\begin{array}{c}0.699 \\
(0.224)\end{array}$ & & $\begin{array}{c}0.753 \\
(0.193)\end{array}$ & & $\begin{array}{l}2.181^{*} \\
(0.789)\end{array}$ & & $\begin{array}{c}1.633 \\
(0.547)\end{array}$ & \\
\hline Weak State ${ }^{*}$ Largest Excl. Group & & & & & $\begin{array}{l}0.089^{* *} \\
(0.069)\end{array}$ & & $\begin{array}{l}0.141^{* *} \\
(0.099)\end{array}$ & \\
\hline $\ln$ (Excluded Population) & & $\begin{array}{c}0.981 \\
(0.174)\end{array}$ & & $\begin{array}{c}1.020 \\
(0.155)\end{array}$ & & $\begin{array}{l}2.490^{*} \\
(0.984)\end{array}$ & & $\begin{array}{c}1.873^{*} \\
(0.528)\end{array}$ \\
\hline Weak State $*$ Excl. Population & & & & & & $\begin{array}{c}0.207^{* * *} \\
(0.087)\end{array}$ & & $\begin{array}{c}0.288^{* * *} \\
(0.097)\end{array}$ \\
\hline Civil War & $\begin{array}{c}3.070^{*} \\
(1.424)\end{array}$ & $\begin{array}{c}3.042^{*} \\
(1.387)\end{array}$ & $\begin{array}{c}2.418^{*} \\
(1.023)\end{array}$ & $\begin{array}{c}2.362^{*} \\
(0.973)\end{array}$ & $\begin{array}{c}2.763^{*} \\
(1.187)\end{array}$ & $\begin{array}{l}2.575^{*} \\
(1.052)\end{array}$ & $\begin{array}{l}2.339^{*} \\
(0.931)\end{array}$ & $\begin{array}{c}2.241^{*} \\
(0.843)\end{array}$ \\
\hline $\ln$ (Population) & $\begin{array}{l}1.508^{+} \\
(0.317)\end{array}$ & $\begin{array}{l}1.481^{+} \\
(0.314)\end{array}$ & $\begin{array}{c}1.419 \\
(0.316)\end{array}$ & $\begin{array}{c}1.355 \\
(0.299)\end{array}$ & $\begin{array}{l}1.796^{*} \\
(0.478)\end{array}$ & $\begin{array}{l}1.897^{*} \\
(0.546)\end{array}$ & $\begin{array}{l}1.748^{*} \\
(0.432)\end{array}$ & $\begin{array}{c}1.806^{*} \\
(0.469)\end{array}$ \\
\hline $\ln ($ Infant Mortality Rate) & $\begin{array}{l}5.235^{*} \\
(4.121)\end{array}$ & $\begin{array}{l}4.677^{+} \\
(3.704)\end{array}$ & $\begin{array}{l}7.562^{*} \\
(6.132)\end{array}$ & $\begin{array}{c}6.649^{*} \\
(5.315)\end{array}$ & $\begin{array}{c}4.574 \\
(4.451)\end{array}$ & $\begin{array}{l}5.584^{+} \\
(5.479)\end{array}$ & $\begin{array}{c}9.282^{*} \\
(8.596)\end{array}$ & $\begin{array}{l}9.567^{* *} \\
(8.253)\end{array}$ \\
\hline Relevant Groups & $\begin{array}{c}1.033 \\
(0.064)\end{array}$ & $\begin{array}{c}1.003 \\
(0.059)\end{array}$ & $\begin{array}{c}0.984 \\
(0.049)\end{array}$ & $\begin{array}{c}0.964 \\
(0.044)\end{array}$ & $\begin{array}{c}1.056 \\
(0.054)\end{array}$ & $\begin{array}{c}0.990 \\
(0.054)\end{array}$ & $\begin{array}{c}0.999 \\
(0.050)\end{array}$ & $\begin{array}{c}0.954 \\
(0.050)\end{array}$ \\
\hline Education & $\begin{array}{c}2.294 \\
(3.577)\end{array}$ & $\begin{array}{c}3.087 \\
(4.673)\end{array}$ & $\begin{array}{c}2.132 \\
(2.766)\end{array}$ & $\begin{array}{c}2.232 \\
(2.859)\end{array}$ & $\begin{array}{c}3.076 \\
(4.955)\end{array}$ & $\begin{array}{c}8.128 \\
(13.727)\end{array}$ & $\begin{array}{c}5.881 \\
(8.352)\end{array}$ & $\begin{array}{l}11.091^{+} \\
(16.033)\end{array}$ \\
\hline Ethnic Diversity & $\begin{array}{c}2.309 \\
(2.046)\end{array}$ & $\begin{array}{c}2.842 \\
(2.653)\end{array}$ & $\begin{array}{c}2.822 \\
(2.815)\end{array}$ & $\begin{array}{c}3.475 \\
(3.592)\end{array}$ & $\begin{array}{c}2.192 \\
(2.137)\end{array}$ & $\begin{array}{c}2.014 \\
(2.086)\end{array}$ & $\begin{array}{c}2.925 \\
(3.231)\end{array}$ & $\begin{array}{c}3.018 \\
(3.472)\end{array}$ \\
\hline Youth Bulges & $\begin{array}{c}1.042 \\
(0.054)\end{array}$ & $\begin{array}{c}1.049 \\
(0.054)\end{array}$ & $\begin{array}{l}1.142^{+} \\
(0.078)\end{array}$ & $\begin{array}{c}1.145^{*} \\
(0.075)\end{array}$ & $\begin{array}{c}1.048 \\
(0.072)\end{array}$ & $\begin{array}{c}1.069 \\
(0.071)\end{array}$ & $\begin{array}{l}1.158^{+} \\
(0.095)\end{array}$ & $\begin{array}{c}1.167^{*} \\
(0.089)\end{array}$ \\
\hline Oil & $\begin{array}{c}0.054 \\
(0.110)\end{array}$ & $\begin{array}{c}0.041 \\
(0.084)\end{array}$ & $\begin{array}{c}0.108 \\
(0.212)\end{array}$ & $\begin{array}{c}0.091 \\
(0.174)\end{array}$ & $\begin{array}{c}0.044 \\
(0.097)\end{array}$ & $\begin{array}{c}0.020 \\
(0.049)\end{array}$ & $\begin{array}{c}0.069 \\
(0.149)\end{array}$ & $\begin{array}{c}0.043 \\
(0.096)\end{array}$ \\
\hline Peace Years & $\begin{array}{l}0.849^{* *} \\
(0.048)\end{array}$ & $\begin{array}{c}0.842^{* *} \\
(0.047)\end{array}$ & $\begin{array}{l}0.828^{* *} \\
(0.049)\end{array}$ & $\begin{array}{c}0.820^{* * *} \\
(0.049)\end{array}$ & $\begin{array}{c}0.882^{*} \\
(0.049)\end{array}$ & $\begin{array}{c}0.871^{*} \\
(0.048)\end{array}$ & $\begin{array}{l}0.865^{* *} \\
(0.048)\end{array}$ & $\begin{array}{l}0.855^{* *} \\
(0.046)\end{array}$ \\
\hline Observations & 961 & 961 & 961 & 961 & 961 & 961 & 961 & 961 \\
\hline AIC & 446.179 & 447.752 & 432.160 & 433.177 & 431.001 & 430.611 & 420.499 & 421.580 \\
\hline LL_0 & -331.929 & -331.929 & -331.929 & -331.929 & -331.929 & -331.929 & -331.929 & -331.929 \\
\hline LL & -205.089 & -205.876 & -196.080 & -196.589 & -197.500 & -197.306 & -191.250 & -191.790 \\
\hline
\end{tabular}


Table D.6: Logistic and Count Regressions: Alternative operationalization of state capacity, 1989-2011

\begin{tabular}{|c|c|c|c|c|c|c|c|c|}
\hline & $\begin{array}{l}\text { (P1) } \\
\text { Logit }\end{array}$ & $\begin{array}{c}\text { (P2) } \\
\text { Count }\end{array}$ & $\begin{array}{l}\text { (P3) } \\
\text { Logit }\end{array}$ & $\begin{array}{c}\text { (P4) } \\
\text { Count }\end{array}$ & $\begin{array}{l}\text { (P5) } \\
\text { Logit }\end{array}$ & $\begin{array}{c}\text { (P6) } \\
\text { Count }\end{array}$ & $\begin{array}{l}(\mathrm{P} 7) \\
\text { Logit }\end{array}$ & $\begin{array}{c}\text { (P8) } \\
\text { Count }\end{array}$ \\
\hline Weak State & $\begin{array}{l}3.716^{*} \\
(2.105)\end{array}$ & $\begin{array}{c}3.147^{* * *} \\
(1.035)\end{array}$ & $\begin{array}{l}3.880^{*} \\
(2.293)\end{array}$ & $\begin{array}{c}3.454^{* * *} \\
(1.169)\end{array}$ & $\begin{array}{l}4.724^{* *} \\
(2.704)\end{array}$ & $\begin{array}{c}4.932^{* * *} \\
(1.865)\end{array}$ & $\begin{array}{l}4.986^{* *} \\
(3.041)\end{array}$ & $\begin{array}{c}5.590^{* * *} \\
(2.320)\end{array}$ \\
\hline Economic Inequality & $\begin{array}{l}2.359^{+} \\
(1.176)\end{array}$ & $\begin{array}{l}2.650^{*} \\
(1.127)\end{array}$ & $\begin{array}{l}2.404^{+} \\
(1.271)\end{array}$ & $\begin{array}{l}2.763^{*} \\
(1.254)\end{array}$ & & & & \\
\hline Poorest Group & & & & & $\begin{array}{c}13.917^{* * *} \\
(11.063)\end{array}$ & $\begin{array}{c}14.173^{* * *} \\
(7.698)\end{array}$ & $\begin{array}{l}13.395^{* *} \\
(10.990)\end{array}$ & $\begin{array}{c}14.408^{* * *} \\
(8.496)\end{array}$ \\
\hline Richest Group & & & & & $\begin{array}{c}1.172 \\
(0.339)\end{array}$ & $\begin{array}{c}1.292 \\
(0.341)\end{array}$ & $\begin{array}{c}1.193 \\
(0.376)\end{array}$ & $\begin{array}{c}1.343 \\
(0.377)\end{array}$ \\
\hline ln(Largest Excluded Group) & $\begin{array}{l}0.452^{*} \\
(0.177)\end{array}$ & $\begin{array}{l}0.540^{*} \\
(0.141)\end{array}$ & & & $\begin{array}{l}0.481^{*} \\
(0.170)\end{array}$ & $\begin{array}{l}0.568^{*} \\
(0.147)\end{array}$ & & \\
\hline ln(Excluded Population) & & & $\begin{array}{c}0.710 \\
(0.173)\end{array}$ & $\begin{array}{c}0.790 \\
(0.137)\end{array}$ & & & $\begin{array}{c}0.753 \\
(0.173)\end{array}$ & $\begin{array}{c}0.822 \\
(0.134)\end{array}$ \\
\hline Civil War & $\begin{array}{c}6.022^{* * *} \\
(2.554)\end{array}$ & $\begin{array}{l}3.379^{* *} \\
(1.355)\end{array}$ & $\begin{array}{c}5.311^{* * *} \\
(2.243)\end{array}$ & $\begin{array}{l}3.198^{* *} \\
(1.197)\end{array}$ & $\begin{array}{c}4.366^{* * *} \\
(1.862)\end{array}$ & $\begin{array}{l}2.009^{+} \\
(0.782)\end{array}$ & $\begin{array}{l}3.791^{* *} \\
(1.645)\end{array}$ & $\begin{array}{l}1.886^{+} \\
(0.683)\end{array}$ \\
\hline $\ln$ (Population) & $\begin{array}{c}1.299 \\
(0.232)\end{array}$ & $\begin{array}{l}1.336^{+} \\
(0.222)\end{array}$ & $\begin{array}{c}1.265 \\
(0.236)\end{array}$ & $\begin{array}{c}1.302 \\
(0.221)\end{array}$ & $\begin{array}{c}1.383 \\
(0.277)\end{array}$ & $\begin{array}{l}1.430^{*} \\
(0.225)\end{array}$ & $\begin{array}{c}1.332 \\
(0.265)\end{array}$ & $\begin{array}{l}1.374^{*} \\
(0.218)\end{array}$ \\
\hline $\ln$ (Infant Mortality Rate) & $\begin{array}{c}3.951 \\
(3.482)\end{array}$ & $\begin{array}{l}3.361^{*} \\
(1.605)\end{array}$ & $\begin{array}{c}3.362 \\
(2.751)\end{array}$ & $\begin{array}{l}3.086^{*} \\
(1.485)\end{array}$ & $\begin{array}{c}11.563^{*} \\
(12.842)\end{array}$ & $\begin{array}{c}14.055^{* * *} \\
(8.251)\end{array}$ & $\begin{array}{c}9.913^{*} \\
(10.201)\end{array}$ & $\begin{array}{c}12.859^{* * *} \\
(7.459)\end{array}$ \\
\hline Relevant Groups & $\begin{array}{c}1.124 \\
(0.113)\end{array}$ & $\begin{array}{c}1.074 \\
(0.058)\end{array}$ & $\begin{array}{l}1.118 \\
(0.111)\end{array}$ & $\begin{array}{c}1.067 \\
(0.062)\end{array}$ & $\begin{array}{l}1.038 \\
(0.117)\end{array}$ & $\begin{array}{c}1.022 \\
(0.047)\end{array}$ & $\begin{array}{c}1.035 \\
(0.109)\end{array}$ & $\begin{array}{c}1.015 \\
(0.048)\end{array}$ \\
\hline Peace Years & $\begin{array}{l}0.875^{*} \\
(0.059)\end{array}$ & $\begin{array}{l}0.868^{*} \\
(0.049)\end{array}$ & $\begin{array}{l}0.861^{*} \\
(0.062)\end{array}$ & $\begin{array}{l}0.857^{* *} \\
(0.049)\end{array}$ & $\begin{array}{c}0.853^{*} \\
(0.059)\end{array}$ & $\begin{array}{l}0.849^{* *} \\
(0.044)\end{array}$ & $\begin{array}{l}0.840^{*} \\
(0.061)\end{array}$ & $\begin{array}{c}0.839^{* * *} \\
(0.044)\end{array}$ \\
\hline Spline 1 & $\begin{array}{l}0.433^{* *} \\
(0.124)\end{array}$ & $\begin{array}{l}0.507^{* *} \\
(0.106)\end{array}$ & $\begin{array}{l}0.436^{* *} \\
(0.122)\end{array}$ & $\begin{array}{l}0.503^{* *} \\
(0.106)\end{array}$ & $\begin{array}{l}0.512^{* *} \\
(0.123)\end{array}$ & $\begin{array}{l}0.609^{* *} \\
(0.104)\end{array}$ & $\begin{array}{l}0.509^{* *} \\
(0.120)\end{array}$ & $\begin{array}{l}0.598^{* *} \\
(0.104)\end{array}$ \\
\hline Spline 2 & $\begin{array}{c}236.732^{*} \\
(623.081)\end{array}$ & $\begin{array}{c}56.738^{*} \\
(104.523)\end{array}$ & $\begin{array}{l}232.325^{*} \\
(601.928)\end{array}$ & $\begin{array}{c}61.905^{*} \\
(114.944)\end{array}$ & $\begin{array}{c}78.719^{+} \\
(187.010)\end{array}$ & $\begin{array}{l}17.604^{+} \\
(28.907)\end{array}$ & $\begin{array}{c}89.138^{+} \\
(208.674)\end{array}$ & $\begin{array}{l}21.816^{+} \\
(36.672)\end{array}$ \\
\hline Spline 3 & $\begin{array}{l}0.000^{+} \\
(0.001)\end{array}$ & $\begin{array}{l}0.003^{+} \\
(0.009) \\
\end{array}$ & $\begin{array}{l}0.000^{+} \\
(0.001) \\
\end{array}$ & $\begin{array}{l}0.003^{+} \\
(0.008)\end{array}$ & $\begin{array}{c}0.002 \\
(0.007)\end{array}$ & $\begin{array}{c}0.018 \\
(0.048)\end{array}$ & $\begin{array}{l}0.001^{+} \\
(0.005)\end{array}$ & $\begin{array}{c}0.012 \\
(0.035)\end{array}$ \\
\hline Observations & 961 & 961 & 961 & 961 & 961 & 961 & 961 & 961 \\
\hline AIC & 294.493 & 452.302 & 299.804 & 457.519 & 280.014 & 422.394 & 285.425 & 427.809 \\
\hline LL_0 & -245.631 & -331.929 & -245.631 & -331.929 & -245.631 & -331.929 & -245.631 & -331.929 \\
\hline LL & -135.247 & -213.151 & -137.902 & -215.760 & -127.007 & -197.197 & -129.713 & -199.905 \\
\hline
\end{tabular}

Exponentiated coefficients; Standard errors in parentheses.

AIC, LL_0 and LL are averaged values for the ten imputed datasets.

${ }^{+} p<0.10,{ }^{*} p<0.05,{ }^{* *} p<0.01,{ }^{* * *} p<0.001$ 
Table D.7: Count Regressions with Interactions: Alternative operationalization of state capacity, 1989-2011

\begin{tabular}{|c|c|c|c|c|c|c|c|c|}
\hline & \multicolumn{4}{|c|}{ Economic Inequality } & \multicolumn{4}{|c|}{ Political Inequality } \\
\hline & (P9) & $(\mathrm{P} 10)$ & $(\mathrm{P} 11)$ & $(\mathrm{P} 12)$ & (P13) & $(\mathrm{P} 14)$ & $(\mathrm{P} 15)$ & $(\mathrm{P} 16)$ \\
\hline Weak State & $\begin{array}{c}1.723 \\
(0.578)\end{array}$ & $\begin{array}{l}1.874^{+} \\
(0.611)\end{array}$ & $\begin{array}{c}1.231 \\
(1.767)\end{array}$ & $\begin{array}{c}1.260 \\
(1.957)\end{array}$ & $\begin{array}{c}0.386 \\
(0.302)\end{array}$ & $\begin{array}{c}1.381 \\
(0.651)\end{array}$ & $\begin{array}{c}1.509 \\
(0.932)\end{array}$ & $\begin{array}{l}3.360^{* *} \\
(1.351)\end{array}$ \\
\hline Economic Inequality & $\begin{array}{c}1.627 \\
(0.553)\end{array}$ & $\begin{array}{c}1.660 \\
(0.594)\end{array}$ & & & $\begin{array}{c}2.480^{*} \\
(1.023)\end{array}$ & $\begin{array}{l}2.527^{*} \\
(1.102)\end{array}$ & & \\
\hline Weak State $*$ Ec. Inequality & $\begin{array}{c}11.515^{* * *} \\
(8.167)\end{array}$ & $\begin{array}{c}11.973^{* * *} \\
(8.756)\end{array}$ & & & & & & \\
\hline Poorest Group & & & $\begin{array}{c}10.801^{* * *} \\
(5.974)\end{array}$ & $\begin{array}{c}10.848^{* * *} \\
(6.432)\end{array}$ & & & $\begin{array}{c}11.171^{* * *} \\
(5.693)\end{array}$ & $\begin{array}{c}11.290^{* * *} \\
(6.147)\end{array}$ \\
\hline Weak State $*$ Poorest & & & $\begin{array}{c}0.983 \\
(1.349)\end{array}$ & $\begin{array}{c}1.043 \\
(1.497)\end{array}$ & & & & \\
\hline Richest Group & & & $\begin{array}{c}1.008 \\
(0.247)\end{array}$ & $\begin{array}{c}1.032 \\
(0.272)\end{array}$ & & & $\begin{array}{c}1.249 \\
(0.336)\end{array}$ & $\begin{array}{c}1.269 \\
(0.362)\end{array}$ \\
\hline Weak State $*$ Richest & & & $\begin{array}{l}2.498^{+} \\
(1.283)\end{array}$ & $\begin{array}{l}2.530^{+} \\
(1.305)\end{array}$ & & & & \\
\hline $\ln$ (Largest Excluded Group) & $\begin{array}{c}0.533^{*} \\
(0.155)\end{array}$ & & $\begin{array}{c}0.572^{*} \\
(0.159)\end{array}$ & & $\begin{array}{c}1.057 \\
(0.397)\end{array}$ & & $\begin{array}{c}0.815 \\
(0.297)\end{array}$ & \\
\hline Weak State ${ }^{*}$ Largest Excl. Group & & & & & $\begin{array}{l}0.264^{* *} \\
(0.135)\end{array}$ & & $\begin{array}{l}0.481^{+} \\
(0.209)\end{array}$ & \\
\hline $\ln$ (Excluded Population) & & $\begin{array}{c}0.762 \\
(0.151)\end{array}$ & & $\begin{array}{c}0.825 \\
(0.147)\end{array}$ & & $\begin{array}{c}1.256 \\
(0.369)\end{array}$ & & $\begin{array}{c}1.023 \\
(0.234)\end{array}$ \\
\hline Weak State * Excl. Population & & & & & & $\begin{array}{c}0.433^{*} \\
(0.153)\end{array}$ & & $\begin{array}{c}0.657 \\
(0.171)\end{array}$ \\
\hline Civil War & $\begin{array}{l}3.179^{* *} \\
(1.362)\end{array}$ & $\begin{array}{l}3.039^{* *} \\
(1.222)\end{array}$ & $\begin{array}{l}2.051^{+} \\
(0.793)\end{array}$ & $\begin{array}{l}1.925^{+} \\
(0.697)\end{array}$ & $\begin{array}{l}2.970^{* *} \\
(1.163)\end{array}$ & $\begin{array}{l}2.679^{* *} \\
(0.957)\end{array}$ & $\begin{array}{l}1.967^{+} \\
(0.722)\end{array}$ & $\begin{array}{l}1.817^{+} \\
(0.616)\end{array}$ \\
\hline $\ln$ (Population) & $\begin{array}{c}1.199 \\
(0.164)\end{array}$ & $\begin{array}{c}1.174 \\
(0.166)\end{array}$ & $\begin{array}{l}1.354^{+} \\
(0.225)\end{array}$ & $\begin{array}{c}1.300 \\
(0.216)\end{array}$ & $\begin{array}{l}1.334^{+} \\
(0.215)\end{array}$ & $\begin{array}{c}1.312 \\
(0.217)\end{array}$ & $\begin{array}{l}1.464^{*} \\
(0.244)\end{array}$ & $\begin{array}{l}1.436^{*} \\
(0.246)\end{array}$ \\
\hline $\ln$ (Infant Mortality Rate) & $\begin{array}{l}3.705^{* *} \\
(1.643)\end{array}$ & $\begin{array}{l}3.419^{* *} \\
(1.513)\end{array}$ & $\begin{array}{c}11.813^{* * *} \\
(6.763)\end{array}$ & $\begin{array}{c}10.607^{* * *} \\
(5.984)\end{array}$ & $\begin{array}{c}3.769^{*} \\
(1.991)\end{array}$ & $\begin{array}{l}3.881^{* *} \\
(1.965)\end{array}$ & $\begin{array}{c}13.595^{* * *} \\
(8.655)\end{array}$ & $\begin{array}{c}13.253^{* * *} \\
(7.989)\end{array}$ \\
\hline Relevant Groups & $\begin{array}{l}1.122^{*} \\
(0.052)\end{array}$ & $\begin{array}{c}1.119^{*} \\
(0.057)\end{array}$ & $\begin{array}{c}1.041 \\
(0.048)\end{array}$ & $\begin{array}{c}1.034 \\
(0.050)\end{array}$ & $\begin{array}{l}1.104^{+} \\
(0.064)\end{array}$ & $\begin{array}{c}1.092 \\
(0.062)\end{array}$ & $\begin{array}{c}1.042 \\
(0.053)\end{array}$ & $\begin{array}{c}1.031 \\
(0.052)\end{array}$ \\
\hline Peace Years & $\begin{array}{l}0.849^{* *} \\
(0.050)\end{array}$ & $\begin{array}{l}0.839^{* *} \\
(0.050)\end{array}$ & $\begin{array}{c}0.837^{* *} \\
(0.046)\end{array}$ & $\begin{array}{c}0.826^{* * *} \\
(0.046)\end{array}$ & $\begin{array}{c}0.876^{*} \\
(0.048)\end{array}$ & $\begin{array}{l}0.866^{* *} \\
(0.047)\end{array}$ & $\begin{array}{l}0.858^{* *} \\
(0.043)\end{array}$ & $\begin{array}{c}0.848^{* * *} \\
(0.042)\end{array}$ \\
\hline Spline 1 & $\begin{array}{l}0.529^{* *} \\
(0.113)\end{array}$ & $\begin{array}{l}0.523^{* *} \\
(0.113)\end{array}$ & $\begin{array}{l}0.614^{* *} \\
(0.107)\end{array}$ & $\begin{array}{l}0.603^{* *} \\
(0.109)\end{array}$ & $\begin{array}{l}0.557^{* *} \\
(0.108)\end{array}$ & $\begin{array}{l}0.549^{* *} \\
(0.103)\end{array}$ & $\begin{array}{l}0.634^{* *} \\
(0.104)\end{array}$ & $\begin{array}{l}0.618^{* *} \\
(0.104)\end{array}$ \\
\hline Spline 2 & $\begin{array}{l}45.057^{+} \\
(89.588)\end{array}$ & $\begin{array}{c}50.308^{+} \\
(101.724)\end{array}$ & $\begin{array}{l}19.331^{+} \\
(32.570)\end{array}$ & $\begin{array}{l}24.082^{+} \\
(42.228)\end{array}$ & $\begin{array}{l}24.044^{+} \\
(42.116)\end{array}$ & $\begin{array}{c}28.654^{*} \\
(48.483)\end{array}$ & $\begin{array}{c}11.366 \\
(18.014)\end{array}$ & $\begin{array}{l}14.949^{+} \\
(24.291)\end{array}$ \\
\hline Spline 3 & $\begin{array}{c}0.004^{+} \\
(0.014)\end{array}$ & $\begin{array}{l}0.004^{+} \\
(0.012)\end{array}$ & $\begin{array}{c}0.015 \\
(0.042) \\
\end{array}$ & $\begin{array}{c}0.010 \\
(0.030) \\
\end{array}$ & $\begin{array}{c}0.012 \\
(0.033) \\
\end{array}$ & $\begin{array}{l}0.009^{+} \\
(0.024)\end{array}$ & $\begin{array}{c}0.036 \\
(0.096) \\
\end{array}$ & $\begin{array}{c}0.023 \\
(0.062) \\
\end{array}$ \\
\hline Observations & 961 & 961 & 961 & 961 & 961 & 961 & 961 & 961 \\
\hline $\mathrm{AIC}$ & 439.136 & 444.157 & 422.690 & 427.793 & 422.120 & 447.112 & 418.483 & 426.638 \\
\hline LL_0 & -331.929 & -331.929 & -331.929 & -331.929 & -331.929 & -331.929 & -331.929 & -331.929 \\
\hline LL & -205.568 & -208.079 & -195.345 & -197.896 & -207.06 & -209.556 & -195.242 & -198.319 \\
\hline
\end{tabular}


Table D.8: Alternative Methods: Rare event logistic and zero inflated negative binomial regression, 1989-2011

\begin{tabular}{|c|c|c|c|c|c|c|c|c|}
\hline & $\begin{array}{c}(1) \\
\text { RElogit }\end{array}$ & $\begin{array}{c}(2) \\
\text { RElogit }\end{array}$ & $\begin{array}{c}(3) \\
\text { RElogit }\end{array}$ & $\begin{array}{c}(4) \\
\text { RElogit }\end{array}$ & $\begin{array}{c}(5) \\
\text { ZINB }\end{array}$ & $\begin{array}{c}(6) \\
\text { ZINB }\end{array}$ & $\begin{array}{c}(7) \\
\text { ZINB }\end{array}$ & $\begin{array}{c}(8) \\
\text { ZINB }\end{array}$ \\
\hline Weak State & $\begin{array}{l}3.869^{* *} \\
(1.979)\end{array}$ & $\begin{array}{l}4.289^{* *} \\
(2.208)\end{array}$ & $\begin{array}{l}4.067^{* *} \\
(2.008)\end{array}$ & $\begin{array}{l}4.532^{* *} \\
(2.303)\end{array}$ & $\begin{array}{c}2.907^{*} \\
(1.357)\end{array}$ & $\begin{array}{l}3.281^{* *} \\
(1.450)\end{array}$ & $\begin{array}{c}2.811^{*} \\
(1.138)\end{array}$ & $\begin{array}{l}3.735^{* *} \\
(1.669)\end{array}$ \\
\hline Economic Inequality & $\begin{array}{l}2.301^{+} \\
(1.103)\end{array}$ & $\begin{array}{l}2.382^{+} \\
(1.181)\end{array}$ & & & $\begin{array}{c}1.439 \\
(0.703)\end{array}$ & $\begin{array}{c}1.412 \\
(0.814)\end{array}$ & & \\
\hline Poorest Group & & & $\begin{array}{l}8.194^{* *} \\
(6.010)\end{array}$ & $\begin{array}{l}7.878^{* *} \\
(5.828)\end{array}$ & & & $\begin{array}{c}9.470^{* * *} \\
(4.645)\end{array}$ & $\begin{array}{l}7.191^{* *} \\
(4.745)\end{array}$ \\
\hline Richest Group & & & $\begin{array}{c}1.296 \\
(0.358)\end{array}$ & $\begin{array}{c}1.334 \\
(0.387)\end{array}$ & & & $\begin{array}{c}0.672 \\
(0.339)\end{array}$ & $\begin{array}{c}0.832 \\
(0.703)\end{array}$ \\
\hline ln(Largest Excluded Group) & $\begin{array}{c}0.574 \\
(0.227)\end{array}$ & & $\begin{array}{c}0.589 \\
(0.220)\end{array}$ & & $\begin{array}{c}0.610 \\
(0.326)\end{array}$ & & $\begin{array}{c}0.451 \\
(0.272)\end{array}$ & \\
\hline $\ln$ (Excluded Population) & & $\begin{array}{c}0.819 \\
(0.197)\end{array}$ & & $\begin{array}{c}0.849 \\
(0.195)\end{array}$ & & $\begin{array}{c}0.853 \\
(0.253)\end{array}$ & & $\begin{array}{c}1.253 \\
(0.324)\end{array}$ \\
\hline Civil War & $\begin{array}{c}5.404^{* * *} \\
(2.243)\end{array}$ & $\begin{array}{c}4.942^{* * *} \\
(2.008)\end{array}$ & $\begin{array}{c}3.983^{* * *} \\
(1.599)\end{array}$ & $\begin{array}{l}3.624^{* *} \\
(1.438)\end{array}$ & $\begin{array}{l}2.096^{+} \\
(0.846)\end{array}$ & $\begin{array}{c}1.989^{+} \\
(0.733)\end{array}$ & $\begin{array}{c}1.174 \\
(0.230)\end{array}$ & $\begin{array}{c}1.585 \\
(0.648)\end{array}$ \\
\hline $\ln$ (Population) & $\begin{array}{c}1.318 \\
(0.224)\end{array}$ & $\begin{array}{c}1.288 \\
(0.223)\end{array}$ & $\begin{array}{l}1.356^{+} \\
(0.247)\end{array}$ & $\begin{array}{c}1.306 \\
(0.230)\end{array}$ & $\begin{array}{c}1.311 \\
(0.231)\end{array}$ & $\begin{array}{c}1.272 \\
(0.223)\end{array}$ & $\begin{array}{c}1.516^{*} \\
(0.290)\end{array}$ & $\begin{array}{l}1.509^{+} \\
(0.326)\end{array}$ \\
\hline ln(Infant Mortality Rate) & $\begin{array}{c}1.794 \\
(1.646)\end{array}$ & $\begin{array}{c}1.544 \\
(1.296)\end{array}$ & $\begin{array}{c}4.573 \\
(4.972)\end{array}$ & $\begin{array}{c}3.910 \\
(3.932)\end{array}$ & $\begin{array}{c}2.116 \\
(1.412)\end{array}$ & $\begin{array}{c}1.892 \\
(1.319)\end{array}$ & $\begin{array}{l}8.234^{* *} \\
(5.914)\end{array}$ & $\begin{array}{c}6.052^{*} \\
(4.340)\end{array}$ \\
\hline Relevant Groups & $\begin{array}{c}1.080 \\
(0.100)\end{array}$ & $\begin{array}{c}1.072 \\
(0.098)\end{array}$ & $\begin{array}{c}1.021 \\
(0.099)\end{array}$ & $\begin{array}{c}1.017 \\
(0.092)\end{array}$ & $\begin{array}{c}1.054 \\
(0.066)\end{array}$ & $\begin{array}{c}1.044 \\
(0.077)\end{array}$ & $\begin{array}{c}1.019 \\
(0.075)\end{array}$ & $\begin{array}{c}0.926 \\
(0.055)\end{array}$ \\
\hline Peace Years & $\begin{array}{c}0.869^{*} \\
(0.056)\end{array}$ & $\begin{array}{c}0.861^{*} \\
(0.057)\end{array}$ & $\begin{array}{c}0.848^{*} \\
(0.057)\end{array}$ & $\begin{array}{c}0.838^{*} \\
(0.058)\end{array}$ & $\begin{array}{l}0.855^{* *} \\
(0.049)\end{array}$ & $\begin{array}{l}0.848^{* *} \\
(0.050)\end{array}$ & $\begin{array}{c}0.852^{* * *} \\
(0.040)\end{array}$ & $\begin{array}{l}0.838^{* *} \\
(0.052)\end{array}$ \\
\hline Spline 1 & $\begin{array}{c}0.479^{* *} \\
(0.129)\end{array}$ & $\begin{array}{l}0.484^{* *} \\
(0.128)\end{array}$ & $\begin{array}{l}0.539^{* *} \\
(0.126)\end{array}$ & $\begin{array}{c}0.545^{* *} \\
(0.126)\end{array}$ & $\begin{array}{l}0.534^{* *} \\
(0.102)\end{array}$ & $\begin{array}{l}0.538^{* *} \\
(0.102)\end{array}$ & $\begin{array}{c}0.618^{* *} \\
(0.115)\end{array}$ & $\begin{array}{c}0.609^{* *} \\
(0.113)\end{array}$ \\
\hline Spline 2 & $\begin{array}{c}164.506^{*} \\
(403.743)\end{array}$ & $\begin{array}{l}146.569^{*} \\
(351.502)\end{array}$ & $\begin{array}{c}84.912^{*} \\
(189.813)\end{array}$ & $\begin{array}{c}76.332^{*} \\
(166.798)\end{array}$ & $\begin{array}{c}52.915^{*} \\
(92.316)\end{array}$ & $\begin{array}{c}49.806^{*} \\
(89.734)\end{array}$ & $\begin{array}{l}23.988^{+} \\
(40.904)\end{array}$ & $\begin{array}{c}34.080^{*} \\
(56.520)\end{array}$ \\
\hline Spline 3 & $\begin{array}{l}0.000^{+} \\
(0.002)\end{array}$ & $\begin{array}{l}0.001^{+} \\
(0.002)\end{array}$ & $\begin{array}{l}0.001^{+} \\
(0.005)\end{array}$ & $\begin{array}{c}0.002^{+} \\
(0.006)\end{array}$ & $\begin{array}{c}0.003^{*} \\
(0.009)\end{array}$ & $\begin{array}{l}0.003^{+} \\
(0.010)\end{array}$ & $\begin{array}{c}0.010 \\
(0.029)\end{array}$ & $\begin{array}{l}0.006^{+} \\
(0.015)\end{array}$ \\
\hline Economic Inequality & & & & & $\begin{array}{c}0.000 \\
(0.000)\end{array}$ & $\begin{array}{c}0.000 \\
(0.000)\end{array}$ & & \\
\hline Poorest Group & & & & & & & $\begin{array}{c}12.077 \\
(35.792)\end{array}$ & $\begin{array}{c}1.047 \\
(4.139)\end{array}$ \\
\hline Richest Group & & & & & & & $\begin{array}{c}0.000 \\
(0.001)\end{array}$ & $\begin{array}{c}0.000 \\
(0.000)\end{array}$ \\
\hline ln(Largest Excluded Group) & & & & & $\begin{array}{c}1.956 \\
(7.623)\end{array}$ & & $\begin{array}{c}0.513 \\
(1.061)\end{array}$ & $\begin{array}{c}47.222 \\
(299.248)\end{array}$ \\
\hline $\ln$ (Excluded Population) & & & & & & $\begin{array}{c}1.380 \\
(3.503)\end{array}$ & & \\
\hline Civil War & & & & & $\begin{array}{c}0.005 \\
(0.184)\end{array}$ & $\begin{array}{c}0.074 \\
(1.345)\end{array}$ & $\begin{array}{c}0.004 \\
(0.086)\end{array}$ & $\begin{array}{c}0.026 \\
(0.133)\end{array}$ \\
\hline $\begin{array}{l}\text { Observations } \\
\text { AIC } \\
\text { LL_0 } \\
\text { LL }\end{array}$ & 961 & 961 & 961 & 961 & $\begin{array}{c}961 \\
447.836 \\
-283.314 \\
-206.918\end{array}$ & $\begin{array}{c}961 \\
456.395 \\
-286.087 \\
-211.197\end{array}$ & $\begin{array}{c}961 \\
431.093 \\
-272.188 \\
-196.547\end{array}$ & $\begin{array}{c}961 \\
429.036 \\
-272.188 \\
-195.518\end{array}$ \\
\hline
\end{tabular}

Exponentiated coefficients; Clustered and robust standard errors in parentheses.

AIC, LL_0 and LL are averaged values for the ten imputed datasets.

$+p<0.10,{ }^{*} p<0.05,{ }^{* *} p<0.01,{ }^{* * *} p<0.001$ 
Table D.9: Alternative Methods: Interactions with rare event logistic regression, 19892011

\begin{tabular}{|c|c|c|c|c|c|c|c|c|}
\hline & \multicolumn{4}{|c|}{ Economic Inequality } & \multicolumn{4}{|c|}{ Political Inequality } \\
\hline & (1) & (2) & $(3)$ & $(4)$ & $(5)$ & (6) & $(7)$ & $(8)$ \\
\hline Weak State & $\begin{array}{l}2.312^{+} \\
(1.148)\end{array}$ & $\begin{array}{c}2.587^{*} \\
(1.246)\end{array}$ & $\begin{array}{c}3.471 \\
(5.485)\end{array}$ & $\begin{array}{c}4.777 \\
(7.203)\end{array}$ & $\begin{array}{l}0.114^{+} \\
(0.145)\end{array}$ & $\begin{array}{c}0.830 \\
(0.416)\end{array}$ & $\begin{array}{c}0.225 \\
(0.279)\end{array}$ & $\begin{array}{c}1.113 \\
(0.634)\end{array}$ \\
\hline Economic Inequality & $\begin{array}{c}1.591 \\
(0.606)\end{array}$ & $\begin{array}{c}1.641 \\
(0.637)\end{array}$ & & & $\begin{array}{l}2.104^{+} \\
(0.949)\end{array}$ & $\begin{array}{c}2.044 \\
(0.933)\end{array}$ & & \\
\hline Weak State ${ }^{*}$ Ec. Inequality & $\begin{array}{l}7.939^{+} \\
(8.936)\end{array}$ & $\begin{array}{l}7.671^{+} \\
(8.767)\end{array}$ & & & & & & \\
\hline Poorest Group & & & $\begin{array}{l}8.025^{* *} \\
(5.631)\end{array}$ & $\begin{array}{l}8.212^{* *} \\
(5.704)\end{array}$ & & & $\begin{array}{c}5.450^{*} \\
(3.706)\end{array}$ & $\begin{array}{l}5.041^{*} \\
(3.335)\end{array}$ \\
\hline Weak State $*$ Poorest & & & $\begin{array}{c}0.278 \\
(0.368)\end{array}$ & $\begin{array}{c}0.224 \\
(0.290)\end{array}$ & & & & \\
\hline Richest Group & & & $\begin{array}{c}1.032 \\
(0.278)\end{array}$ & $\begin{array}{c}1.045 \\
(0.295)\end{array}$ & & & $\begin{array}{c}1.228 \\
(0.324)\end{array}$ & $\begin{array}{c}1.222 \\
(0.323)\end{array}$ \\
\hline Weak State $*$ Richest & & & $\begin{array}{c}3.563 \\
(2.798)\end{array}$ & $\begin{array}{c}3.750 \\
(3.111)\end{array}$ & & & & \\
\hline ln(Largest Excluded Group) & $\begin{array}{c}0.552 \\
(0.237)\end{array}$ & & $\begin{array}{c}0.627 \\
(0.228)\end{array}$ & & $\begin{array}{c}1.735 \\
(0.788)\end{array}$ & & $\begin{array}{c}1.437 \\
(0.624)\end{array}$ & \\
\hline Weak State ${ }^{*}$ Largest Excl. Group & & & & & $\begin{array}{l}0.099^{* *} \\
(0.085)\end{array}$ & & $\begin{array}{c}0.153^{*} \\
(0.123)\end{array}$ & \\
\hline $\ln$ (Excluded Population) & & $\begin{array}{c}0.788 \\
(0.203)\end{array}$ & & $\begin{array}{c}0.884 \\
(0.196)\end{array}$ & & $\begin{array}{l}1.712^{+} \\
(0.525)\end{array}$ & & $\begin{array}{c}1.518 \\
(0.394)\end{array}$ \\
\hline Weak State * Excl. Population & & & & & & $\begin{array}{c}0.235^{* * *} \\
(0.103)\end{array}$ & & $\begin{array}{l}0.307^{* *} \\
(0.130)\end{array}$ \\
\hline Civil War & $\begin{array}{c}5.386^{* * *} \\
(2.210)\end{array}$ & $\begin{array}{c}4.937^{* * *} \\
(1.983)\end{array}$ & $\begin{array}{c}4.093^{* * *} \\
(1.637)\end{array}$ & $\begin{array}{c}3.747^{* * *} \\
(1.494)\end{array}$ & $\begin{array}{c}4.574^{* * *} \\
(1.758)\end{array}$ & $\begin{array}{c}3.980^{* * *} \\
(1.494)\end{array}$ & $\begin{array}{c}3.688^{* * *} \\
(1.431)\end{array}$ & $\begin{array}{l}3.225^{* *} \\
(1.239)\end{array}$ \\
\hline $\ln$ (Population) & $\begin{array}{c}1.216 \\
(0.185)\end{array}$ & $\begin{array}{c}1.188 \\
(0.188)\end{array}$ & $\begin{array}{c}1.304 \\
(0.263)\end{array}$ & $\begin{array}{c}1.248 \\
(0.241)\end{array}$ & $\begin{array}{l}1.314^{+} \\
(0.214)\end{array}$ & $\begin{array}{c}1.310 \\
(0.216)\end{array}$ & $\begin{array}{c}1.359 \\
(0.267)\end{array}$ & $\begin{array}{c}1.349 \\
(0.258)\end{array}$ \\
\hline $\ln$ (Infant Mortality Rate) & $\begin{array}{c}2.301 \\
(2.238)\end{array}$ & $\begin{array}{c}1.951 \\
(1.743)\end{array}$ & $\begin{array}{c}4.474 \\
(4.966)\end{array}$ & $\begin{array}{c}3.853 \\
(3.944)\end{array}$ & $\begin{array}{c}1.197 \\
(1.010)\end{array}$ & $\begin{array}{c}1.282 \\
(1.056)\end{array}$ & $\begin{array}{c}2.902 \\
(3.107)\end{array}$ & $\begin{array}{c}2.894 \\
(2.896)\end{array}$ \\
\hline Relevant Groups & $\begin{array}{c}1.121 \\
(0.097)\end{array}$ & $\begin{array}{c}1.115 \\
(0.095)\end{array}$ & $\begin{array}{c}1.031 \\
(0.098)\end{array}$ & $\begin{array}{c}1.025 \\
(0.089)\end{array}$ & $\begin{array}{c}1.131 \\
(0.098)\end{array}$ & $\begin{array}{c}1.116 \\
(0.095)\end{array}$ & $\begin{array}{c}1.076 \\
(0.104)\end{array}$ & $\begin{array}{c}1.066 \\
(0.098)\end{array}$ \\
\hline Peace Years & $\begin{array}{c}0.863^{*} \\
(0.054)\end{array}$ & $\begin{array}{l}0.854^{*} \\
(0.055)\end{array}$ & $\begin{array}{c}0.848^{*} \\
(0.056)\end{array}$ & $\begin{array}{l}0.838^{* *} \\
(0.057)\end{array}$ & $\begin{array}{c}0.878^{*} \\
(0.058)\end{array}$ & $\begin{array}{c}0.866^{*} \\
(0.057)\end{array}$ & $\begin{array}{c}0.864^{*} \\
(0.059)\end{array}$ & $\begin{array}{c}0.851^{*} \\
(0.058)\end{array}$ \\
\hline Spline 1 & $\begin{array}{l}0.502^{* *} \\
(0.134)\end{array}$ & $\begin{array}{c}0.507^{* *} \\
(0.133)\end{array}$ & $\begin{array}{c}0.560^{*} \\
(0.132)\end{array}$ & $\begin{array}{c}0.567^{*} \\
(0.131)\end{array}$ & $\begin{array}{l}0.515^{* *} \\
(0.123)\end{array}$ & $\begin{array}{l}0.519^{* *} \\
(0.117)\end{array}$ & $\begin{array}{l}0.556^{* *} \\
(0.123)\end{array}$ & $\begin{array}{c}0.559^{* *} \\
(0.119)\end{array}$ \\
\hline Spline 2 & $\begin{array}{c}89.729^{+} \\
(223.002)\end{array}$ & $\begin{array}{c}80.700^{+} \\
(197.629)\end{array}$ & $\begin{array}{c}52.690^{+} \\
(121.635)\end{array}$ & $\begin{array}{c}46.256^{+} \\
(104.059)\end{array}$ & $\begin{array}{c}88.427^{*} \\
(197.361)\end{array}$ & $\begin{array}{c}84.882^{*} \\
(182.157)\end{array}$ & $\begin{array}{c}65.000^{+} \\
(138.894)\end{array}$ & $\begin{array}{c}61.646^{*} \\
(127.338)\end{array}$ \\
\hline Spline 3 & $\begin{array}{c}0.001 \\
(0.006)\end{array}$ & $\begin{array}{c}0.002 \\
(0.007)\end{array}$ & $\begin{array}{c}0.003 \\
(0.012)\end{array}$ & $\begin{array}{c}0.004 \\
(0.014)\end{array}$ & $\begin{array}{l}0.001^{+} \\
(0.005)\end{array}$ & $\begin{array}{l}0.001^{+} \\
(0.005)\end{array}$ & $\begin{array}{l}0.002^{+} \\
(0.007)\end{array}$ & $\begin{array}{l}0.002^{+} \\
(0.008)\end{array}$ \\
\hline Observations & 961 & 961 & 961 & 961 & 961 & 961 & 961 & 961 \\
\hline
\end{tabular}

Exponentiated coefficients; Clustered and robust standard errors in parentheses.

${ }^{+} p<0.10,{ }^{*} p<0.05,{ }^{* *} p<0.01,{ }^{* * *} p<0.001$ 
Table D.10: Alternative Methods: Interactions with zero inflated negative binomial regression, 1989-2011

\begin{tabular}{|c|c|c|c|c|c|c|c|c|}
\hline & & Economic & Inequality & & & Political I & nequality & \\
\hline & (1) & $(2)$ & (3) & $(4)$ & $(5)$ & (6) & $(7)$ & $(8)$ \\
\hline Weak State & $\begin{array}{c}1.345 \\
(0.722)\end{array}$ & $\begin{array}{c}1.594 \\
(0.784)\end{array}$ & $\begin{array}{c}3.622 \\
(4.342)\end{array}$ & $\begin{array}{c}4.756 \\
(6.014)\end{array}$ & $\begin{array}{c}0.077^{*} \\
(0.096)\end{array}$ & $\begin{array}{c}0.765 \\
(0.234)\end{array}$ & $\begin{array}{l}0.190^{+} \\
(0.179)\end{array}$ & $\begin{array}{c}1.222 \\
(0.333)\end{array}$ \\
\hline Economic Inequality & $\begin{array}{c}0.888 \\
(0.368)\end{array}$ & $\begin{array}{c}0.923 \\
(0.397)\end{array}$ & & & $\begin{array}{c}1.657 \\
(1.794)\end{array}$ & $\begin{array}{c}1.084 \\
(0.599)\end{array}$ & & \\
\hline Weak State ${ }^{*}$ Ec. Inequality & $\begin{array}{l}8.785^{* *} \\
(6.289)\end{array}$ & $\begin{array}{l}8.382^{* *} \\
(6.306)\end{array}$ & & & & & & \\
\hline Poorest Group & & & $\begin{array}{l}12.414^{+} \\
(17.643)\end{array}$ & $\begin{array}{c}13.510^{* * *} \\
(7.939)\end{array}$ & & & $\begin{array}{l}6.035^{* *} \\
(3.388)\end{array}$ & $\begin{array}{l}4.726^{* *} \\
(2.813)\end{array}$ \\
\hline Weak State $*$ Poorest & & & $\begin{array}{l}0.164^{+} \\
(0.167)\end{array}$ & $\begin{array}{l}0.135^{* *} \\
(0.096)\end{array}$ & & & & \\
\hline Richest Group & & & $\begin{array}{c}0.462 \\
(0.661)\end{array}$ & $\begin{array}{l}0.413^{+} \\
(0.200)\end{array}$ & & & $\begin{array}{c}0.643 \\
(0.273)\end{array}$ & $\begin{array}{c}0.614 \\
(0.286)\end{array}$ \\
\hline Weak State $*$ Richest & & & $\begin{array}{l}4.922^{+} \\
(4.322)\end{array}$ & $\begin{array}{c}5.364^{*} \\
(4.550)\end{array}$ & & & & \\
\hline ln(Largest Excluded Group) & $\begin{array}{c}0.525 \\
(0.215)\end{array}$ & & $\begin{array}{c}0.568 \\
(0.574)\end{array}$ & & $\begin{array}{c}1.719 \\
(0.683)\end{array}$ & & $\begin{array}{c}1.331 \\
(0.679)\end{array}$ & \\
\hline Weak State ${ }^{*}$ Largest Excl. Group & & & & & $\begin{array}{l}0.084^{* *} \\
(0.070)\end{array}$ & & $\begin{array}{l}0.150^{* *} \\
(0.103)\end{array}$ & \\
\hline $\ln$ (Excluded Population) & & $\begin{array}{c}0.779 \\
(0.181)\end{array}$ & & $\begin{array}{c}0.940 \\
(0.372)\end{array}$ & & $\begin{array}{l}1.871^{*} \\
(0.565)\end{array}$ & & $\begin{array}{l}1.765^{+} \\
(0.601)\end{array}$ \\
\hline Weak State ${ }^{*}$ Excl. Population & & & & & & $\begin{array}{c}0.205^{* * *} \\
(0.075)\end{array}$ & & $\begin{array}{c}0.318^{* * *} \\
(0.097)\end{array}$ \\
\hline Civil War & $\begin{array}{l}1.894^{+} \\
(0.710)\end{array}$ & $\begin{array}{l}1.819^{+} \\
(0.619)\end{array}$ & $\begin{array}{c}1.242 \\
(0.300)\end{array}$ & $\begin{array}{c}1.256 \\
(0.353)\end{array}$ & $\begin{array}{c}1.530 \\
(0.467)\end{array}$ & $\begin{array}{c}1.259 \\
(0.248)\end{array}$ & $\begin{array}{c}1.107 \\
(0.268)\end{array}$ & $\begin{array}{c}1.136 \\
(0.277)\end{array}$ \\
\hline $\ln$ (Population) & $\begin{array}{c}1.190 \\
(0.172)\end{array}$ & $\begin{array}{c}1.152 \\
(0.175)\end{array}$ & $\begin{array}{c}1.368 \\
(0.543)\end{array}$ & $\begin{array}{c}1.356 \\
(0.298)\end{array}$ & $\begin{array}{l}1.376^{*} \\
(0.221)\end{array}$ & $\begin{array}{l}1.351^{+} \\
(0.213)\end{array}$ & $\begin{array}{l}1.626^{*} \\
(0.381)\end{array}$ & $\begin{array}{l}1.598^{+} \\
(0.402)\end{array}$ \\
\hline ln(Infant Mortality Rate) & $\begin{array}{c}3.353^{*} \\
(1.996)\end{array}$ & $\begin{array}{l}2.899^{+} \\
(1.684)\end{array}$ & $\begin{array}{c}8.277 \\
(11.017)\end{array}$ & $\begin{array}{l}7.870^{* *} \\
(5.374)\end{array}$ & $\begin{array}{c}2.639 \\
(1.778)\end{array}$ & $\begin{array}{l}2.781^{+} \\
(1.699)\end{array}$ & $\begin{array}{l}7.375^{*} \\
(5.923)\end{array}$ & $\begin{array}{c}7.047^{*} \\
(5.815)\end{array}$ \\
\hline Relevant Groups & $\begin{array}{c}1.111^{*} \\
(0.059)\end{array}$ & $\begin{array}{l}1.104^{+} \\
(0.064)\end{array}$ & $\begin{array}{c}1.033 \\
(0.162)\end{array}$ & $\begin{array}{c}0.999 \\
(0.076)\end{array}$ & $\begin{array}{l}1.148^{*} \\
(0.068)\end{array}$ & $\begin{array}{l}1.134^{*} \\
(0.064)\end{array}$ & $\begin{array}{c}1.070 \\
(0.073)\end{array}$ & $\begin{array}{c}1.032 \\
(0.067)\end{array}$ \\
\hline Peace Years & $\begin{array}{l}0.843^{* *} \\
(0.048) \\
\end{array}$ & $\begin{array}{l}0.835^{* *} \\
(0.048) \\
\end{array}$ & $\begin{array}{l}0.841^{* *} \\
(0.049) \\
\end{array}$ & $\begin{array}{l}0.829^{* *} \\
(0.049) \\
\end{array}$ & $\begin{array}{c}0.879^{*} \\
(0.049) \\
\end{array}$ & $\begin{array}{l}0.875^{* *} \\
(0.045) \\
\end{array}$ & $\begin{array}{c}0.885^{*} \\
(0.042) \\
\end{array}$ & $\begin{array}{l}0.873^{* *} \\
(0.044) \\
\end{array}$ \\
\hline Economic Inequality & $\begin{array}{c}0.000 \\
(0.000)\end{array}$ & $\begin{array}{c}0.000 \\
(0.000)\end{array}$ & & & $\begin{array}{c}0.000 \\
(0.000)\end{array}$ & $\begin{array}{c}0.000 \\
(0.000)\end{array}$ & & \\
\hline Poorest Group & & & $\begin{array}{c}10.937 \\
(32.990)\end{array}$ & $\begin{array}{c}19.526^{*} \\
(26.798)\end{array}$ & & & $\begin{array}{c}4.683 \\
(6.806)\end{array}$ & $\begin{array}{c}5.247 \\
(7.200)\end{array}$ \\
\hline Richest Group & & & $\begin{array}{c}0.000 \\
(0.000)\end{array}$ & $\begin{array}{c}0.000 \\
(0.000)\end{array}$ & & & $\begin{array}{c}0.000 \\
(0.000)\end{array}$ & $\begin{array}{c}0.000 \\
(0.000)\end{array}$ \\
\hline ln(Largest Excluded Group) & $\begin{array}{c}0.871 \\
(2.399)\end{array}$ & & $\begin{array}{c}0.938 \\
(4.395)\end{array}$ & & $\begin{array}{c}1.437 \\
(3.918)\end{array}$ & & $\begin{array}{c}1.316 \\
(2.231)\end{array}$ & \\
\hline $\ln$ (Excluded Population) & & $\begin{array}{c}0.972 \\
(1.702)\end{array}$ & & $\begin{array}{c}1.734 \\
(2.436)\end{array}$ & & $\begin{array}{c}1.094 \\
(1.337)\end{array}$ & & $\begin{array}{c}3.654 \\
(6.453)\end{array}$ \\
\hline Civil War & $\begin{array}{l}0.000^{+} \\
(0.000)\end{array}$ & $\begin{array}{l}0.000^{+} \\
(0.000)\end{array}$ & $\begin{array}{c}0.010 \\
(0.192) \\
\end{array}$ & $\begin{array}{c}0.058^{*} \\
(0.076) \\
\end{array}$ & $\begin{array}{c}0.027 \\
(0.228) \\
\end{array}$ & $\begin{array}{c}0.037 \\
(0.125) \\
\end{array}$ & $\begin{array}{c}0.024 \\
(0.103) \\
\end{array}$ & $\begin{array}{c}0.042^{+} \\
(0.072)\end{array}$ \\
\hline Observations & 961 & 961 & 961 & 961 & 961 & 961 & 961 & 961 \\
\hline $\mathrm{AIC}$ & 447.049 & 450.749 & 425.940 & 428.481 & 422.141 & 424.093 & 416.730 & 417.766 \\
\hline LL_0 & -283.314 & -286.087 & -272.188 & -276.332 & -283.314 & -286.087 & -272.188 & -276.332 \\
\hline LL & -205.524 & -207.374 & -191.970 & -193.241 & -193.071 & -194.046 & -188.365 & -188.883 \\
\hline
\end{tabular}


Figure D.1: Influential Observations: Cook's statistic, model 5

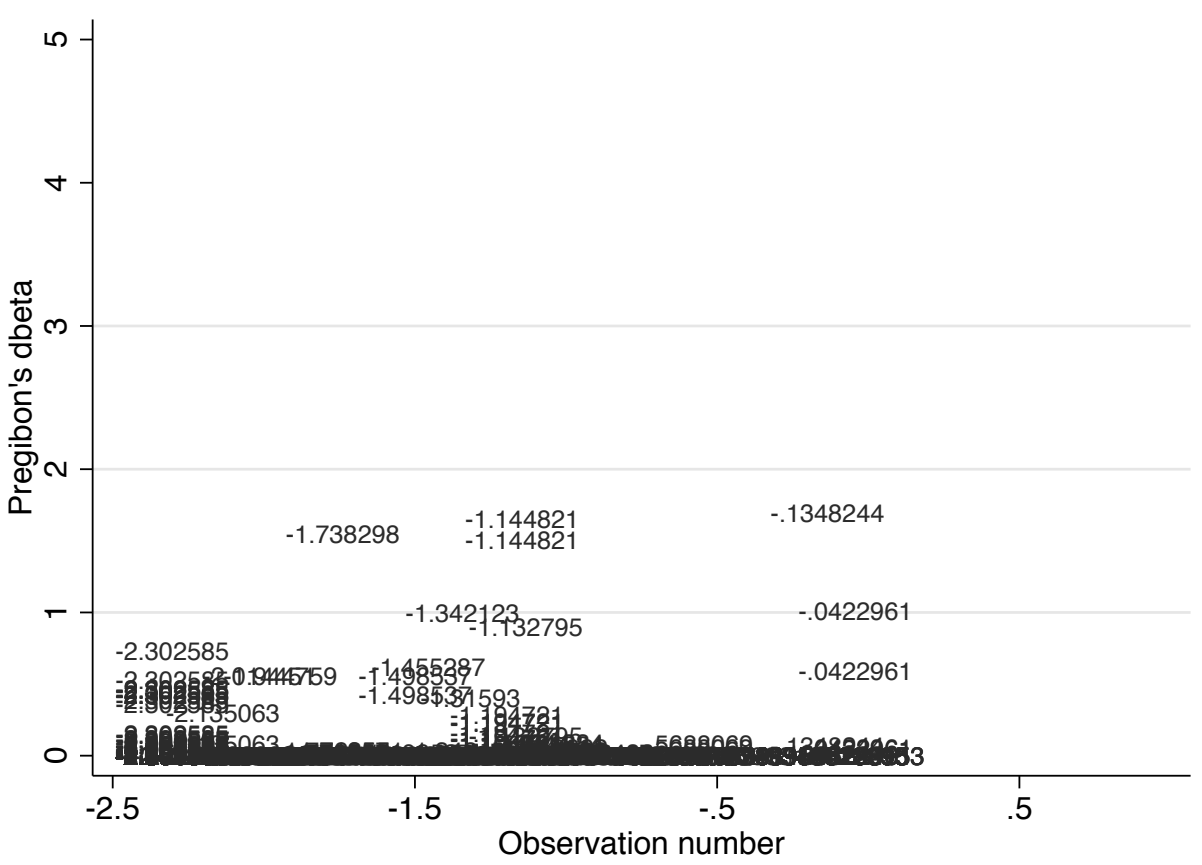




\section{Appendix E}

\section{Do-file}

All do-files for tables, figures and regression models can be found on the attached CD. For the tables and regression models, I have used Stata, while I have applied R for most figures. All syntax can also be provided upon request: idarud@gmail.com. 